\section{RECEIVED}

JUN 011997

OSTI

\title{
Instrumentation of the Thermal/Structural Interactions In Situ Tests at the Waste Isolation Pilot Plant (WIPP)
}

Darrell E. Munson, David L. Hoag, Douglas A. Blankenship, Wesley F DeYonge, Daniel M. Schiermeister, Robert L. Jones, Glenn T. Baird

$$
4
$$

Prepared by

Sandia National Laboratories

Albuquerque, New Mexico 87185 and thermore, California 94550

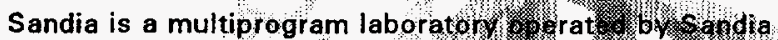

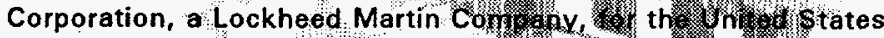

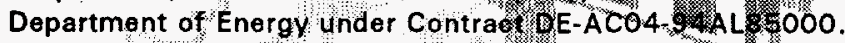

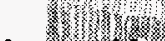

Apptoved for public release; distribution is unlimited

\section{团 Sandia I \\ mink}
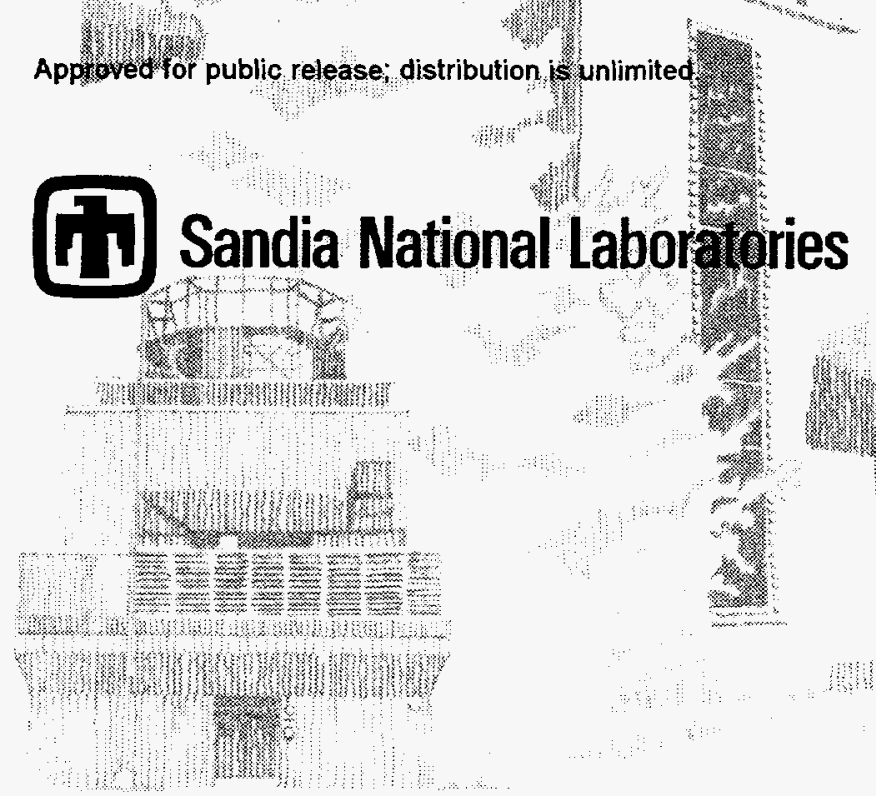

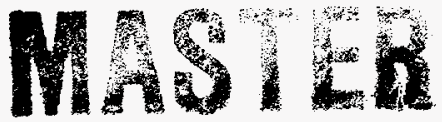


Issued by Sandia National Laboratories, operated for the United States Department of Energy by Sandia Corporation.

NOTICE: This report was prepared as an account of work sponsored by an agency of the United States Government. Neither the United States Government nor any agency thereof, nor any of their employees, nor any of their contractors, subcontractors, or their employees, makes any warranty, express or implied, or assumes any legal liability or responsibility for the accuracy, completeness, or usefulness of any information, apparatus, product, or process disclosed, or represents that its use would not infringe privately owned rights. Reference herein to any specific commercial product, process, or service by trade name, trademark, manufacturer, or otherwise, does not necessarily constitute or imply its endorsement, recommendation, or favoring by the United States Government, any agency thereof, or any of their contractors or subcontractors. The views and opinions expressed herein do not necessarily state or reflect those of the United States Government, any agency thereof, or any of their contractors.

Printed in the United States of America. This report has been reproduced directly from the best available copy.

Available to DOE and DOE contractors from

Office of Scientific and Technical Information

P.O. Box 62

Oak Ridge, TN 37831

Prices available from (615) 576-8401, FTS 626-8401

Available to the public from

National Technical Information Service

U.S. Department of Commerce

5285 Port Royal Rd

Springfield, VA 22161

NTIS price codes

Printed copy: A09

Microfiche copy: A01 
Darrell E. Munson

Repository Isolation Systems Division Sandia National Laboratories

PO Box 5800, Albuquerque, NM 87185

David L. Hoag, Douglas A. Blankenship, Wesley F. DeYonge, Daniel M. Schiermeister $\mathrm{RE} / \mathrm{SPEC}$, Inc.

4775 Indian School Road NE, Suite 300 Albuquerque, NM 87110

Robert I. Jones, Glenn T. Baird Tech Reps, Inc.

5000 Marble Avenue NE, Albuquerque, NM 87110

\section{ABSTRACT}

The Department of Energy has constructed the Waste Isolation Pilot Plant (WIPP) to develop the technology for the disposal of radioactive waste from defense programs. Sandia National Laboratories had the responsibility for the experimental activities at the WIPP and fielded several large-scale Thermal/Structural Interactions (TSI) in situ tests to validate techniques used to predict repository performance. The instrumentation of these tests involved the placement of over 4,200 gages including room closure gages, borehole extensometers, stress gages, borehole inclinometers, fixed reference gages, borehole strain gages, thermocouples, thermal flux meters, heater power gages, environmental gages, and ventilation gages. Most of the gages were remotely read instruments that were monitored by an automated data acquisition system, but manually read instruments were also used to provide early deformation information and to provide a redundancy of measurement for the remote gages. Instruments were selected that could operate in the harsh environment of the test rooms and that could accommodate the ranges of test room responses predicted by pretest calculations. Instruments were tested in the field prior to installation at the WIPP site and were modified to improve their performance. Other modifications were made to gages as the TSI tests progressed using knowledge gained from test maintenance. Quality assurance procedures were developed for all aspects of instrumentation including calibration, installation, and maintenance. The instrumentation performed exceptionally well and has produced a large quantity of quality information. 


\section{CONTENTS}

1 Introduction

2 The Instrumentation Process 8

2.1 Gage Selection

2.2 Gage Calibration

2.3 Gage Location

2.4 Gage Installation

2.5 Data Acquisition

2.6 Gage Maintenance

2.7 Quality Assurance $\quad 22$

3 Gage Descriptions 23

3.1 Room Closure Gages $\quad 23$

3.1 .1 Mining Sequence Closure Gages $\quad 26$

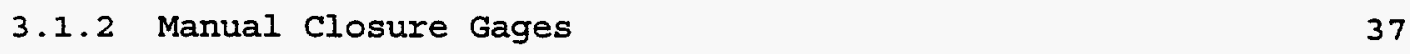

3.1.3 Research Inc. Remote Closure Gages 45

3.2 Extensometers $\quad 53$

3.2.1 Terrametrics Anchor Bolt Extensometers 54

3.2.2 Serata E-200L Wire Extensometers $\quad 59$

3.2.3 Serata E-300 wire Extensometers 71

3.2.4 IRAD 4000-I Rod Extensometers $\quad 77$

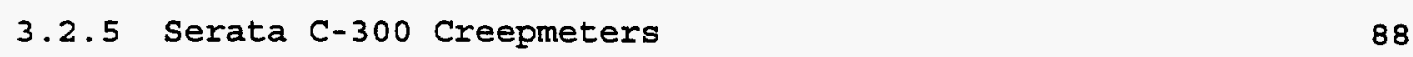

3.3 Stress Gages 93

3.3 .1 Strain-Gaged stressmeters 94

3.3 .2 Bureau of Mines Pressure Cells 103

3.4 SINCO Inclinometers $\quad$. 109

3.5 Reference Gages $\quad 116$

$\begin{array}{llr}3.5 .1 & \text { Fixed Reference } & 117\end{array}$

3.5 .2 Rod and Level 121

$\begin{array}{lll}3.5 .3 \text { Fluid Level } & 122\end{array}$

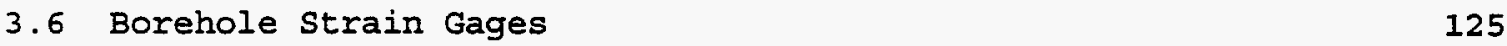

$\begin{array}{llr}3.7 & \text { Thermocouples } & 129\end{array}$

3.8 Thermal Flux Meters 144

3.9 Power Meters 151 
7rominop

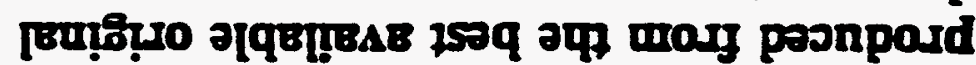

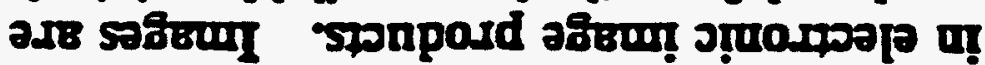

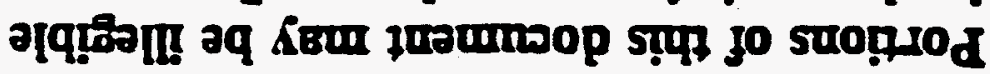

\&EINTTSTa 


\section{DISCLAIMER}

This report was prepared as an account of work sponsored by an agency of the United States Government. Neither the United States Government nor any agency thereof, nor any of their employees, make any warranty, express or implied, or assumes any legal liability or responsibility for the accuracy, completeness, or usefulness of any information, apparatus, product, or process disclosed, or represents that its use would not infringe privately owned rights. Reference herein to any specific commercial product, process, or service by trade name, trademark, manufacturer, or otherwise does not necessarily constitute or imply its endorsement, recommendation, or favoring by the United States Government or any agency thereof. The views and opinions of authors expressed herein do not necessarily state or reflect those of the United States Government or any agency thereof. 
CONTENTS (CONTINUED)

Page

3.10 Environmental and Ventilation Gages

3.11 Shear Detectors

158

160

4.1 SINCO Tape Extensometers

161

4.2 Terrametrics Anchor Bolt Extensometers

164

4.3 Remote Displacement Gages

165

4.4 Stressmeters

170

4.5 Thermocouples

170

4.6 Comments

171

5 Summary

173

References

176 
Figure 1.0.1. WIPP Surface and Underground Facilities, Planned and Existing

Figure 1.0.2. WIPP In Situ Test Matrix

Figure 1.0.3. As-Built Plan of the WIPP Underground Experimental Area

Figure 2.2.1. Principal Station and Room Coordinate systems

Figure 2.2.2. Plan View of Instrument Locations, Room B

Figure 2.4.1. Instrument Collar Installation

Figure 2.5.1. Schematic of the Data Acquisition System

Figure 3.1.1. Cross section of a Mining sequence closure station

Figure 3.1.2. Mining sequence closure Point Installation

Figure 3.1.3. Early Closure Point Emplacement Machine, AIS

Figure 3.1.4. Mining Sequence Closure Point Installation, ISBT

Figure 3.1.5. Mining sequence Closure Point Installation, Room $Q$

Figure 3.1:6. Manual Closure Point Installation

Figure 3.1.7. Cross section of a Manual closure Gage station

Figure 3.1.8.

Cross Section of a Remedial closure Gage station

Figure 3.1.9. SINCO Tape Extensometer (Model 518115)

Figure 3.1.10. Research Inc. Remote Closure Gage Installation

Figure 3.1.11. Cross section of a Closure Gage and Extensometer station

Figure 3.1.12. Remote Remedial Closure Gage Installation 50

Figure 3.1.13. Remote Brow Closure Gage Installation 51

Figure 3.2.1. Terrametrics Anchor Bolt Extensometer Installation 55

Figure 3.2.2. Serata E-200I Wire Extensometer Installation 60

Figure 3.2.3. Piggyback wire Extensometer Installation 62

Figure 3.2.4. Serata E-300 wire Extensometer Installation 72

Figure 3.2.5. Irad 4000-L Rod Extensometer Installation 79

Figure 3.2.6. Serata C-300 Creepmeter 90

Figure 3.2.7. Creepmeter Installation 91

Figure 3.3.1. Schematic of Bureau of Mines Pressure Cells and 95 Strain-Gaged stressmeters

Figure 3.3.2. Cross section of a strain-Gaged stressmeter station 96

Figure 3.3.3. Cross section of a Bureau of Mines Pressure Cell station 97 
Figure 3.3.4. Strain-Gaged Stressmeter $\quad 98$

Figure 3.3.5. Bureau of Mines Pressure Cells 104

Figure 3.4.1. Cross Section of an Inclinometer Station 110

Figure 3.4.2. SINCO Inclinometer Installation 112

Figure 3.5.1. Fixed Reference Gage Installation $\quad 118$

Figure 3.5.2. Fluid Level Installation 123

$\begin{array}{ll}\text { Figure 3.6.1. Borehole Strain Gage } & 127\end{array}$

Figure 3.7.1. Cross Section of a Far-Field Thermocouple Station 130

Figure 3.7.2. Plan View of a Near-Field Thermocouple and Flux Meter 131 Installation, Room B

Figure 3.7.3. Heater Thermocouple Installations 132

Figure 3.7.4. Gordon Head Thermocouple Connector 134

Figure 3.7.5. Far-Field Thermocouple Installation 138

Figure 3.7.6. Cross Sections of a Near-Field Thermocouple and 139 Flux Meter Installation

Figure 3.7.7. Canister Heater with Thermocouples 141

Figure 3.7.8. Air-Stream Thermocouple Installation 142

Figure 3.8.1. Thermal Flux Meter 146

Figure 3.8.2. Thermal Flux Meter Installations on Heaters 148

Figure 3.8.3. Thermal Flux Meter Installations in Room Floor 149

Figure 3.10.1. Location of Ventilation Gages Near the A and B Test 154 Rooms

Figure 3.10.2. Ventilation Thermocouple Installation 


\section{LIST OF TABLES}

Table

Page

Table 1.0.1. Acronyms and Abbreviations

Table 2.1.1. Gage Measurement Ranges

Table 3.0.1. Quantities of Gages Installed, TSI In Situ Tests 24

Table 4.0.1. Gage Measurement Accuracy 160

Table 4.3.1. Remote Displacement Gage Measurement Uncertainties 166 


\section{INTRODUCTION}

In 1981, the U.S. Department of Energy (DOE) began construction of the Waste Isolation Pilot Plant (WIPP) in southeastern New Mexico to develop the technology for disposing of radioactive waste from defense programs. This facility may eventually become a repository for defense transuranic (TRU) wastes, provided the facility is demonstrated to be acceptable. Although the complete facility includes both surface and underground construction, as depicted in Figure 1.0.1, Sandia National Laboratories (Sandia) is primarily concerned with the experimental activities in the underground portion of the facility.

The Thermal/structural Interactions (TSI) in situ tests were part of a suite of underground test programs (Figure 1.0.2) that were instituted to research the technology needed for a repository. The in situ tests and demonstrations consisted of several large-scale tests and many small-scale tests (Figure 1.0.3) which directly addressed the compliance and technology development issues in the Repository Isolation systems (RIS), Disposal Room Systems (DRS), and Fluid Flow and Transport (FFT) Programs. The in situ testing specifically addressed the disposal and isolation of contact-handled $(\mathrm{CH})$ and remote-handled (RH) TRU waste generated by current and past defense programs. Although some tests initially addressed the disposal of defense high-level waste (DHLW), this waste is currently slated for disposal in another repository, and the test results will contribute to the validation of TRU waste disposal technology.

Originally, there were five major experiments within the TSI tests: (1) the $18-\mathrm{W} / \mathrm{m}^{2}$ Mockup for $\mathrm{DHLW}$ in Rooms $\mathrm{A1}, \mathrm{A} 2$, and $\mathrm{A} 3$; (2) the overtest for Simulated DHLW in Room B; (3) the Geomechanical Evaluation in Room G; (4) the Heated Axisymmetric Pillar in Room $H$; and (5) the In Situ Stress 


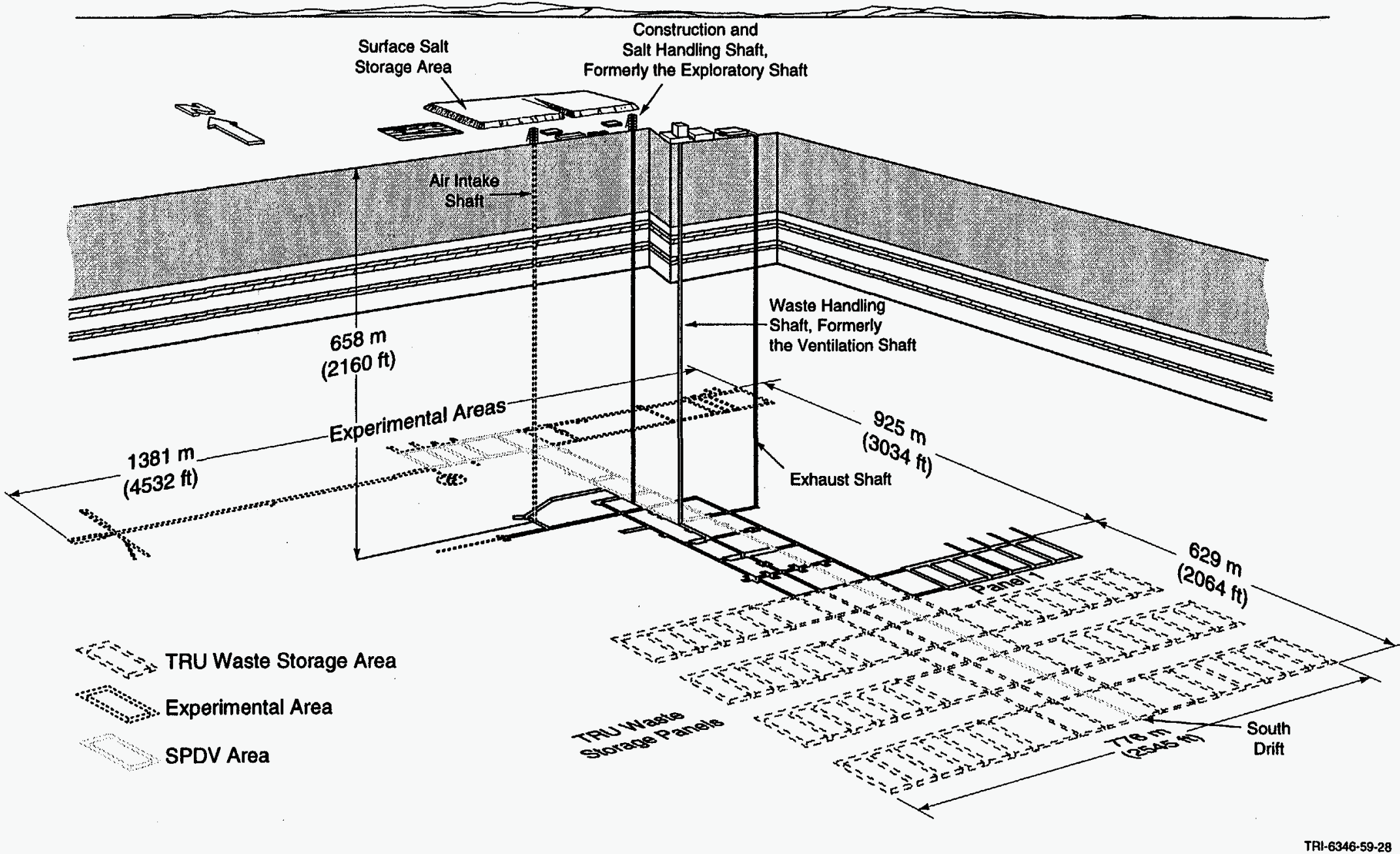

Figure 1.0.1. WIPP Surface and Underground Facilities, Planned and Existing 


\begin{tabular}{|c|l|l|}
\hline SPDV & $\begin{array}{l}\text { Technology } \\
\text { Experiments }\end{array}$ & Demonstrations \\
\hline
\end{tabular}

Site Characterization and Evaluation

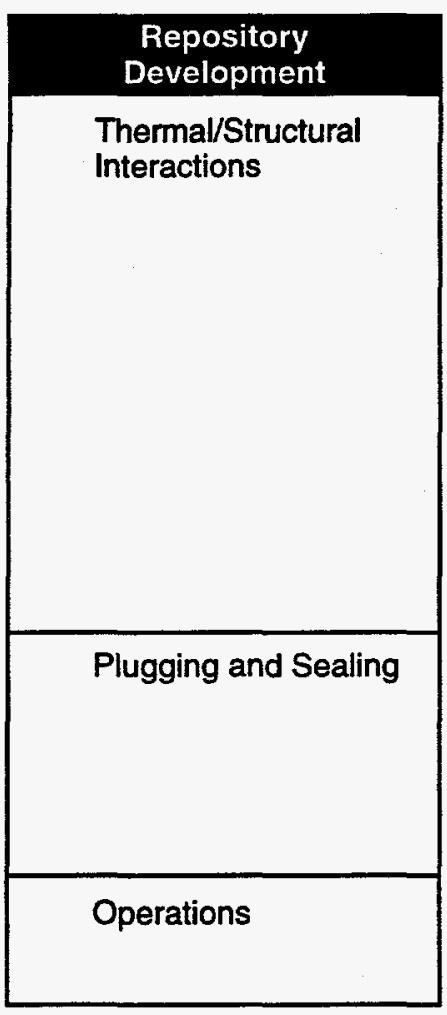

\section{Waste Package} Interactions

Waste Package

Performance

Near-Field Effects

\begin{tabular}{|l|l|l|}
\hline $\begin{array}{l}\text { - Site } \\
\text { Validation } \\
\text { Investigation }\end{array}$ & $\begin{array}{l}\bullet \text { Hydrological and } \\
\text { Geological Studies }\end{array}$ & \\
\hline
\end{tabular}

\begin{tabular}{|c|c|c|}
\hline \multirow[t]{3}{*}{$\begin{array}{l}\text { Preliminary } \\
\text { Design } \\
\text { Validation }\end{array}$} & $\begin{array}{l}\text { - } 18 \mathrm{~W} / \mathrm{m}^{2} \text { Mockup } \\
\text { - DHLW Overtest } \\
\text { - Geomechanical } \\
\text { Evaluations } \\
\text { - Heated Axisymmetric } \\
\text { Pillar } \\
\text { - In Situ Stress Field } \\
\text { - Direct Shear of Clay } \\
\text { Seam (not performed) } \\
\text { - Air Intake Shaft } \\
\text { Performance Tests } \\
\text { - Intermediate Scale } \\
\text { Borehole Test }\end{array}$ & \\
\hline & $\begin{array}{l}\text { - Permeability Tests } \\
\text { - Plug Test Matrix } \\
\text { - Field (Borehole) Tests } \\
\text { - Gas Testing } \\
\text { - Small-Scale Seal Tests }\end{array}$ & \\
\hline & & $\begin{array}{l}\text { - Mock TRU } \\
\text { Waste Handling }\end{array}$ \\
\hline
\end{tabular}

\begin{tabular}{|l|l|l|}
\hline & $\begin{array}{l}\text { - Simulated-Waste } \\
\text { Package Performance } \\
\text { Simulated TRU Waste } \\
\text { Technology Experiments }\end{array}$ & \\
\hline & $\begin{array}{l}\text { Brine Migration } \\
\text { Large Scale Brine Inflow } \\
\text { Test }\end{array}$ & \\
\hline
\end{tabular}




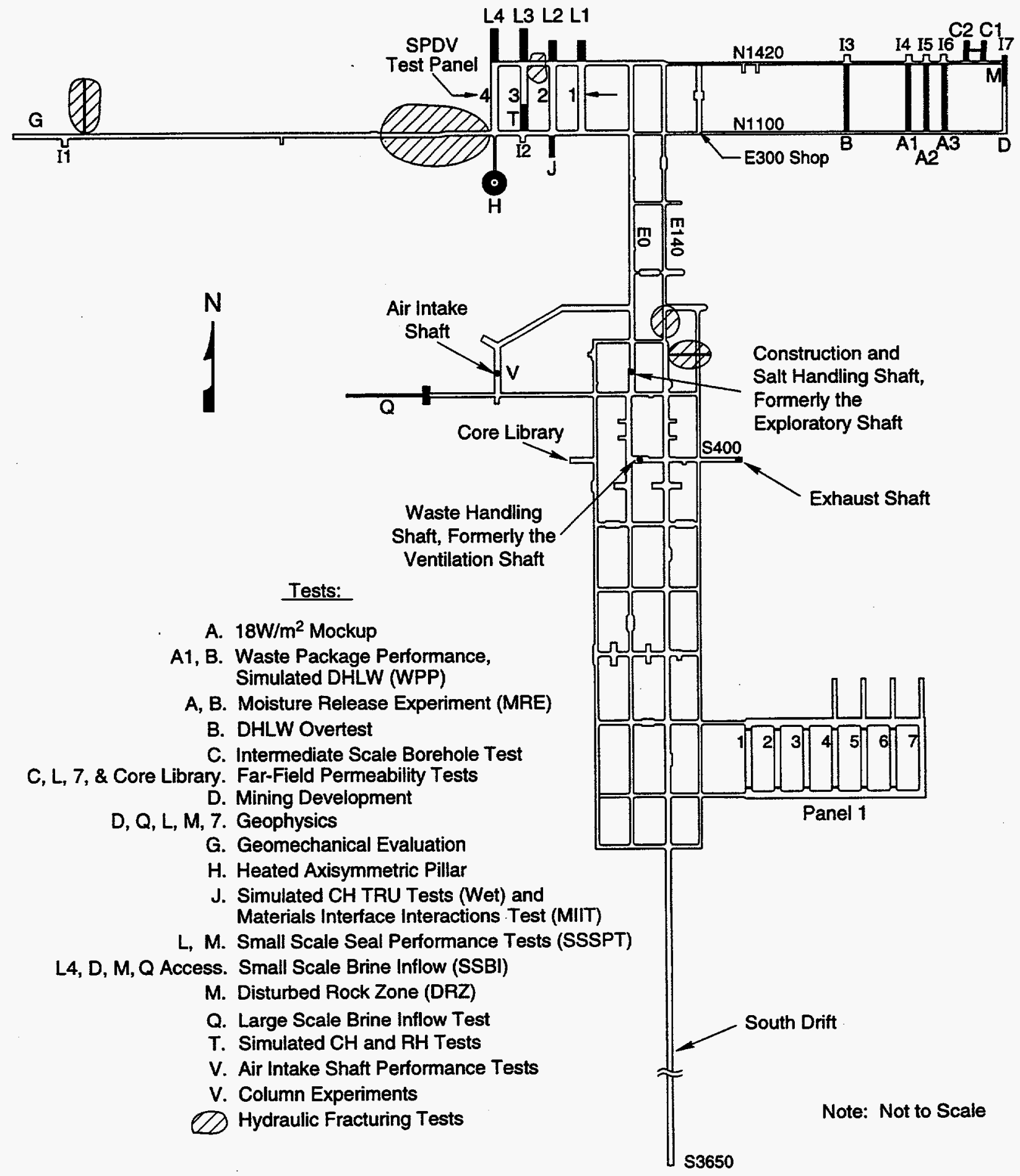

TMM-16815-1

Figure 1.0.3. As-Built Plan of the WIPP Underground Experimental Area 
Field - Hydraulic Fracturing Tests in Room $G$ and elsewhere in the Experimental Area. A Clay seam Shear Test was originally planned, but never proceeded beyond the testing of prototype instrumentation. In situ data have also been obtained from Room $D$, an early excavation initially created for facility ventilation. Other major tests were later added to the experimental program that contributed to TSI objectives: (1) the Air Intake Shaft (AIS) Performance Tests in the Air Intake Shaft (Shaft V), (2) the Intermediate Scale Borehole Test (ISBT) between Rooms C1 and C2, and (3) the Large-Scale Brine Inflow Test in Room $Q$.

The original tests were fielded between 1983 and 1986, beginning with the initial Hydraulic Fracturing test in December, 1983. Mining and instrumentation of the test rooms started essentially in the same time frame with Room D being fielded in March and April, 1984; Room B in May and June, 1984; Room A2 in June and July, 1984; Room Al in September and October, 1984; Room A3 in October and November, 1984; Room G between November, 1984 and January, 1985; and Room $\mathrm{H}$ in January and February, 1985. The fielding of these original tests culminated with another Hydraulic Fracturing test in February, 1986. The other tests that supported the TSI program came latex, with the AIS being fielded between May, 1988 and December, 1990; Room $Q$ in July and August, 1989; and the ISBT in December, 1990 (between Rooms C1 and C2 which were mined in March and April, 1984). Acquisition of data started as the rooms were being mined. Most of the TSI experiments have been terminated and their gages are no longer monitored. However, the testing in Room $D$ and the AIS remains active as of this writing (1996) and data acquisition continues.

This report was started in 1987, but completion was delayed until 1996 to permit the inclusion of all TSI instrumentation. The original report 
number has been retained because it has been referenced in many reports. This report provides a detailed discussion of the instrumentation used in the TSI tests. Chapter 2 provides general information about the various components of the instrumentation process, while detailed information specific to individual gage types is given in Chapter 3 . Chapter 4 discusses the accuracy of some of the more important gages used in the tests. Finally, a summary of the instrumentation process is presented in Chapter 5. Several other documents provide details on the planning and implementation of the TSI in situ tests [1-12]. Data reports for the various experiments [13-21] discuss test configurations and include the engineering data produced by test instrumentation. Details of the Hydraulic Fracturing test instrumentation are not included herein but are discussed in another reference [22]. Table 1.0.1 lists the acronyms and abbreviations used in this report. 
Table 1.0.1. Acronyms and Abbreviations

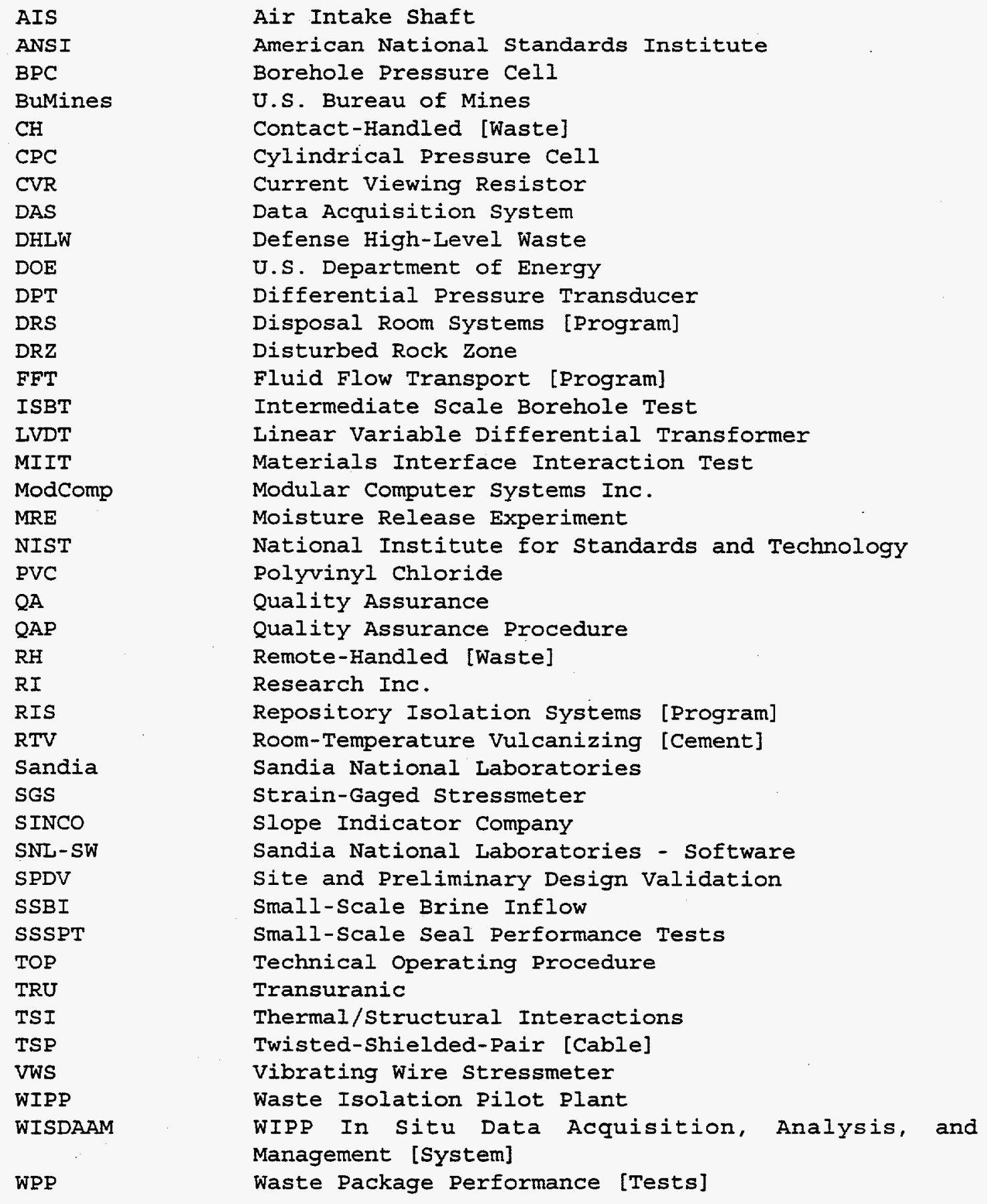


This page intentionally left blank. 
The instrumentation of the TSI in situ tests was a complex process that involved several steps. This process began with the selection of gages that could accurately measure the anticipated range of responses in the experiments and that could withstand the severe test environment for several years. In order to ensure test accuracy, the gages were calibrated before use and were installed within a surveyed coordinate system. Gages were monitored by a comprehensive data acquisition system and measurements were placed in a computerized engineering database to facilitate data reduction and analysis. The gages were maintained on a regular schedule to ensure long-term success for the experiments. All of the above steps were performed according to established quality assurance procedures.

\subsection{Gage Selection}

The selection of instruments began early in the planning stage of the TSI testing program. The selection process was initiated by reviewing commercially available instrumentation in an effort to minimize design and field trials, although some applications required instruments to be designed by sandia because suitable instrumentation from commercial sources was not available. Gages were sought that could operate in the harsh underground test environment of the WIPP where brine and heat could be detrimental to instrument performance. In addition, it was required that the instruments be durable enough to provide data for the duration of the tests (several years).

Prior to ordering, candidate instruments were evaluated on the ability to meet anticipated operating conditions. Stress gages were evaluated in the field at two different sites: the International salt company (now the 
Akzo Nobel salt Companyl salt mine at Avery Island, Louisiana, and the Mississippi Chemical Corporation potash mine near Carlsbad, New Mexico. Thermocouples and closure gages had been used by sandia in the past in numerous applications and no new evaluations were necessary. Other gages were tested in the laboratory or evaluated from design drawings. Gage components that were susceptible to failure were modified to minimize environmental degradation, and modifications were passed on to the manufacturers through detailed specifications in purchase orders. Additional modifications to enhance gage operation were made at the wIPP site by Sandia personnel before gage installation. Details of the various gage designs and modifications are discussed in Chapter 3 of this report.

It was also necessary that the gages be capable of measuring the full range of the predicted room response or that they could be adjusted as needed to allow measurement to continue over the full duration of the test. Early in the TSI test design phase, preliminary calculations were performed to provide estimates of room response for each of the tests [23-30]. This thermal and structural modeling, together with the experience and technical judgement of the test designers, enabled the development of initial predictions of test room deformation, stress, and temperature. The preliminary calculations for the DHLW Overtest in Room B were believed to provide upper bounds to the test room responses because of the amount of heat to be generated in Room B [26]. Preliminary specifications for gage performance, as listed below in Table 2.1.1, were therefore based on the pretest response estimates for Room B. It should be noted that during the course of these tests, the requirement for elevated temperatures was eliminated when the decision was taken that the WIPP would not consider high-level waste. 
Table 2.1.1. Gage Measurement Ranges

\begin{tabular}{lrl}
\hline Measurement & Range \\
\hline Vertical Room Closure & $0-0.9 \mathrm{~m}(0-3 \mathrm{ft})$ \\
Back Extensometer Displacement & $0-0.3 \mathrm{~m}(0-1 \mathrm{ft})$ \\
Floor Extensometer Displacement & $0-0.6 \mathrm{~m}(0-2 \mathrm{ft})$ \\
Stress & $0-20 \mathrm{MPa}(0-3 \mathrm{ksi})$ \\
Temperature & $25-200^{\circ} \mathrm{C}$ & $\left(80-400^{\circ} \mathrm{F}\right)$ \\
\end{tabular}

\subsection{Gage Calibration}

Most of the individual gages used in the TSI in situ tests, including room closure gages, extensometers, borehole stressmeters, and air velocity sensors (after 1990) were calibrated by Sandia. Early in the TSI testing program, gages were calibrated at the Sandia standards Laboratory in Albuquerque, NM. After 1985, gages were calibrated at the Sandia WIPP Site Calibration Laboratory. The traceability of this process has been given by schuhen and Dean [31]. During the calibration procedure, gages were calibrated at several measurement points (displacements, pressures, or velocities) throughout their range using specially designed calibration fixtures and standard testing equipment. The transfer standards at the WIPP Site Calibration Laboratory were traceable to the Sandia secondary Standards Laboratory and ultimately to the National Institute for Standards Technology (NIST). The calibration points and the associated voltages were fit to linear or polynomial equations using regression analysis. Other gages, including thermal flux gages and air velocity sensors (before 1990), relied on calibrations that were supplied by the manufacturer. The resulting calibration coefficients for each individual gage were stored in the Gage Calibration File on the ModComp (Modular Computer systems Inc.) computer system (Section 2.5). The coefficients were then used with function routines to convert gage voltages to 
engineering units, as defined by Technical Operating Procedure 217 [TOP 2171. (Throughout this report, TOP citations, as given in brackets, are the specific applicable operating procedures; the general TOP reference is given in the Reference section.) As an exception to the above procedure, the thermocouples relied on NIST Thermocouple Reference Tables [32, 33] for the conversion of voltages to temperatures.

\subsection{Gage Location}

In order to ensure accurate emplacement of instruments, it was necessary to devise a well defined system of room surveying and instrument location that would consistently account for the natural variation in stratigraphy and the as-built variation in room dimensions. The specified plan locations of the test rooms were easily established from the contract drawings using standard surveying methods. However, the sedimentary beds in the facility horizon dip gently towards the south and west. In addition, slight undulations of the beds are present throughout the facility. In order to avoid any unnecessary ground control problems and to keep the test rooms in the same geologic horizon, it was necessary to maintain excavation elevations relative to the stratigraphy. That is, all cross sections of a test room appeared the same in relation to the stratigraphy. As a consequence, the elevations of the room centerlines were neither horizontal nor straight, but varied with the stratigraphy as shown in Figure 2.2.1.

To have used the continuously varying stratigraphic horizon as the reference for instrument locations would have been difficult and was unnecessary. Instead, the concept of the local coordinate system with principal stations was used to simplify both gage location and subsequent data analysis. If one examines the Room B instrument placement shown in 


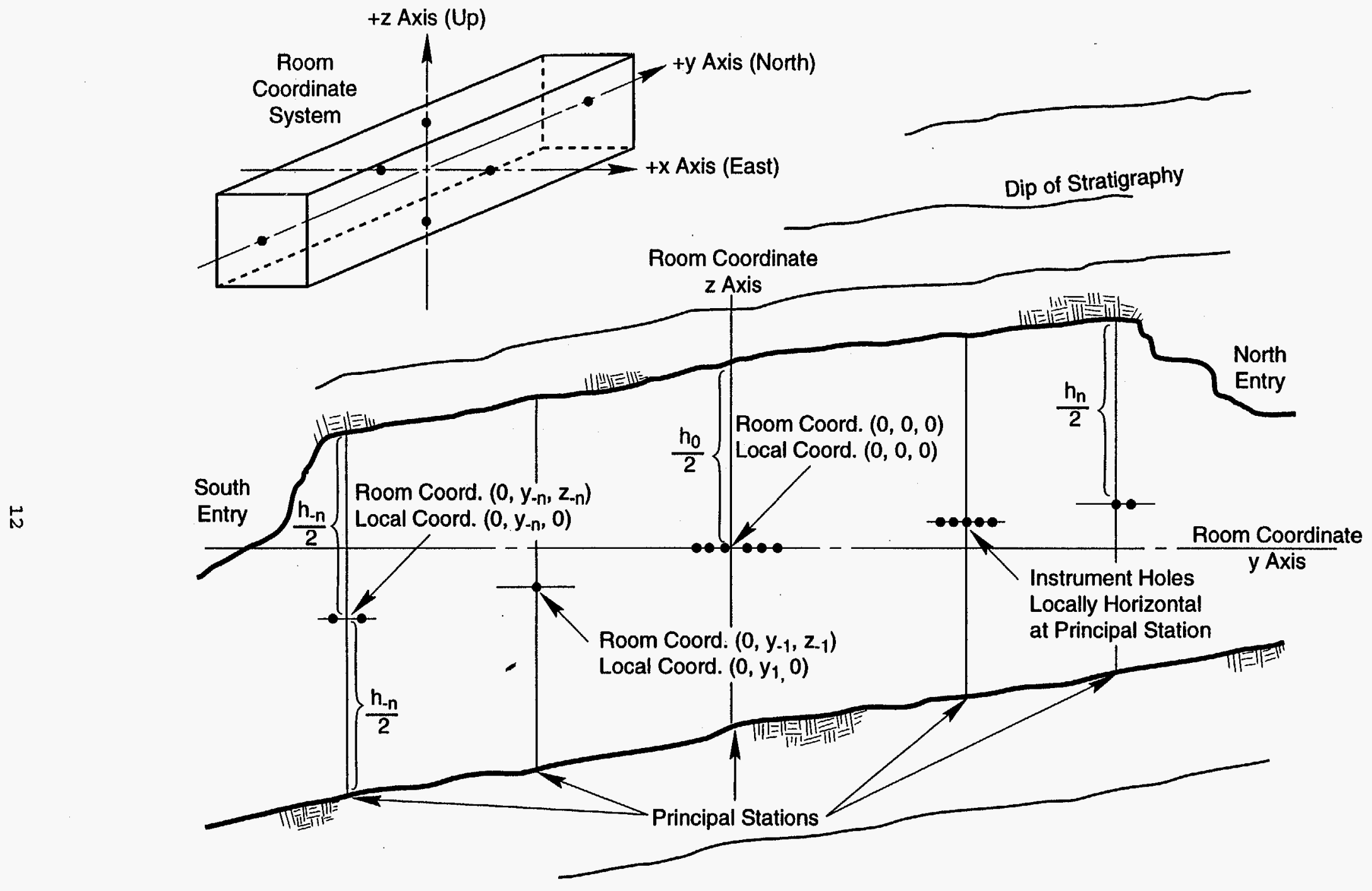


Figure 2.2.2, it is evident that during initial test planning, the instruments were intentionally located in concentrated groups, rather than distributed uniformly throughout the length of the room. Each of these groups of instruments was assigned to a separate principal station, with the local vertical zero being defined as the room midheight at that station, and the horizontal axis of the station intersecting the local zero. By this system, the instrumentation holes assigned to a principal station, even though several feet to either side of the station, were surveyed to the same local horizontal axis. The exaggerated schematic of Figure 2.2.1 illustrates several principal stations with locally defined horizontal axis segments.

As a result, test room gages were located using two different coordinate systems: the local system described above and the room system. The room coordinate system was based on an origin defined as the average center of the room. As a consequence, gages were given two sets of vertical coordinates; one set was relative to the local coordinate system, the other to the test room coordinate system. Details of individual instrument locations can be found in the TSI experiment data reports $[13-21]$

The method of identifying principal stations was the same for all test rooms that used Cartesian coordinates. In these rooms, principal stations were defined as vertical sections located at discrete points along the length of the room. In Room H, which was developed using cylindrical coordinates, principal stations were defined as vertical sections located at selected angles around the room axis. In the AIS, which also used cylindrical coordinates, principal stations were defined as horizontal sections at discrete elevations in the shaft. 


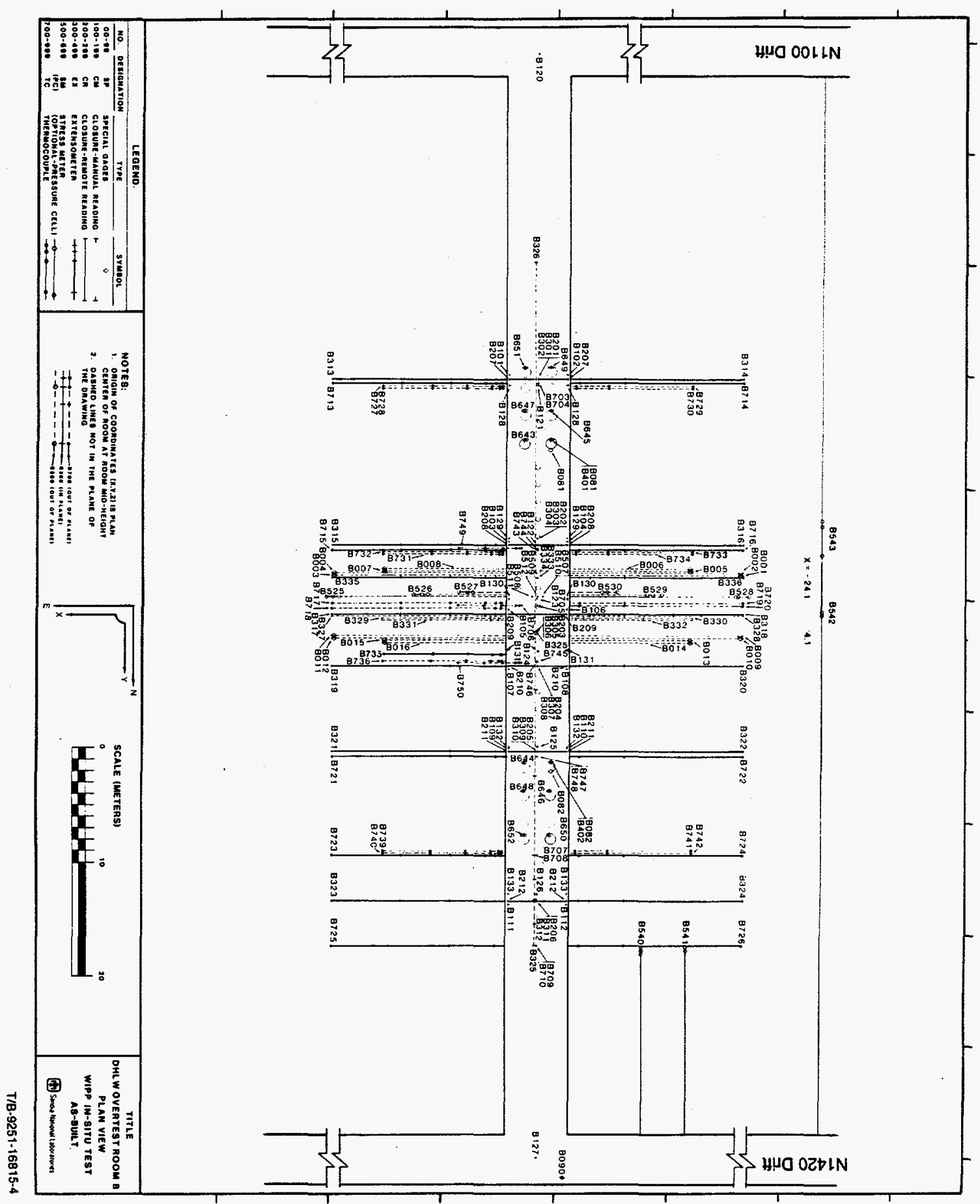


In addition to the coordinate systems discussed above, the individual room coordinate systems were located within a global survey system that was based on surface benchmarks.

\subsection{Gage Installation}

Most instrument holes were fitted with steel collars by the mining contractor during test room construction [34]. During the drilling process, the instrument hole was drilled first, then a larger diameter, $460 \mathrm{~mm}$ (18 in) long hole collar hole was drilled without moving the drilling rig. A pilot bit was used for drilling the collar holes to ensure concentricity with the gage holes.

After drilling, the collars were grouted in place by the mining contractor as shown in Figure 2.4.1. Typically, a circular foam rubber disk was placed at the far end of the collar hole to serve as a grout seal. The collar was then pushed tightly against the foam disk; collars in vertical-up installations were temporarily held in place with steel straps secured to the formation surface with "Ramset" studs. Two grout tubes, one for filling and one for bleeding, were placed in the annulus of the collar, and the near end of the annulus was sealed with hand-packed grout. Finally, the annulus was pumped full of grout after the seal had set.

The typical collar was made of a $530 \mathrm{~mm}(21 \mathrm{in})$ length of schedule 40 steel pipe with a steel pipe flange welded to one end. Near-field thermocouple installations (Section 3.7), as an exception, used collars made of $300 \mathrm{~mm}(12 \mathrm{in})$ lengths of pipe. Most gages were fitted with collars made of $76 \mathrm{~mm}$ (3 in) nominal diameter pipe while wire extensometers (Section 3.2.2) were fitted with collars made of $127 \mathrm{~mm}$ (5 in) nominal diameter pipe. Centralizers made of short pieces of round 


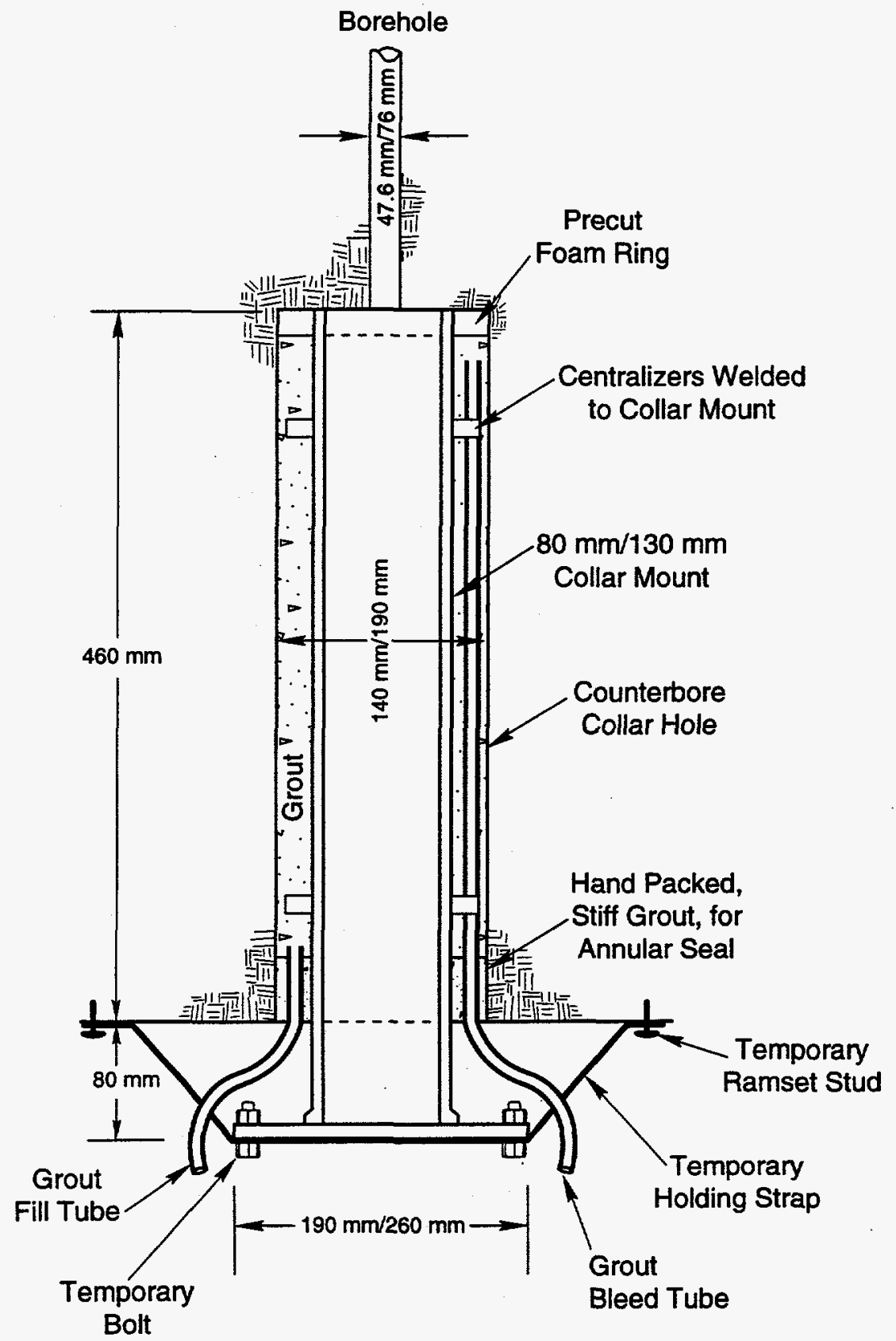

Figure 2.4.1. Instrument Collar Installation 
steel stock were welded to the collar pipes to approximate the diameter of the collar hole.

Three types of instrument holes were not fitted with collars as described above. Manual closure points were protected by a short length of steel pipe (section 3.1.2). Anchor bolt extensometers (section 3.2.1) had protective steel collars that were installed with the gage head. Inclinometer holes (Section 3.4) were cased with special extruded aluminum casing.

Permanent, mechanical response gages were generally installed within a period of three weeks after a test room was released to sandia by the mining contractor. Thermal response gages were installed later, but before test heaters were energized. Details of gage installation procedures for the various gage types are discussed in Chapter 3 .

After installation, the instrumentation was checked with portable power supplies and digital multimeters to verify that the gages were operating correctly. Typically, input and output voltages and resistances were measured and recorded before connecting the gage to the DAs (Section 2.5).

\subsection{Data Acquisition}

The TSI in situ tests required an automated Data Acquisition System (DAS) to be incorporated into the experiment design because of the long duration of the tests and the large number of remotely monitored gages to be used; the TSI tests were active for several years and eventually included over 3,500 remote gages. The DAs consisted of underground instrument sheds that were connected to a surface-based computer system by an IEEE-488 bus (a standard data-transmission system) and to the test instrumentation by an extensive cabling system, as shown schematically in 
Figure 2.5.1. The DAS was previously developed for use in a large-scale oil shale retort testing program, and is described in detail in another report [35].

Each of the major TSI test rooms had a separate underground instrument shed that was located in an alcove dedicated to that particular room; the smaller tests were served by sheds belonging to the major tests. The sheds served as data acquisition hubs by providing continuous excitation to the gages, acquiring data from the gages, and transmitting the data to the surface-based computer system. Each shed contained power supplies, scanners, multiplexers, digital multimeters, calibration standards, video terminals, and modems. The equipment in the sheds was connected to the gages in the test rooms by an extensive array of jumper cables.

The surface-based computer system included a ModComp computer with video terminals, modems, printers, disc drives, magnetic tape drives, a backup power system, and a backup computer. The system was served by a library of over 50 separate software programs for data acquisition and other activities such as data management, system diagnostics, and plotting. DAS software has been qualified under quality Assurance Procedure (QAP) 19-1 Rev. 2 as either SNL-SW (Sandia National Laboratory Software) or as Developed Codes. There is no further development or use planned for these codes and they will eventually be classified as "retired".

All remotely read instrumentation was connected to the DAS and scanned at regular intervals, typically every four hours, although scan periods as small as 15 seconds were used for a limited number of gages. The system was capable of handling 65,534 measurands, where a measurand is a single measured value such as resistance, voltage, current, or a calculated 


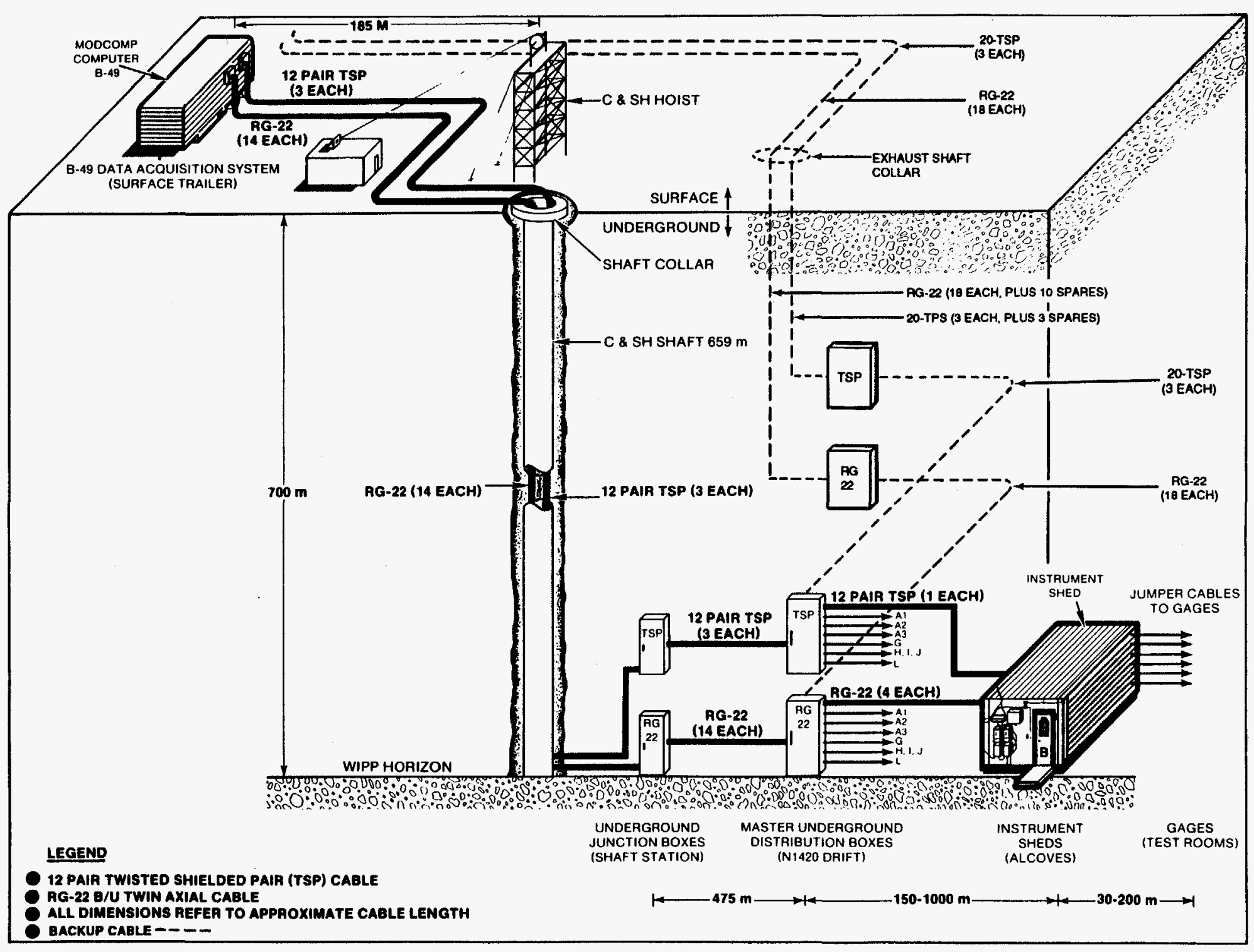

Figure 2.5.1. Schematic of the Data Acquisition System 
engineering value such as displacement, temperature, or pressure. At one time, the system scanned as many as 16,000 measurands once every four hours.

The entire system of data collection, archival, reduction and retrieval is known as the WIPP In Situ Data Acquisition and Management (WISDAAM) system [36]. Programs on the ModComp computer calculated engineering values using the measured values and gage calibration equations. The calculated and measured data were recorded on magnetic tapes [TOP 151] which were transferred to Sandia offices in Albuquerque, $\mathrm{NM}$ on a regular basis where they were used to build an engineering database. This database is maintained on a Microvax computer system and is available for data reduction and analysis. The data were also archived on copies of the transfer tapes and on optical disks. Data collected from almost 700 manually read gages (Table 3.0.1) were added to the WISDAAM system to form a complete database. WISDAAM UNDERDOG Mod. 2.00-00 was qualified as SNL-SW under QAP 19-1 Rev. 1 before it was retired. No further development of WISDAAM is anticipated.

In 1996, the ModComp data acquisition functions were terminated and a simpler data acquisition system based on a personal computer was emplaced to continue monitoring the TSI experiments in the AIS and Room D. This system was designed to record the data in a format that would allow easy integration of the data into the existing WISDAAM database. The system is qualified according to QAP 19-1 Rev. 2 as in the case of the previously discussed DAS.

\subsection{Gage Maintenance}

Instrumentation was maintained on a regular schedule with each test room originally scheduled for maintenance once every six weeks [TOP OI8], 
although the frequency was decreased as the experiments aged. All gages were maintained by this program which included a technical review of the gage output and a visual inspection of the gages in the field by the instrumentation staff. Based on this review, maintenance was initiated for gages that needed cleaning or repair. Minor items were attended to with the gage in place, while major problems were corrected by replacing the gage, when this was possible. Gages were monitored for some time after repairs had been made to ensure that the problems had been remedied. If a gage was not repairable, it would be deactivated and no longer scanned by the DAS. All maintenance activities were performed according to established $Q A$ (quality assurance) procedures, and were requested and logged on specially prepared QA forms (Section 2.7). It is important to note that the maintenance program also provided QA documentation that gages were periodically checked and were operating properly.

Gage failures were brought to light by two methods in addition to the regular maintenance program. A telephone hotline was available early in the experimental program for underground personnel to report gages that had been accidentally damaged or disturbed. The hotline had an answering machine that was checked daily for messages regarding gages that needed attention. The second method utilized a computer-generated Event Log to flag gages needing attention [TOP 006]. By this method, a record was written to the Event Log by the DAS computer if the difference between two consecutive measurements for a particular gage exceeded a predefined tolerance, or if the computer was unable to interrogate a gage. Typically, repairs initiated by these methods were integrated into the regularly scheduled maintenance program. 
The gage maintenance program also included the development of modifications to gage systems. These modifications were implemented either to simplify routine maintenance tasks, or to replace components prone to failure and malfunction. This process began with a stringent evaluation of gage components prior to installation and evolved as the gages were placed in operation. As additional experience with these systems was gained, different problems would arise and solutions would be developed and implemented. The modification process continued as long as the gages were in service.

\subsection{Quality Assurance}

To ensure that all TSI instrumentation was calibrated, installed, monitored, and maintained properly and consistently, over 500 Tops were developed to provide detailed instructions for every type of instrument utilized in the TSI experiments. Remember that in the case of the thermocouples and stressmeters, calibrations were only representative of a group or batch of gages. The appropriate personnel were trained to these procedures on a defined schedule. Accompanying the procedures were standardized forms that were required to be completed when performing these activities. These procedures and forms were written and updated by the personnel who had developed the procedures in the field, or who were responsible for performing the tasks. To ensure accuracy, the procedures and forms were reviewed by the PI and others. These documents not only ensured that the tasks were performed correctly, but provided a permanent record of how and when each task was completed. The procedures and completed forms are maintained on file at the Nuclear waste Management Program Libraries at the WIPP site and at the sandia offices in Albuquerque, NM. 
Over 4,200 individual gages were installed in the TSI in situ tests including about 3,500 remotely monitored and 700 manually monitored gages. The various types of instruments included room closure gages, extensometers, stress gages, inclinometers, survey reference gages, borehole strain gages, thermocouples, thermal flux meters, heater power gages, air velocity gages, and shear detectors. Moreover, there were several distinct designs for some gage types. This chapter describes each type of gage used in the tests, and discusses their calibration, installation, operation, and maintenance procedures. Table 3.0.1 lists the quantities of each type of gage installed in the various test rooms.

\subsection{Room Closure Gages}

Room closure gages are devices that measure the convergence of excavation surfaces. In the TSI in situ tests, both manually monitored and remotely monitored closure gages were employed to monitor convergence. The manual closure gages were measured with tape extensometers and are discussed below in section 3.1.2. The remote closure gages were based on displacement transducers that were monitored by the DAS and are discussed in section 3.1.3. The mining sequence closure gages, although actually a special application of the manual closure gages, were unique in their contribution to the tests and are discussed as a separate gage type in section 3.1.1. The quantities of the various types of room closure gages installed in the TSI tests are shown in Table 3.0.1.

The manual and remote closure gages were used in five different applications in the TSI in situ tests: mining sequence, temporary, permanent, remedial, and brow. Mining sequence gages were special gages 
Table 3.0.1. Quantities ${ }^{*}$ of Gages Installed, TSI In Situ Tests

\begin{tabular}{|c|c|c|c|c|c|c|c|c|c|c|c|}
\hline Room - & - Al & A2 & A3 & B & C & $\mathrm{D}$ & G & $\mathbf{H}$ & $Q$ & & Total \\
\hline \multicolumn{12}{|l|}{ Manual Gages } \\
\hline Mining Sequence Closure & 21 & 21 & 21 & 21 & 14 & 21 & 12 & 19 & 8 & 8 & 166 \\
\hline Temporary Closure & 8 & 8 & 8 & 14 & - & - & 12 & 11 & - & 10 & 71 \\
\hline Permanent Closure & 20 & 18 & 20 & 12 & - & 6 & - & 8 & - & 6 & 90 \\
\hline Remedial Closure & 50 & 50 & 50 & 28 & - & - & - & - & - & - & 178 \\
\hline Brow Closure & 8 & 6 & 8 & 6 & - & 8 & - & - & - & - & 36 \\
\hline Anchor Bolt Extensometers & - & - & - & - & - & - & 96 & - & - & - & 96 \\
\hline Inclinometers & - & 24 & - & 16 & - & 3 & - & 10 & - & - & 53 \\
\hline Fixed Reference & - & 1 & - & 1 & - & - & 1 & 1 & - & - & 4 \\
\hline Manual Gage Total & 107 & 128 & 107 & 98 & 14 & 38 & 121 & 49 & 8 & 24 & 694 \\
\hline \multicolumn{12}{|l|}{ Remote Gages } \\
\hline Permanent Closure & 9 & 10 & 9 & 12 & 18 & 2 & 14 & 8 & 12 & - & 94 \\
\hline Remedial Closure & 12 & 12 & 12 & - & - & - & - & - & - & - & 36 \\
\hline Brow Closure & - & 2 & - & 2 & - & - & - & - & - & - & 4 \\
\hline \multicolumn{12}{|l|}{ Extensometers } \\
\hline Serata E-200L & 92 & 132 & 87 & 170 & 60 & 20 & - & 56 & - & - & 617 \\
\hline Serata $E-300$ & - & - & - & - & - & - & - & 24 & - & - & 24 \\
\hline Irad Model 4000 & 19 & 18 & 19 & 20 & - & - & 100 & 38 & - & 60 & 274 \\
\hline Serata $\mathrm{C}-300$ & - & 11 & - & 8 & - & - & - & - & - & - & 19 \\
\hline \multicolumn{12}{|l|}{ Stress Gages } \\
\hline Strain-Gaged & - & 72 & - & 6 & 60 & - & 21 & 9 & - & - & 168 \\
\hline Bureau of Mines & - & 6 & 15 & 42 & 43 & - & 21 & 60 & - & - & 187 \\
\hline \multicolumn{12}{|l|}{ Thermocouples } \\
\hline Far-Field & 78 & 186 & 176 & 207 & - & - & - & 100 & - & 36 & 783 \\
\hline Neax-Field & 78 & 186 & 150 & 162 & - & - & - & - & - & - & 576 \\
\hline Heater ${ }^{\star \star}$ & 70 & 104 & 54 & 134 & - & - & - & - & - & - & 362 \\
\hline Flux Meter & 35 & 39 & - & 36 & - & - & - & 8 & - & - & 118 \\
\hline Air Stream & - & - & - & - & - & - & - & - & - & 6 & 6 \\
\hline Flux Meters & 35 & 39 & - & 36 & - & - & - & 8 & - & - & 118 \\
\hline Heater Power ${ }^{* \star}$ & 19 & 32 & 17 & 29 & - & - & - & 19 & - & - & 116 \\
\hline Environmental, Ventilation & 4 & 4 & 4 & 9 & - & - & - & 7 & - & - & 28 \\
\hline Borehole strain & 2 & 2 & 2 & - & 8 & - & - & - & - & - & 14 \\
\hline Remote Gage Total & 453 & 855 & 545 & 873 & 189 & 22 & 156 & 337 & 12 & 102 & 3544 \\
\hline Grand Tota & 560 & 983 & 652 & 971 & 203 & 60 & 277 & 386 & 20 & 126 & 4238 \\
\hline
\end{tabular}

* Quantities of individual gages, as opposed to multiple-gage units.

** Includes WPP gages that also contributed to the TSI experiments. 
that were installed and measured during the excavation process in order to capture the earliest deformation data. Temporary, manually read closure gages followed the mining sequence gages and were installed and measured by geotechnical crews within eight hours after a room had been excavated to final dimensions. These gages were referred to as temporary because they provided interim data, although many were retained on a permanent basis. After release of a test room to Sandia, permanent closure gages were emplaced to remain in use for the life of the experiment.

Remedial closure gages were a special application of closure gages that were added to the test configurations to investigate the effects of room geometry on the rate of room closure. Test room mining was controlled by specifications that set tolerances for room dimensions and bearing. During mining, however, portions of Room A2 (see Figure 1.0.3 for location) were excavated outside the specified tolerances [34]. At the time of test construction, it was not clear what effect the overexcavation would have on deformation, and it was felt that additional attention to test room closure was necessary. The remediation for this nonconformance required, in part, that the contractor provide additional closure gages. In Room A2, dense arrays of closure gages were installed at five stations. For comparative purposes, similar arrays of closure gages were installed in Rooms $A 1, A 3$, and $B$ because of their identical room geometries.

Brow closure gages were another special application of room closure gages that measured the vertical closure at the entrances to the test rooms. The backs of the $A, B$, and $D$ test rooms were higher than those of the access drifts, as shown in Figure 2.2.1; brow gages measured closure and monitored separation at this transition. A set of brow gages were 
installed at each end of these test rooms.

3.1.1 Mining Sequence Closure Gages: Mining sequence closure points were installed and measured as mining progressed in order to minimize the loss of valuable closure data by providing the earliest deformation measurements. The A, B, D, G, and $H$ test rooms (see Figure 1.0 .3 for locations) required up to four excavation passes to develop the specified dimensions, and required additional trim passes to meet the tolerances specified for smoothness [34]. In these rooms, closure points were installed in the ribs, floor, and back during each pass as shown in Figure 3.1.1. The AIS, the ISBT borehole, and Room Q, in contrast, required only one excavation pass. In all tests, mining sequence points were established at three or more stations along the length of the test room during each pass.

Design: In the $A, B, D, G$, and $H$ test rooms, mining sequence closure points consisted of eyebolts attached to $6 \mathrm{~mm}(1 / 4 \mathrm{in})$ diameter "Ramset" threaded studs that were shot into the formation (Figure 3.1.2). ("Ramset" is a fastening system that uses a .22 caliber blank charge to set a steel stud into the formation.) The eyebolts were threaded onto the studs with coupling nuts and secured with "Loctite" thread adhesive. Floor points were recessed in $64 \mathrm{~mm}(2.5 \mathrm{in})$ diameter, $100 \mathrm{~mm}$ (4 in) deep holes and were protected by steel caps.

In the AIS, a unique Early Closure point Emplacement Machine was designed and fabricated by Sandia to install and measure early closure points in the shaft during the shaft boring process [37]. The machine was made from a $6.02 \mathrm{~m}$ (19 ft $9 \mathrm{in})$ length of $250 \mathrm{~mm}(10 \mathrm{in})$ diameter polyvinyl chloride (PVC) pipe with smaller diameter sections of pipe in each end (Figure 3.1.3). The smaller pipe sections contained electric 

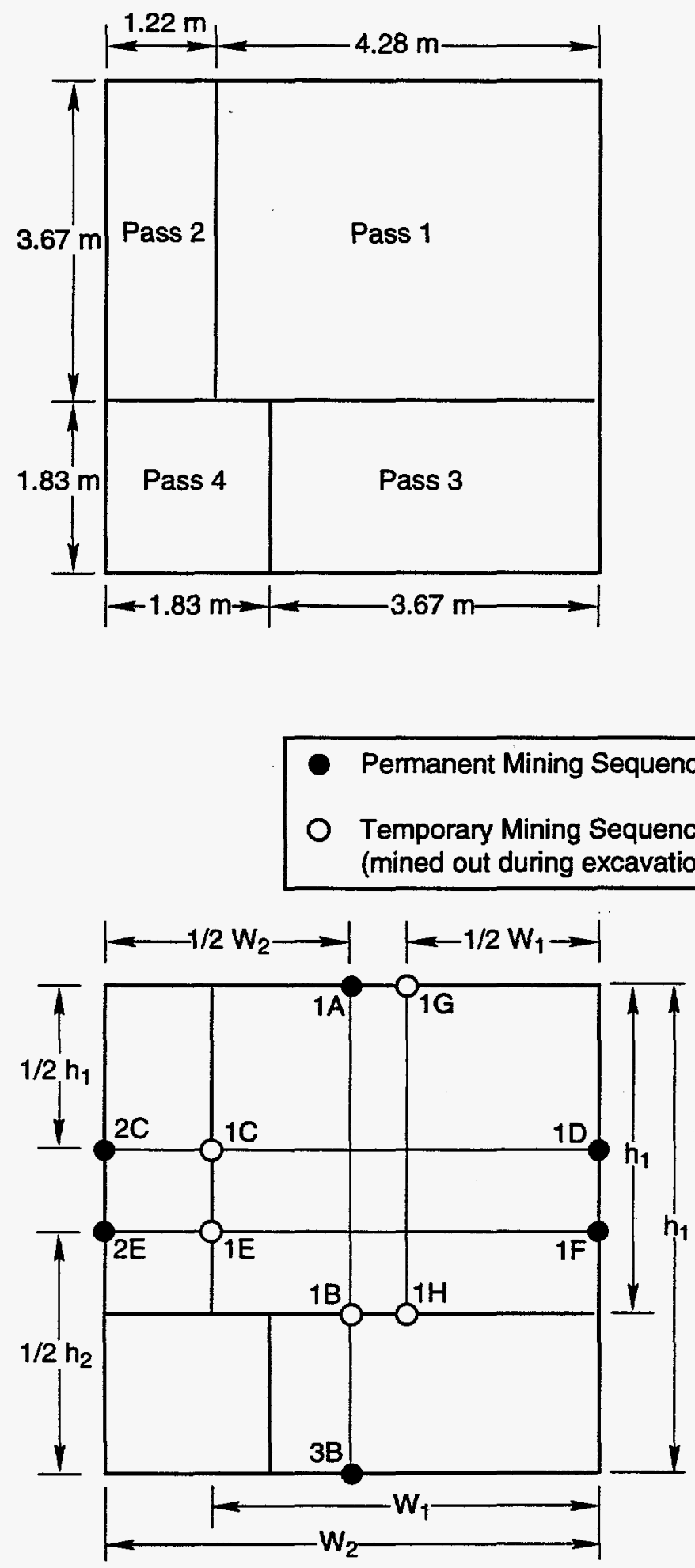

TM-16815-14

Figure 3.1.1. Cross Section of a Mining Sequence Closure Station 


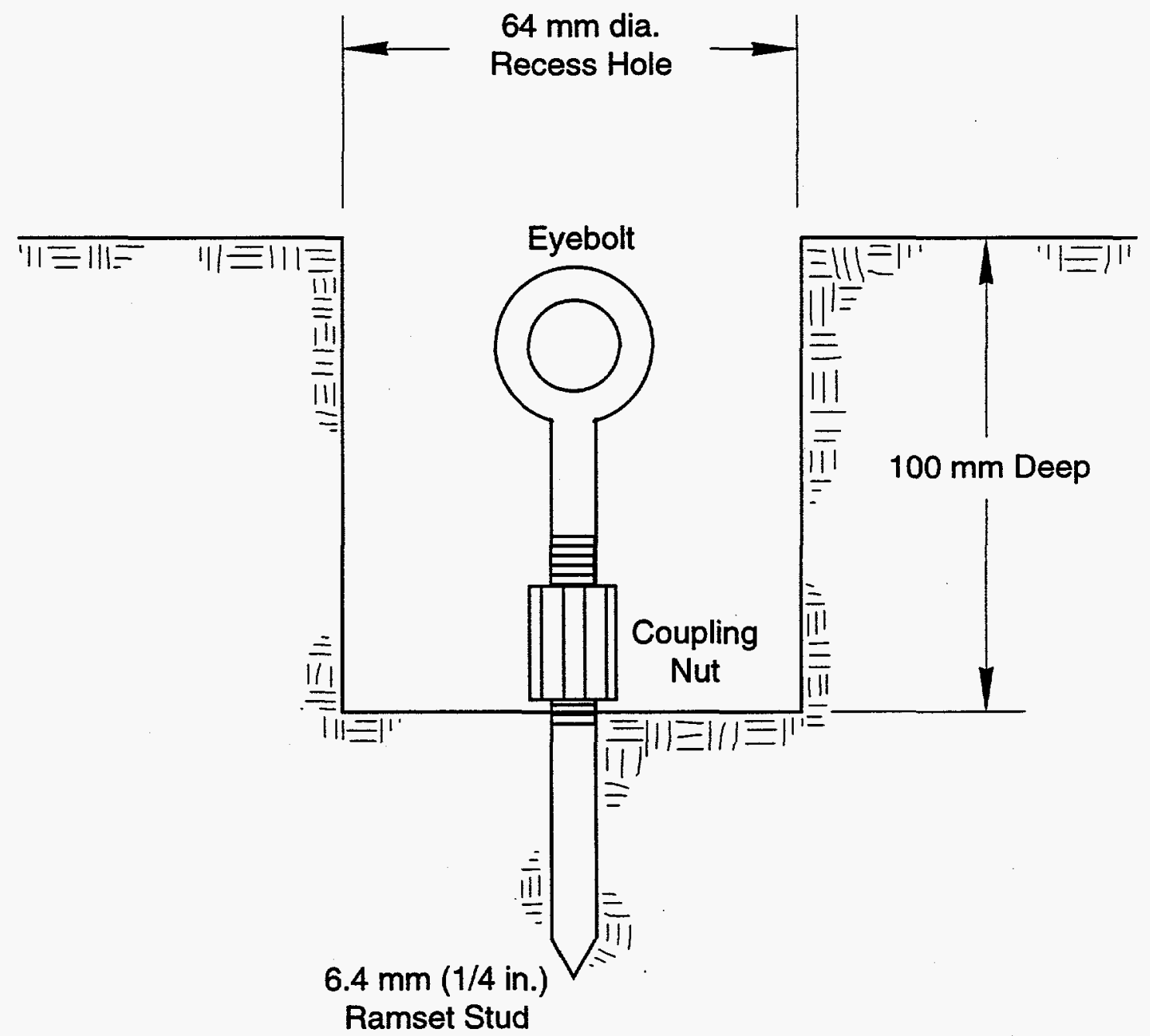

$T / M-16060-11$

Figure 3.1.2. Mining Sequence Closure Point Installation 


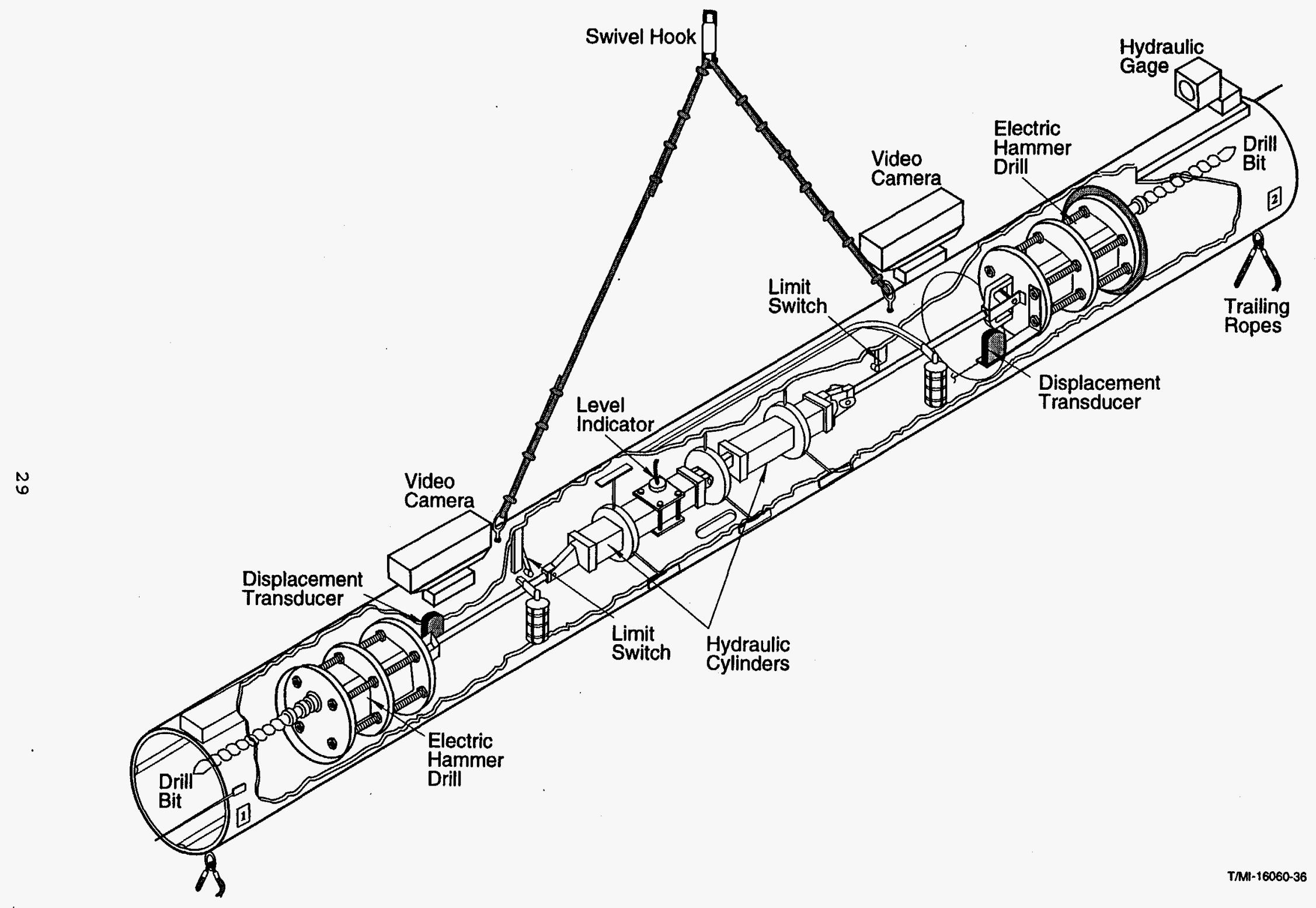

Figure 3.1.3. Early Closure Point Emplacement Machine, AIS 
rotary hammer drills with $25 \mathrm{~mm}$ ( 1 in) diameter bits that were pushed radially outward or inward with double-acting hydraulic cylinders. Two Research Incorporated (R.I.) displacement transducers (Section 3.1.3) measured the distance traveled by the cylinders and drills. In addition, limit switches on each assembly indicated travel of the individual drills so that it was possible to bore approximately equal depths with each drill. The machine also included a level sensor to ensure that the assembly was approximately horizontal during drilling. An instrument cart situated at the bottom of the shaft contained the instrumentation necessary to monitor all components of the machine including the displacement transducers, microswitches, level indicator, and hydraulic cylinders. In addition, three video cameras were used to monitor the machine during setup and drilling; one was mounted on the cart to monitor the orientation of the machine and two were mounted on the ends of the machine to monitor drilling.

In the ISBT, the closure points were based on $13 \mathrm{~mm}(1 / 2 \mathrm{in})$ diameter "Hilti" fasteners. The fasteners were installed in $14 \mathrm{~mm}(9 / 16$ in) diameter boreholes with recess holes that measured $38 \mathrm{~mm}(1.5$ in) in diameter and $75 \mathrm{~mm}(3 \mathrm{in})$ in depth. The fasteners were threaded, stainless steel rods that were epoxied in small, countersunk holes in the wall of the test borehole (Figure 3.1.4). The deep ends of the rods were in the form of chisel points that were designed to mix the epoxy as the rods were installed. A concave, spherical depression was machined in the outer end of each rod to serve as the measurement seat for an inside micrometer. The rods were threaded so that brackets for permanent displacement transducers could be attached at a later time with bolts and coupling nuts. 


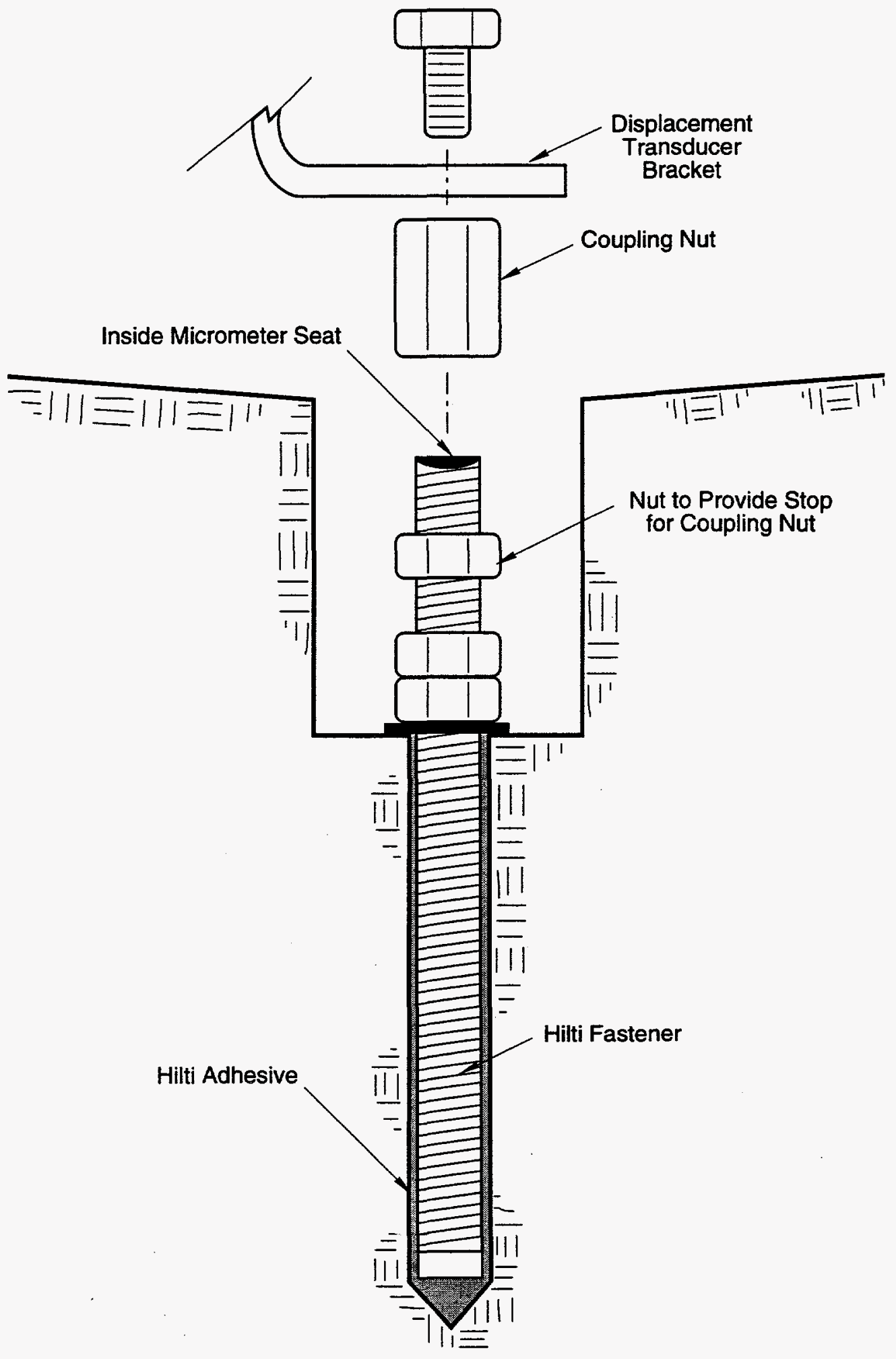

TM-16060-35

Figure 3.1.4. Mining Sequence Closure Point Installation, ISBT 
In Room Q, mining sequence closure points were based on the "Hilti" fasteners described above, but the outer ends of the rods were drilled and threaded (Figure 3.1.5). Eyebolts with a shank diameter of $6 \mathrm{~mm}(1 / 4 \mathrm{in})$ were threaded into the ends of the rods and were secured with lock nuts and "Loctite" thread adhesive [TOP 076]. In Room $Q$, the dimensions of the recess holes were modified to make installation easier; the recesses measured $100 \mathrm{~mm}(4 \mathrm{in})$ in diameter and $75 \mathrm{~mm}(3 \mathrm{in})$ in depth.

Calibration: Slope Indicator Company (SINCO) tape extensometers were used to measure the mining sequence closure gages in the $A, B, D, G, H$, and $Q$ test rooms. These instruments were calibrated as described in Section 3.1.2.

The Early Closure Point Emplacement Machine used in the AIS was calibrated with a pair of specially fabricated calibration fixtures that fit over the drill bits, two sINCO tape extensometers, and a depth micrometer. Each fixture was a T-shaped bracket that was made from a short length of steel pipe (the leg of the $T$ ) that was welded to a short length of channel beam (the cross of the $T$ ). The pipes were designed to fit over the drill bits while the beams contained hooks for the extensometers. To calibrate the machine, the two fixtures were placed over the drill bits and the two tape extensometers were stretched between the fixtures (parallel to the machine) to maintain the fixtures in balance. The extensometers measured the distance between the fixtures while depth micrometers measured the depth of the drill bits inside the fixtures. The measurements given by the extensometers and micrometers were then used to determine the distance between the ends of the two drill bits. These measurements were made at two different extensions of the drills: one slightly past the minimum extension (to remove the effects of 


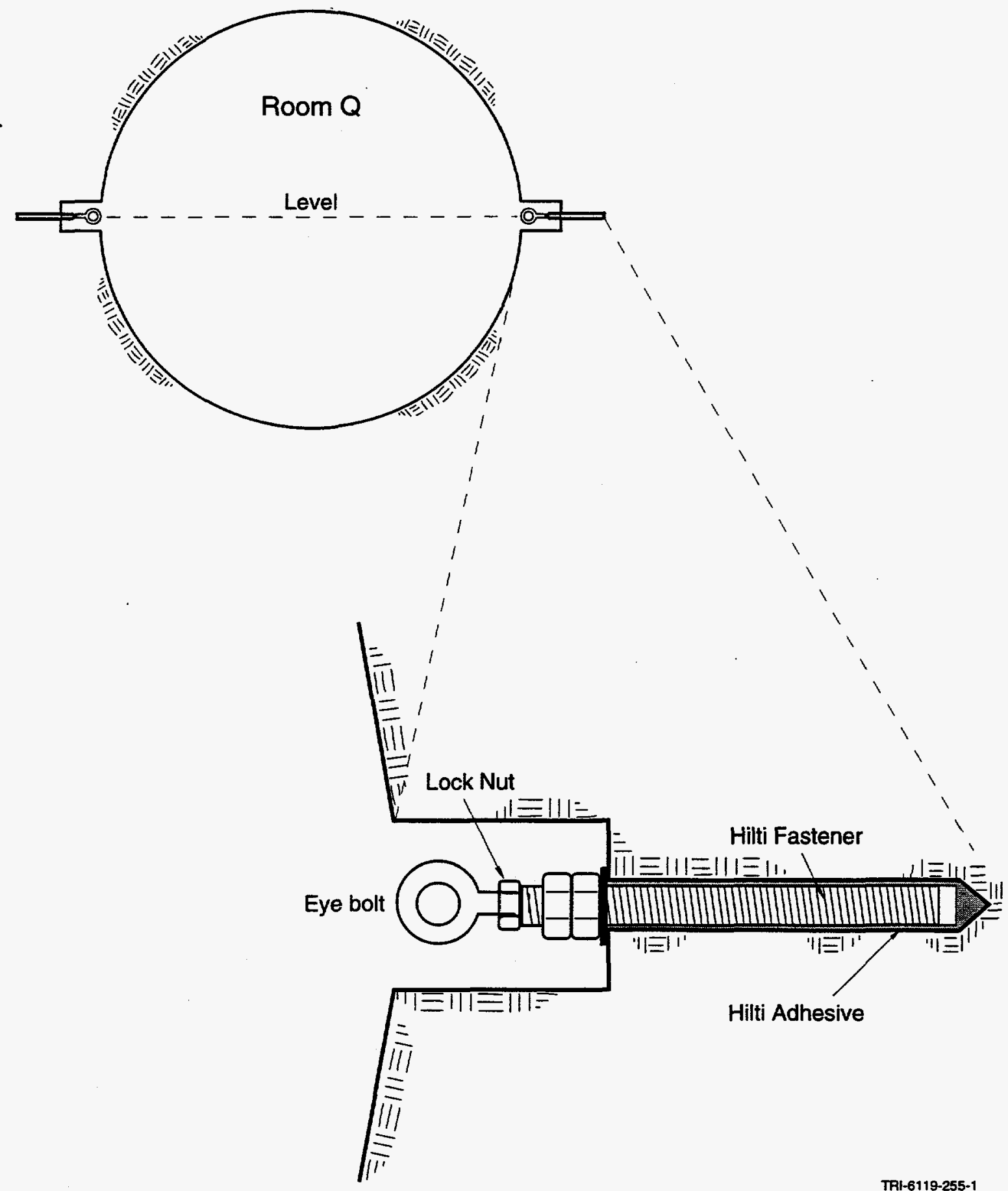

Figure 3.1.5. Mining Sequence Closure Point Installation, Room $Q$ 
play in the system), and one at the maximum extension. During this process, transducer voltages were monitored by digital voltmeters as described in the calibration discussion of section 3.1.3. Linear regression analysis was then used to correlate transducer voltages to the distance between the drill bits. In addition, the effects of machine compression were evaluated by setting up the machine between the ribs of Room G, pressurizing the hydraulic cylinders to force the drills against the ribs, and measuring the distance between the ribs at five different cylinder pressures.

In the ISBT, a digital inside micrometer was used to make early closure measurements. This gage was calibrated by the same method used to calibrate the outside micrometer that was used for measuring convergence of the fixed reference gage anchors (Section 3.5.1). It was also checked occasionally on a fixture mounted to the rib adjacent to the test borehole.

Installation: The procedures for the installation of mining sequence closure points were developed and practiced in Room 4 of the SPDV (Site and Preliminary Design Validation) test panel, Room D, Room G, and in a $0.9 \mathrm{~m}$ (3 ft) diameter borehole in the rib of the $\mathrm{N} 1420$ drift near Room $\mathrm{C2}$ (see Figure 1.0.3 for locations). Although these locations were existing excavations, they provided opportunities to test, verify, and modify, if necessary, the surveying and installation methods. The methods were appropriately adjusted to minimize installation time and disturbance to the mining operations.

In the $A, B, D, G$, and $H$ test rooms, the actual installation and initial measurement of the mining sequence closure points was an efficient operation that required excavation to be interrupted for no more than 
15 minutes [TOP 076]. During test room excavation, the mining machine was stopped after it had passed a mining sequence station by about $2 \mathrm{~m}$ ( $6 \mathrm{ft}$ ) so that installation crews could locate and install the closure points. The closure points were located with abbreviated survey methods that used tape measures, plumb bobs, string lines, and hand levels. After the first pass, manual closure points were placed at the midpoints of the floor, back, and ribs as depicted by points 1C, ID, 1G, and $1 \mathrm{H}$ in Figure 3.1 .1 . Closure points were also placed at the intersection of the final room centerlines and the existing excavation faces (points $1 A, 1 B, 1 E$, and IF). On the second pass, measurements were taken at the aforementioned points as the mining machine approached and passed the station. This required points $2 \mathrm{C}$ and $2 \mathrm{E}$ to be installed in the newly mined surface to replace points $1 \mathrm{C}$ and $1 \mathrm{E}$. Similar measurements were taken during the third pass, and point $3 B$ was installed to replace point $1 B$. At the conclusion of the measurements, the floor points were covered with protective caps and excavation was allowed to continue.

During excavation of the AIs, the upward reaming of the shaft was interrupted after about $46 \mathrm{~m}$ (150 ft) of progress to allow closure points to be installed and measured with the Early Closure Point Emplacement Machine [TOP 166]. The drilling was stopped once for this purpose and closure points were installed at depths of $630.0 \mathrm{~m}(2067 \mathrm{ft})$ and $611.7 \mathrm{~m}$ $(2007 \mathrm{ft})$. To install and measure these points, the machine was hoisted up the shaft by a wire rope that was lowered through the drill string from the surface. Once the machine was at the desired elevation in the shaft, ropes were used to level the machine and place it in the proper orientation. After the machine was oriented, the drills and hydraulic cylinders were activated and drilling commenced. When indicators showed 
that the bits had drilled to a depth of $200 \mathrm{~mm}$ ( 8 in), drilling was stopped and the diameter was measured remotely with the displacement transducers. All machine operations were remotely controlled and monitored because safety concerns prohibited personnel from entering the shaft area [37]. Eighteen months later, after shaft excavation and outfitting activities were completed, access to the early closure points was again possible and a second set of measurements was made. This time, the measurements were taken by inserting the original drill bits into the closure point holes and measuring the diameter with extension rods and a tape measure [TOP 396]. At that time, supplemental, permanent closure points were installed adjacent to the early closure points.

In the ISBT, early closure points were emplaced at seven different stations along the length of the borehole. The ISBT borehole was drilled with a $0.9 \mathrm{~m}$ (3 ft) long, $0.9 \mathrm{~m}(3 \mathrm{ft})$ diameter masonry bit. During the drilling operation, the drill string and bit were withdrawn from the borehole after each $0.9 \mathrm{~m}$ ( 3 feet) of progress to allow the core to be broken off and removed. These operations allowed instrumentation crews access to the borehole for installing and measuring mining sequence closure points. The points were located with abbreviated survey methods that made use of string lines, plumb bobs, carpenters levels, compasses, and machinist's curve markers. Chords and plumb lines were used to check the location of the points and ensure that they were placed at the exact top, bottom, and sides of the excavation.

In Room $Q$, one set of vertical and horizontal closure points was installed at each of four mining sequence stations. Room $Q$ was excavated with a tunnel boring machine that was operated during the day shift only. After the machine had passed a mining sequence closure station, it would 
be backed up about $2 \mathrm{~m}\left(\begin{array}{ll}6 & \mathrm{ft}\end{array}\right)$ at the end of the shift to give the instrumentation crew access to the excavation face. During the evening shift, the crew would crawl through the length of the boring machine to reach the excavation face. Once there, the crew would install and measure the mining sequence closure points. Abbreviated survey methods, similar to those discussed above for the ISBT, were used to locate the closure points. The anchors were installed in countersunk holes for protection and floor points were filled with salt cuttings after measurement. The points were established within $0.8 \mathrm{~m}(2.5 \mathrm{ft})$ of the mining face.

Operation: Mining sequence closure measurements were generally taken with the SINCO tape extensometer as described in section 3.1.2. The exceptions were in the ISBT where closure measurements were made with an inside micrometer, and the AIS where the first measurements were made with the Early Closure Point Emplacement machine. The mining sequence closure gages were originally intended to be monitored until permanent manual and remote closure points could be installed, generally within a period of one month. In reality, however, many of these gages were monitored for several years and generated consistent and reliable closure data.

Maintenance: During routine measurement schedules, the closure points were inspected for damage, but none were found to have worked loose. If closure points were required for long term measurements, the "Ramset" studs were replaced with the more secure mechanical anchors shown in Figure 3.1 .6 .

3.1.2 Manual Closure Gages: Manual closure gages consisted of pairs of closure points installed in opposing faces of a test room. A closure point was simply an eye bolt anchored in the excavation surface; distance between pairs of points was measured with SINCO tape extensometers. These 


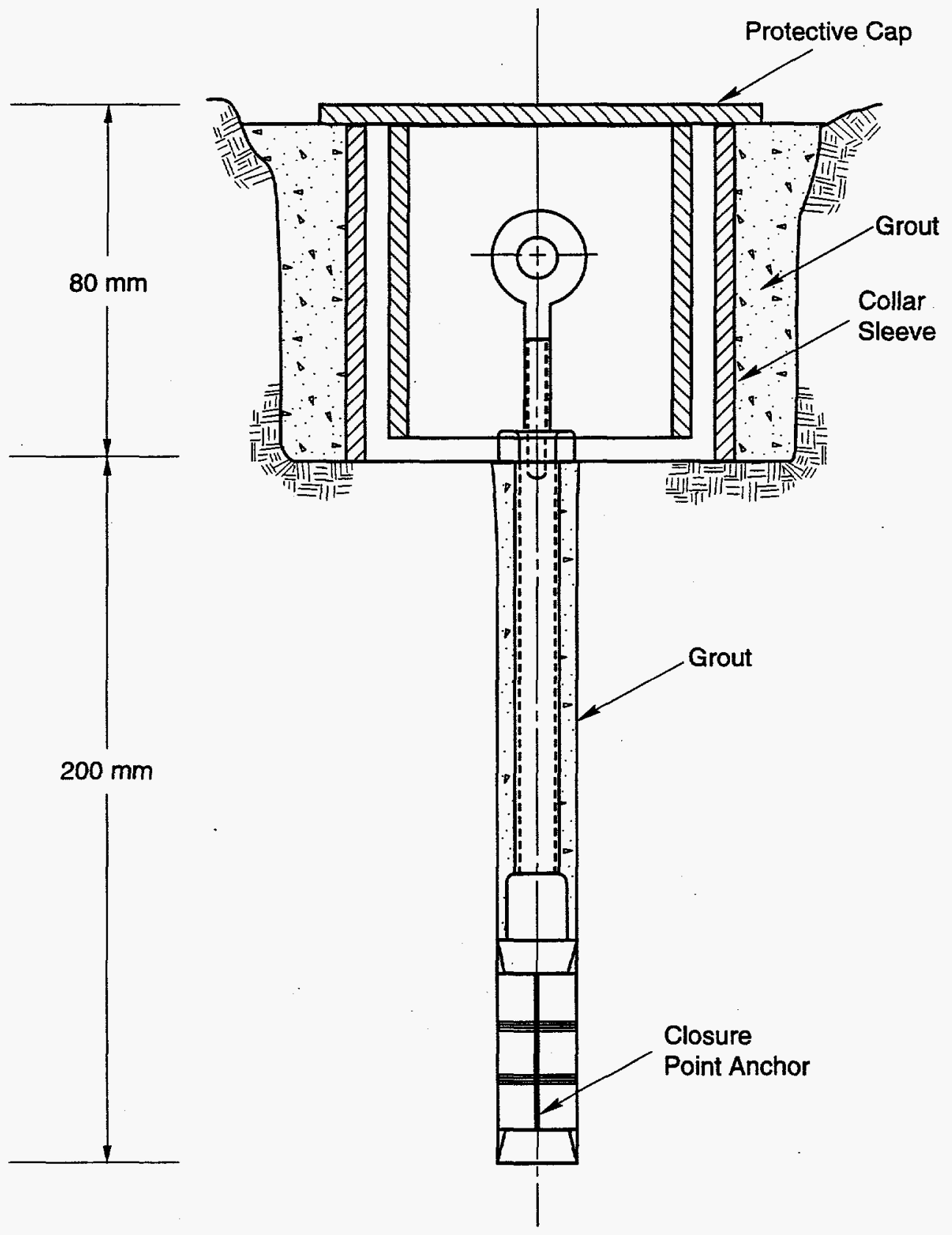

TM-16815-8

Figure 3.1.6. Manual Closure Point Installation 
gages were typically installed in groups with some gages monitoring horizontal closure and others vertical. A typical manual closure gage station is shown in Figure 3.1.7. Exceptions to the typical configuration were the manual remedial closure stations, which were configured as shown in Figure 3.1.8, and the brow gages discussed in section 3.1 .

Design: A manual closure point consisted of an eyebolt, an anchor bolt, and a double expansion-shield anchor (Figure 3.1.6). The eyebolt was made of stainless steel and had a shank diameter of $6 \mathrm{~mm}(1 / 4 \mathrm{in})$. The anchor bolt was a $13 \mathrm{~mm}(1 / 2 \mathrm{in})$ diameter by $200 \mathrm{~mm}(8 \mathrm{in})$ long hex-head bolt that was modified by drilling and tapping the head to accommodate the eyebolt. The bolt was also modified by welding a collar onto the shank so that both ends of the anchor would expand when the bolt was tightened.

Model 518115 SINCO Tape Extensometers (Figure 3.1.9) were used as the measuring device for all manual closure gages and most of the mining sequence gages. (The exceptions were the ISBT where mining sequence points were measured with an inside micrometer and the AIs where mining sequence points were measured by the Early Closure Point Machine.) The tape extensometer consisted of two components: a tape measure and a precision measuring instrument. The tape measure was a $20 \mathrm{~m}$ (66 ft) long steel oil-gaging tape that was graduated in feet and inches, and had holes punched along the length at $50.8 \mathrm{~mm}(2 \mathrm{in})$ intervals. The measuring instrument contained a dial gage, a knurled tensioning collar, and a compression spring. The dial gage measured a range of $50 \mathrm{~mm}(2 \mathrm{in})$ and was graduated in thousandths of an inch. One end of the tape was reeled up on the end of the instrument while the other end was free to pass through the nose of the instrument. A pin in the nose was used to engage 


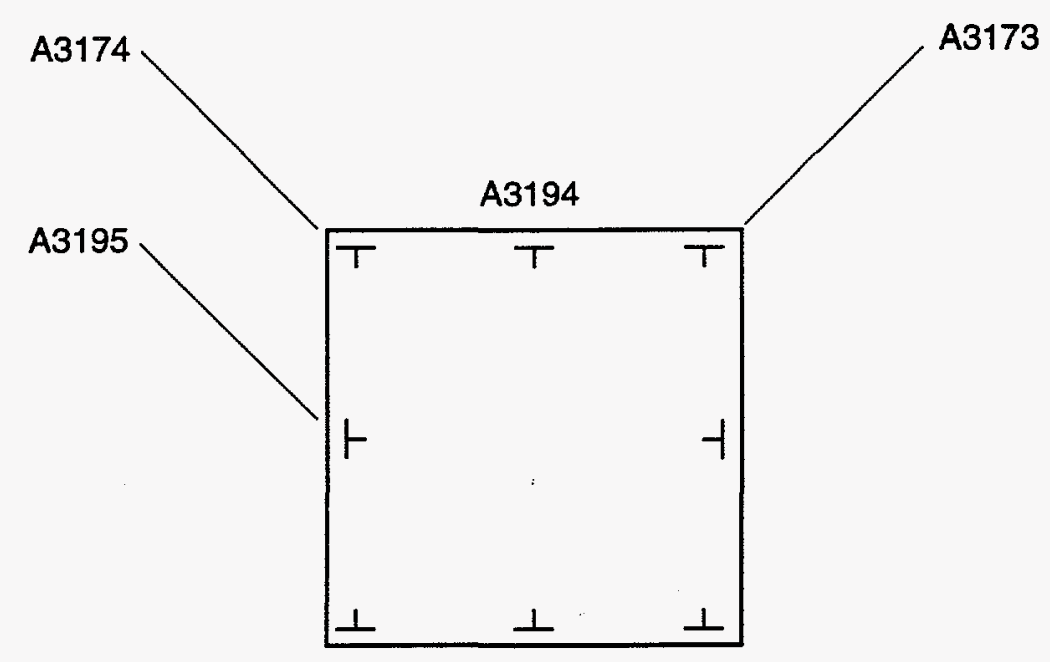

\begin{tabular}{|l|c|}
\hline \multicolumn{4}{|c|}{ Legend } \\
No. Designation $\quad$ Type $\quad$ Symbol \\
\hline $100-199 \quad$ CM & Closure-Manual Reading $+\quad+1$ \\
\hline
\end{tabular}

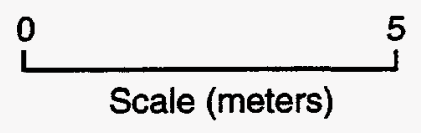

Figure 3.1.7. Cross Section of a Manual Closure Gage station

$T M-16060-28$

a hole in the tape when taking a measurement. The knurled collar and compression spring were used to tension the tape to a repeatable load of approximately $100 \mathrm{~N}(22 \mathrm{lb})$ by aligning a set of index marks. The tape and dial gage were used together to make measurements. The tape extensometer had a resolution of $0.025 \mathrm{~mm}(0.001 \mathrm{in})$ and a repeatability of $0.13 \mathrm{~mm}(0.005 \mathrm{in})$, as stated by the manufacturer.

Calibration: SINCO tape extensometers were calibrated on two different specially fabricated frames at the WIPP site; one was mounted underground, and, since 1992, a second was located on the surface at the Sandia WIPP Site Calibration Laboratory [TOPs 099, 393, and 462]. Seven different standard distances could be measured on the underground frame between eight eyebolts and four distances could similarly be measured on 


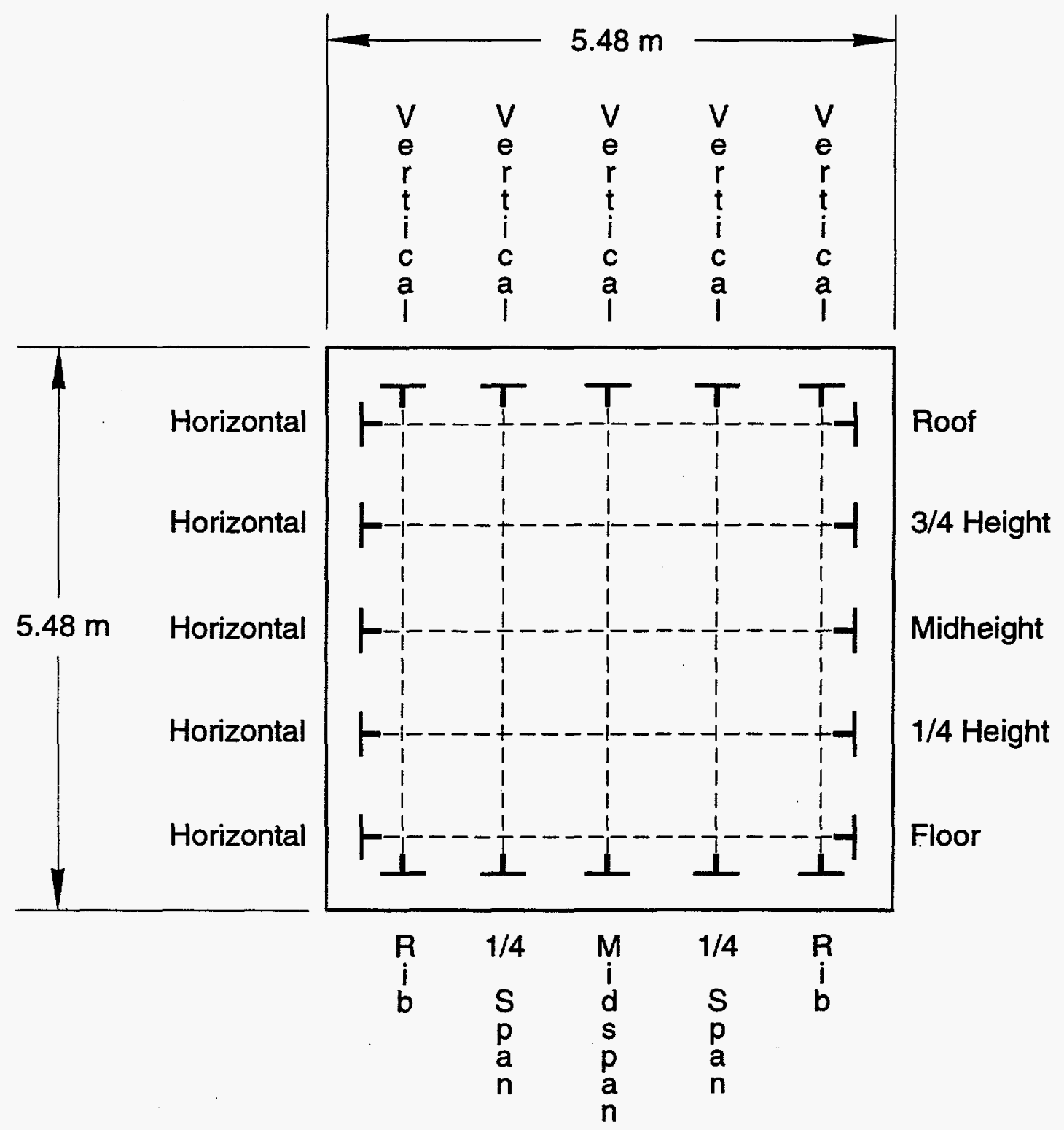

$T / M-16060-12$

Figure 3.1.8. Cross Section of a Remedial Closure Gage Station 

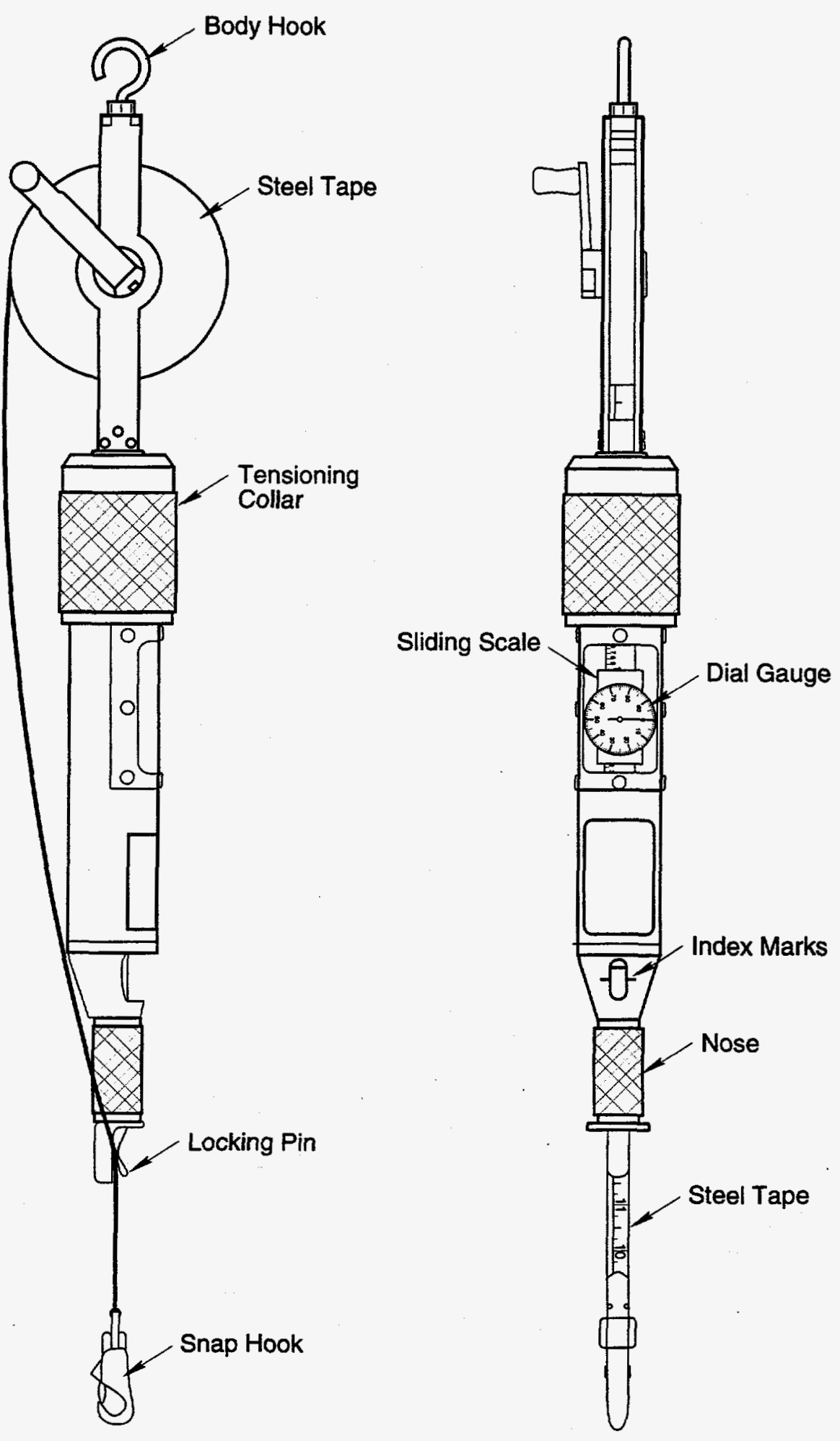

TM-16060-34

Figure 3.1.9. SINCO Tape Extensometer (Model 518115) 
the surface frame. The distances on the frames were measured and certified by instruments that were traceable to NIST standards. The frames were recertified when moved or repaired.

The tape extensometers were calibrated before taking each set of in situ measurements. During calibration, four different measurements were taken at each point and averaged. The calibration distances and instrument readings were later fit to a calibration equation by linear regression [TOP 326]. The calibration equation was used at the time of data reduction to compensate for the differences in the individual tape extensometers and to calculate a true point-to-point distance. Calibrations also provided a determination that the instrument was working properly; if the four calibration measurements were not within $0.13 \mathrm{~mm}$ $(0.005 \mathrm{in})$, the instrument would be sent to the manufacturer for inspection and repair.

The length of the extension rods used for vertical measurements was also determined before taking each set of measurements. The lengths were determined by measuring a vertical room closure station with and without the extension rod [TOPs 153 and 393]. Four different measurements were taken and averaged for each set of measurements; the difference between the two averages was used as the rod length.

Installation: Manual closure points were installed in recessed holes that were drilled with electric rotary hammer drills (Figure 3.1.6). Originally in the testing program, the installation procedure called for drilling a $150 \mathrm{~mm}$ (6 in) diameter recess hole to a depth of about $75 \mathrm{~mm}$ (3 in) and then drilling a $22 \mathrm{~mm}(7 / 8 \mathrm{in})$ diameter anchor hole in the center of the recess for a total depth of $300 \mathrm{~mm}(12 \mathrm{in})$. Iater in the experimental program, the procedure was changed and called for drilling 
the anchor hole first and then drilling a $100 \mathrm{~mm}$ (4 in) diameter recess hole [TOP 082]. BY drilling the bolt hole first, it was easier to center the hole on the survey mark. As an added benefit, the smaller diameter of the recess hole allowed both holes to be drilled with the same rotary hammer drill. In either case, an anchor bolt and expansion anchor were installed in the anchor hole. Next, an eyebolt was threaded into the anchor bolt and secured with a locknut and "Loctite" thread adhesive. Finally, floor points were protected with grouted collar sleeves and removable steel caps.

operation: To take a closure measurement with a tape extensometer, the snap hook on the end of the tape was first attached to a closure point [TOP 069]. The tape was then unreeled as the instrument was carried to the opposite closure point. The hook on the end of the instrument body was attached to this closure point and the tape was reeled in to remove the slack. The tape locking pin was then engaged in the nearest hole in the tape, and the instrument was tightened to a repeatable tension by turning the knurled collar until the index marks were aligned. Finally, the closure measurement was taken by summing the distance indicated by the tape (feet and inches) and the dial (inches, tenths, hundredths, and thousandths of inches). Measurements were taken until two successive readings agreed within $0.2 \mathrm{~mm}(0.008 \mathrm{in})$. Calibrated extension rods were used to eliminate the use of ladders when taking vertical closure readings. The protective steel caps on floor points were replaced after measurements were made.

The simple design of the manual closure points allowed these gages to survive the duration of the TSI tests and provide reliable and consistent closure data. Most permanent manual closure points were read for several 
years after installation, although room access restrictions due to unstable backs prematurely halted gage measurements in the $A$ and $B$ test rooms. A small number of closure points were permanently obstructed by other gages or hardware.

Maintenance: The tape extensometer was prone to few problems. Rarely, a tape would be replaced because of corrosion or because it had been accidentally bent. After extensive use, an instrument would need to be replaced because the tape holes and locking pins would become worn. There were few manual closure point failures; some were known to have been removed during routine scaling operations.

3.1.3 Research Inc. Remote Closure Gages: Model 4040 (later renamed Model 7704) displacement transducers manufactured by R.I. were utilized to provide remotely monitored room closure data. In the typical application, remote closure gages were physically linked to extensometer heads at opposite sides of a test room. The transducer was attached to one extensometer while a span wire was stretched across the room and attached to an eyebolt on the other (Figure 3.1.10). Typically, this closure gage and extensometer configuration was installed in both the vertical and horizontal orientations at a station (Figure 3.1.11) to give a complete measurement of displacement around the room. If no extensometers were present, the gages were anchored directly to the formation, using an installation with a transducer bracket on one side, and a manual closure point installation on the other.

Remote closure transducers were also used in the remedial and brow applications. The remote remedial gages were emplaced in a configuration similar to that of the manual remedial gages shown in Figure 3.1 .8 , except that gages adjacent to the ribs, floor, and roof (back) were omitted. 


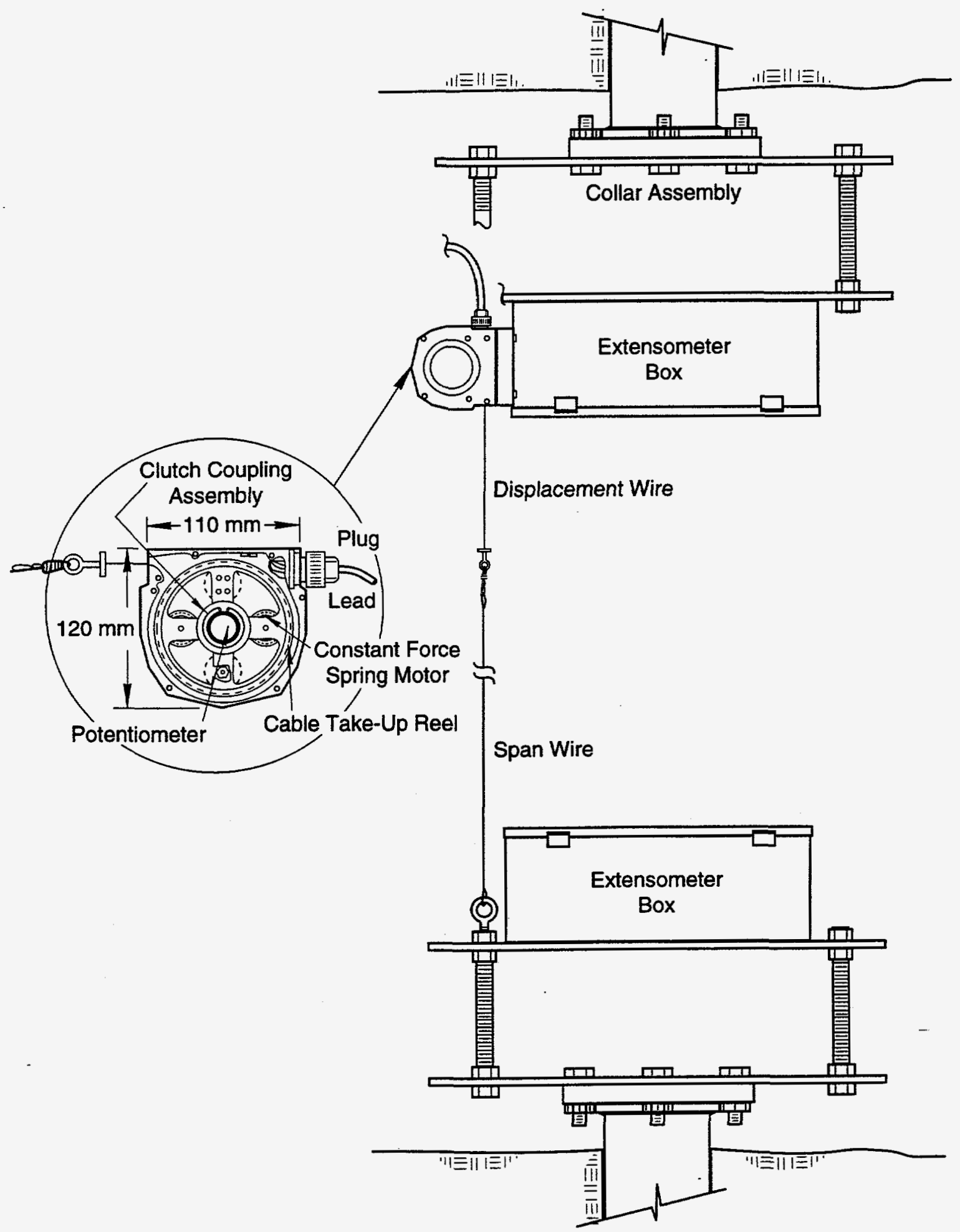

$T / M-16060-2$

Figure 3.1.10. Research Inc. Remote Closure Gage Installation 


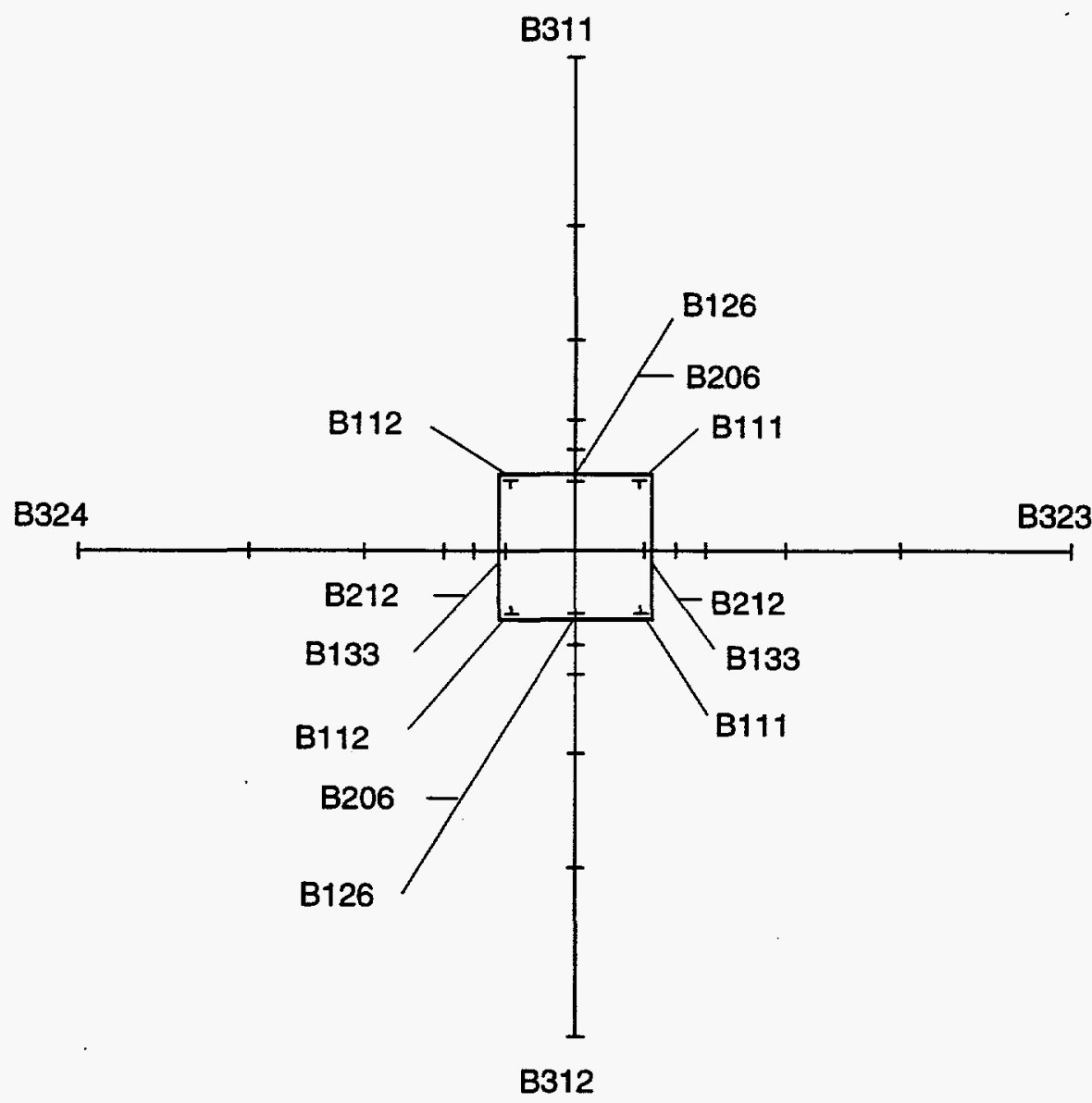

\begin{tabular}{|c|c|c|c|c|}
\hline \multicolumn{5}{|c|}{ Legend } \\
\hline No. & Designatio & ion & Type & Symbol \\
\hline $100-199$ & $\mathrm{CM} \mathrm{O}$ & Closu & anual $\mathrm{f}$ & $n g \vdash f$ \\
\hline $200-299$ & CR $\mathrm{C}$ & Closu & emote & ing $\longmapsto$ \\
\hline
\end{tabular}

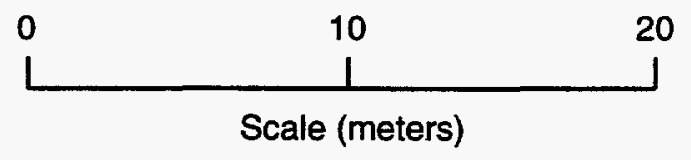

T/M-16060-19

Figure 3.1.11. Cross Section of a Closure Gage and Extensometer station 
Remote brow gages were installed at the entrances to the A, B, and D test rooms to monitor separation of the formation in the brow.

Design: The R.I. displacement transducer consisted of a rotary potentiometer coupled to a cable take-up reel, a displacement wire, and three or four (depending on the range of the gage) constant force springs to maintain the assembly under tension. A potentiometer is an electrical device that is composed of a resistive element and a wiper (a moveable conductor). Within the potentiometer, the wiper is placed in contact with the resistive element to form a voltage divider. Most of the displacement gages used in the TSI tests, including the R.I. displacement transducers, were based on potentiometers. In these gages, the potentiometer wipers were mechanically connected to the formation to measure displacement. A constant excitation voltage was supplied across the potentiometer while rotation or displacement of the wiper (as a result of displacement within the formation) caused a linear change in output voltage.

The displacement wire was made of $0.87 \mathrm{~mm}(0.034$ in) diameter stainless steel wire rope that was wound around the cable take-up reel and was terminated by a swivel connector outside the head. The gages utilized had ranges of 0.3 and $0.9 \mathrm{~m} \mathrm{(} 1$ and $3 \mathrm{ft}$ ) the shorter-range gages were installed in the $C, G$, and $Q$ test rooms where relatively small amounts of closure were expected, while the longer-range gages were used in the $A$, $B$, $D$, and $H$ test rooms (see Figure 1.0 .3 for locations). A span wire made of nylon-coated, seven-by-seven construction, $0.87 \mathrm{~mm}(0.034$ in) diameter, stainless steel wire rope was used to increase the span of the gage beyond its internal range. "The gage was typically installed with the span wire spanning the width or height of a test room. 
Calibration: The displacement gages used in the TSI in situ tests, including the R. I. displacement transducers, were calibrated on special fixtures that were certified by the sandia standards Laboratory to be traceable to NIST standards [TOP 023]. During the calibration process, the gages were attached to the calibration fixtures and extended to several different steps of known displacement while the input and output voltages of the potentiometers were measured and recorded at each step. Later in the experimental program, the gages were calibrated on a computer-controlled Daedal rail table which, together with higher precision voltmeters, provided greater accuracy and less chance for human error [TOP 316]. The output voltages from the calibration process were plotted against the displacements and linear regression analysis was used to determine calibration equations. The coefficients from these equations were stored in the ModComp Gage Calibration File and were used to convert voltages to units of displacement (inches) by the following equation:

Displacement $($ in $)=A+B x$, where

$A$ and $B=$ calibration coefficients,

$\mathrm{x}(\mathrm{V})=\mathrm{E}_{\mathrm{O}} * \mathrm{E}_{\mathrm{C}} / \mathrm{E}_{\mathrm{s}^{\prime}}$

$E_{0}(V)$ = measured gage output,

$E_{C}(V)$ = calibration excitation, and

$E_{S}^{C}(V)=$ measured gage excitation.

Installation: In a typical installation [TOP 070], the displacement transducer was bolted to an extensometer head (Figure 3.1.10) or, in the case of a remedial gage, to a bracket attached to an instrument collar (Figure 3.1.12). In other applications, such as brow gages and gages in Room G, the gages were attached to anchor bolts in the formation, similar to those in Figure 3.1.13. In the ISBT, brackets were used to attach the gages to the studs of the mining sequence closure points (Figure 3.1 .4 ). In Room $Q$, access restrictions prompted the use of dual gages to provide a 


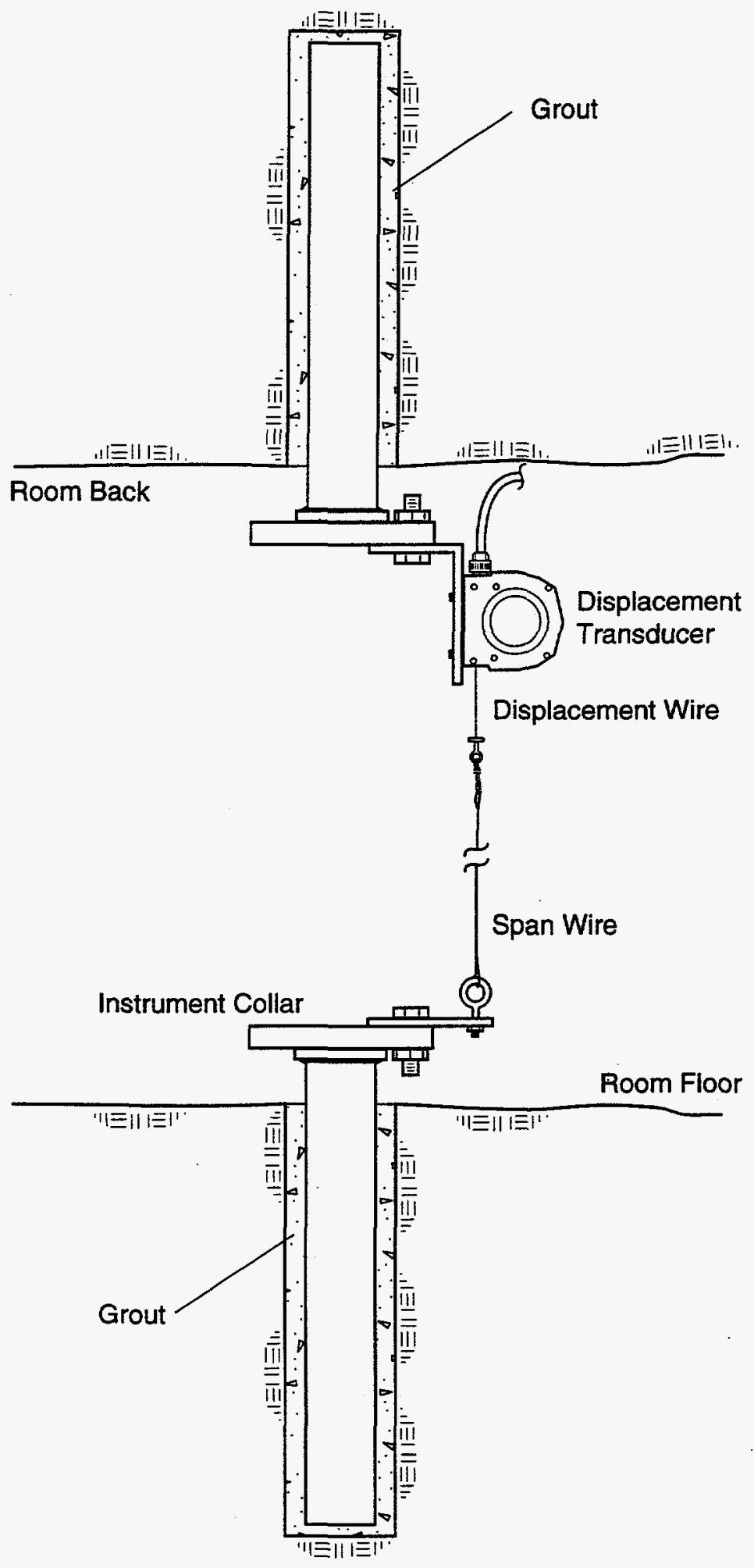

$T M-16060-6$

Figure 3.1.12. Remote Remedial Closure Gage Installation 


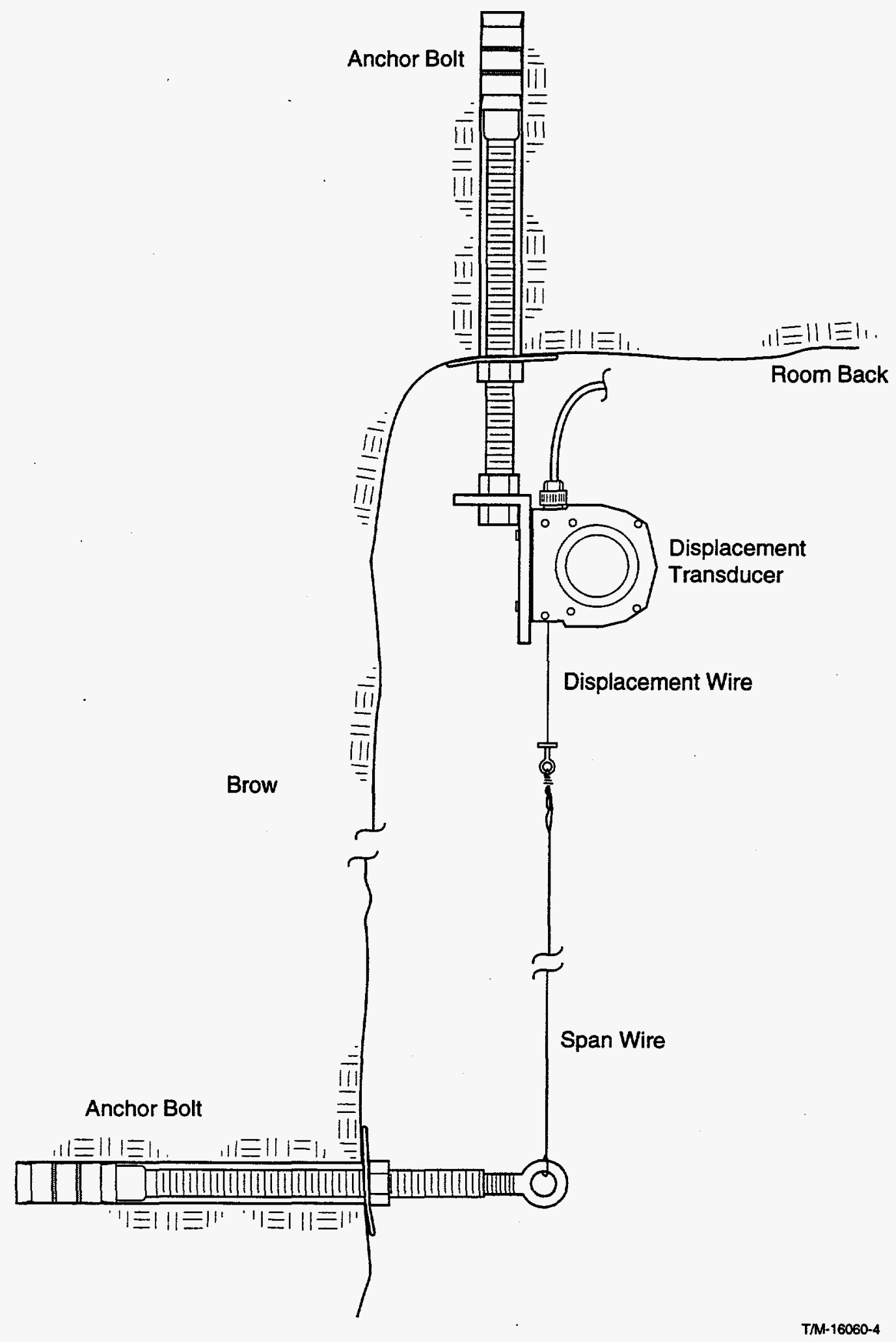

Figure 3.1.13. Remote Brow Closure Gage Installation 
redundancy of measurement; two remote closure transducers operating in parallel were attached to a single anchor bolt with a U-shaped bracket.

After a transducer was installed, a span wire was looped through the snap-swivel connector on the end of the gage displacement wire and secured with a crimping sleeve. The span wire was then looped through an eyebolt on the opposite side of the room. The spring-loaded displacement wire was then pulled out of the gage to $90 \%$ of the gage's range, and the loop on the opposite side of the room was secured with a crimping sleeve. Finally, a brightly colored bungee cord was strung across the room alongside the span wire to increase visibility and alert personnel to the presence of the wire. Gage voltages and resistances were manually measured and recorded to verify operation before connecting the gage to the DAS. Gage installation procedures were practiced in Room 4 of the SPDV test panel and in Room D (see Figure 1.0 .3 for locations) prior to the instrumentation of the TSI test rooms.

Operation: After installation, remote closure gages were monitored by the DAS (Section 2.5), and no manual operations were required other than maintenance and repair. The DAS maintained a constant excitation voltage across the potentiometers while output voltages were scanned on a periodic basis. Gage operation was occasionally interrupted while the span wire was retracted to allow other activities in the room to proceed; the span wires were easily disconnected and reconnected without any portion of the gage needing to be reinstalled. This practice was kept to a minimum, however, because gage disturbances resulted in hysteresis and offsets in the data.

The remote closure gages generated very clean and reliable closure data. Although the gages were susceptible to damage by personnel and 
vehicles passing through the room, the gages were easily replaced and maintained. Virtually all of these gages were kept in good working order during the periods (two to seven years) covered by the data reports $[13-21]$.

Maintenance: Maintenarice activities associated with the remote closure gages were minimal. The primary task was the removal of salt deposits that could inhibit the movement of the displacement wire. Many remote closure gages were damaged, especially during test construction, by personnel or vehicles passing by and snagging the span wire. Damaged gages were replaced with new or reconditioned gages; old gages were repaired, recalibrated, and placed in inventory.

Modifications: Few modifications were needed for this instrument. The manufacturer's swiveling snap link on the displacement wire was easily broken and was replaced by a stronger nonswiveling snap link. Some of the potentiometers supplied by the manufacturer were of a wire-wound type that produced a stepped output. These were latex replaced by higher quality, continuous-wound, "infinite-resolution" potentiometers that produced smoother data curves.

Vertical remote closure gages were originally designed with the displacement transducers to be installed near the test room floor. Prior to installation, however, it was realized that transducers emplaced in this configuration would be open to brine and dust penetration through the port where the displacement wire exits the gage. To eliminate this problem, the transducers were installed near the backs of the test rooms so that the port would face downward.

\subsection{Extensometers}

Extensometers are devices used to monitor rock mass extension by 
measuring the relative displacement between an anchor set at some depth in a borehole and the borehole collar. Single-point extensometers consist of a single borehole anchor connected to a gage head at the borehole collar. Multiple-point extensometers have anchors set at different depths in a single borehole and are connected to a single gage head at the borehole collar. In the TSI in situ tests, extensometers were typically installed in an array of boreholes surrounding a test room, as shown in Figure 3.1.11, with anchors set at borehole depths of $0.91,1.83,4.88$, 9.14, and $15.24 \mathrm{~m}(3,6,16,30$, and $50 \mathrm{ft})$. Extensometers were generally installed with room closure gages to provide a complete measurement of displacement around the test rooms.

Five types of extensometers were used in the TSI test rooms including Terrametrics anchor bolts, Serata E-200L and E-300 wire extensometers, and Irad 4000-I rod extensometers. The fifth type, serata C-300 creepmeters, were special gages that were used to monitor extension along the length of test rooms. The anchor bolt extensometers were manually read while the other extensometers were remotely monitored by the DAS. Table 3.0.1 shows the quantities of the various extensometers installed in the TSI test rooms.

3.2.1 Terrametrics Anchor Bolt Extensometers: The anchor bolt, manufactured by Terrametrics Inc., was the simplest of the extensometers used in the TSI tests. This gage was selected for use in Room G (see Figure 1.0.3 for location) where ruggedness and durability were of primary importance because of the relatively long duration of the Geomechanical Evaluation. The gage was basically a rock bolt with a free-floating rod at the borehole collar (Figure 3.2 .1 ) and was supplied in various lengths from 1.5 to $16.8 \mathrm{~m}$ (5 to $55 \mathrm{ft}$ ). The anchor bolt extensometers were 


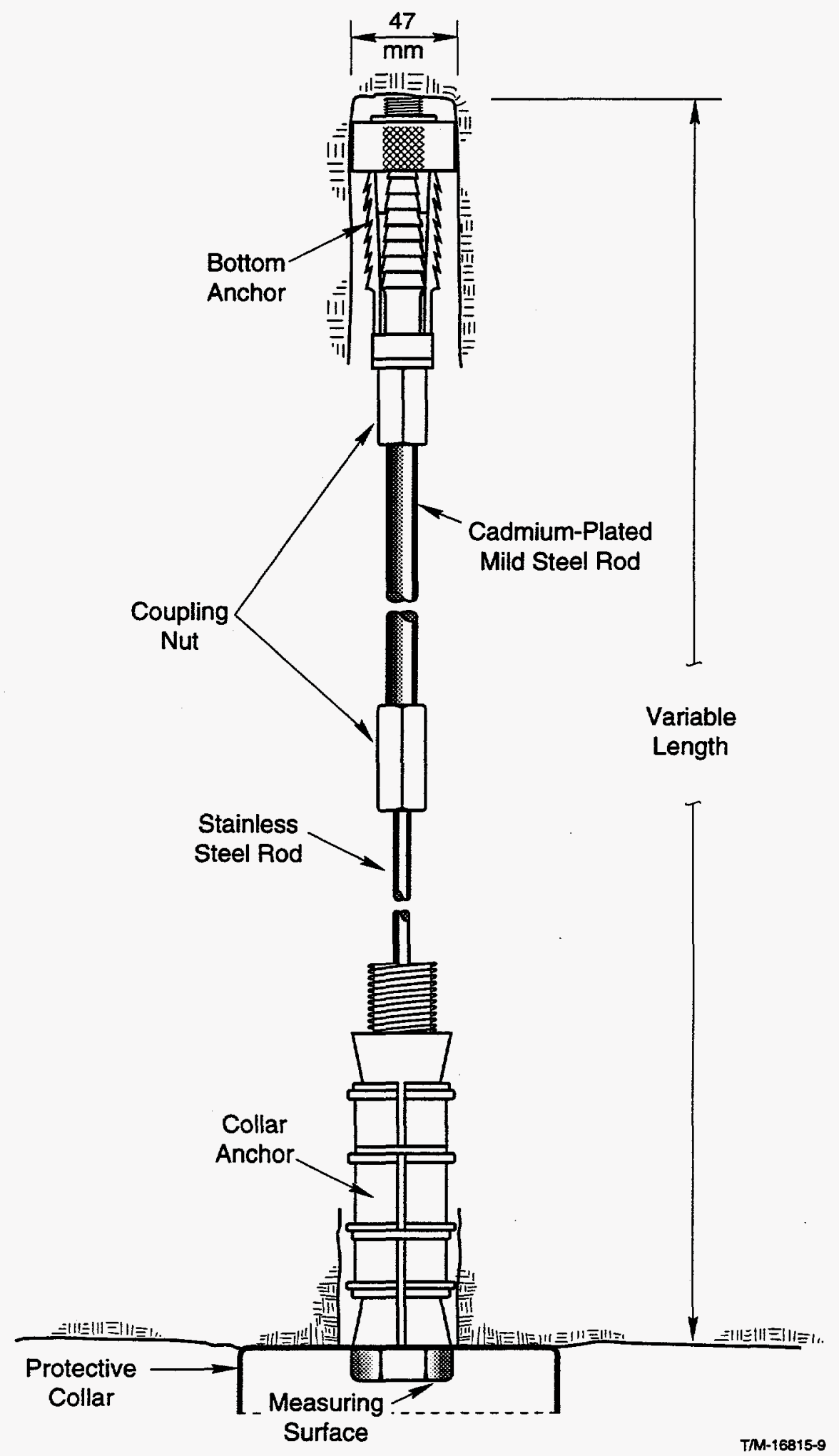

Figure 3.2.1. Terrametrics Anchor Bolt Extensometer Installation 
single-point extensometers that required a separate borehole for each gage. Groups of anchor bolts were placed in closely spaced boreholes of varying depths to form a multiple-gage unit.

Design: An anchor bolt extensometer consisted of a string of steel rods that were coupled to an anchor in the bottom of a borehole, but floated freely through a hole drilled in a collar anchor. The rods were supplied in sections up to $3 \mathrm{~m}(10 \mathrm{ft})$ long that were joined during installation with coupling nuts to achieve various lengths. The deeper sections were made of $13 \mathrm{~mm}(1 / 2 \mathrm{in})$ diameter cadmium-plated, mild steel rods while the section nearest the collar was a $6 \mathrm{~mm}(1 / 4 \mathrm{in})$ diameter, $460 \mathrm{~mm}$ (18 in) long stainless steel rod. The bottom anchor consisted of a rock bolt that was modified by the gage manufacturer by welding shims to the anchor to accommodate the $47.6 \mathrm{~mm}$ (1.875 in) boreholes and plating the assembly with cadmium. The collar anchor consisted a $19 \mathrm{~mm}(3 / 4$ in $)$ diameter, $300 \mathrm{~mm}$ ( $12 \mathrm{in)}$ long stainless steel bolt and a double expansion-shield anchor.

Calibration: The anchor bolt extensometers were originally read with a Starrett dial indicator that had a 0 to $150 \mathrm{~mm}(0$ to 6 in) range and a resolution of $0.025 \mathrm{~mm}(0.001 \mathrm{in})$. The dial indicator, however, had measurement problems. Accurate measurements were difficult to make because dirt and corrosion would cause the instrument to bind. In addition, the dial pointer would bend from shock if the gage was removed from the anchor bolt too quickly and the spring-loaded rod was allowed to snap back to zero. Later on in the experimental program, the dial indicator was replaced by a starrett digital depth gage that had the same range and resolution. This gage's performance was also affected by dirt deposits on its removable measurement rods, but the problem was minimized 
by bringing the gage to the calibration station once a month for cleaning and zeroing. Both types of gages were recalled at regular intervals for calibration and, later in the experimental program, were calibrated by the user before taking a set of measurements.

Installation: The anchor bolts were installed in $47.6 \mathrm{~mm}$ ( $1.875 \mathrm{in}$ ) diameter holes of varying depths [TOP 096]. To install a gage, a length of $13 \mathrm{~mm}(1 / 2 \mathrm{in})$ diameter rod was attached to the bottom anchor with a coupling nut and secured with Loctite permanent thread adhesive. Rubber centralizers with a diameter of $44 \mathrm{~mm}(13 / 4$ in) were then slipped onto the rod and positioned at $1.5 \mathrm{~m}(5 \mathrm{ft})$ intervals. The centralizers kept the rod string in the center of the borehole and prevented it from adhering to the borehole wall. The rod with the attached anchor and centralizers was then inserted into the borehole. Additional rods with centralizers were attached to the string with coupling nuts and permanent thread adhesive, and pushed into the borehole until the desired depth was reached.

The last two rods of the string consisted of the final $13 \mathrm{~mm}$ rod and the $6 \mathrm{~mm}$ stainless steel measurement rod. These rods were preassembled by threading the smaller rod into a hole drilled and tapped into the end of the larger rod. A coupling nut was also threaded on to the end of the larger rod for use with the a special installation wrench. During installation, this assembly was coupled to the string as one piece. When installing a gage in the rib, this assembly was coupled to the rod string with the use of removable thread adhesive to allow the string to be shortened in the future. (The original test plan also called for the test room to be widened at a later date). With the anchor at the proper depth, the rod string was turned with the installation wrench to expand and 
tighten the bottom anchor. Finally, the collar anchor was set by slipping the anchor over the last section of rod and tightening the bolt with a wrench. The installation procedure was validated during practice sessions in Room 4 of the SPDV test panel (see Figure 1.0.3 for location). The gages were installed approximately two months after the initial excavation of Room G.

Operation: Depth micrometers with a resolution of $0.025 \mathrm{~mm}(0.001 \mathrm{in})$ were used to measure the distance between the milled end of the stainless steel rod and the milled measuring surface of the collar anchor [TOP 106]. Measurements were taken over time to monitor relative displacement between the bottom and collar anchors. The measurements obtained from the anchor bolt extensometers were very reliable and consistent, even though they were susceptible to human error. Data from these gages had very few offsets because the gages were relatively maintenance free. Moreover, the stiff, heavy-duty rods provided data that was free of hysteresis.

An advantage of the anchor bolt extensometers was that they could be measured before the remotely read extensometers could be connected to the DAS. Besides giving early data, the anchor bolts provided a redundancy in measurement to the remotely read extensometers. In addition, the simple and heavy duty design of these gages enabled almost all of these gages to produce reliable data for the duration of the Geomechanical Evaluation in Room G. A disadvantage of these gages was that they were subject to operational constraints. For example, gage monitoring was suspended for about a year during 1990 and 1991 while the test room back was bolted.

Maintenance: The only maintenance that the anchor bolt extensometers required was that the measuring surface be cleaned before taking a 
measurement. In particular, the measurement surfaces of many of the gages became encrusted with salt during the roof-bolting period. A thorough cleaning was sufficient to restore most of the gages to good working order.

Modifications: The smaller diameter measurement rods were shortened by about $75 \mathrm{~mm}(3 \mathrm{in})$ to give the rod string the same length as the designed collar-to-bottom distance. The rods were also drilled and tapped to accommodate extensions, although no extensions were added.

The vertical-down gages required special modifications because of their location in the room floor. The gage holes were countersunk into the floor for protection from traffic and a large washer conforming to the diameter of the countersunk hole was added to hold the collar anchor in place during installation. A few vertical-down holes tended to fill with brine and the measurement surface in the gage head would become covered with salt deposits. To alleviate this problem, holes were drilled at an angle from the room floor to the instrument holes below the collar anchors. The access provided by these holes allowed compressed air to be used to blow brine out of the hole from below the collar anchor. Removing brine on a regular basis prevented deposits from forming on the measurement surfaces.

3.2.2 Serata E-200L wire Extensometers: The Model E-200L extensometer manufactured by Serata Geomechanics was the most widely used extensometer in the TSI experiments. The gages were based on spring-loaded linear potentiometers that were connected to borehole anchors with small diameter wire rope. A complete extensometer unit was composed of four to six gages that were attached to anchors installed at different depths in a single borehole (Figure 3.2.2). This gage was also 


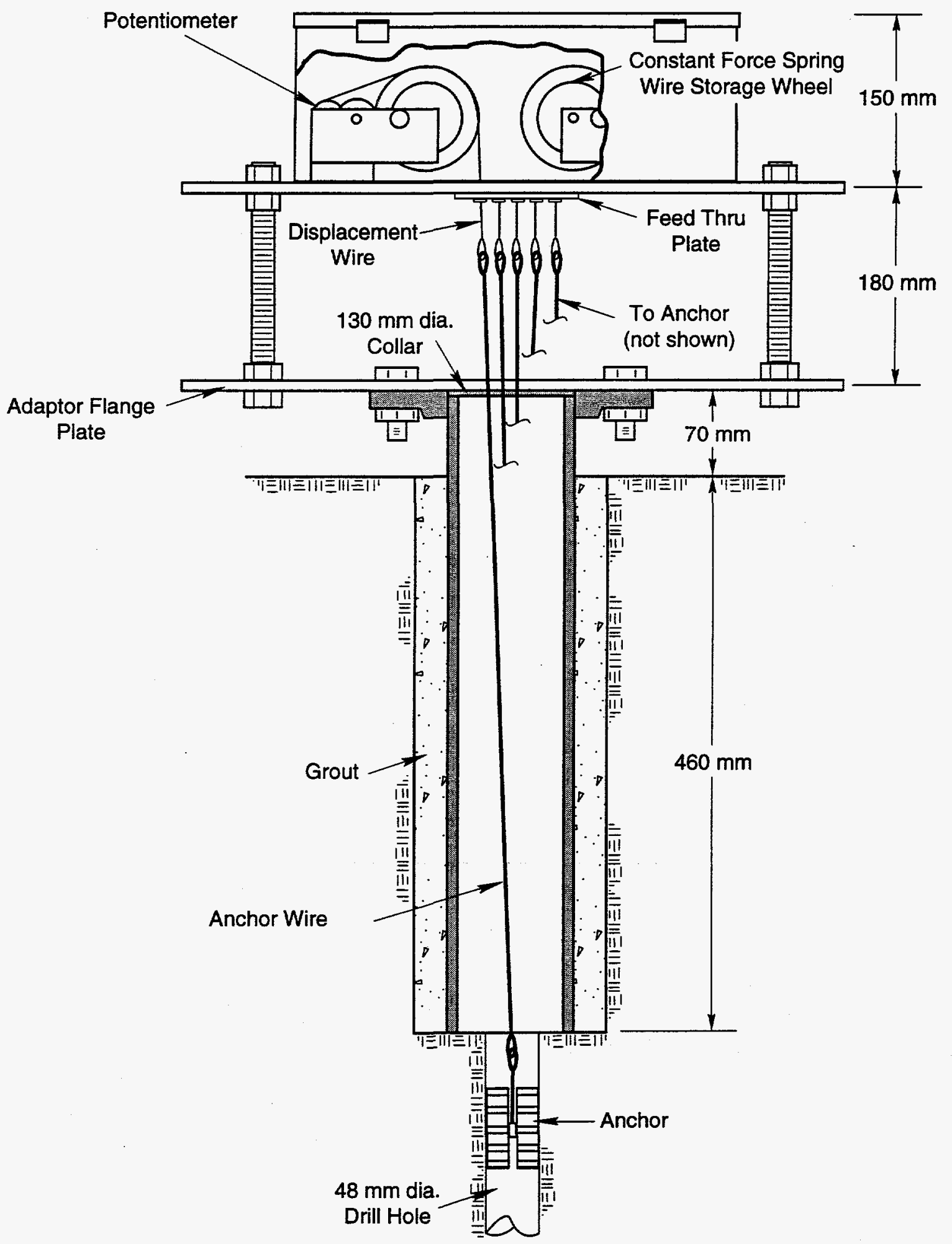

T/M-16060-21

Figure 3.2.2. Serata E-200L Wire Extensometer Installation 
used in a special "piggyback" configuration wherein two five-gage units were installed on the same collar mount (Figure 3.2.3). The piggyback configuration was designed to help evaluate the effects of thermal expansion of the anchor wires on the data; one unit used single-strand stainless steel anchor wires, the other used single-strand Invar. Invar was chosen for the second set of anchor wires because of its comparatively small coefficient of thermal expansion. All four piggyback assemblies were installed in Room B (see Figure 1.0.3 for location).

Design: The serata E-200I extensometer consisted of four to six anchors installed in a single borehole that were connected to potentiometers in an instrument head by small diameter wire rope (Figure 3.2.2). A borehole anchor was made of two anodized aluminum semi-cylindrical shells that were connected with a spring-loaded cross tube. The anchors were designed to fit $47.6 \mathrm{~mm}(1.875$ in) diameter boreholes. The anchor wires were made of nylon-coated, seven-by-seven construction, $1.59 \mathrm{~mm}$ (1/16 in) diameter, stainless steel wire rope. The anchor wires were attached to the anchors with stainless steel crimping sleeves and to eyelets on gage displacement wires with copper crimping sleeves. The displacement wires in the gage head were coiled onto wire storage reels that were loaded by. constant-force springs to maintain tension on the wires. Borehole extension was translated to reel rotation which in turn was transmitted to rotary potentiometers by a system of pulleys and wire rope. The wire storage reels, constant-force springs and potentiometers were housed in a protective metal box which was backed by an anodized aluminum plate. The backing plate of the unit was bolted to a similar adapter flange plate on the instrument collar with standoff rods to give the box a $180 \mathrm{~mm}(7 \mathrm{in})$ offset from the borehole collar. The 


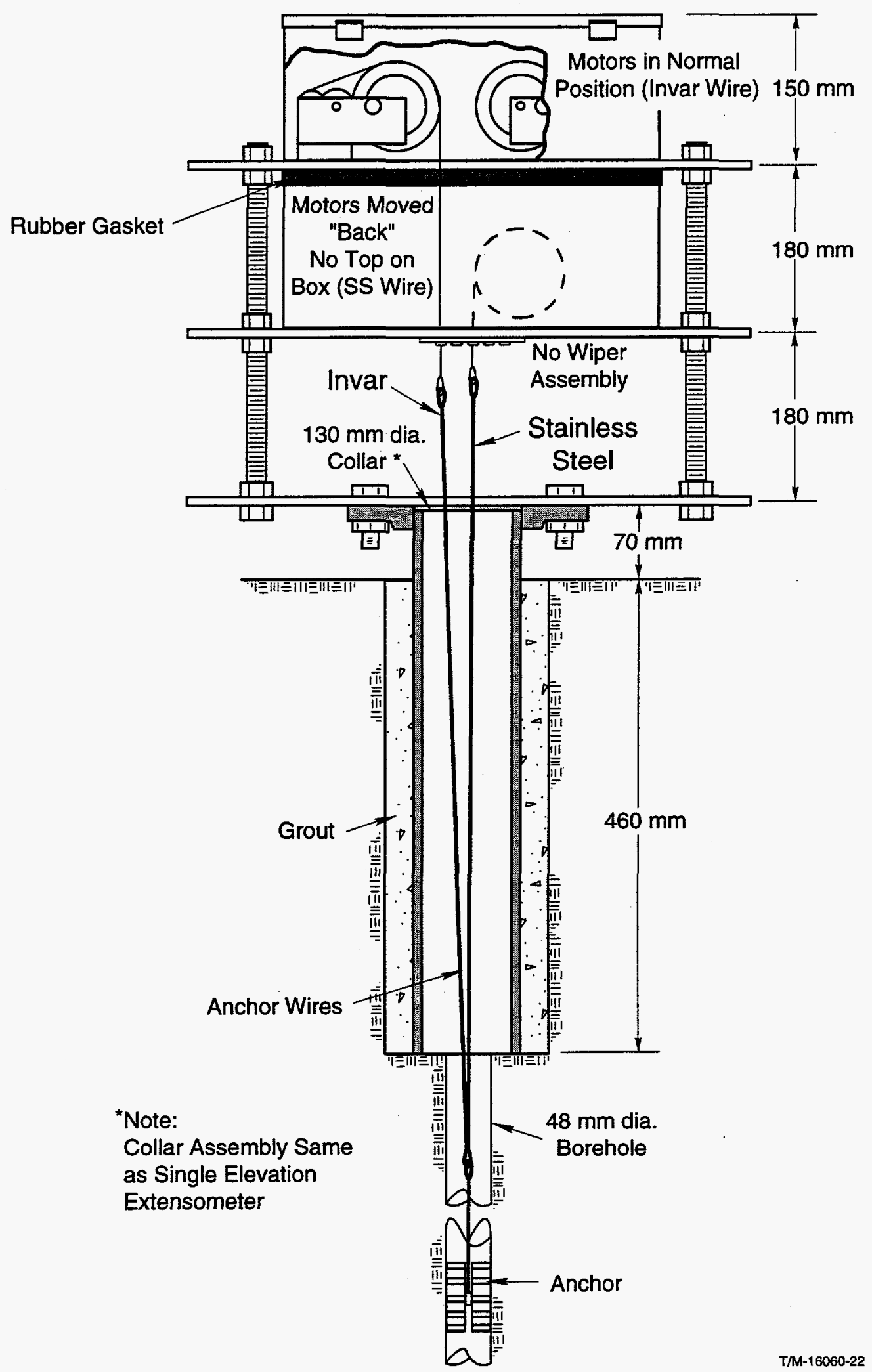

Figure 3.2.3. Piggyback Wire Extensometer Installation 
offset provided access to the anchor wire connections during installation and maintenance.

The gages were supplied with either three-turn or ten-turn rotary potentiometers to allow for two ranges of displacement. The three-turn potentiometers had a range of $200 \mathrm{~mm}(8 \mathrm{in})$ and were used in the back, floor, and outer rib of Room H, and in Room C (see Figure 1.0 .3 for locations). The ten-turn potentiometers had a range of $760 \mathrm{~mm}(30$ in) and were used in the $A, B$, and $D$ test rooms.

Calibration: The E-200L wire extensometers were calibrated by the method described in section 3.1.3, [TOPs 022 and 315]. The calibration constants were stored in the ModComp Gage Calibration File and were used with Equation 3.1 .3 to convert voltages to units of displacement (inches).

Installation: Wire extensometers were installed at the completion of the contractor activities in the test rooms. Prior to installation, all anchor wires were cut to the required length (with an excess for connections) and attached to borehole anchors. To install a gage, the adapter flange plate was first bolted to the borehole collar flange (Section 2.4) to serve as a reference surface for anchor depths. The anchors and anchor wires were then inserted into the borehole and positioned using a setting tool and rods supplied by the manufacturer [TOP 067]. (The wires from the deeper anchors passed through the hollow shells of the shallower anchors). The instrument head was then mounted to the flange plate with threaded standoff rods. Finally, the anchor wires were attached to the displacement wires just outside the gage head. During this process, the displacement wires were held out about $25 \mathrm{~mm}$ (1 in) from the gage head with temporary spacers to ensure that the wires would be under tension when released. Input and output resistances and 
voltages were manually measured and recorded to verify operation before connecting the gage to the DAS. Initial installation procedures were practiced in Room 4 of the SPDV test panel (see Figure 1.0.3 for location). Additional practice under test conditions was gained when gages were installed in Room $D$ and in the access drift to Room $H$.

Operation: After installation, the E-20OL extensometers were monitored by the DAS (Section 2.5 ) and no manual operations were required other than maintenance and repair. The relatively long range of the gages (up to $760 \mathrm{~mm}$ or $30 \mathrm{in}$ ) enabled the gages to operate for long periods without needing to be reset. The E-200L wire extensometers did not, however, operate as smoothly as did the rod extensometers described in Section 3.2.4. Friction in the constant-force springs and complex pulley systems caused considerable hysteresis in the data each time a gage was disturbed. Because these gages required frequent maintenance, many offsets occurred in the data. However, if a disturbed gage was left undisturbed thereafter, the hysteresis would correct itself and the gage would again operate properly.

The greatest advantage of the wire extensometers was that their anchors and anchor wires could be removed and replaced relatively easily. Extensive maintenance and modifications, as described below, enabled most of these gages to continue operating for the life of the experiments. Despite a significant amount of missing data due to hysteresis and gage malfunction, the gage maintenance program enabled over $80 \%$ of these gages to operate through the periods (two to six years) covered by the data reports $[13-20]$.

Maintenance: Shortly after the first installations, gage maintenance reviews detected anomalies in the data recorded by the DAS. The primary 
cause of these problems was later found to be the aforementioned hysteresis caused by stretching of the anchor wires and friction in the various gage components. However, during the initial gage inspections it was also noted that brine and salt deposits were accumulating on the adapter flange plates of the vertical-up installations and in the instrument collar behind the base plate on horizontal installations. As a result of these problems, a comprehensive maintenance effort was implemented. This effort consisted of a technical review of gage output, a visual inspection of gage components, and an extensive cleaning of the instrument head to remove brine and salt deposits. Problems noted during this process were then assessed and prioritized. If appropriate, a gage would be repaired and all current modifications, as discussed below, would be made to the instrument.

E-200L wire extensometer failures were of two types: downhole equipment failures and failure of components in the gage head. Corrosion of anchor tie wires (see the Modifications section below) and anchor wires were the two most frequent downhole failures. A complete reinstallation of the gage, anchors, and anchor wires was necessary to replace corroded wires. In addition, the hole frequently needed to be reamed before reinstallation because of borehole closure and salt deposits. Failures in the gage head included breakage of the constant-force springs, slippage in the potentiometer pulley system, and breakage of displacement wires. Malfunctioning instrument heads were replaced with new or reconditioned units. Old units were repaired, calibrated, and placed in inventory.

Modifications: Prior to ordering the gages from the manufacturer, Sandia specified several modifications to the wire extensometers. Wire rope was substituted for the original single-strand wire that was 
specified for the anchor and displacement wires to increase flexibility and strength. The base plate of the gage head was drilled with extra holes for attaching bungee cords, closure gage wires, creepmeter wires, and small bolts for survey points. A wiper plate was added to the base plate where the displacement wires exited the box. The wiper plate was drilled with small holes and fitted with small rubber grommets to allow the displacement wires to exit the gage head while minimizing the entry of brine and debris.

Additional modifications were made to the E-200L wire extensometers during the life of the experiments as problems arose and as experience was gained through the maintenance program. The modifications were necessary to improve the operation of the gages and to extend their life. These changes affected practically all components of the gages, including the anchors, anchor wires, and potentiometers. The many modifications made to these extensometers are discussed in the following paragraphs.

Early plots of gage data showed that the displacement curves were not smooth and continuous but were stepped. This phenomenon was attributed to two aspects of the gage operation: friction in the bearings and constant force springs, and stretching of the $0.87 \mathrm{~mm}(0.034 \mathrm{in})$ diameter anchor wires. In effect, the thin ropes were being stretched until the tension was sufficient to overcome the friction and rotate the wire storage wheels. This problem was remedied by making changes to various components in the system. The original open bearings were replaced with sealed bearings for reduced corrosion and smoother operation. In addition, the constant-force springs were lubricated with LPS-3 to reduce friction and inhibit corrosion. Finally, the anchor wires were replaced with larger diameter rope to reduce stretching. Various types of wire rope were 
evaluated for the anchor wires, but $1.59 \mathrm{~mm}(1 / 16 \mathrm{in})$ diameter, seven-by-seven construction, nylon-coated, stainless steel wire rope was found to work well. The displacement wires in the gage head were also replaced with nylon-coated rope, but the smaller diameter was retained. These changes were initially made by test personnel but were eventually incorporated into units supplied by the manufacturer.

A related problem was caused by friction and binding in the potentiometers. The potentiometers that were originally supplied by the manufacturer were mounted by means of threaded spindles. These potentiometers were often poorly aligned with the other components and the resulting friction was sufficient to cause the potentiometer to bind. When this happened, the pulley system would slip and cause flat spots in the data curves. To remedy this problem, shims were used to shift the alignment of the potentiometers. Alignment by this method was tedious, however, and the original potentiometers were eventually replaced with "servo-mount" potentiometers that were mounted with a flange and small screws. This design allowed the potentiometers to be easily adjusted and aligned when the instrument was being set up prior to the calibration process. Later in the testing program, these potentiometers were included in units supplied by the manufacturer.

The wire extensometers required extensive cleaning to remove brine and salt deposits from the collar area and from the exterior of the instrument housing. In order to minimize problems associated with brine entering the gages in vertical-up installations, split plastic funnels were installed around the gage wires on top of the base plates and filled with high-temperature grease. The grease prevented brine from entering the gage box and made it easier to remove salt deposits from the gage head and 
anchor wires. Horizontal and diagonal-down installations were fitted with metal shields to protect the gages from dripping brine and falling debris. Some vertical-down installations were fitted with splash guards to deflect brine that dripped from wet boreholes directly above.

The adapter flange plate was initially designed with a $47.6 \mathrm{~mm}$ (1.875 in) diameter hole to allow passage of the anchor and displacement wires. This diameter was selected to agree with the borehole size, but unfortunately impeded the free flow of brine from the borehole. As a result, salt deposits would build up and bridge from the plate to the wires and prevent the wires from moving freely. The problem was solved by increasing the size of the hole in the flange plate to $140 \mathrm{~mm}(5.5 \mathrm{in})$. The modified design was first incorporated into the Room $H$ instrumentation; earlier installations required retrofitting during maintenance periods.

It was found soon after test construction that brine and salt deposits inside the borehole were restricting movement by causing the wires to bind together and to the borehole. As a result, installation procedures were changed to include sheathing the wires with $6 \mathrm{~mm}(1 / 4$ in $)$ diameter polypropylene tubing. This modification was first implemented in Room Al; earlier installations were retrofitted with this modification during maintenance and repair.

The displacement wires in the gage head were terminated with crimped eyelets. The anchor wires in the borehole were originally attached to these eyelets with $0.6 \mathrm{~m}(2 \mathrm{ft})$ long loops and crimping sleeves. The long loops were made to provide excess wire for maintenance and repair. Later in the experimental program, stainless steel snap links (the same links used with the R.I. displacement transducers, section 3.1.3) were added to 
the loops to make removal and reconnection of the extensometer head a simple task. At this time, the loops were shortened because the double-barrel crimping sleeves that were used to secure the loops would catch on the polypropylene sheathing. Late in the experimental program, the method of making additions to the anchor wires was modified by using in-line splices. Short pieces of small diameter stainless steel tubing were used to make the splices by crimping the tubes to the ends of the wires.

Sometime thereafter, it became evident that the crimping sleeves used to attach the anchor wires to the displacement wires at the instrument head could eventually be drawn up to and catch on the sheathing, thereby preventing accurate measurement of extension. To preclude this problem, the sheathing was trimmed back about $0.6 \mathrm{~m}$ (2 ft) from the collar leaving the anchor wires exposed for this length. To protect the unsheathed portions of the anchor wires from brine and salt, $1.2 \mathrm{~m}$ (4 ft) lengths of $10 \mathrm{~mm}$ (3/8 in) diameter heat-shrink tubing were slipped over the wires. The tubing pieces were preshrunk at the down-hole end and greased to lightly grip the polypropylene sheathing while the remainder loosely covered the anchor wires up to the instrument head.

The original wire extensometer installations had problems with anchor wires corroding and breaking away from the anchors. The anchors were originally supplied by the manufacturer with short, single-strand tie wires that were looped around the cross tubes of the anchors and secured with crimping sleeves. During installation, anchor wires were spliced to eyelets on these wires with loops and crimping sleeves. However, the bare, single-strand tie wire was found to corrode and fail at the point where it was crimped. In addition, the sharp radius of loop in the wire 
rope increased stress in that portion of the rope and made the rope susceptible to failure. This method of attachment was eventually modified by eliminating the single-strand tie wire and looping the nylon-coated anchor wire directly around the cross bar. This modification eliminated the bare wires and sharp radii at the points of attachment. Unfortunately, this problem did not become apparent until after the completion of the instrumentation in Room H. The modification was eventually made as a retrofit to all installations during maintenance periods.

Early installations had problems with anchors slipping in the boreholes. In an effort to improve their holding strength and inhibit corrosion, the anchors were coated with a mixture of grit and high-temperature paint. To ensure that the anchors were holding, they were tested with a pulling force of $90 \mathrm{~N}(20$ lb) immediately after installation and prior to the installation of the next anchor. These modifications were initiated with the instrumentation of Room Al and became standard features in subsequent installations. Earlier installations were upgraded with this modification during repair and maintenance.

Extensometers that were installed in diagonal boreholes drilled from the corners of the test rooms were found to need additional clearance from the test room walls. When these gages were first installed, the adapter flange plates were found to be very close to the test room walls. In fact, some installations required the formation to be chipped away in order to gain enough clearance to install the plates. As the formation deformed, however, the test room walls would come into contact with the adapter flange plates and slowly deform the gage assembly. As a solution, 
these gages were retrofitted with collar extensions to give the gages additional clearance. The extensions were fabricated by welding two pipe flanges together in a back-to-back configuration. The $180 \mathrm{~mm}(7 \mathrm{in}$ ) long extensions moved the gage heads away from the formation and gave the gages the extra clearance needed to operate for the duration of the tests.

In the ISBT extensometer installations, the length of the standoff rods connecting the adapter plate to the base plate was increased from $265 \mathrm{~mm}(10.5 \mathrm{in})$ to $420 \mathrm{~mm}(16.5 \mathrm{in})$ to give more working space for maintenance. The longer rods, however, resulted in a greater moment arm on the plates. To increase rigidity, the thickness of the $6 \mathrm{~mm}(1 / 4$ in) thick aluminum plates was doubled, first by installing two plates, and ultimately by installing single, $13 \mathrm{~mm}(1 / 2 \mathrm{in})$ thick plates. These modifications were first implemented during the construction of the ISBT, but were made to a few gages in other tests during repair periods.

3.2.3 Serata E-300 Wire Extensometers: The Model E-300 wire extensometer, manufactured by serata Geomechanics, was similar in operation to the E-200L model (Section 3.2.2). As in the E-200I, displacement was measured by linear potentiometers that were connected to borehole anchors by small diameter wire rope. The E-300 had a more compact gage head, however, and was therefore selected for use in the heated pillar in Room H (see Figure 1.0.3 for location). The smaller diameter head minimized interference with the heater strips and insulating blankets [13]. A total of six E-300 units were installed in Room H; none were installed in the other test rooms.

Design: The serata E-300 extensometer was composed of four borehole anchors that were connected to four potentiometers inside the instrument head by small diameter wire rope (Figure 3.2.4). The anchors consisted of 


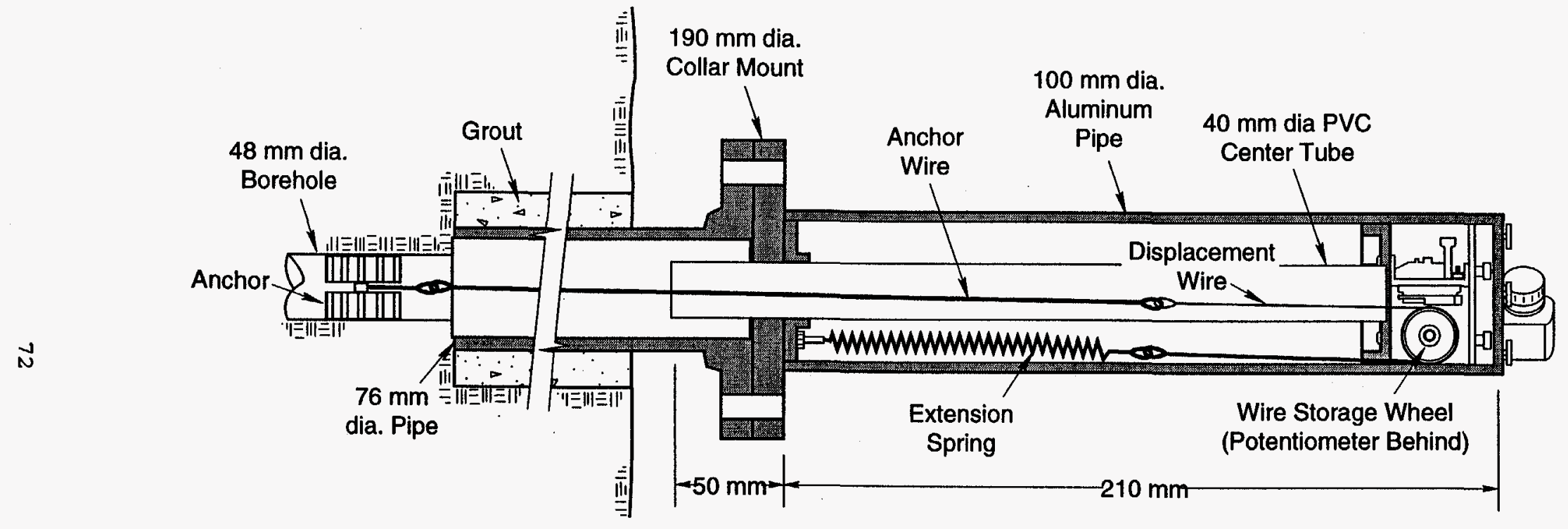

TRI-16060-24 
two semi-cylindrical, anodized aluminum shells that were joined by a spring-loaded cross tube and were designed to fit $47.6 \mathrm{~mm}$ (1.875 in) diameter boreholes. The anchor wires were made of nylon-coated, seven-by-seven construction, $1.59 \mathrm{~mm}$ (1/16 in) diameter, stainless steel wire rope and were spliced to $0.87 \mathrm{~mm}(0.034 \mathrm{in})$ diameter displacement wires inside the gage head.

Four potentiometer assemblies were located inside the instrument head. Each assembly contained a rotary, linear potentiometer that was coupled directly to a pair of wire storage reels. A short length of wire rope was connected to each reel with a set screw. The wire on the inner reel was attached to an extension spring to maintain the system under tension while the wire on the outer reel (the displacement wire) was spliced to an anchor wire. Borehole extension was thereby translated directly to potentiometer rotation.

The gages were supplied with one-turn potentiometers that had a range of about $75 \mathrm{~mm}$ (3 in). About four turns of displacement wire were coiled onto the wire storage reels to give the gages a total range of about $300 \mathrm{~mm}(12 \mathrm{in})$. The two reels were coupled to each other by means of a peg on one reel and a series of holes in the other. The potentiometers and inner reels could be uncoupled from the outer reels and rezeroed a number of times in order to achieve the total range of the gage.

The potentiometer and reel assemblies contained mechanical stops at the maximum and minimum points of displacement. The maximum stop prevented mechanical damage to components of the assembly when the gage reached the end of its range (but unfortunately would cause the displacement wire to break). The minimum stop prevented damage to components of the spring-loaded assembly if a displacement wire broke. 
Finally, a center tube made from a length of PVC pipe helped support the internal parts and kept the displacement wires away from the extension springs. The internal assembly was attached to a pipe flange that was in turn bolted to a grouted collar flange. The entire collar assembly was housed inside a protective cover made from a length of anodized aluminum pipe.

Calibration: The E-300 wire extensometers were calibrated by the method described in section 3.1.3, [TOPs 045 and 317]. The calibration constants were stored in the ModComp Gage Calibration File and were used with Equation 3.1 .3 to convert voltages to units of displacement (inches).

Installation: The E-300 extensometers were installed in the Room H pillar within one month after the completion of excavation and drilling. Installation of an E-300 assembly began by inserting the anchors and anchor wires into a borehole and positioning the anchors at the desired depths using a setting tool and rods supplied by the manufacturer [TOP 068]. (The wires from the deeper anchors passed through the hollow shells of the shallower anchors). After setting all four anchors, the anchor wires were spliced to short lengths of displacement wire with crimping sleeves. The wires were then fed through the instrument head and the head was bolted to the collar flange (Section 2.4). Next, the displacement wires were wound around and attached to the outer reels. The outer reels were then rotated to remove slack in the anchor wires while the inner reels were rotated to partially relax the extension springs. The two reels were then locked together. A portable power supply and digital voltmeter were connected to the gage and the potentiometers were rotated to set their output to about $0.75 \mathrm{~V}$. (The potentiometers output ranged from zero to ten volts; the potentiometers were set with their 
initial outputs to be slightly greater than zero.) Finally, the end plate and cap were installed on the instrument head. Input voltages and resistances were also measured and recorded to verify gage operation before connecting the assembly to the DAS.

Operation: After installation, the E-300 extensometers were monitored by the DAS (Section 2.5), and no manual operations were required other than maintenance and repair. Approximately $95 \%$ of the gages were maintained in good working order through the period (two years) covered by the data report [13].

The stair-stepped displacement curves associated with the E-200L model (Section 3.2.2) were not observed with these gages. The smooth operation of the gage and the good quality of the data were believed to be the result of several design factors. Because these gages were used only in the Room H pillar, the deepest anchor point was only $7.62 \mathrm{~m}$ (25 ft) from the borehole collar. Also, $1.59 \mathrm{~mm}$ (1/16 in) diameter anchor wires were used instead of the original $0.87 \mathrm{~mm}(0.034 \mathrm{in})$ diameter wires. The shorter and thicker anchor wires made stiffer connections to the potentiometers. In addition, the extension springs used in this model were not affected by internal friction as were the constant-force springs used in the E-200L model. Finally, the configuration of mounting the potentiometer directly to the cable reel eliminated the effects of several moving parts and provided a smoother output.

Maintenance: The $E-300$ extensometers needed to be reset after the potentiometers had reached the end of their $75 \mathrm{~mm}(3 \mathrm{in})$ measurement range. This adjustment involved disengaging the inner pulley from the outer pulley and allowing the extension spring to rotate the inner pulley and the potentiometer back to the assembly's minimum stop. After 
reengaging the two reels, the potentiometer was rotated slightly to set the potentiometer slightly past its zero point and within its operating range. A gage could be reset several times since there was about $300 \mathrm{~mm}$ (12 in) of displacement wire coiled around the outer reel. To gain additional range, the gage needed to be disassembled to allow extensions to be spliced to the anchor wires. These resetting procedures needed to be performed often because of the relatively great amount of displacement in the heated pillar and the short range of the gages. If a gage was not reset, a potentiometer would reach the end of its range and the maximum stop on the assembly would cause the displacement wire to break.

Most of the early failures were associated with routine maintenance wherein removal and replacement of the protective cover for cleaning and inspection would inadvertently sever the electrical leads. This activity was deferred until necessary after the problem was identified. Later in the testing program, these gages were not repaired if a downhole failure occurred because borehole closure and salt deposits made reinstallation extremely difficult.

Modifications: A flanged base was added to the instrument head so that the head could be bolted to the grouted instrument collars (Section 2.4). This was a modification to the manufacturer's design and was included in the original purchase order for the E-300L extensometers.

The E-300 extensometers were installed in Room $\mathrm{H}$ after the mechanical instrumentation in the $A$ and $B$ test rooms had been emplaced. Much had been learned about the wire extensometers in the A and B rooms and the E-300 installations utilized many of the modifications made to the E-200L extensometer (Section 3.2.2). The anchors were painted with a mixture of grit and high-temperature paint to improve their holding strength and to 
retard corrosion. The aforementioned larger diameter wire rope was used to ensure smoother gage output and longer wire life. Polypropylene tubing was used to sheath the wires and prevent them from becoming entrapped in salt deposits.

In addition to the above modifications that were made to all wire extensometers, there were additional modifications made to the E-300 model. Two $6 \mathrm{~mm}(1 / 4 \mathrm{in})$ diameter stainless steel bolts were added to the center tube to prevent the four anchor wires from fouling. These bolts were placed at right angles to each other in holes drilled in the downhole end of the tube to form a cross for separating the anchor wires; one wire passed through each quadrant of the cross. During installation, Teflon washers were slipped over the anchor wires prior to splicing them to the displacement wires. The Teflon washers were designed to prevent brine and debris from entering the gage head. Unfortunately, the washers also prevented the anchor-wire splices from passing through the housing during normal operation as the boreholes extended. Because of this unanticipated problem, the washers were later removed.

An accumulation of brine and salt in a gage head would cause a catastrophic failure. To minimize this problem, the instrument heads were later offset from the borehole collar flanges by stainless steel washers to provided a path for brine to flow. Unfortunately, this modification was not effective in boreholes that produced large quantities of brine because salt deposits would fill the gap and block the flow of brine.

3.2.4 IRAD 4000-L Rod Extensometers: The Model 4000-L rod extensometer, manufactured by the Irad Gage Division of Creare Products, Inc. (later Roctest, Inc.), consisted of borehole anchors that were connected to potentiometers in a gage head by metal rods. A complete 
extensometer unit was composed of four or five gages with anchors installed at different depths in a single borehole.

Design: IRAD rod extensometers were composed of borehole anchors, rod strings, rod sheathing, rod spacers, and a gage head containing linear potentiometers (Figure 3.2.5). These gages were installed in several of the TSI test rooms and were therefore exposed to different ranges of temperatures. To accommodate the different temperatures, the gage components were manufactured for standard-, moderate-, and high-temperature applications. The standard-temperature applications used in Room $G$ and the AIS utilized Delrin plastic anchors and spacers, and stainless steel rods sleeved in plastic tubing. The moderate-temperature applications used in Rooms $A 1, A 2, A 3$, and $H$ utilized Delrin plastic anchors and spacers, and super Invar rods sleeved in stainless steel tubing. The high-temperature applications in Room B utilized stainless steel anchors and spacers, and super Invar rods sleeved in stainless steel tubing.

The anchors were designed for use in $76 \mathrm{~mm}(3 \mathrm{in})$ boreholes and consisted of cylinders of stainless steel or Delrin plastic that were fitted with c-style internal retaining rings to grip the borehole wall. The rod strings were made up from segments of stainless steel or super Invar rod with a $6 \mathrm{~mm}(1 / 4 \mathrm{in}$ ) diameter. (Invar is a metal with a comparatively small coefficient of thermal expansion.) The individual rod segments were up to $3 \mathrm{~m}(10 \mathrm{ft})$ in length and were drilled and tapped so that they could be coupled together with set screws to make up different lengths.

The rod strings were typically attached to the anchors with set screws. However, in Room $G$ and the AIS (see Figure 1.0.3 for locations), 


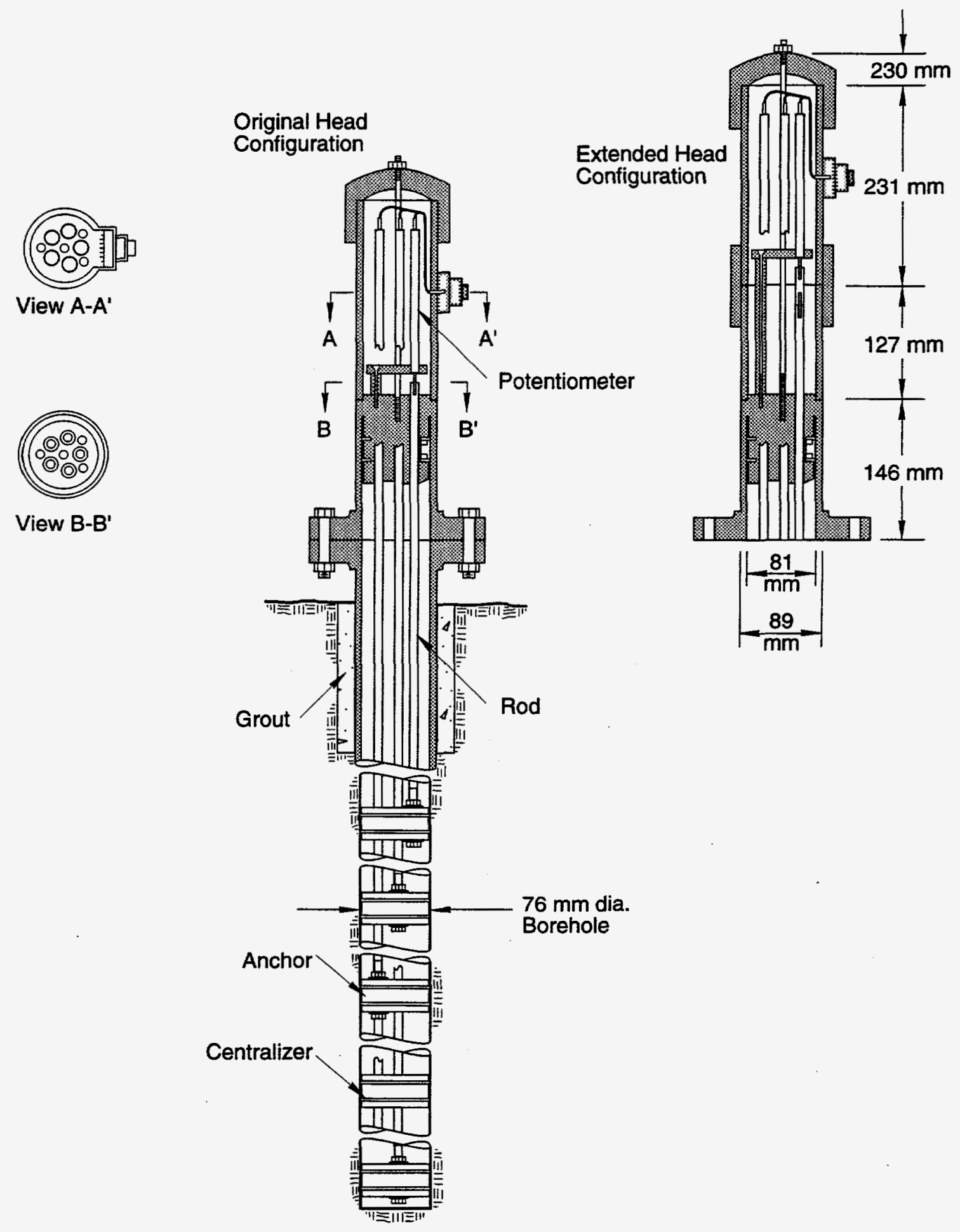

TM-16060-33

Figure 3.2.5. Irad 4000-L Rod Extensometer Installation 
detachable bayonet-type couplers were used to attach the rods to the anchors so that rod strings could be removed from the borehole. The ends of these rods contained pins that were pressed into holes drilled perpendicular to the rod axes. The rods were attached to the anchors by inserting the rods into special bayonet connector sockets in the anchors and twisting the rods to engage the pins in slots located in the sockets.

For protection from brine and salt, the rods were sheathed in $13 \mathrm{~mm}$ $(1 / 2$ in) tubes of stainless steel or plastic. Spacers similar in design and construction to the anchors were used to maintain the rods parallel to each other, and to keep the rods from contacting the borehole wall. The anchors and spacers were fabricated with holes for passing rods and sheathing from deeper anchors.

Inside the gage head, linear potentiometers with a range of $100 \mathrm{~mm}$ (4 in) were sealed inside protective cases that were mounted to a base plate. The base plate was in turn mounted to the head anchor with $25 \mathrm{~mm}$ (1 in) long standoffs. Within the potentiometer cases, connecting rods were attached to the potentiometer wipers and exited the cases through double o-ring seals. Outside the potentiometer cases, the connecting rods were threaded to the rod strings with adapters. The adapters were made of $25 \mathrm{~mm}(1 \mathrm{in})$ segments of anchor rod that were threaded with 6-32 threads on one end to mate with the connecting rod, and with 10-32 threads on the other to mate with the set screws of the rod string. Finally, the gage heads were housed in protective covers made from lengths of PVC pipe.

Calibration: The IRAD rod extensometers were calibrated by the method described in section 3.1 .3 [TOPs 042 and 314]. The calibration constants were stored in the ModComp Gage Calibration File and were used with Equation 3.1 .3 to convert voltages to units of displacement (inches). 
Installation: The first step in the installation of a rod extensometer was to bolt the collar extension to the collar flange. Next, in medium- and high-temperature applications, the first lengths of rod and protective tubing were attached to an anchor, and the assembly was inserted into the borehole using an installation tool and setting rods supplied by the manufacturer [TOP 081]. Lengths of rod and tubing were then added as the assembly was pushed into the hole until the desired depth had been reached. Each rod segment was threaded to the next segment with small diameter set screws that were secured with removable Loctite thread adhesive. (When installing gages for use in standard-temperature applications, the anchor and a continuous length of plastic sheathing were installed first followed by the rod string.) The final segment of rod in each string was the $25 \mathrm{~mm}$ (1 in) long adapter. Next, the retaining rings in the anchor were set by pulling a release pin and the installation hardware was removed from the borehole. The installation hardware was then used to install a spacer half way to the next anchor point. This procedure was repeated for the remaining anchors and rod strings until all were installed.

After setting all anchors, rod strings, and sheathing, the instrument head was anchored in the collar extension and the potentiometer connecting rods were threaded to the rod strings. Finally, the protective cover was installed. After installation, input and output voltages and resistances were manually measured and recorded to verify gage operation before connecting the assembly to the DAS. Initial installation procedures were developed and verified during gage installation practice in Room 4 of the SPDV test panel (see Figure 1.0 .3 for location). 
Operation: After installation, the rod extensometers were monitored by the DAS (Section 2.5), and no manual operations were required other than maintenance and repair. The rod extensometers provided very clean and smooth data compared to the data from the E-200I wire extensometers described in section 3.2.2. The stiffness of the rod sets, and the simple and direct connection of the rods to the potentiometers produced data with a minimal amount of hysteresis.

Gage maintenance and repair activities kept over $85 \%$ of the rod extensometers in good condition during the periods (two to seven years) covered by the data reports [13-21]. Gage heads were accessible for repair or replacement, but problems with anchors and rods were often irreparable. In addition, there were access restrictions of varying duration (some permanent) because of roof stability problems in the $A, B$, and $\mathrm{G}$ test rooms. These restrictions prevented damaged gage heads from being repaired and prevented gages that had reached the end of their ranges from being reset.

Extensometers in the AIS were afflicted by a unique problem. The air temperature in the shaft varied with the seasons, and the temperature effects on the formation and gage components produced a sinusoidal component in the data. Some of the rod extensometers had difficulty measuring the negative portions of the sinusoidal cycle, possibly due to play in the detachable rod couplers at the anchor points. This problem resulted in flat segments in the data curves that were sometimes so pronounced, especially in the case of shallower anchors, that the data became difficult to interpret.

Maintenance: Failures in the rod extensometer heads were usually caused by the intrusion of brine and the development of salt deposits in 
and around the electrical leads and potentiometers. Intrusion of brine in the circuitry caused corrosion and short circuits, while accumulation of salt deposits on the potentiometers or within the rod passageways would restrict free movement of the rod strings. To help avoid these problems, brine and salt deposits were removed by cleaning any exposed parts. An additional attempt at preventing brine intrusion was made by packing grease on top of the gage heads in vertical-up installations. However, oil separating from the grease would leak into the potentiometers and cause further problems, so this procedure was eventually abandoned. Failures in the instrument heads were generally rectified by replacing the heads with new or refurbished units. The old units were repaired, calibrated, and placed in inventory.

Another problem in the gage heads was the development of corrosionstress fractures in the carbon steel retaining rings that anchored the head to the collar mount. These rings would weaken with age and would often fail during maintenance activities. This problem was rectified by replacing the carbon steel rings with stainless steel rings. No failures of downhole anchors were experienced, however, because borehole closure enabled the borehole walls to hold the anchors in place.

In addition to the brine-induced problems, the wiper strips of the potentiometers developed an oxide coating over time that caused the gages to produce noisy data. Although the underground environment contributed to this aging effect, gages stored above ground were also affected by this phenomenon. To minimize this problem, the wiper strips were cleaned with a pencil eraser and the wipers, wiper strips, and associated components were coated with a light application of high-temperature dielectric grease. 
Brine-induced failures of downhole components included the failure of the detachable rod couplers used in the stainless steel rod strings. These failures were caused by corrosion of the mild steel pins used to secure the rod ends to the anchors. This problem was remedied by removing the rods from the borehole and replacing the original pins with stainless steel pins. Brine and salt deposits would also foul rods and restrict free movement. Because of the difficulty in removing anchors, however, rod extensometers with downhole failures were generally abandoned.

Certain types of failures, however, could sometimes be repaired. The Invar rod strings were susceptible to corrosion especially at the joints. The dissimilar metal (stainless steel) of the set screws used to couple the rods accelerated corrosion in these areas. Moreover, the thin walls around the tapped holes in the end of the rods were weak points that were prone to failure. Later in the testing program, innovative procedures were used with limited success to restore broken Invar rods. One procedure used specially designed and fabricated overshot threading dies for splicing broken rods. By this procedure, a broken rod segment was pulled from a borehole and fitted with the die. The rod was then reinserted into the borehole and pushed up to the anchored segment of rod. After contact was made, the free end of the rod was turned and the overshot die would grip the anchored segment. A similar method was used with some success to reattach rod strings to anchors. This procedure involved attaching a specially fabricated threading tap to the end of a rod string that had broken from an anchor. The string was then reinserted in the borehole and turned to lock the tap into the anchor. Both procedures worked surprisingly well, however success was limited because the rod strings would often break at another point during reinstallation 
or soon thereafter.

In Room G, maintenance activities were found to disturb the detachable rod couplers and produce steps in the data curves. The different parts of the couplers were fit together with a small amount of play which would be taken up slowly with borehole extension. When a coupler was disturbed, there would again be play in the system and the process would be repeated. Each disturbance would result in a flat step in the data curve as the play in the coupler was taken up by extension. After this problem was identified, maintenance of rod extensometers was reduced to visual inspections and washing with a hose; repairs were deferred until necessary.

One unique problem existed that was not related to corrosion or salt deposits. Cracks developed in the formation in response to stress field perturbations around the excavations and slabs formed that separated from the formation. Besides measuring the extension of the formation, extensometers that crossed such separations would also measure the amount of separation. In some cases the movement of the slab had a shear component. If an extensometer borehole crossed a shear plane, the resulting offset would impede free movement of the rods and the gages would be abandoned.

Modifications: Before installing the gages in the test rooms, a modification was made to the method of mounting the gages to the instrument collars. Instead of anchoring the instrument heads in the grouted collars, the heads were anchored in $90 \mathrm{~mm}(31 / 2$ in) long collar extensions that were fabricated from steel pipe flanges and short lengths of pipe. c-style internal retaining rings anchored the heads in the collar extensions which were bolted to the grouted instrument collar 
flanges. The collar extensions were originally intended to make maintenance and repair easier because the gage heads could be removed by unbolting the adapters instead of extracting the heads against the force of the retaining rings. In practice, however, the adapters were not very effective in simplifying maintenance. A special puller, similar to a gear puller, was fabricated for removing gage heads from the collars. This allowed the gage heads to be removed without disturbing the R.I. displacement transducers (Section 3.1.3) which were often attached to a collar bolt.

Many modifications were made to the gages as the experiments progressed to alleviate problems due to brine and salt deposits. The steel collar extensions were sandblasted and painted to minimize corrosion of the retaining rings in the gage head. Later in the experimental program, horizontal installations were modified by placing washers between the collar flanges and the collar extensions. The resulting space provided a path for brine to flow in an effort to minimize the amount of brine entering the gage heads. This modification required that the head anchors be shortened so that they would not extend past the collar extension. Horizontal installations were also modified by drilling $25 \mathrm{~mm}$ ( 1 in) diameter holes at a $45^{\circ}$ angle up through the formation and instrument collar to intersect the borehole and provide a drainage path for brine. Splash guards were installed over the vertical-down instruments to prevent brine from dripping onto the gage heads.

Vertical-up gages had four $6 \mathrm{~mm}(1 / 4 \mathrm{in})$ diameter holes drilled in the protective caps to allow for drainage and minimize the collection of brine and salt in the instrument head. Eventually, the protective covers were eliminated altogether. The electrical connectors were encapsulated in 
epoxy for reinforcement and waterproofing. Finally, rubber sleeve bellows were installed on the potentiometer rods; although the potentiometers were sealed with double o-ring wipers, the sleeves provided additional protection from brine. The bellows were originally sealed with automotive trim cement, but later were sealed with room-temperature vulcanizing (RTV) cement and tied with wax string for a seal that was more easily broken during maintenance.

Another major design modification was made to the rod extensometer heads to make resetting of the gages easier. Because of the relatively short $100 \mathrm{~mm}$ (4 in) range of the potentiometers, it was necessary to reset the gages frequently, especially the deeper gages in the heated test rooms since they experienced more displacement. The original design required the gages to be reset by adding extensions to the rod strings. However, by the time a gage had displaced $25 \mathrm{~mm}$ ( $1 \mathrm{in})$, the end of the $25 \mathrm{~mm}$ ( $1 \mathrm{in}$ ) long adaptor would have moved down into the head anchor leaving only the delicate potentiometer connecting rod accessible. However, breaking this connection would result in bending and scarring of the connecting rod surface which would render the potentiometer inoperable. Corrosion and the use of thread adhesive contributed to the difficulty in breaking the connection. To eliminate this problem, the assembly was redesigned so that the end of the adapter would still be outside the collar mount when the potentiometer was at the end of its range. This was accomplished by increasing the length of the potentiometer assembly standoffs from $25 \mathrm{~mm}$ ( 1 in) to $127 \mathrm{~mm} \mathrm{(5} \mathrm{in)} \mathrm{and} \mathrm{adding} \mathrm{extensions} \mathrm{to} \mathrm{the} \mathrm{rod} \mathrm{strings.} \mathrm{In}$ addition, a similar length of PVC pipe was coupled between the protective cover and the attachment plate, as shown in Figure 3.2.5. To make disconnection easier, anti-seize compound was used on the connections to 
be broken instead of thread adhesive, and a removable locknut was used on the connecting rod to secure it to the rod string. During this process, a variety of extensions ranging from 25 to $100 \mathrm{~mm}$ ( 1 to 4 in) were added to the rod strings in order to optimize the range of each gage.

In the AIS, rod extensometer installations needed to be modified from the standard design to give the gages a low profile in the shaft. The gages were installed in large countersunk holes that were about $0.5 \mathrm{~m}$ (1.5 ft) deep. In addition, the collar extensions were omitted and the protective cover extension was shortened. The result of these modifications was that the gages were installed completely within the shaft wall out of the way of the conveyance system and falling debris.

As described above, the sliding rod couplers used in Room $G$ and the AIs contained a small amount of play in the components. In an effort to reduce the amount of play in the system and its effects on the data, small compression springs were added to the ends of the rod strings next to the anchors. The springs were intended to tighten the loose connections and reduce the effect on gage output by maintaining the connections under tension. In practice, however, the problems caused by play in the connection remained after the springs were added.

The polyethylene rod sheathing used in Room $\mathrm{G}$ was found to deteriorate over time. Because of this, nylon air brake hose was substituted for the sheathing in the AIS installations. The nylon tubing was found to be a more durable material.

3.2.5 Serata C-300 Creepmeters: Model C-300 creepmeters manufactured by Serata Geomechanics were used to evaluate the elongation of selected test rooms. Groups of creepmeters were installed near the midpoint of the A2 and B test rooms and were connected to span wires that were anchored at 
various points along the length of each room. Linear potentiometers in the meters measured the displacement and were monitored by the DAS.

Design: A creepmeter is a single-channel extensometer that consists of a potentiometer in a gage head that is connected to an anchor at some distance by small diameter wire rope. Several creepmeters were installed in a group near the center of a test room with anchors at different points along the length of the test room. Both the gage heads and the anchor points were installed near the back of the test rooms. Inside the gages heads, displacement wires were attached to cable reels and were maintained under tension by constant-force springs (Figure 3.2.6). Linear, rotary potentiometers connected directly to the cable reels measured displacement and were monitored by the DAS. The C-300 was similar in construction to the Serata E-200L wire extensometer (Section 3.2.2), but the cable reel was smaller in diameter to exert greater tension on the span wires (which were up to $27 \mathrm{~m}$ (90 ft) long) and to provide greater sensitivity. Outside the gage heads, span wires were connected to eyelets on the displacement wires at one end and to anchor points at the other. Nylon-coated, seven-by-seven construction, $0.87 \mathrm{~mm}(0.034 \mathrm{in})$ diameter, stainless steel wire rope was used for span wires, while eyebolts served as anchor points.

Calibration: Creepmeters were calibrated by the method described in Section 3.1.3 [TOP 043]. The calibration constants were stored in the ModComp Gage Calibration File and were used with Equation 3.1 .3 to convert voltages to units of displacement (inches).

Installation: Several single-point creepmeters were bolted to a single "H-frame" (Figure 3.2.7) made of welded, anodized aluminum plate that was bolted next to the base plate of a serata E-200L wire 


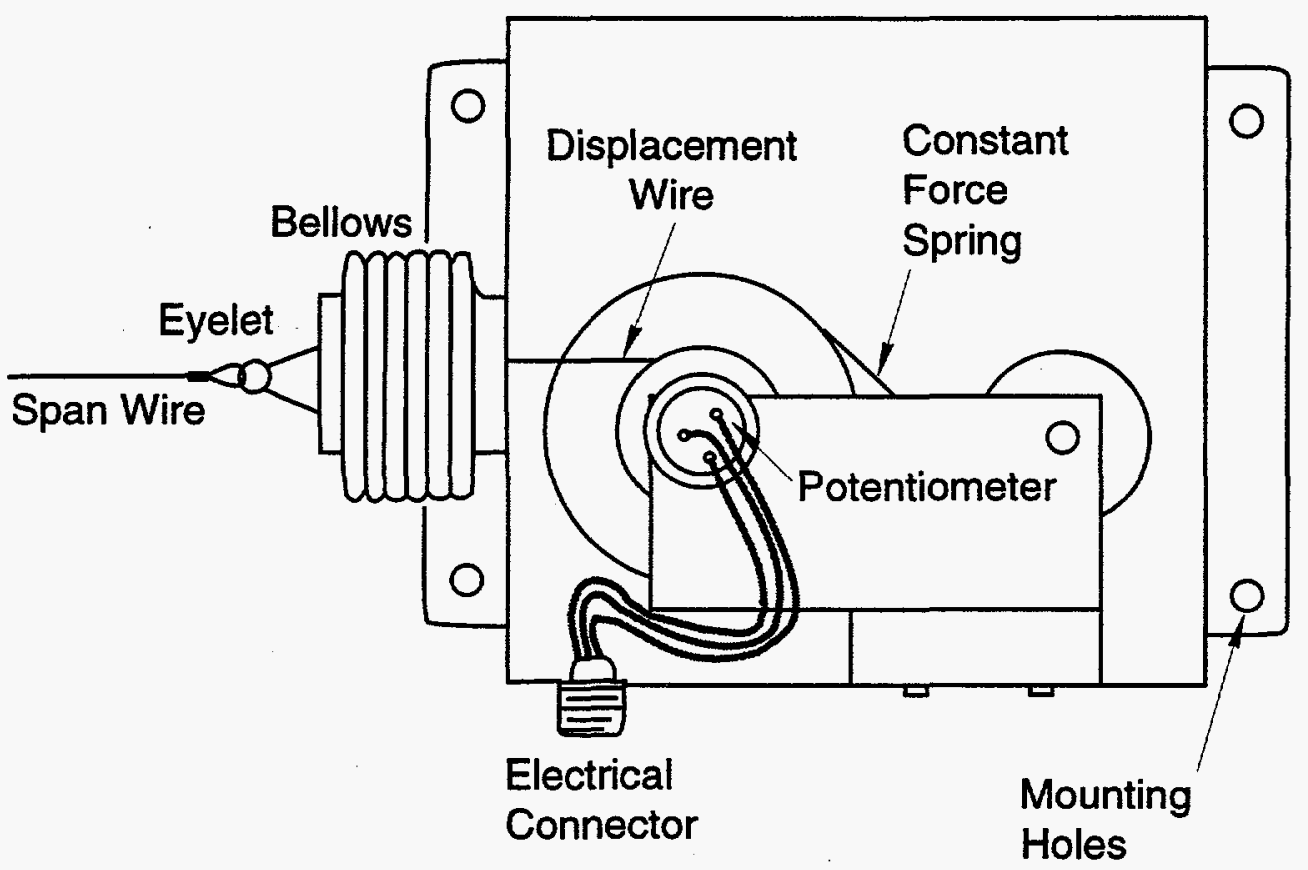

$T M-16060-3$

Figure 3.2.6. Serata C-300 Creepmeter

extensometer [TOP 066]. One frame was installed at the back of each of the A2 and B test rooms (see Figure 1.0.3 for locations) near the center of the rooms. The anchor points were also installed in the back but at different locations along the length of the room. Although the frame could accommodate twelve gages (Figure 3.2.7), only eight were installed in Room B and eleven in Room A2. The anchor point eyebolts were either threaded into E-200L wire extensometer baseplates, or into anchor bolts similar to those of the manual closure points (Figure 3.1 .6 ). The gages had a $100 \mathrm{~mm}$ (4 in) range but were held at midrange during installation by placing a cotter pin in a specially drilled hole in the cable reel. (By installing the gage at midrange, both elongation and contraction of the test rooms could be measured.) The span wires were then attached to 


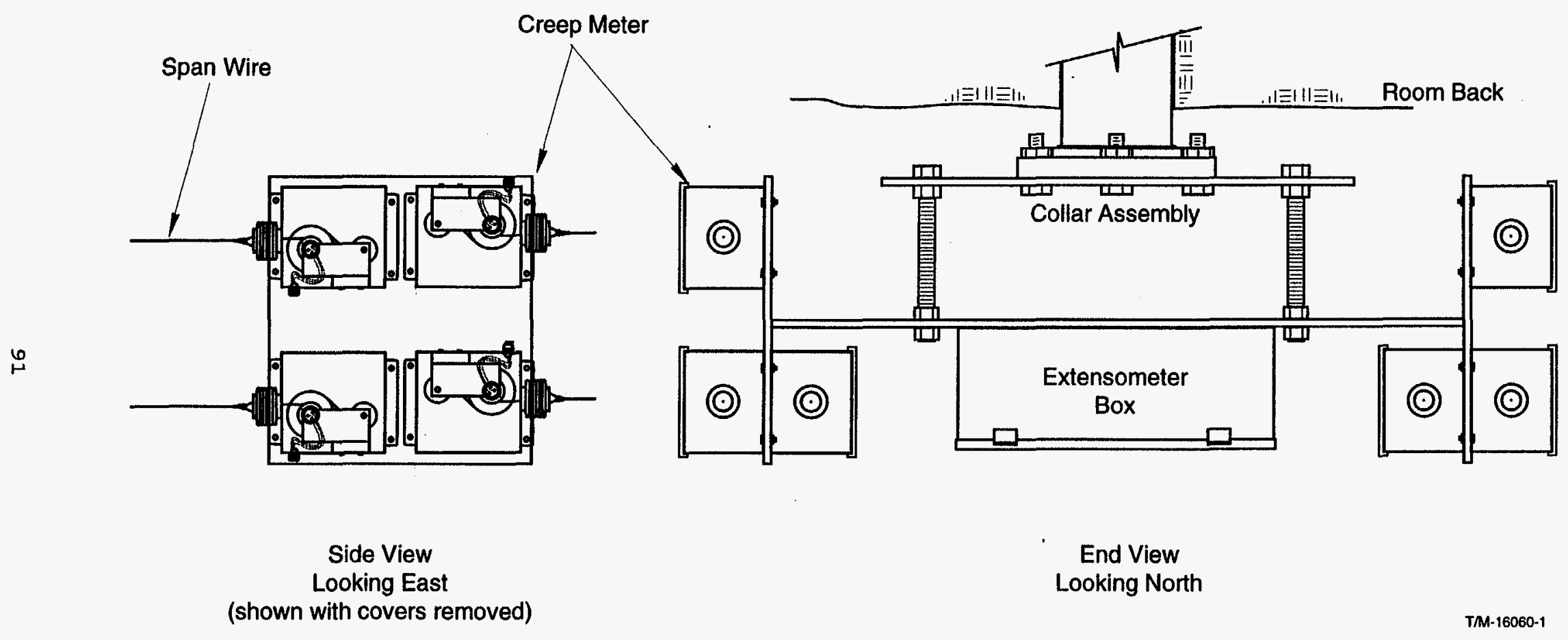

Figure 3.2.7. Creepmeter Installation 
anchor eyebolts on one end and to displacement cable eyelets on the other by looping the wire through the eyes, lightly tensioning the wires, and securing with crimping sleeves. After the span wires were installed, the cotter pins were removed from the cable reels to free the gages for measurement. Input and output voltages and resistances were manually measured and recorded to verify gage operation before connecting the assemblies to the DAS.

Operation: After installation, the creepmeters were monitored by the DAS (Section 2.5), and no manual operations were required other than maintenance and repair. All of the creepmeters were kept in good operating condition through the periods (four to five years) covered by the data reports $[15,16]$.

Test room elongation was small compared to room closure $[15,16]$ and its measurement was complicated by the thermal expansion of the span wires. Thermal expansion was caused by heat from the canister heaters, but thermal contraction occurred when the room doors were opened for maintenance and the room was temporarily ventilated. Since test room elongation was of the same magnitude as the thermal expansion of the wires, the data produced by the creepmeters were difficult to interpret quantitatively. In addition, creepmeter span wires were often disturbed and considerable hysteresis resulted on each occasion. Besides occasionally needing repairs themselves, the creepmeters (as well as some of the anchor points) were attached to E-200I extensometers and needed to be disconnected each time the extensometers were repaired. The offsets and hysteresis resulting from disturbances and maintenance added to the difficulty in interpreting the data. 
Maintenance: Maintenance of the creepmeters was needed to repair broken gages and to prevent corrosion of the constant-force spring in the gage head. The creepmeter span wires were small in diameter and difficult to see; as a result, the span wires were sometimes accidentally snagged by personnel working near the test room backs. When this happened, the constant force springs and potentiometers in the gage heads were often damaged from the recoil of the springs. Maintenance in these instances required replacement of the span wires and, if necessary, the gage heads. Damaged gage heads were replaced by new or rebuilt units; old units were repaired, calibrated, and placed in inventory. LPS-3, a heavy lubricating oil, was sprayed on the constant-force springs to minimize corrosion.

Modifications: The original displacement wires in the gage heads were made of small diameter wire rope that was easily broken when the span wires were accidentally snagged. To reduce the frequency of damage to internal parts, the original displacement wires were replaced by larger diameter wires that would not break so easily when the span wires were broken. For further protection, a bolt was added to the cable reel to act as a mechanical stop at the end of the gages range.

\subsection{Stress Gages}

The stress gages used in the TSI in situ tests were designed to measure components of the formation stress field from a borehole. Two types of stress gages were used: strain-gaged stressmeters (SGSs) and Bureau of Mines (BuMines) pressure cells. The sGs gages were based on strain-gaged beams and measured in situ stress components normal to the borehole. Typically, three sGs gages were installed in close proximity in a single borehole to measure stress components in three radial directions. The BuMines unit consisted of two borehole pressure cells 
(BPCs) and one cylindrical pressure cell (CPC) to measure two radial components of the stress field and the mean normal stress. The gages are depicted schematically in Figure 3.3.1, and are described in greater detail in other publications [38-42]. Stress gages were generally installed in arrays of boreholes around the test rooms, as shown in Figures 3.3 .2 and 3.3.3. In other applications, stress gages were installed in boreholes that paralleled the test rooms.

3.3.1 Strain-Gaged Stressmeters: The sGS was developed by sandia after evaluating existing vibrating-wire stressmeters (VWS) [39-42]. The evaluation showed that the VwS was difficult to set at the desired load during installation because the gage would become imbedded in the formation. (The elastic modulus of the gage was "stiff" with respect to the modulus of formation.) Furthermore, the Vws had a limited range, and required a special data logger to monitor gage output. The sGS was designed to alleviate these problems by having a reduced elastic modulus, a greater range, and a voltage output that could be monitored by the DAs.

A single sGS gage was designed to measure a single component of stress normal to the borehole axis. Two- or three-gage units (Figure 3.3 .1 ) were used to evaluate the biaxial stress state of the formation in the plane normal to the borehole axis. The sGs gages were manufactured to sandia specifications by specialty Engineering Associates and Team specialty Products. Table 3.0 .1 shows the quantities of SGs gages emplaced in the test rooms.

Design: The sGS had three major components: a pair of steel platens, a stainless steel body containing a brass stressmeter beam, and a steel wedge for loading the gage in the borehole (Figure 3.3.4). When assembled and loaded in the borehole, the load of the formation normal to the gage 


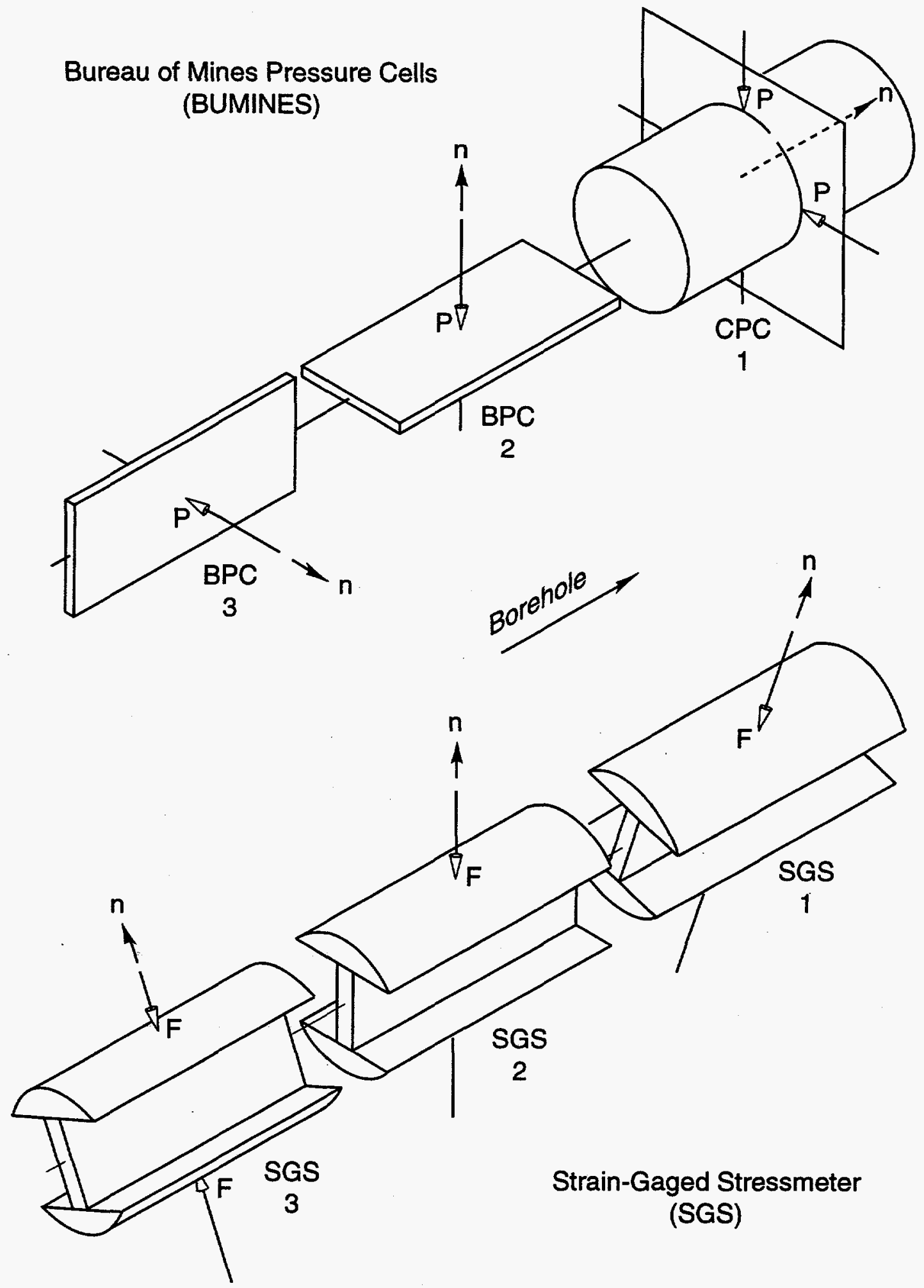

T/M-16060-20

Figure 3.3.1. Schematic of Bureau of Mines Pressure Cells and Strain-Gaged Stressmeters 


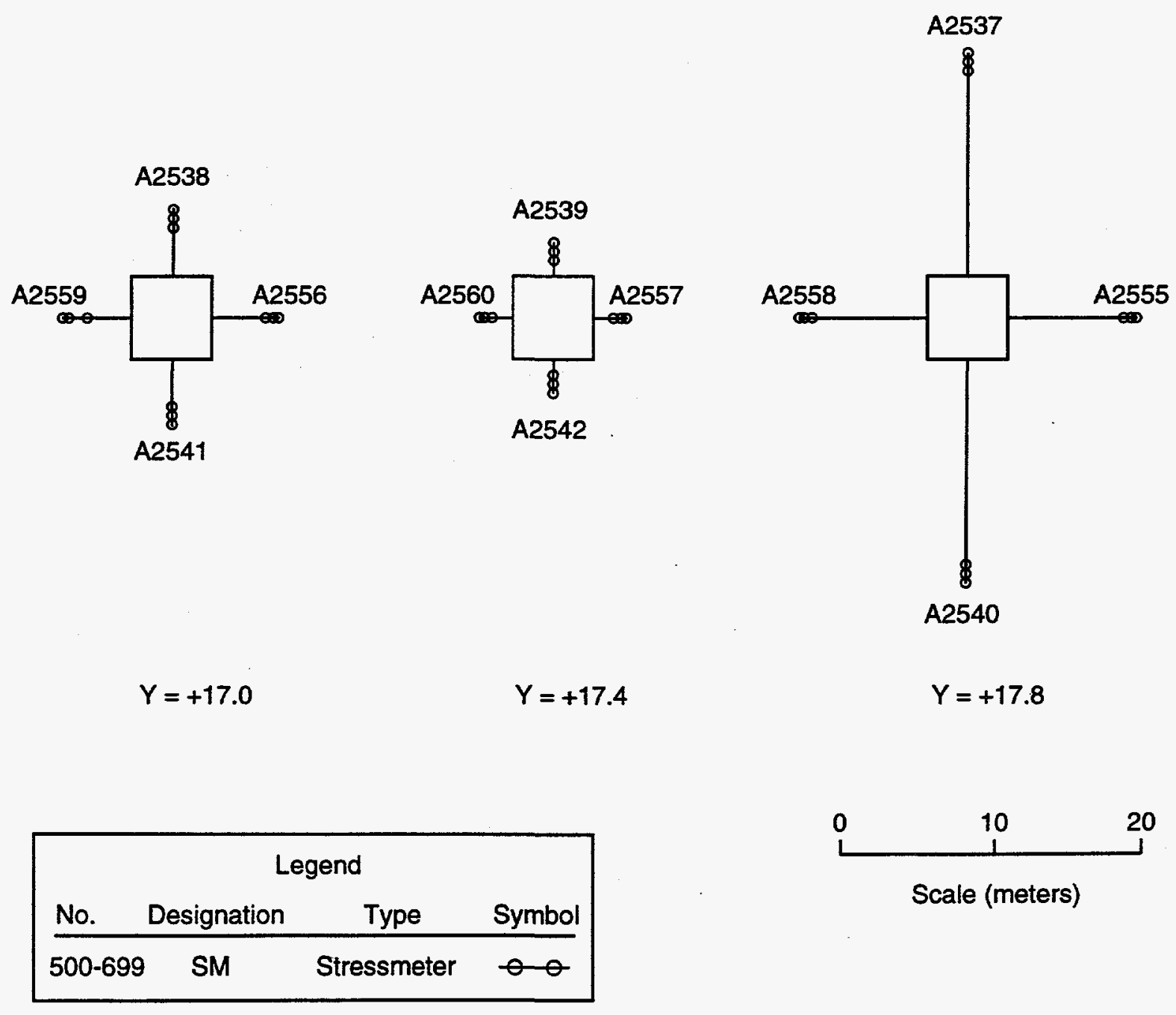

T/M-16060-18

Figure 3.3.2. Cross Section of a Strain-Gaged Stressmeter Station 


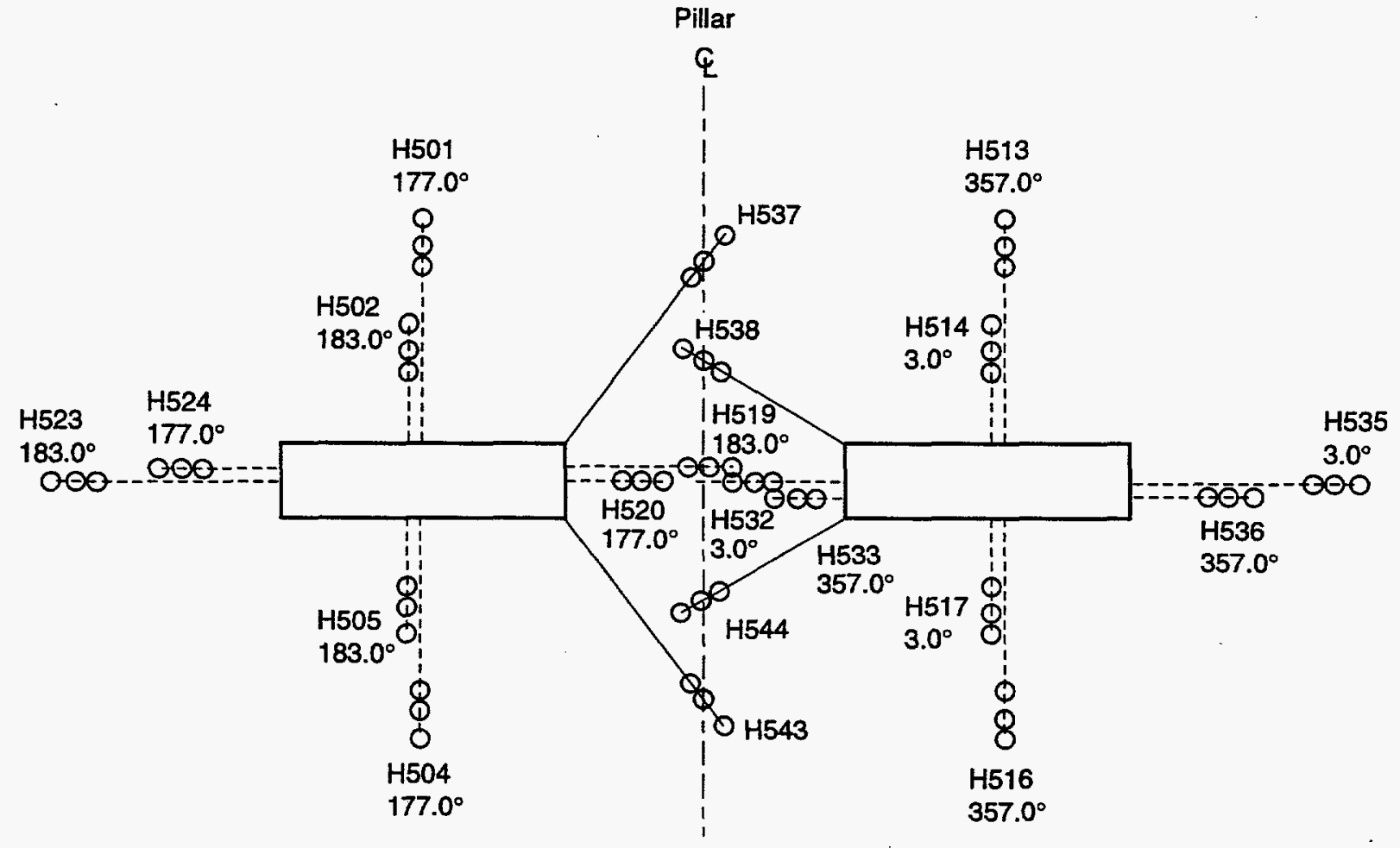

Section $180.0^{\circ}$

Section $0.0^{\circ}$

Looking North

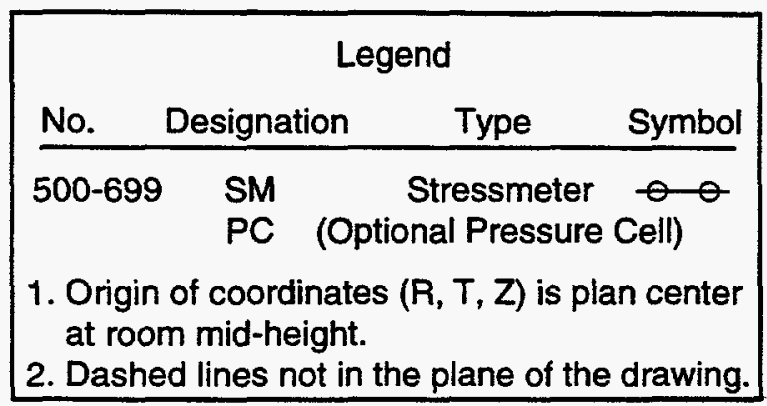

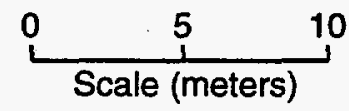

Figure 3.3.3. Cross Section of a Bureau of Mines Pressure Cell station 


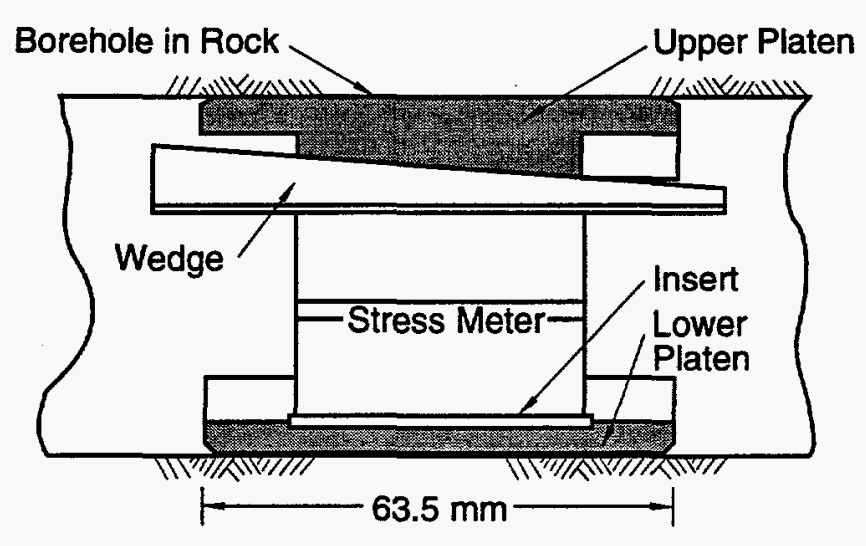

Side View
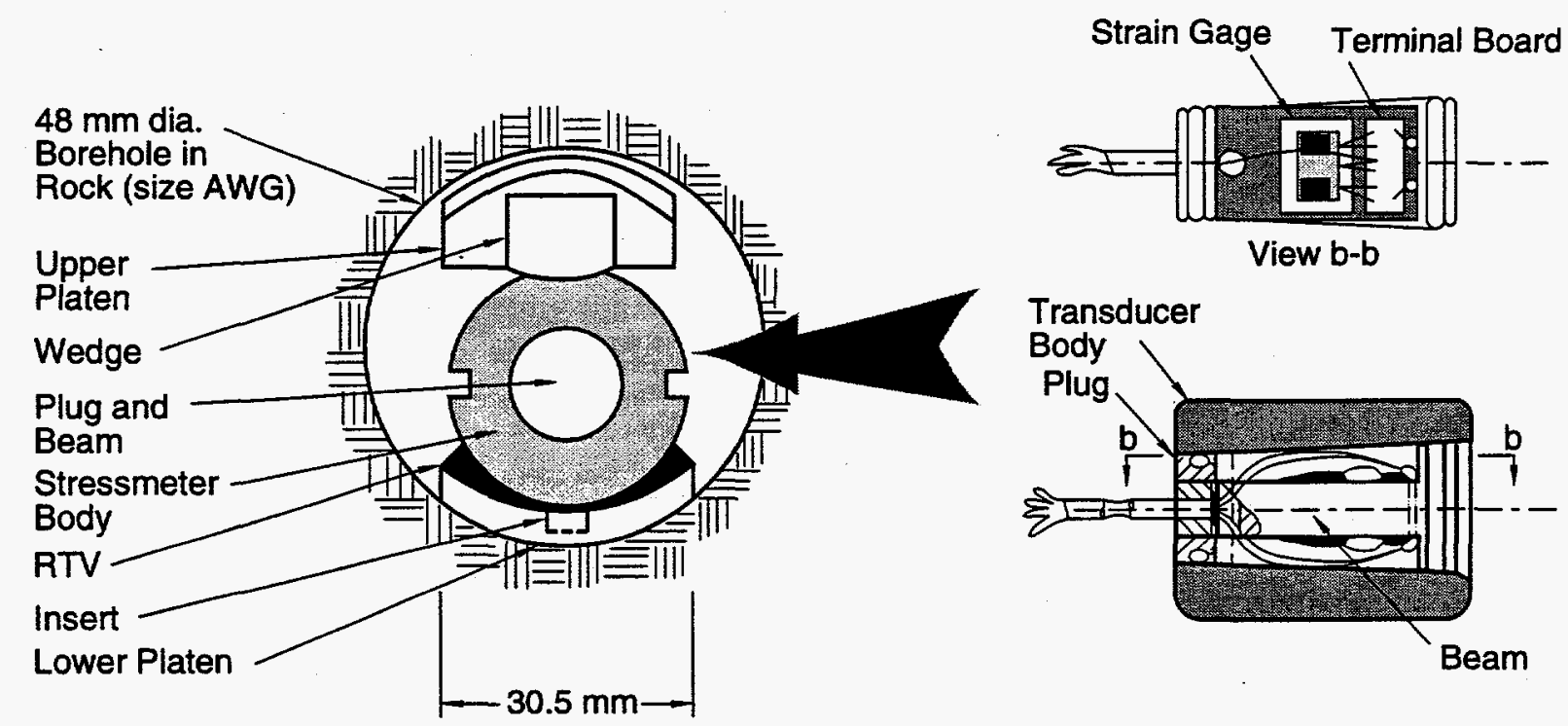

End View

TMM-16060-31

Figure 3.3.4. Strain-Gaged stressmeter 
would be transferred to the stressmeter beam. Strain in the beam was then measured by four strain gages cemented to the beam in a temperaturecompensating bridge.

Calibration: The strain-gaged stressmeters were calibrated by a two-step procedure. First, each gage was placed in a split block of aluminum and loaded uniaxially with a universal testing machine or laboratory press to calibrate gage output to force on the gage [TOP 289]. A constant voltage was applied across the bridge while voltage output was measured with a digital volt meter. Force on the gage was measured by a load cell. Due to the nonlinear response of the gage, a two-part regression analysis was performed with a third-order polynomial fit to data below a breakpoint and a linear equation fit to data above:

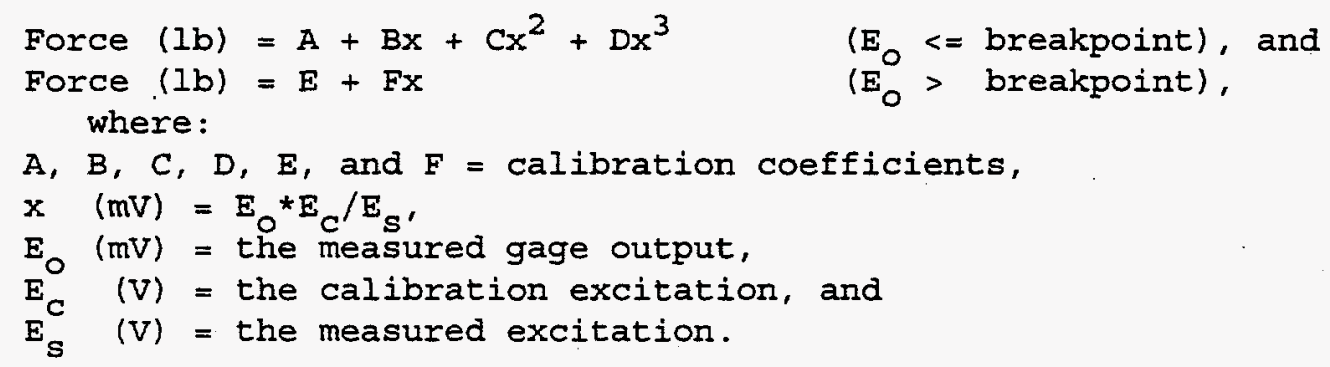

The second step related stress in the rock to force on the gage by placing a gage in a borehole drilled in a large block of salt and loading the block uniaxially in a universal testing machine. This also required a two-part conversion with data below a breakpoint of 2,650 pounds having been fit to a linear equation, and data above fit to a fourth-order polynomial :

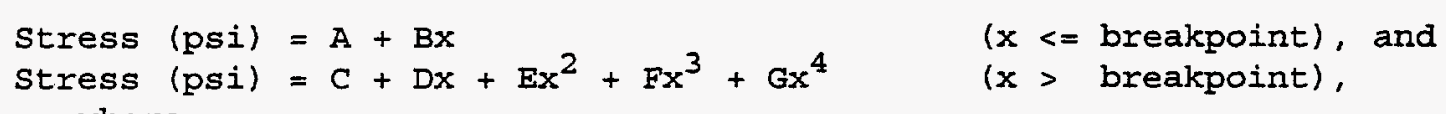
where:

$A, B, C, D, E, F, G=$ conversion constants, and $x(1 b)=$ Eorce.

This procedure was performed during the development of the gages, and the 
calibration constants that were determined at that time were applied to all sGS gages used in the TSI tests.

The calibration coefficients, break points, excitation voltages, and conversion constants were stored in the ModComp Gage Calibration File and were used with the above equations to convert voltages to units of rock stress (pounds per square inch).

Installation: Three sGs gages were typically installed in a single borehole with their sensing directions oriented $30^{\circ}$ from one another (Figure 3.3.1). In the ISBT, however, two gages were installed at right angles to each other. The gages were set at slightly different depths in the borehole with a spacing of about $0.3 \mathrm{~m}$ ( 1 ft) between each gage; a three gage unit was thus located within a $0.6 \mathrm{~m}$ (2 ft) segment. During installation, each gage was attached to a hydraulic ram and inserted into a $47.75 \mathrm{~mm}(1.880 \mathrm{in})$ diameter borehole and positioned at the desired depth [TOP 073]. The ram was attached to the eyelet in the wedge and was used to pull the wedge and force the platens against the borehole wall. The hydraulic pressure was then increased until the output voltage indicated a formation stress of $8.3 \mathrm{MPa}(1,200 \mathrm{psi})$, as related by the calibration values. This stress was chosen for installation because higher stresses tended to break the pulling eyelet in the wedge. In fact, many of the gages were installed at lower stresses because the eyelets would sometimes break prematurely. After emplacement, input and output voltages and resistances, along with the resistances between the leads and shielding, were manually measured and recorded to verify operation before connecting the gages to the DAS. Installation was practiced in Room 4 of the SPDV Test Panel (see Figure 1.0 .3 for location) and in the access drift to Room $\mathrm{H}$ prior to the instrumentation of the test rooms. 
Operation: After installation, the SGS gages were monitored by the DAS (Section 2.5). The DAS supplied a constant excitation voltage across the strain-gage bridges and monitored bridge output with digital voltmeters. Both the raw voltages and the calculated stress values were collected by the DAS. No manual operations were required other than maintenance and repair.

Although the SGS gages were sensitive to small changes in the stress field, their output was not easily assessed. The measurement of stress in salt is difficult because of the time-dependent creep of the formation around both the test room and the borehole. A period of time is necessary for the gage pressure to come into equilibrium with the surrounding stress field. Moreover, the reliability of the gages was low; almost $45 \%$ of the SGS gages failed during the periods (two to seven years) covered by the data reports $[13-20]$.

Maintenance: The most typical failure of the SGS gages was high impedance, capacitive short circuits between the strain-gage bridge conductors and the stressmeter body. These short circuits were caused by brine intrusion and resulted in noisy data or drastic changes in gage output. These failures were easily detected by reviewing DAS alarm logs or by reviewing data plots during routine maintenance (see section 2.6). During initial calibration and during installation, the electrical resistances of the input and output sides of the strain-gage bridges, and the resistances of cable leads to shield were determined with high impedance ohmmeters. When gage operation was questionable, these resistances were measured again and compared to the original resistances. A decrease in resistance between the leads and shield normally indicated a short circuit between the strain gage and the stressmeter body (which was 
grounded to the cable shield). If a short circuit was noted, the gage would be disconnected from the DAS to avoid loading the remaining gages in the unit (a common power supply was used for all gages in each borehole).

Occasionally an open circuit in the electrical leads would occur. This failure was most often the result of fatigue in the thin, 28-gauge conductors which were damaged by improper stripping during connection of the gage to the DAS. This problem was solved by using thermal strippers to reterminate the cables.

During gage installation, gages would occasionally fail to stabilize at the proper setting pressure because of gage failure or anomalies (such as soft clay seams) in the borehole. Gages that failed to seat properly were removed by knocking out the wedge with a removal tool, pulling the stressmeter and lower platen assembly out of the hole, and fishing out the upper platen and wedge with a magnet [TOP 073]. Installation was then tried again either with a different gage or at a slightly different borehole depth. Gage removal and replacement was usually limited to gages that had failed within a short time after installation, but gages could sometimes be removed successfully long after installation. Failed gages that could not be replaced were deactivated from the DAS.

Modifications: The SGS gages required $47.75 \mathrm{~mm}(1.880$ in) diameter boreholes for installation. However, the diameter of the holes was specified with a tolerance of $\pm 0.25 \mathrm{~mm}( \pm 0.01 \mathrm{in})$ and the drilling contractor typically provided holes that were at the low end of the specification. Borehole closure and salt deposits made the holes smaller yet. Because the gages had a tight borehole diameter tolerance, it was necessary to ream the boreholes prior to installation. A hand-held drill with a diamond masonry bit was used to ream the holes to the proper 
diameter. Small diameter (XRW, a standard drilling size), light-weight aluminum drill rod with specially fabricated centralizers was used to reach the depths required. The centralizers were machined from steel stock and were pressed onto drill rod coupling pins. Reaming became a standard part of the SGS installation procedures.

Later in the experimental program, two modifications were made to the SGS gages to increase their resistance to brine and retard corrosion. The first was to coat the ends of the brass stress meter beams with silicone RTV cement to seal the junction between the beam and body. The second was to replace the original spiral-wound, Teflon-jacketed leads with cable sheathed in solid Teflon. The original spiral-wound jacketing tended to catch on hardware during installation and the resulting damage made the cables susceptible to brine intrusion. Later in the experimental program, SGS gages were supplied with the solid Teflon jacketing.

3.3.2 Bureau of Mines pressure Cells: The typical BuMines unit was composed of one CPC and two BPCs. The CPC measured the mean radial stress around the borehole while the BPCs were installed at right angles to each other to measure radial stress components in two orthogonal directions (Figure 3.3.1). The unit was designed to determine the biaxial stress field of the formation in the plane normal to the borehole axis. The gages were developed by the U. S. Bureau of Mines and were manufactured by Roger's Arms and Machine Company. Table 3.0 .1 shows the quantity of BuMines gages installed in the test rooms.

Design: The BuMines unit consisted of one CPC and two BPCs installed in a single borehole. The CPC was a cylindrical jack with a copper shell and solid steel core (Figure 3.3.5). The BPCs were mild steel flat-jacks that were painted with epoxy and embedded in cylinders of grout. The BPCs 


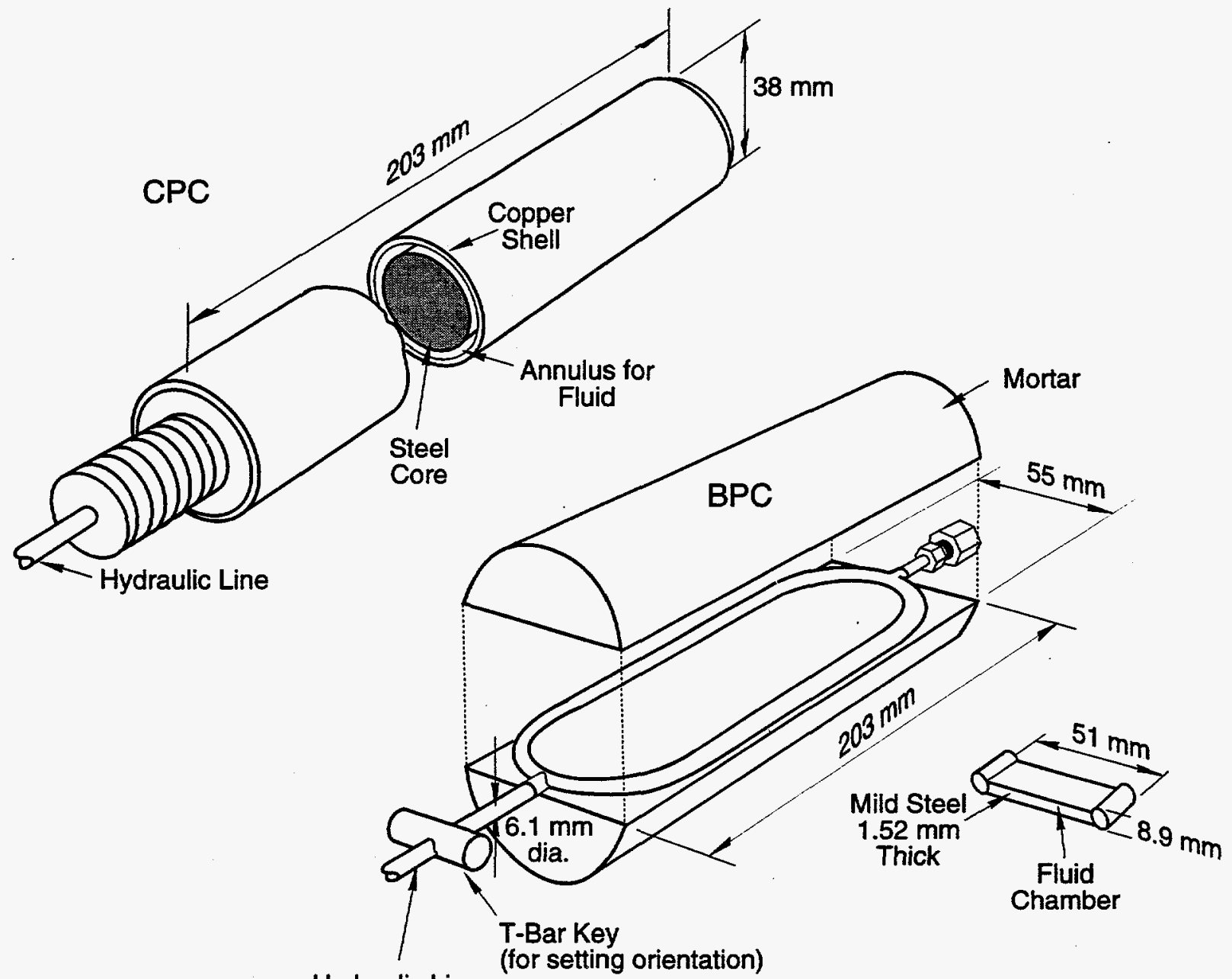

Hydraulic Line

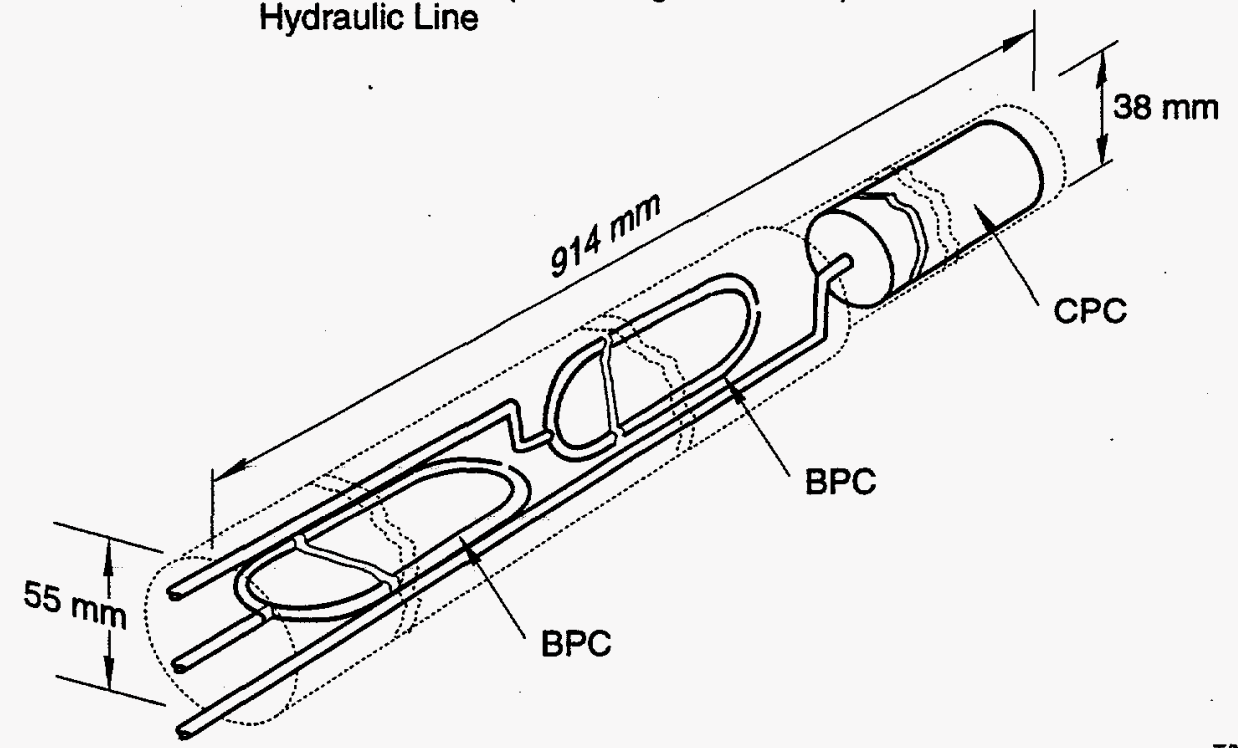

$T / M-16060-32$

Figure 3.3.5. Bureau of Mines Pressure Cells 
each had two lengths of $10 \mathrm{~mm}$ (3/8 in) nominal diameter pipe embedded in the grout to serve as conduits for hydraulic lines from deeper gages. The hydraulic line from each gage was terminated at the borehole collar with a three-way valve assembly that was connected to a $35 \mathrm{MPa}$ (5,000 psi) dial gage and a Kulite pressure transducer. The third port on the assembly was for connection to a hydraulic hand pump for pressurization of the gage. The pressure transducers were of the strain-gaged diaphragm type and produced a voltage output in the millivolt range that was monitored by the DAS .

Calibration: The BuMines gages were calibrated in three steps. First, the voltage output from each pressure transducer was calibrated to hydraulic pressure using a deadweight pressure tester and a digital volt meter. A two-part correlation was performed with a third-order polynomial fit to data below a breakpoint and a linear equation fit to data above:

$$
\begin{array}{ll}
\text { Pressure }(p s i)=A+B x+C x^{2}+D x^{3} & \left(E_{0}<=\text { breakpoint }\right), \text { and } \\
\text { Pressure (psi) }=E+F x & \left(E_{0}>\text { breakpoint }\right),
\end{array}
$$
where:

$A, B, C, D, E$, and $F=$ calibration coefficients,

$x(\mathrm{mV})=E_{o} * E_{C} / E_{S}$

$E_{0}(\mathrm{mV})=$ the measured gage output,

$E_{C}(V)=$ the calibration excitation, and

$E_{S}(V)=$ the measured excitation.

Second, a conversion factor was used to convert hydraulic pressure to force on the gage:

Force $(1 \mathrm{~b})=$ Pressure $(\mathrm{psi}) * 0.011387 \mathrm{lb} / \mathrm{psi}$.

The third step correlated rock stress to force on the gage by placing a gage in a borehole drilled in a large block of salt and loading the block uniaxially in a universal testing machine. This also required a two-part conversion with data fit to two separate third-order polynomials above and below a breakpoint: 


$$
\begin{aligned}
& \text { Stress }(\mathrm{psi})=\mathrm{A}+\mathrm{Bx}+\mathrm{Cx^{2 }}+\mathrm{Dx} \mathrm{x}^{3} \quad \text { ( } \mathrm{x}<=\text { breakpoint), and } \\
& \text { stress (psi) }=\mathrm{E}+\mathrm{Fx}+\mathrm{Gx}^{2}+\mathrm{Hx}^{3} \quad \text { ( } \mathrm{x}>\text { breakpoint), }
\end{aligned}
$$
where:

A, B, C, D, E, F, G, and $H=$ conversion constants, and $x(I b)=$ Force.

The third step was performed during gage development and the conversion constants determined at that time were applied to all BuMines gages throughout the TSI tests.

The calibration coefficients, breakpoints, excitation voltages, and conversion factors were stored in the ModComp Gage Calibration File and were used with the above equations to convert voltages to units of rock stress (pounds per square inch).

Installation: The boreholes for the BuMines units were drilled in two segments with each segment having a different diameter. The shallower segment was drilled or reamed to a diameter of $55.88 \mathrm{~mm}(2.200 \mathrm{in})$. The deeper segment was $38.10 \mathrm{~mm}(1.500 \mathrm{in})$ in diameter and typically extended 0.3 to $0.9 \mathrm{~m}$ ( 1 to $3 \mathrm{ft}$ ) past the end of the first segment. Before installation, the valve assemblies on each gage were disconnected to allow the hydraulic lines of the deeper gages to be routed through the conduits in the shallower gages. The next step was to reconnect the valve assemblies to the hydraulic lines. During installation, the CPC was inserted first in the deeper segment of the borehole. After insertion, the valve assembly was bled and the fittings were closed. The CPC was then pressurized with a hand pump until the pressure transducer indicated a rock stress of $10.3 \mathrm{MPa}(1,500 \mathrm{psi})$. After determining that the gage was functioning properly and not leaking, the BPCs were set in the larger diameter segment of the hole, typically within $1.5 \mathrm{~m}$ (5 ft) of the CPC. The two BPCs were inserted in the borehole (one at a time), bled, and pressurized to the same pressure. This procedure allowed a leaking jack 
to be withdrawn from a borehole and replaced before the remaining jacks of the unit were installed. The input and output voltages and resistances of the transducer, as well as the resistances between the leads and cable shield, were manually measured and recorded to verify operation before connecting the gages to the DAS.

Operation: The BuMines units were monitored by the DAS (Section 2.5) and few manual operations were required. Both the raw voltages and the calculated stress values were collected by the DAS.

The gages were not very reliable as highly corrosive brine, thermal expansion of the hydraulic oil in the heated test rooms, and long test durations contributed to loss of pressure and gage failure. Over 65\% of the Bumines gages failed during the periods (two to six years) covered by the data reports [13-20]. Moreover, the measurement of stress in salt is difficult because of the time-dependent creep of the formation around both the test room and the borehole. A substantial period of time was necessary for the pressure cells to come into equilibrium with the surrounding stress field.

Maintenance: Most of the BuMines gage failures were caused by loss of pressure in the pressure cells. If a gage lost pressure, gage maintenance personnel would repressurize the cell with a hand pump. If this were successful, data acquisition would continue and the gage would be monitored for performance. However, it is necessary to note that only a relatively few (about $2 \%$ ) of the gages that lost pressure could be successfully repressurized. If the gage failed to hold pressure at a future time, repressurization would again be attempted. If a gage failed to hold pressure after a second repressurization, the gage would be deactivated. Occasionally, a gage would leak at the fitting soldered to 
the end of the hydraulic line. This problem would be repaired by removing the fitting and a short length of line, splicing in a new section of line and fitting, and repressurizing the gage. Less frequently, a pressure transducer would fail. This would be repaired by replacing the transducer and repressurizing the gage. In any event, an anomaly would appear in the data since a repressurized gage would again take time to come into equilibrium with the borehole walls.

The electrical leads on the transducers would sometimes fail where connected to the DAS cables. These failures were caused by improperly stripping the electrical leads during installation; if the thin 28 -gauge leads were stripped with a knife, the wires would be damaged and prone to failure. Broken cables were repaired by using thermal strippers to reterminate the cables.

Modifications: The BuMines gages required boreholes with very close tolerances. If a borehole were slightly undersized, the gage could not be inserted; if a borehole were slightly oversized, the gage would generally rupture and lose pressure within a week of installation. Unfortunately, the diameters for the BPCs were incorrectly specified and the drilling contractor drilled the holes with a $55.12 \mathrm{~mm}(2.17 \mathrm{in})$ diameter. Because of this, the BPCs would not quite fit at the time of installation. Although the boreholes were only slightly undersized, the cells were manufactured with square edges and irregularities in the borehole walls tended to catch the edges of the gages. Borehole closure and salt deposits made the problem worse yet. Because of these problems, it was necessary to ream the boreholes by hand prior to gage installation using the same procedure that was used for the SGS gages (Section 3.3.1). The CPC segment was reamed to a diameter of $56.4 \mathrm{~mm}(2.220 \mathrm{in})$ while the BPC 
segment was reamed to $38.1 \mathrm{~mm}(1.500 \mathrm{in})$. It was necessary, however, to install some of the gages before the reaming bits could be delivered. In these cases, the grout surrounding the BPCs was sanded down to a smaller diameter by hand. Care was taken during the sanding operation to maintain the cylindrical shape.

Other efforts were made to improve the longevity of these gages. In order to strengthen the electrical leads of the pressure transducers, the leads were tied to the transducer assemblies to provide strain relief. In the ISBT, the delicate leads were soldered to the DAS cables and the connection was covered with heat-shrink tubing to provide stronger connections. In an effort to inhibit corrosion of the pressure cells, the gages were coated with grease prior to installation. This effort proved to be fruitless, however, as many of the gages failed early in the testing program.

\subsection{SINCO Inclinometers}

Inclinometers manufactured by the slope Indicator Company (SINCO) were used to measure inclination within selected boreholes around the TSI test rooms. The purpose of the inclination measurements was to complement data provided by the extensometers; while the extensometers measured displacement along the axis of the boreholes, the inclinometers were intended to evaluate movement perpendicular to the boreholes. The magnitude, orientation, and rate of change of borehole inclination could be evaluated by comparing measurements taken over a period of time. Figure 3.4.1 shows an inclinometer station with an array of boreholes surrounding a test room. Table 3.0.1 lists the quantities of inclinometer installations in the various TSI test rooms. 


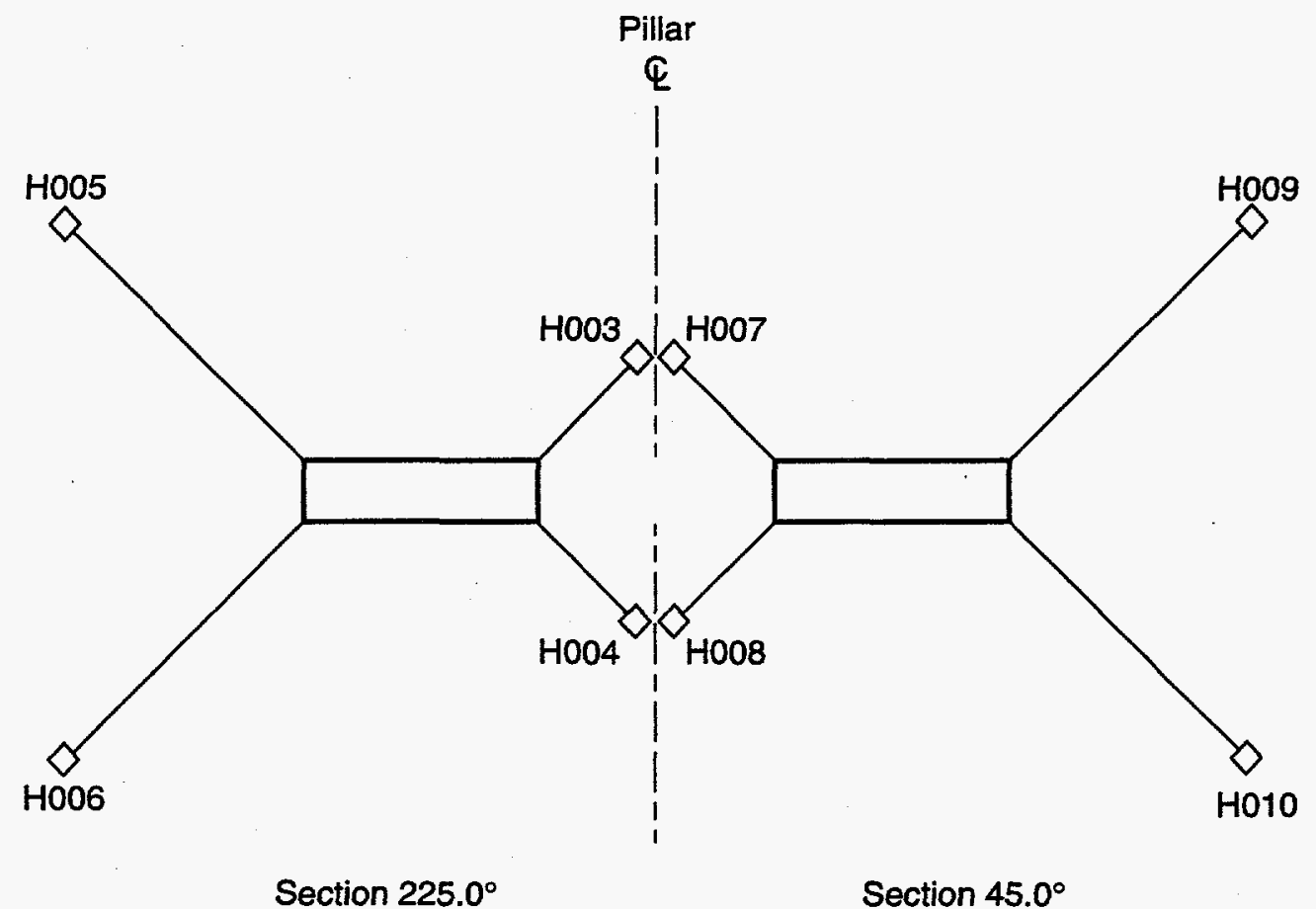

Looking Northwest

\begin{tabular}{|cccc|}
\hline \multicolumn{4}{|c|}{ Legend } \\
No. & Designation & Type & Symbol \\
\hline $0-99$ & SP & Special Gages & $\diamond$ \\
\hline
\end{tabular}

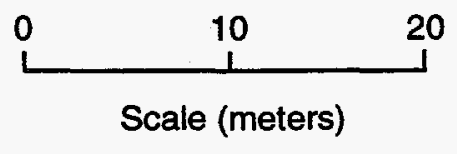

TM-16060-17

Figure 3.4.1. Cross Section of an Inclinometer station 
Design: The inclinometer system was composed of an array of specially cased boreholes around a test room, a manually operated electronic sensor, and a portable data acquisition unit. The casing was made of epoxy-coated, extruded aluminum tubing with an outside diameter of $70.9 \mathrm{~mm}$ $(2.79 \mathrm{in})$. The casing had four longitudinal grooves which were located at right angles to one another in cross section and were used to accommodate the tracking wheels of the sensor. One pair of grooves, located at diametrically opposed sides of the tube, guided the sensor in one orientation while the other pair guided the sensor in the orthogonal direction. In a horizontal hole, for example, one pair of grooves had a vertical orientation, the other horizontal. However, only one pair of grooves was used in the TSI tests. The casing was supplied in 1.5 and $3 \mathrm{~m}$ $(5$ and $10 \mathrm{ft})$ lengths which were coupled together by shorter pieces of tubing that were similar in cross section, but slightly larger in diameter. The couplings were designed to be "telescoping" so that the casing string could lengthen with extension of the formation. Guides for the sensor cable, consisting of short pieces of small-diameter tubing, were riveted to the inside of each segment of casing.

The sensor consisted of a stainless steel body that was equipped with two pairs of spring-loaded tracking wheels (Figure 3.4 .2 ) to follow the grooves in the casing and two accelerometers to measure angles of inclination. The two accelerometers were positioned at right angles to each other to measure the inclination of the borehole in two orthogonal directions. Two models of sensors were used in the TSI tests. A Model 50325-E sensor, which was designed for measuring vertical holes, was originally purchased for the experimental program. since the sensor actually measured the sine of the angle of inclination, the error for 


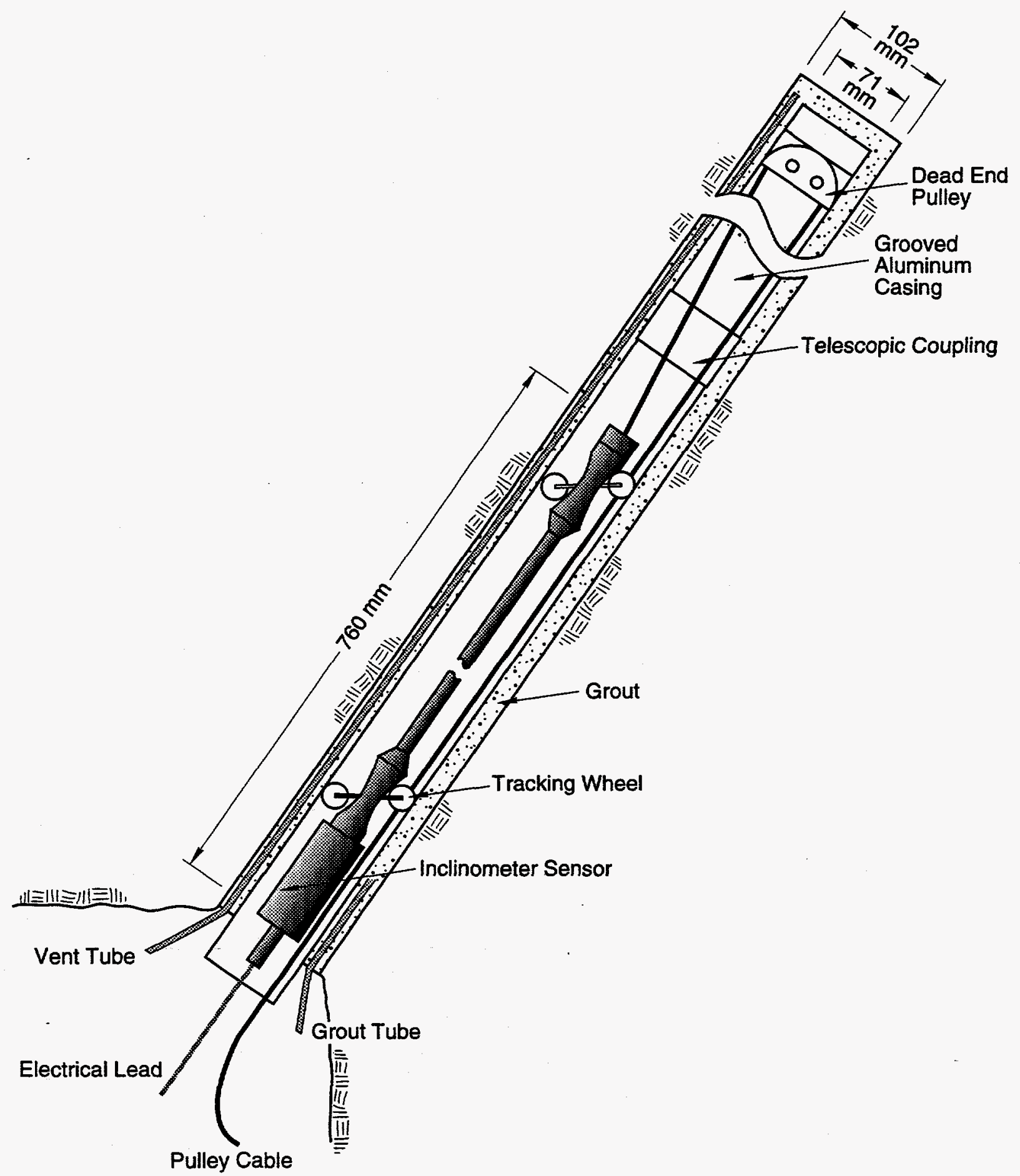

$T / M-16060-05$

Figure 3.4.2. SINCO Inclinometer Installation 
horizontal measurements made with this instrument was large. Consequently, a Model 50329-E sensor, which was designed specifically for horizontal holes, was later added to the program.

The data acquisition unit was an electronic device that measured the voltage output of the sensor, processed the data, and recorded inclination measurements. The unit also contained a power supply and was connected to the sensor by an electrical cable. The Model 50308 indicator that was originally used in the tests included a digital data display and a cassette tape recorder. Subsequently, a Model 50368-RPp indicator was acquired that contained a more advanced microprocessor that processed, recorded, and printed the data.

Calibration: The Model 50325-E sensors were quoted by the manufacturer as having a resolution of \pm 0.0001 ft per 2 ft of casing $(1: 20,000)$, and an accuracy of \pm 0.025 ft per 100 ft of casing $(1: 4,000)$. Similarly, the Model 50329-E sensor was quoted as having a resolution of $1: 10,000$ and an accuracy of \pm 0.0083 ft per 100 ft of casing $(1: 12,000)$. The sensors were sent to the manufacturer periodically for calibration.

Installation: To install an inclinometer, sections of casing were inserted into a $102 \mathrm{~mm}$ (4 in) borehole one at a time and joined with couplings. The couplings were fastened to the casing with "pop-rivets", sealed with butyl rubber tape, and covered with duct tape to protect the butyl rubber. The first (deepest) section of casing was plugged in the far end with an aluminum block that contained a sheave. A continuous loop of wire rope was strung through the sheave to be used for positioning the sensor. To prevent sensor ropes from fouling, the ropes were threaded through the cable guides riveted to the inside of each segment of casing. The sensor rope was installed as a continuous loop with one half of the 
loop threaded through the guides and the other half free for positioning the sensor. In addition, two grout hoses were attached to the outside of the casing: one hose was attached to the entire string of casing while a shorter piece was attached to the end of the shallowest section. After emplacement, the casing of upward installations was temporarily held in place with S-hooks and "Ramset" L-brackets.

After the entire length of casing had been inserted into the borehole, it was permanently grouted in place [TOP 117]. Before grouting, the collar of the annulus was packed with grout by hand to form a seal. After the seal had cured, cement-based grout was pumped into the entire length of the annulus. The two hoses were used for grouting: one was used for injecting grout while the other served as an air vent. Installation procedures were developed in Room 4 of the SPDV test panel and in Room D (see Figure 1.0.3 for locations).

Operation: To take inclination measurements, the sensor was inserted into the casing with the tracking wheels in the grooves. In downward holes, the sensor cable was used to lower the instrument into the hole. In horizontal and upward holes, the instrument was pushed into the hole with rods. A series of measurements was then taken at discrete locations along the length of the borehole with the first reading taken at the far end. The sensor cable was graduated in feet to measure the depth of the sensor at each reading. All test information was processed and recorded by the portable data acquisition unit.

Two sets of measurements were taken in each borehole, both in the same set of grooves [TOPs 016 and 064]. In horizontal holes, the ends of the instrument were reversed for the two sets of readings, but the same side of the sensor was kept in the upward position for both sets. In all other 
holes, the instrument was rotated $180^{\circ}$ about its long axis, but the same end of the sensor was kept towards the borehole collar for both sets of readings.

After completing the measurements, the sensor body was cleaned with fresh water and glass cleaner, the electrical connectors were cleaned with contact cleaner, and the wheels were sprayed with lubricant. The sensor and control unit were stored in protective cases when not in use.

Most of the inclinometer boreholes became obstructed with time and were abandoned. Borehole closure caused some casings to rupture or distort substantially in cross-section. In particular, the openings of some casings became crushed if the collar of the borehole was near the junction of the rib and back, or rib and floor. Salt encrustations that could not be removed made other holes impassable. Some inclinometer holes were cut in two where they crossed shear planes in the formation (planes that had formed in response to perturbations in the stress field around the test room). Reading the inclinometers eventually became futile and the effort was abandoned.

Maintenance: Before taking readings with the sensor, the casing was inspected for salt deposits. A piece of foam rubber or wire brush was used to remove any salt from within the casing. Deposits near the opening were removed with a screwdriver.

Modifications: The casing installed in upward holes was designed to be held in place during grouting with a collar bolted to the end of the casing and to the formation. It was found to be much simpler, however, to hold the casing in place before and during grouting with an $s$-hook and a "Ramset" I-bracket shot into the formation. This allowed all the installations to be grouted in a single operation with inexpensive and 
disposable hardware.

The deep ends of the inclinometer casing were originally designed to be sealed with duct tape. An initial modification was made to fit the casing with dead-end sheaves as shown in Figure 3.4.2. These sheaves had no moving parts, but were actually blocks of aluminum with semicircular grooves that accommodated the wire rope. It was originally thought that a normal pulley with bearings would not function for long in the corrosive underground environment of the WIPP, so the grooved block was used instead. It was found soon after installation, however, that the wire rope would cut its way into the block and the excessive friction that resulted would prevent the rope from moving freely. As a solution, the wire ropes were cut and removed, and the sensor was inserted into the holes using push rods as described above. In Room $\mathrm{H}$, functioning sheaves were installed, but the wire ropes were inadvertently removed. As a result, the sensor was inserted into the Room $\mathrm{H}$ boreholes by the same procedures used in the other test rooms.

\subsection{Reference Gages}

The closure gages and extensometers installed in the TSI test rooms were used for measuring relative displacements in the rock mass surrounding the test rooms. In order to determine the absolute displacement of these gages, underground bench marks were needed in the vicinity of the test rooms. To fulfill this need, fixed reference gages (Section 3.5.1) were installed in the access drifts adjacent to the test rooms. Rod-and-level surveys (Section 3.5.2) and fluid-level surveys (Section 3.5.3) were then used to measure the elevations of the test room gages relative to the fixed references. Ultimately, the absolute positions of the reference gages were established in relation to surface 
bench marks through standard mine surveying procedures.

3.5.1 Fixed Reference: Fixed reference gages were established in the access drifts adjacent to Rooms A2, B, G, and $H$ (see Figure 1.0 .3 for locations) to serve as benchmarks for reference elevation measurements. In a secondary capacity, these gages served as convergence gages.

Design: A fixed reference gage consisted of a survey target suspended between two anchors set at depth in a pair of vertically opposed boreholes as shown in Figure 3.5.1. The target was a horizontal groove machined around the circumference of a small cylinder of stainless steel. Serata extensometer anchors (see section 3.2.2) were set in boreholes above and below the access drift, and were connected to the steel cylinder with small diameter wire rope and extension springs. The extension springs were used primarily to keep the wires taut but also served as convergence points; the change in distance between the outer ends of the springs was monitored manually with a vernier caliper.

Calibration: The caliper that was used for convergence measurements was recertified on a regular basis using length standards and gage blocks at the Sandia Secondary Standards Laboratory or at the Sandia WIPP Site Calibration Laboratory [TOPs 451 and 454]. Before taking a set of readings, the calibration of the caliper was verified by taking a zero reading; if the caliper read $0.00 \mathrm{~mm}(0.000 \mathrm{in})$ with the jaws closed, the instrument was assumed to be in calibration.

Installation: The fixed reference gages were installed in boreholes drilled with multiple diameters that increased towards the collar to prevent the anchor wires from touching and adhering to the borehole walls. The holes were $47.6 \mathrm{~mm}(1.875 \mathrm{in})$ in diameter for the deepest $4.0 \mathrm{~m}(13 \mathrm{ft})$, followed by a diameter of $152 \mathrm{~mm}(6.0 \mathrm{in})$ for the next 


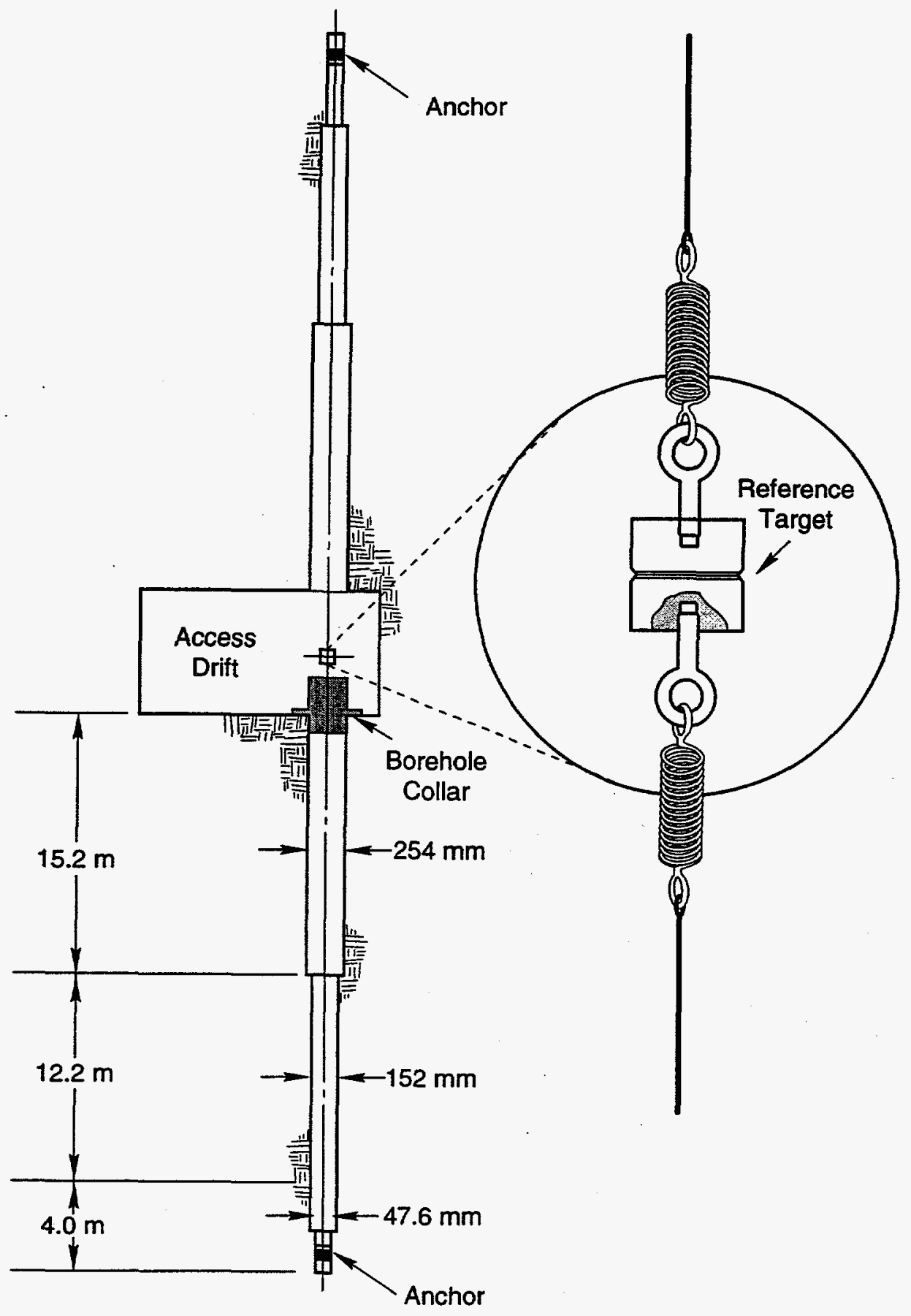

$T M-16815-13$

Figure 3.5.1. Fixed Reference Gage Installation 
$12.2 \mathrm{~m} \mathrm{(40} \mathrm{ft),} \mathrm{and} \mathrm{finally} \mathrm{a} \mathrm{diameter} \mathrm{of} 254 \mathrm{~mm}(10.0$ in) for the shallowest $15.2 \mathrm{~m}(50 \mathrm{ft})$. Serata anchors (Section 3.2.2) were set at depths of $30.5 \mathrm{~m}(100 \mathrm{ft})$ in the $31.4 \mathrm{~m}(103 \mathrm{ft})$ deep boreholes to be $32.0 \mathrm{~m}$ (105 ft) from the drift centerline. After setting the anchors, the wire ropes were connected to the central survey target with extension springs [TOP 071]. Care was taken during installation to ensure that the horizontal groove was placed midway between the floor and back elevations while tensioning and crimping the wire ropes.

Operation: The fixed reference gages served primarily as benchmarks for level surveys. The absolute location of the fixed reference targets was established relative to surface benchmarks through conventional mine surveying techniques. These surveys were performed after the original installation of the gages and after any repairs or modifications were made to the gages.

The gages were used in a secondary capacity as closure gages. Convergence of the two anchor points was monitored by manually measuring the outside distance between the two extension springs with a $0.91 \mathrm{~m}$ (36 in) starrett vernier caliper [TOP 055]. Making a convergence measurement was a delicate operation that necessitated averaging several readings for a single measurement. Care was taken not to extend or compress the springs when measuring convergence since any movement of the springs would affect the measurement. Typically, the variation in a set of readings was within $0.38 \mathrm{~mm}(0.015 \mathrm{in})$ while the total measurement system repeatability was demonstrated to be within $0.51 \mathrm{~mm}(0.020$ in). The anchors were located in vertical boreholes deep in the rock mass to minimize the effects of room and drift excavations and were originally believed to represent stationary points. However, the anchors actually 
converged during the 11 years that convergence measurements were made (1985 through 1995) with total displacements ranging up to $100 \mathrm{~mm}$ (4 in).

Maintenance: Salt deposits were periodically removed from the target and springs to ensure accurate surveys and convergence measurements. LPS-3, a heavy lubricating oil, was routinely sprayed on the springs to inhibit corrosion. The fixed reference gages used the same anchor system that was used with the wire extensometers (Section 3.2.2) and therefore encountered many of the problems suffered by the extensometers. Broken anchor wires or anchor tie wires were repaired by reinstalling new anchors and wires. Usually the deepest portion of the borehole required reaming to restore the proper diameter before installing the new components. Maintenance of the fixed reference gages was kept to a minimum, however, to avoid disturbing the system.

The convergence measurements discussed above also served as checks that the gages were in good condition; plots of the convergence data uncovered problems such as anchors that were slipping or anchor wires that were stuck to the borehole, walls. Anchor wires stuck in salt deposits were repaired by pulling the wires from the salt or by chipping the deposits away. slipping anchors were usually left alone because the anchors would eventually stabilize.

Modifications: Protective collars made from lengths of $250 \mathrm{~mm}$ (10 in) diameter steel pipe were added to the reference gages to protect the anchor wires from personnel and equipment working in the vicinity of the gages. These collars were emplaced in the lower boreholes with about $0.9 \mathrm{~m}$ (3 ft) extending up into the room. This modification was made to the Room $B$ reference gage after installation and was made to the gages in the other test rooms during installation. 
After the initial installation of the fixed reference in Room $H$, the upper anchor wire was found to be touching the sides of the $152 \mathrm{~mm}$ (6 in) diameter portion of the borehole. As a remedy, that portion was reamed to a $254 \mathrm{~mm}$ (10 in) diameter.

Later in the testing program, the anchor and wire rope modifications discussed in section 3.2 .2 were made to the reference gages during major repairs. The $0.87 \mathrm{~mm}(0.034 \mathrm{in})$ diameter wire rope was replaced with $1.59 \mathrm{~mm}$ (1/16 in) diameter, nylon-coated, stainless steel wire rope. The anchor tie wires were eliminated, and the anchors were coated with a mixture of paint and grit to retard corrosion and improve their holding strength.

3.5.2 Rod and Level: Standard rod-and-level surveys [TOP 098] were used to measure changes in elevation of test room gages relative to the fixed reference gage (Section 3.5.1).

Design: The survey points consisted simply of manual closure gage eyebolts, or small bolts placed in extensometer base plates and instrument collars.

Operation: To measure the absolute vertical displacement of a survey point in a test room, a conventional survey traverse was performed between the fixed reference target and the survey point. The absolute displacement of a survey point in the test room back was measured by holding a survey rod up against the point and measuring the elevation relative to the fixed reference target. The absolute displacement of a survey point in the test room floor could be calculated by subtracting the vertical room closure from the absolute displacement of the survey point in the test room back at that station. 
Calibration: Rod and level traverses were verified by closing the traverse loop. Traverse closure with a horizontal error of less than $0.02 \mathrm{ft}$ was considered to be acceptable. Survey instruments were checked before use [TOP 098] to ensure that the vertical error was less than $0.01 \mathrm{ft}$ per $100 \mathrm{ft}(0.01 \%)$. In addition, the instruments were sent to a vendor periodically for cleaning and inspection.

Modifications: The survey transit was replaced with an automatic level later in the experimental program.

3.5.3 Fluid Level: The fluid levels were designed to measure the vertical displacement of test room gages relative to the fixed reference gages [TOP 072]. The fluid levels were originally intended to be used as a quick survey tool during construction of the test rooms. The simplicity and portability of the system allowed for its use in congested and dusty areas with low visibility. A fluid level system was installed with each of the four fixed reference gages.

Design: The fluid level system was composed of a reference fluid level, a relative fluid level, a hose to connect the two levels, a differential pressure transducer, and a digital readout device (Figure 3.5.2). The reference fluid level was attached to a wire rope stretched between the back and floor parallel to and about $0.3 \mathrm{~m}$ ( $1 \mathrm{ft}$ ) from the fixed reference gage. A pointer was clamped to the center of the reference fluid level and was used to center the level with respect to the reference target. The wire ropes were attached to the back and floor with anchor bolts, eyebolts, and turnbuckles; the turnbuckles were used to tension the wire ropes and adjust the elevation of the pointer.

The relative fluid level was connected to the reference fluid level by a sectional hose and quick-connect couplings. A differential pressure 


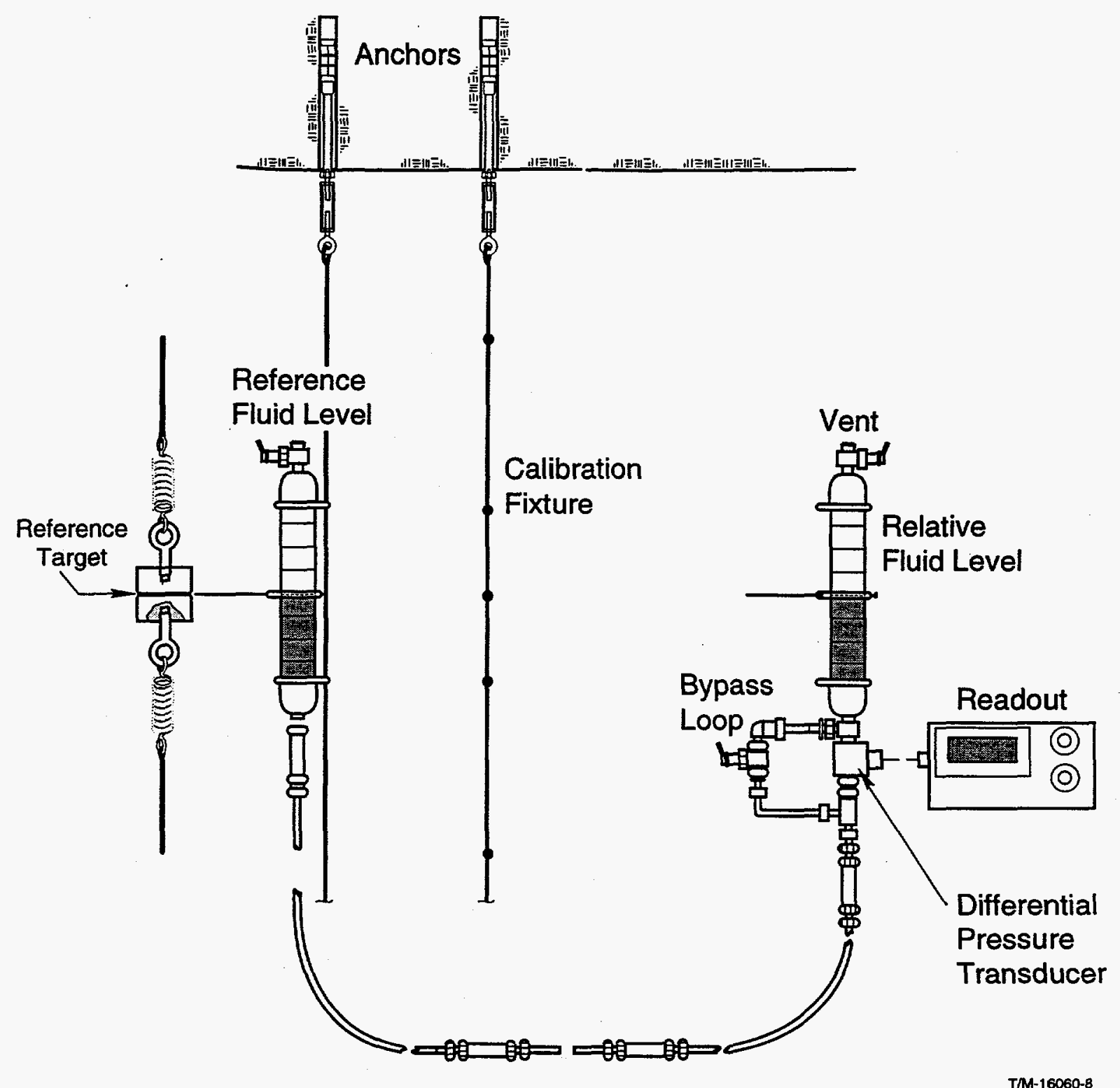

Figure 3.5.2. Fluid Level Installation 
transducer (DPT) was attached to the bottom of the relative level and was used to measure the pressure differential in the system. The electrical leads of the DPT were connected to the digital readout device which measured the voltage output and converted the reading to inches of elevation change. A pointer was clamped to the center of the relative level to avoid interpolation and simplify measurements.

Calibration: The digital readout device and relative fluid level were calibrated on a fixture adjacent to the reference fluid level to correlate fluid pressure to changes in elevation. The fixture consisted of a wire rope that was strung parallel to and about $0.3 \mathrm{~m}$ ( $1 \mathrm{ft}$ ) from the reference fluid level. The rope was attached to the floor and back of the access drift with anchor bolts, eyebolts, and turnbuckles. Five stops were crimped to the rope at the center, and at points 0.30 and $0.91 \mathrm{~m}(12$ and 36 in) above and below the center.

The calibration process was started by zeroing the system. The relative level was clamped to the calibration fixture at the central calibration stop. Both tubes were filled with fluid, if necessary, to bring the level of fluid in both levels to zero. Pointers clamped onto the levels were then aligned with the fixed reference gage by adjusting the turnbuckles. Vents on top of both levels and the DPT bypass loop were opened and the digital readout device was set to zero. The system was calibrated by closing the vents and bypass, raising the reference level up to the $0.91 \mathrm{~m}(36 \mathrm{in})$ stop, and setting the readout device to $0.91 \mathrm{~m}$ (36 in). The reference level was then lowered to the remaining three stops and checked to ensure that the readout device measured the correct elevation within $5 \mathrm{~mm}$ (0.2 in). 
Operation: The fluid level system was used to measure the elevation of a test room gage by holding the relative level up to a survey point on the gage and using the readout device to measure the elevation relative to the fixed reference. Unfortunately, the fluid level did not work well because of problems with accuracy that were caused by the accumulation and compression of air bubbles in the system. Air would leak into the system through the quick-connect couplers during disconnection and reconnection, and through pinholes in the flexible tubing; one bubble could cause measurements to be off by many millimeters (several inches). The fluid levels were eventually replaced by conventional rod-and-level surveys that proved to be more accurate and straightforward.

Modifications: The DPT and readout device were later replaced by a more accurate and compact unit that improved the accuracy and efficiency of the measurements. In addition, efforts were made to eliminate air bubbles in the system. The hoses were routinely purged of air and replaced when suspected of leaking. To minimize puncturing, the hoses were routed under roadways for protection from traffic. These efforts improved the system, but air continued to enter the system and invalidated most of the readings.

\subsection{Borehole strain Gages}

Borehole strain gages were special instruments that were designed and fabricated by Sandia to measure borehole strain. The gages were installed in boreholes that were drilled parallel to the axes of future test rooms to monitor strain in the rock mass in an effort to evaluate changes in the stress field as mining approached. In the A test rooms [16], the gages were installed in boreholes from the N1420 drift before excavation of the test rooms began from the N1100 drift. In the ISBT, which involved coring 
a $0.91 \mathrm{~m} \mathrm{(36} \mathrm{in)} \mathrm{diameter} \mathrm{borehole} \mathrm{between} \mathrm{Rooms} \mathrm{Cl}$ and $\mathrm{C2}$ [20], the gages were installed in the pilot hole ahead of the coring operation. The gages were temporary in nature as they were either destroyed or removed by the excavation process. The quantities of borehole strain gages installed in the test rooms are shown in Table 3.0.1.

Design: The borehole strain gage consisted of a pair of cantilevered beams that were attached to a strain-gaged diaphragm on one end and to diametrically opposed contact pins on the other (Figure 3.6.1). Two of these gages were actually included in one unit and were oriented to measure strain in two orthogonal radial directions (normally the horizontal and vertical directions). The cantilevered beams were spring-loaded to hold the contact pins against the borehole wall while deflection of the beams was measured by four strain gages bonded to the diaphragm in a temperature-compensating bridge. Borehole diameter was measured by supplying a constant excitation to two opposing arms of the bridge and monitoring the output from the remaining pair.

Calibration: The borehole strain gages were calibrated by the method described in section 3.1 .3 [TOPs 250 and 288]. For the ISBT, the calibration constants were stored in the ModComp Gage Calibration File and were used with Equation 3.1 .3 to convert voltages to units of displacement (inches).

Installation: During installation, extensometer setting rods were used to push the gage into a $47.6 \mathrm{~mm}(1.875 \mathrm{in})$ borehole to the desired depth [TOP 332]. A specially designed orientation handle was attached to the last rod to orient the gages in the proper directions (horizontal and vertical). The pull wire was then removed from the gage to release the beams and allow the spring-like action of the gage to force the contact 


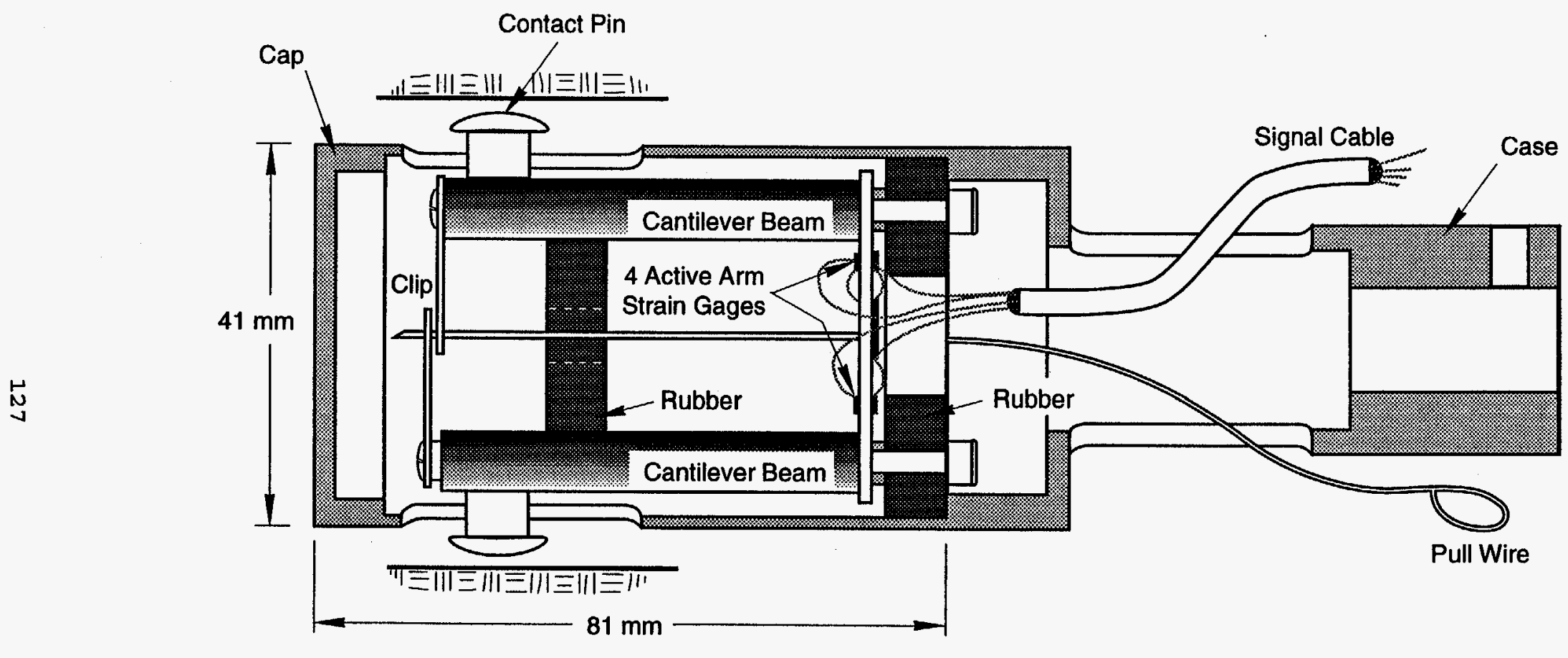


pins against the borehole wall. Input and output resistances and voltages were manually measured and recorded to verify operation before connecting the gage to the DAS.

Operation: In the A test rooms, the borehole strain gages were operated and monitored manually with portable power supplies and voltage meters. In the ISBT, the gages were remotely monitored by the DAS and no manual operations were required after installation. Interpretation of the data is difficult, however, because only a small amount of data was produced and because there was a considerable amount of scatter in the data points.

Maintenance: Because the gages were temporary in nature, no maintenance was needed.

Modifications: Since the borehole strain gages in the A test rooms were monitored manually, data could not be acquired as frequently or as precisely as desired. As a consequence, the gages in the ISBT were configured to be monitored by the DAS to increase the frequency and accuracy of the measurements.

In the ISBT, it was found that the compressed air circulating through the pilot bit would blow the gages down the pilot hole from their installed positions. This, of course, produced questionable data since the change in borehole diameter was due not only to closure, but to change in location as well. Because of this, procedures were developed to prevent the gage from moving in the pilot hole as the coring progressed. The pilot bit was modified to reduce the force of air on the gage by plugging the air hole in the end of the bit and drilling new air holes perpendicular to the axis of the bit. In addition, a serata anchor (Section 3.2.2) was installed behind the gage to help hold the gage in 
place. These efforts improved the operation of the borehole strain gages, but the experience was gained late in the experiment and much of the data produced by these gages is suspect.

\subsection{Thermocouples}

Thermocouples are devices for measuring temperature and were used in four different applications within the TSI program: far-field, near-field, heater, and air-stream. Table 3.0.1 lists the quantities of the various types of thermocouples installed in the test rooms.

Far-field thermocouples measured temperatures of the rock mass in the backs, ribs, and floors of test rooms and were located in arrays of boreholes around the test rooms as shown in Figure 3.7.1. Each borehole was $47.6 \mathrm{~mm}(1.875 \mathrm{in})$ in diameter and was typically $15 \mathrm{~m}$ (50 $\mathrm{ft}$ ) in length. Up to six thermocouples were emplaced in each borehole with junctions at typical depths of $0.46,0.91,1.83,4.88,9.14$, and $15.24 \mathrm{~m}$ $(1.5,3,6,16,30$, and $50 \mathrm{ft})$

Near-field thermocouples were designed to monitor steep and rapidly changing temperature gradients near selected heaters in the floors of the $A$ and $B$ test rooms (see Figure 1.0 .3 for room locations). Near-field thermocouples were emplaced in arrays of vertical-down, $47.6 \mathrm{~mm}$ (1.875 in) diameter, $6.4 \mathrm{~m}(21 \mathrm{ft})$ long boreholes that were located within $1.5 \mathrm{~m}$ (5 ft) of the centerline of the heater as shown in Figure 3.7.2.

Heater thermocouples measured the temperature of canister, guard, and Waste Package Performance (WPP) heaters, and were located on the interior walls of the heaters (Figure 3.7.3). Additional heater thermocouples were placed in the annuli of some of the wPP heaters.

Air-stream thermocouples monitored the temperature of the air moving through the Air Intake shaft. Air stream thermocouples were also used in 


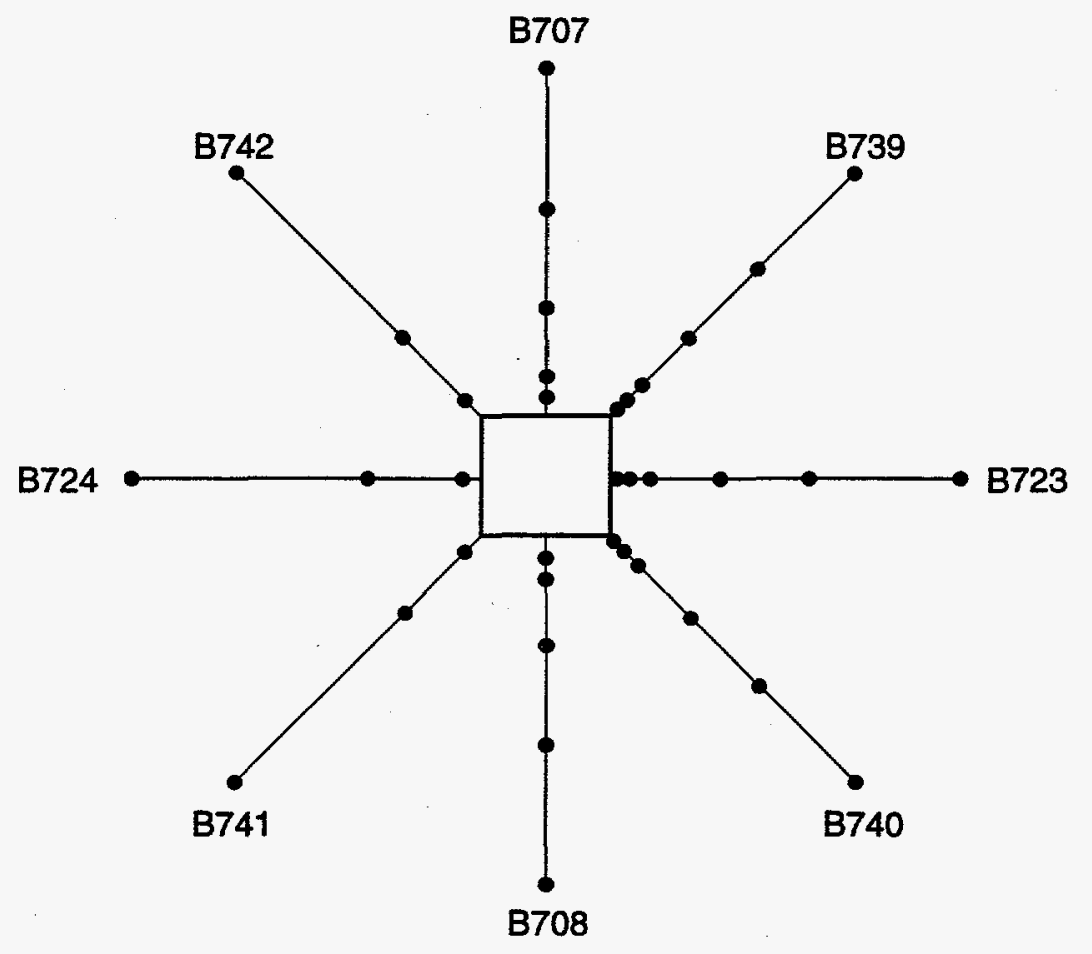

$Y=+22.1$

\begin{tabular}{|lccc|}
\hline \multicolumn{5}{c|}{ Legend } \\
No. Designation & Type & Symbol \\
\hline $700-999$ & TC & Thermocouple & - \\
\hline
\end{tabular}

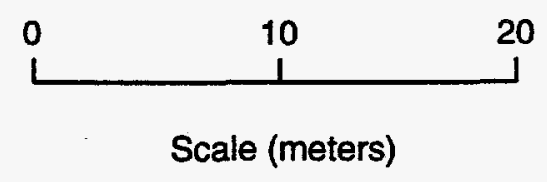

$T / M-16060-25$

Figure 3.7.1 Cross Section of a Far-Field Thermocouple Station 


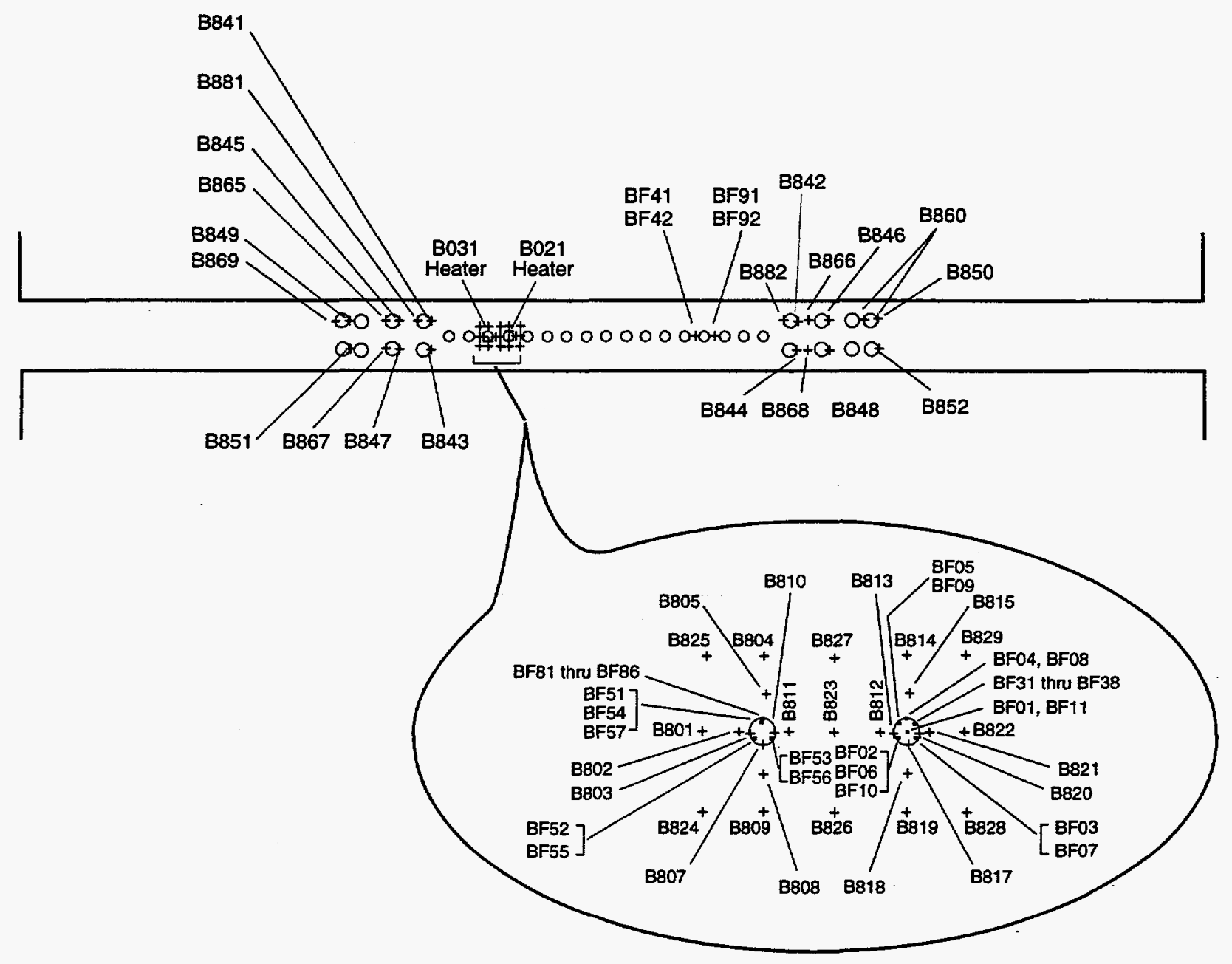

\begin{tabular}{|lccc|}
\hline \multicolumn{5}{|c|}{ Legend } \\
No. & Designation & Type & Symbol \\
\hline $700-999$ & TC & Thermocouple \\
F00-F99 & FM & Fluxmeter \\
\hline
\end{tabular}

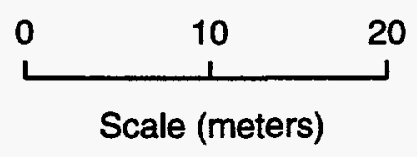

Figure 3.7.2. Plan View of a Near-Field Thermocouple and Flux Meter Installation, Room B 


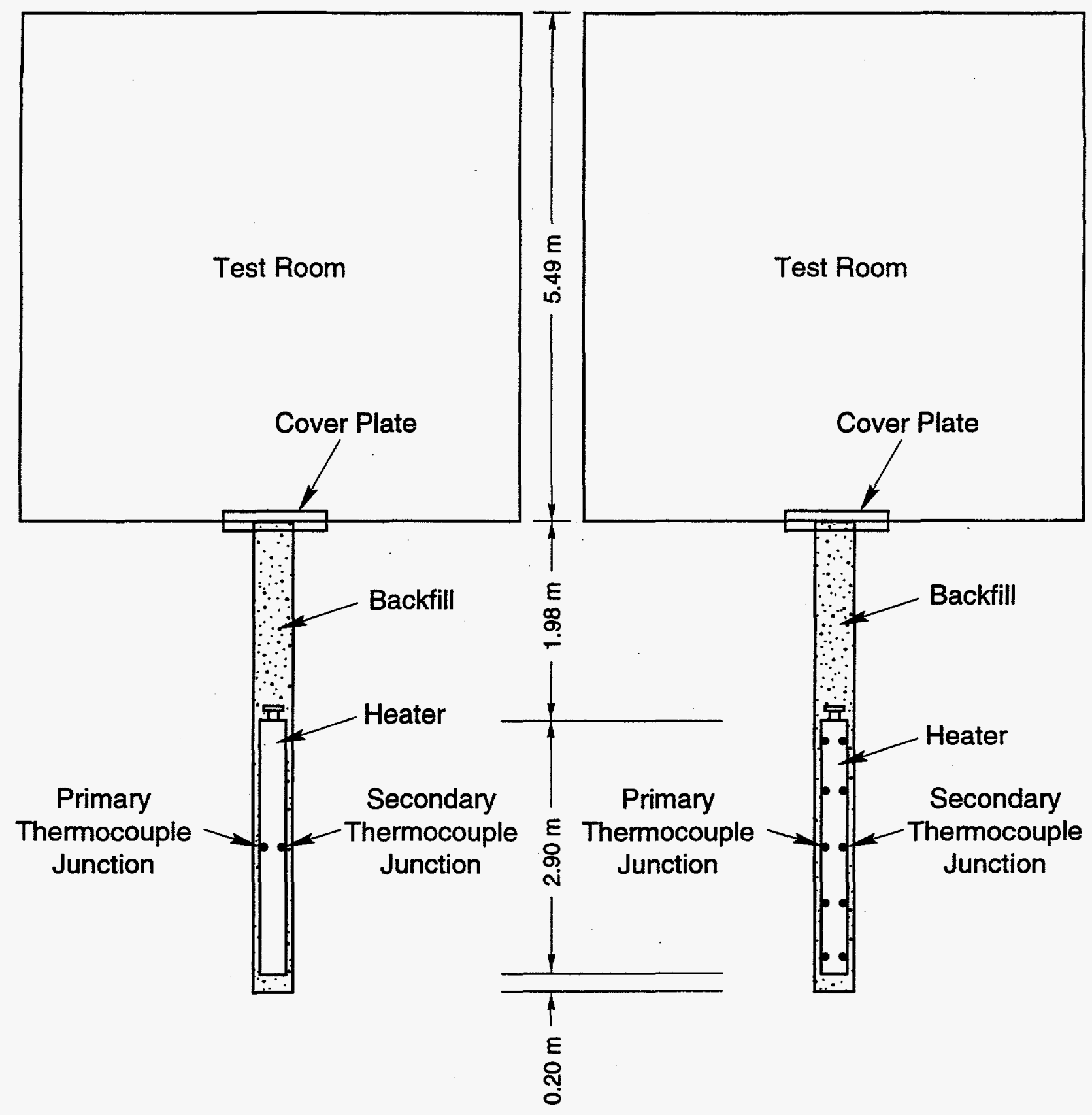
(a) Typical
(b) Multiple 
the $A, B$, and $H$ test rooms, but in a special capacity (see section 3.10 ).

Design: A thermocouple consists of two electrical conductors of dissimilar metals that are joined at the point where temperature is to be measured. The thermocouple junction produces a millivolt range output that is a function of temperature and is measured by a voltmeter at a reference junction some distance from the point of measurement. The thermocouple system used in the TSI tests included the thermocouples themselves, Gordon head connectors, thermocouple extension cables, and reference junctions. Premium grade, Type-E thermocouples with ungrounded junctions, high purity magnesium oxide insulation, and Inconel 600 sheathing were selected for use in the tests. "Premium grade" denotes conductors made of high-purity alloys that ensure greater measurement accuracy, while "Type-E" denotes junctions of chromel and constantan conductors. The thermocouples were emplaced in boreholes, heaters, or air streams with their junctions located at the points where temperatures were to be monitored. Two- and four-wire thermocouples were installed in the TSI tests. Both were conventional Type-E thermocouples, but the four-wire design contained two chromel and two constantan leads welded together to provide a redundancy of measurement. The four-wire thermocouples were used in far-field applications, while the two-wire models were used in all other applications. Both were manufactured by ARI Industries, Inc. and Gordon, Inc.

The chromel and constantan thermocouple leads were terminated inside Gordon head connectors where the conductors were joined to thermocouple extension cables made of the same materials. The connectors, manufactured by Watlow Gordon, were simply terminal blocks housed in small metal canisters (Figure 3.7.4), and were generally referred to as "Gordon heads" 


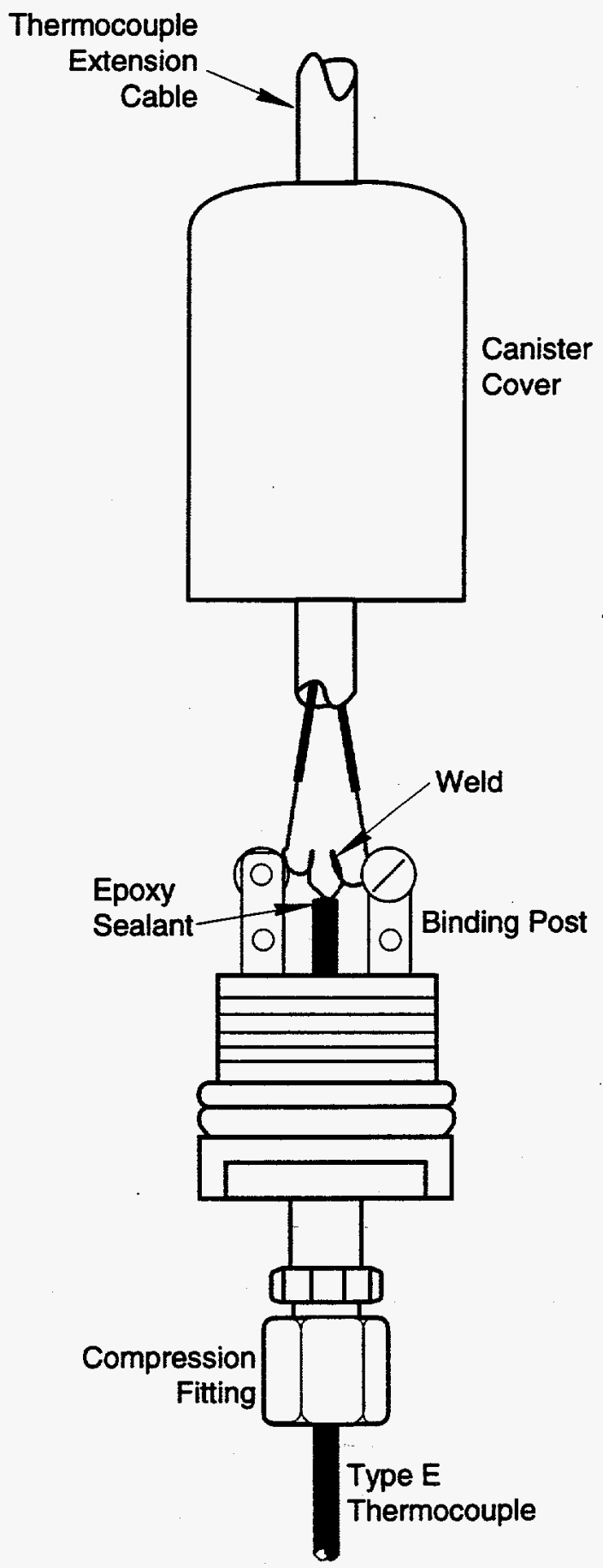

TM-16060-9

Figure 3.7.4. Gordon Head Thermocouple Connector 
at the WIPP site. The extension cables were used to connect the thermocouples to the DAS hardware inside the instrument sheds and were made of twisted-shielded-pair (TSP) cable. Since the conductors in the thermocouples and extension cables were made of the same materials, the creation of additional thermocouple junctions was avoided.

Inside the instrument sheds, the extension cables were connected to the DAS through relay multiplexer cards installed in Hewlett Packard HP3497A data control units and HP3498A extenders. Each card had the capacity of terminating 19 thermocouples. The reference junctions, where the extension cables were joined to the copper conductors of the DAS, were made on isothermal blocks. Each block contained an integrated circuit transducer to provide reference junction temperatures for compensation purposes.

Calibration: One important consideration in the calculation of thermocouple temperature measurements is the reference junction where the thermocouple extension cables are connected to the copper conductors of the DAS. The reference junctions create additional thermocouples in the circuits whose voltages must be accounted for before temperature measurements can be made. Thermocouple voltage-temperature relationships assume that reference junctions are maintained at the ice point $\left(0^{\circ} \mathrm{C}\right)$, but compensations can be made for reference junctions at other temperatures. In the TSI in situ tests, this was done by software compensation using function routines on the ModComp computer. These routines converted the measured voltage from the integrated circuit transducer to a reference junction temperature by a linear relation $\left(10^{\circ} \mathrm{C} / \mathrm{V}\right)$. The routines then accessed NIST Thermocouple Reference Tables [32, 33] to convert the reference temperature to a compensating voltage. The final steps added 
the compensating voltage to the measured thermocouple voltage and accessed NIST tables to convert the resulting voltage to a temperature value.

The routines that accessed the Reference Tables introduced small errors into the temperature measurements because linear interpolation was used to estimate compensating voltages and temperatures between the points given in the tables. Later in the experimental program, a new set of routines was installed on the ModComp for making thermocouple calculations. The new routines used NIST polynomials [32, 33] to calculate compensating voltages and temperature values, thereby eliminating errors of interpolation:

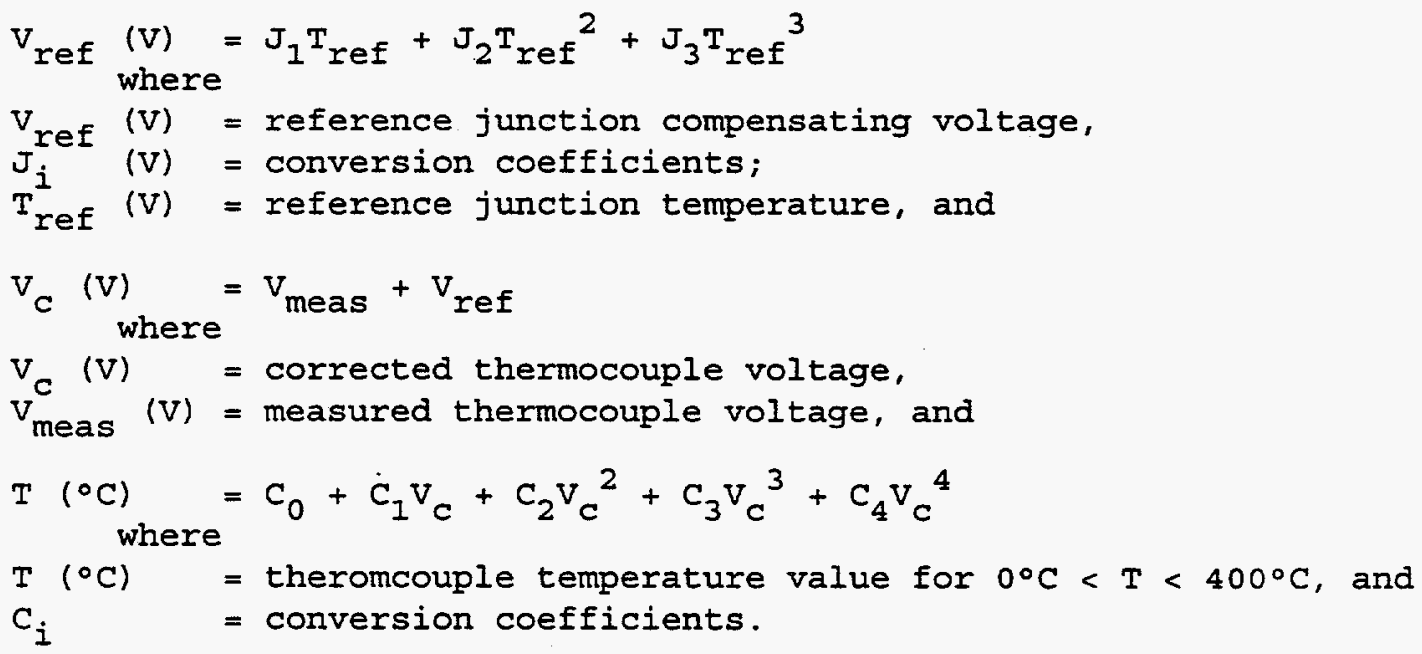

Installation: Well before installation, the thermocouple sheathing was cut to length and the open ends of the sheathing were immediately sealed with epoxy to prevent moisture from entering the insulation [TOP 063]. The next step was to determine the polarity of the thermocouple conductors. Polarity of the two-wire thermocouples was determined by applying a heat source to the junction and measuring the gage output with a voltmeter; an increase in voltage denoted normal polarity while a decrease indicated reversed leads. The polarity of four-wire thermocouples was determined by comparing the resistances of the 
various combinations of conductors (the resistance of chromel is approximately 1.3 times the resistance of constantan). After determining polarity, the negative conductors (constantan) were marked with a red marking pen. Finally, Gordon heads were placed on the thermocouple ends and the thermocouples were marked with a color denoting length. At this time, the thermocouples were placed in inventory.

Far-field and near-field thermocouple assemblies were constructed by Sandia prior to installation and consisted of up to six thermocouples and a fiberglass measuring tape that were taped to the outside of a grout tube [TOP 086]. During fabrication, the ends of the thermocouples were bent back in the shape of hooks and the thermocouples were taped to the grout tube with their ends pointing away from the tube as shown in Figure 3.7.5. This arrangement placed the thermocouples firmly in contact with the borehole wall after installation. Finally, a second, shorter tube was taped to the near end of the longer tube; one tube was used for injecting grout while the other served as a vent tube.

To install far-field thermocouples, the entire assembly was inserted into a borehole and a small amount of grout was packed into the collar by hand to form a seal. After the seal had set, the boreholes were pumped full of grout to insure good thermal contact with the rock mass [TOP 233].

Installation of the near-field thermocouples was identical to that of the far-field thermocouples (Figure 3.7.5) except that the boreholes and hoses were backfilled with crushed mine salt rather than grout [TOP 087]. Near-field thermocouples were installed in boreholes with their junctions placed in the direction of the nearest heater (Figure 3.7.6). In the case of boreholes midway between two heaters, the junctions were oriented to be 


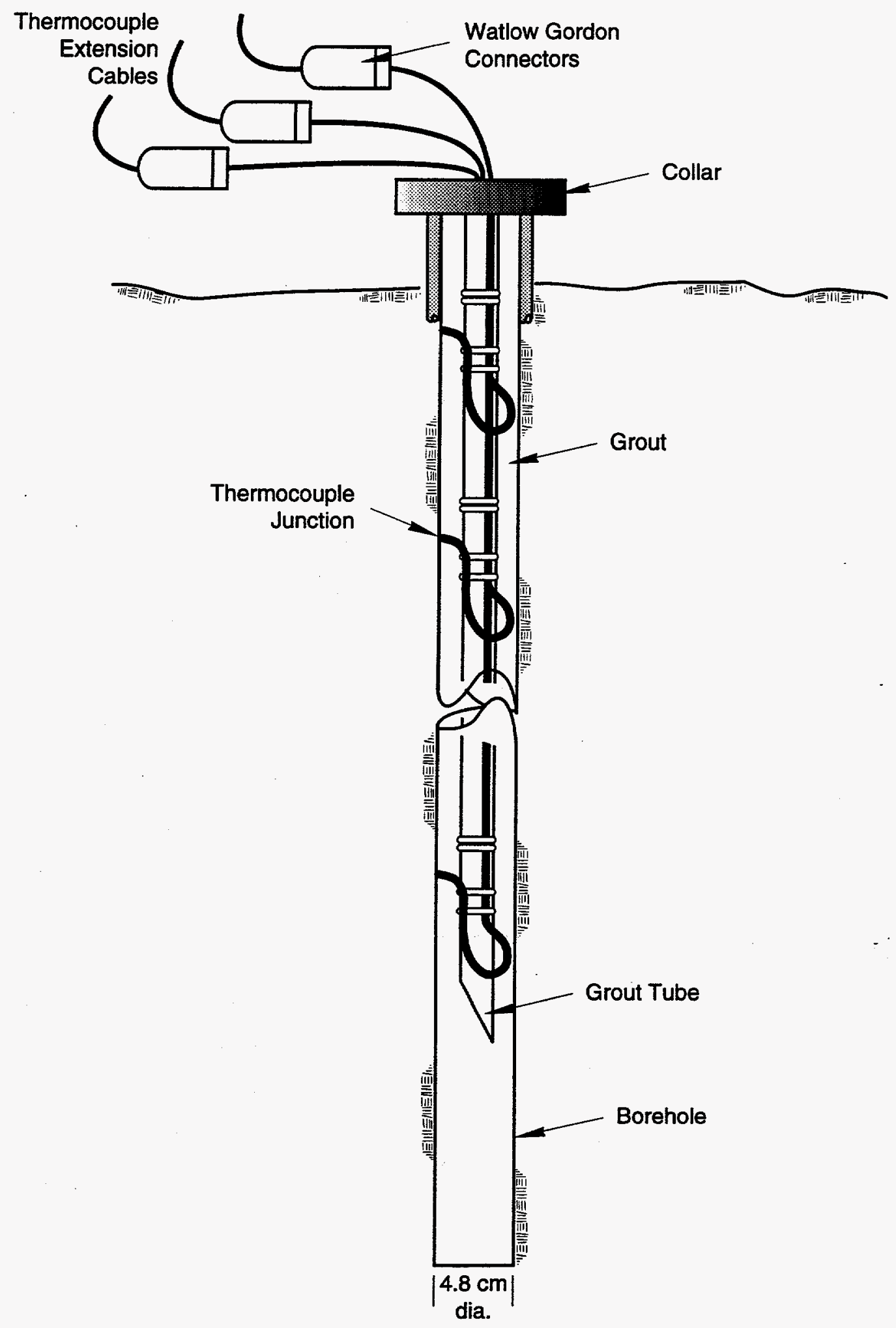

T/M-16060-10

Figure 3.7.5. Far-Field Thermocouple Installation 


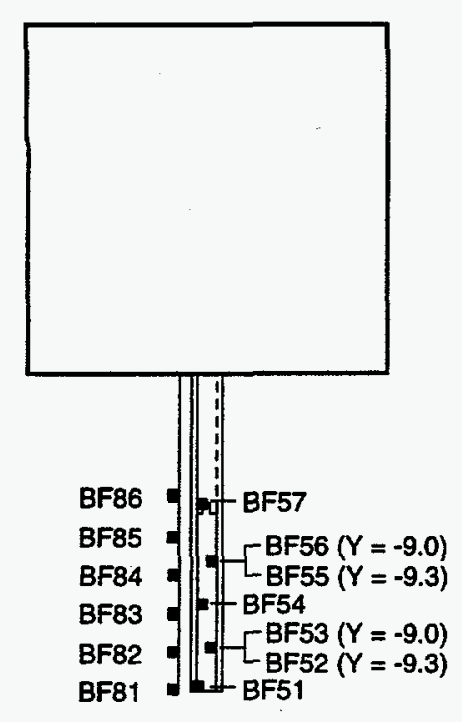

$Y=-9.1$

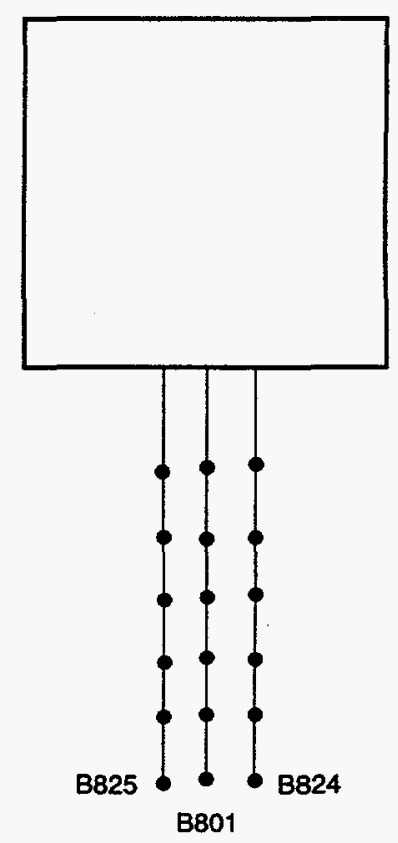

$\mathrm{B} 802(\mathrm{Y}=-9.5)$

$Y=-9.9$

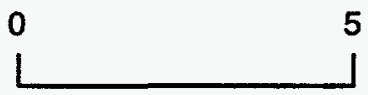

Scale (meters)

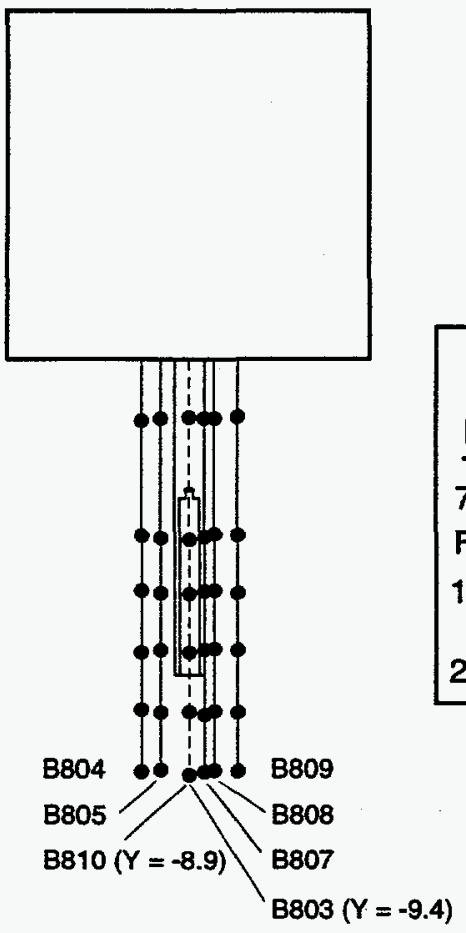

\section{Legend}

No. Designation Type Symbol
700-999 TC Thermocouple F00-F99 FM Fluxmeter

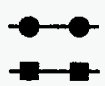

1. Origin of coordinates $(X, Y, Z)$ is plan center at room height.

2. Dashed lines not in the plane of the drawing.

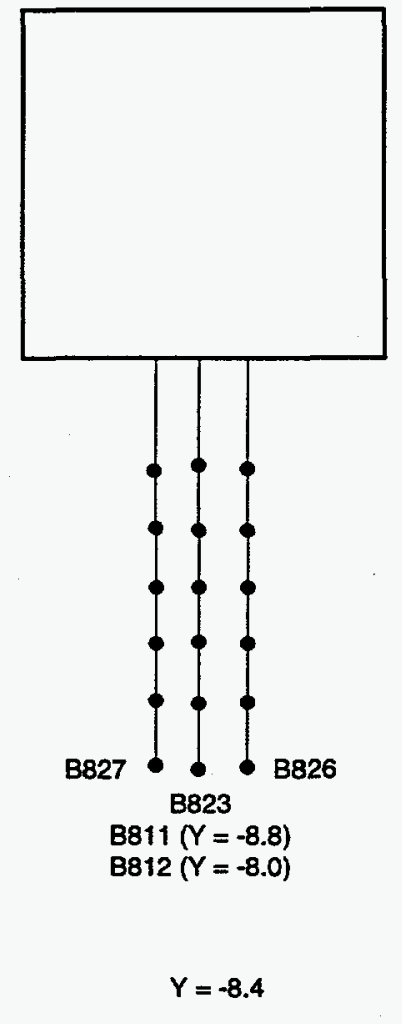

$T M-16060-26$

Figure 3.7.6. Cross Sections of a Near-Field Thermocouple and Flux Meter Installation 
midway between the two heaters. This careful placement of junctions facilitated thermal analysis by providing accurate locations for measurements in the relatively steep and rapidly changing temperature gradient. In addition, it placed the junctions in the direction nearest the heat source to reduce the effects of backfill material on the temperatures recorded.

Heater thermocouples were built into heaters during fabrication and were supported by spring-loaded brackets, as shown in Figure 3.7.7. The brackets held the junctions in contact with the interior heater wall in order to provide direct measurement of the wall temperature. To ensure accurate temperature measurements, radiation shields were placed between the heater elements and the thermocouple junctions. Generally, two thermocouples, one primary and one backup, were included in each heater; the backup thermocouple was not connected to the DAS unless the primary thermocouple failed. Selected heaters contained two strings of thermocouples with six gages in each string; the two strings were located along diametrically opposed sides of the heater. Both heater thermocouple configurations are shown in Figure 3.7.3. In addition to the heater thermocouples, the WPP heaters in Rooms $A 1$ and $B$ contained thermocouples on the outside surfaces of the heaters, in the annuli around the heaters, and on the borehole walls.

Air-stream thermocouples were used to monitor the temperature of the air moving through the Air Intake shaft [TOP 223]. These thermocouples were mounted on metal brackets that were attached to the shaft wall with "Ramset" fasteners as shown in Figure 3.7.8. A short section of small diameter iron pipe was used to house the thermocouple junction and to damp the effects of thermal transients. 
View A-A'

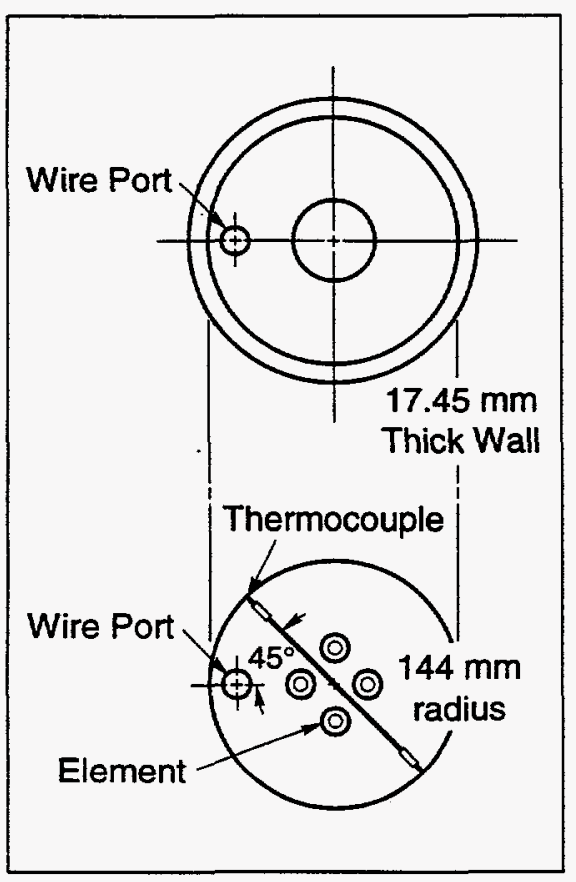

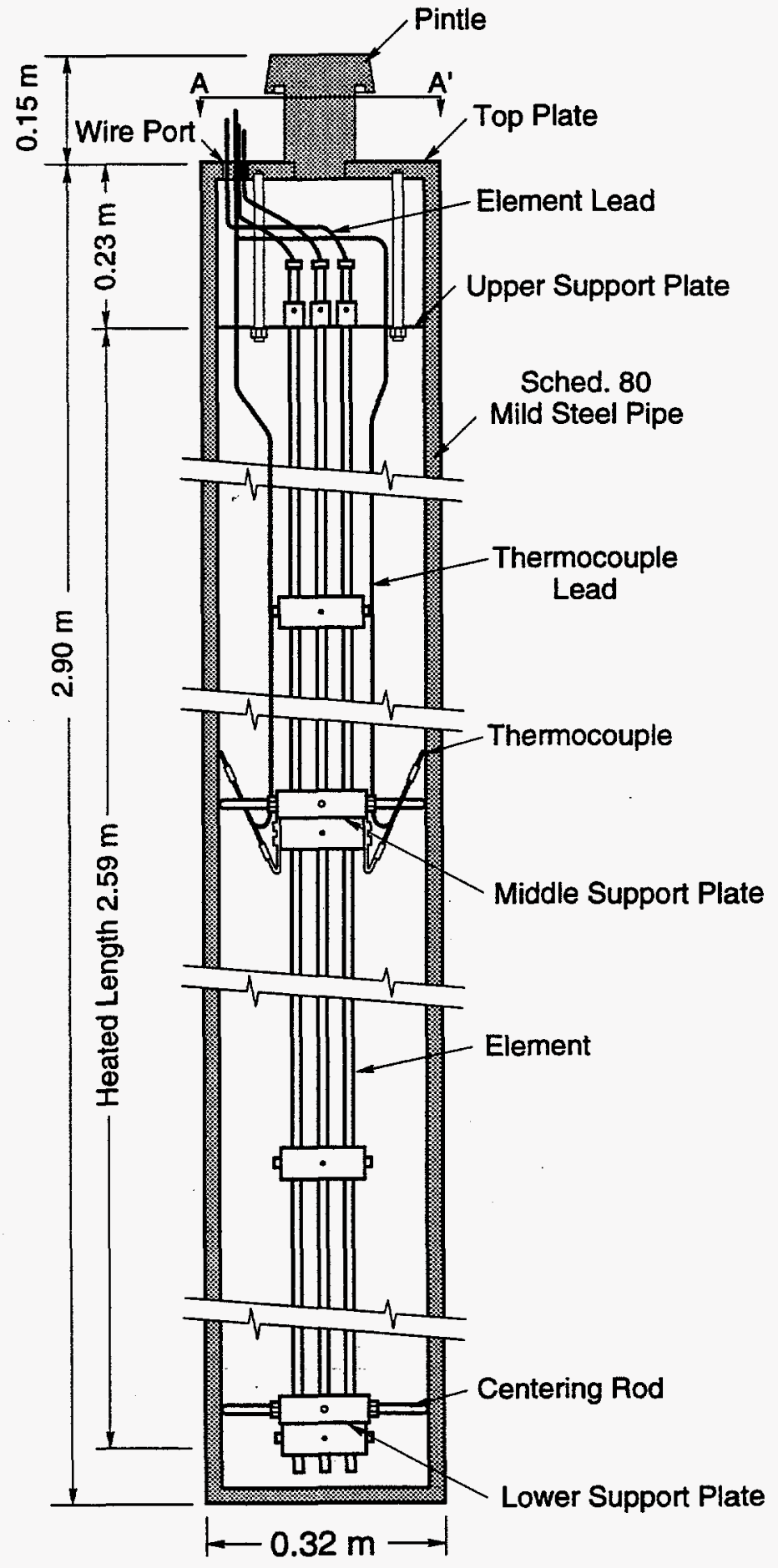

TM-16060-23

Figure 3.7.7. Canister Heater with Thermocouples 


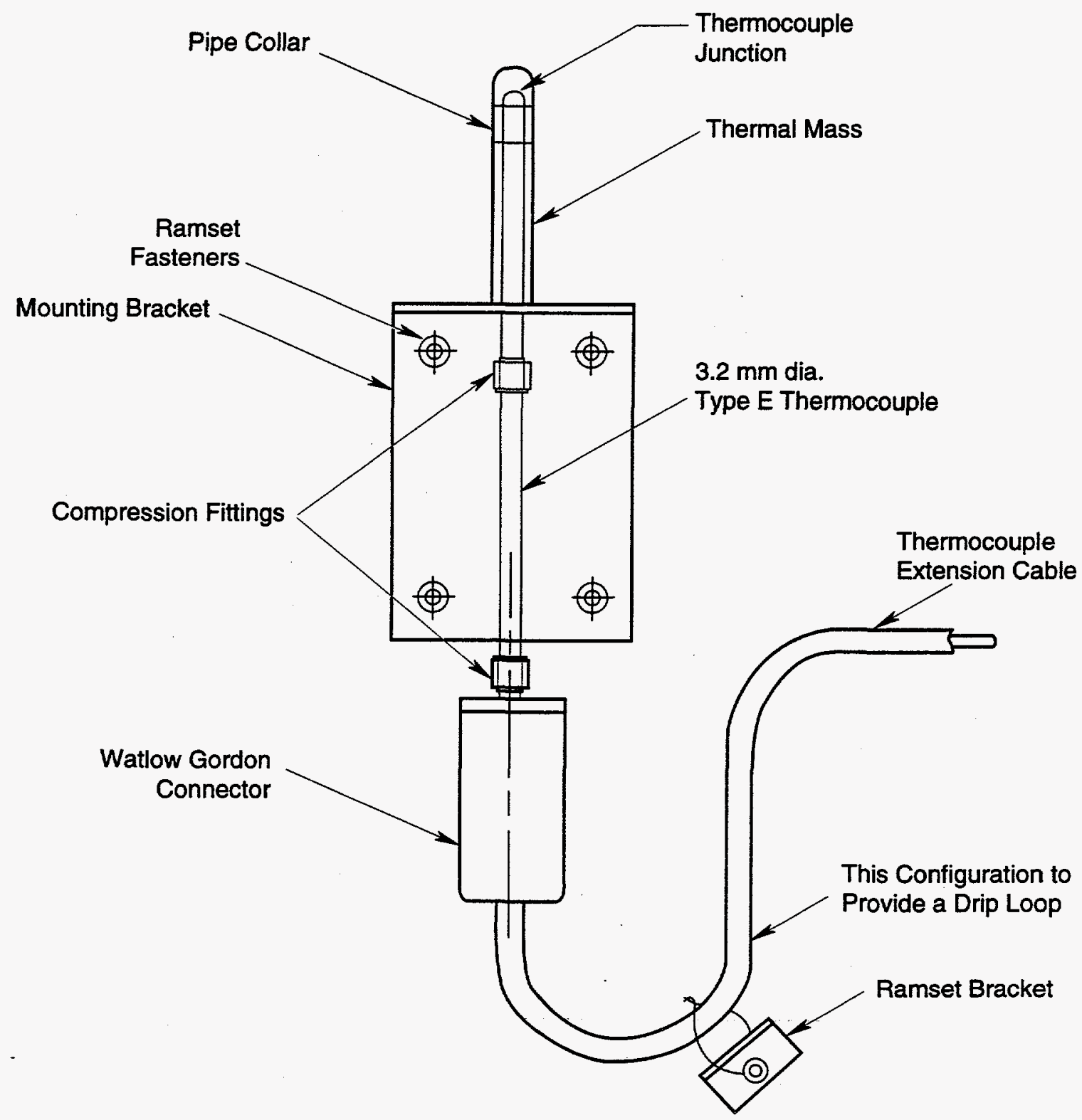

TRI-61 19-006-1

Figure 3.7.8. Air-Stream Thermocouple Installation 
After installation and grouting, the thermocouple and extension cables were joined inside Gordon heads (Figure 3.7.4) where the leads were wrapped around screw posts, twisted together, and welded with, a TIG (tungsten inert gas) welding machine [TOPs 177 and 331]. Before installing the head covers, thermocouple output was measured with a digital thermocouple thermometer and the forward and reverse loop resistances were measured with an ohmmeter to verify correct operation of the thermocouple. All manual readings were recorded before connecting the unit to the DAS.

Operation: The thermocouples were monitored by the DAS (Section 2.5) and no manual operations were required. The thermocouples tended to produce small amounts of obviously spurious data which were easily discernible from the temperature measurements because of their excessive values and random scatter. The point to be noted here is that thermocouples are either reading correctly or incorrectly, and incorrect readings are obvious. Although some thermocouples failed due to corrosion, short circuits, or mechanical damage, over 85\% survived through the periods (two to seven years) covered by the Data Reports [13-21] and generated good data. The near-field thermocouples, which were located in the test room floors, experienced the greatest number of failures. The near-field failures were due, for the most part, to corrosion and moisture from brine that collected in the vertical-down boreholes. In addition, the location of the near-field thermocouples in the room floors made the electrical leads vulnerable to physical damage.

Maintenance: The thermocouples used in the TSI tests were designed to be used in applications such as furnaces where refractory insulation is needed and moisture poses no problem. The magnesium oxide insulation used 
in the thermocouples is hygroscopic, however, and becomes a poor but troublesome conductor when moist. Unfortunately, the ends of the thermocouples were not sealed adequately during fabrication and moisture invaded the insulation of many of the thermocouples after installation. The moist insulation caused high resistance (megohm range) short circuits between the conductors and the sheathing, and caused the gages to produce erratic data. If enough of a thermocouple were exposed at the borehole collar, a repair could be made by trimming back the end of the sheathing, heating the exposed portion of the thermocouple to drive out moisture, and resealing the thermocouple with epoxy cement [TOP 115]. Fortunately, most of the thermocouples had enough lead exposed to make a repair and a major effort was made to retrofit the thermocouple installations. It eventually became a standard procedure to check the resistance between the thermocouple leads and sheathing with a high-range ohmmeter before installation. Thermocouples with a lead-to-sheathing resistance less than 300 megohms were not installed. In general, it was not possible to replace a thermocouple if it failed; units that failed were disconnected from the DAS.

\subsection{Thermal Flux Meters}

A thermal flux meter is a device used to measure heat transfer. "Micro-Foil" heat fIux sensors, manufactured by the RdF Corporation, were used in the heated test rooms to monitor heat flow from the heaters into the rock mass. The gages were emplaced on the surfaces of heaters and heater holes in the $A$ and $B$ test rooms (Figures 3.7 .2 and 3.7 .6 ), in the floors of the $A$ and $B$ test rooms, and in the Room $H$ pillar (see Figure 1.0.3 for room locations). Table 3.0 .1 gives the quantities of flux meters installed in the test rooms. 
Desion: A thermal flux meters is composed of a thermopile to measure heat flow and a thermocouple to provide a reference temperature for calibration purposes. A thermopile consists of a number of thermocouples that are joined in series and bonded to a thin substrate. with junctions on both sides of the substrate, flux meters generate an output in the microvolt range that is a function of the temperature differential across the substrate. The thermal flux meters used in the TSI tests were small, thin gages that sensed the component of heat flow in the direction normal to the plane of the gage (Figure 3.8.1). The gages were directional with a positive reading indicating heat flow in one direction, and a negative reading indicating flow in the other. The readings could be reversed by cementing the gage to the surface upside down, or by reversing the leads. The reference temperature was provided by a Type-T thermocouple (a junction of copper and constantan conductors).

Calibration: A true calibration of a thermal flux meter would be a difficult, if not impossible, task. Conventional sensors, such as potentiometers or strain gages, are normally installed within a gage which can be calibrated as a unit. Since these sensors were installed directly in the test environment, a conventional calibration process could not be used. In addition, any thermal barriers between the heat source and heat sink would need to be considered. In the TSI tests, these barriers would include the epoxy adhesive used to bond the gage to the measurement surface, and the crushed salt or epoxy cement used to fill the borehole annulus. Consequently, flux meter output (microvolts) was converted to thermal flux (watts per square meter) by the manufacturer's gage factors. Thermal flux was calculated by the following equation: 


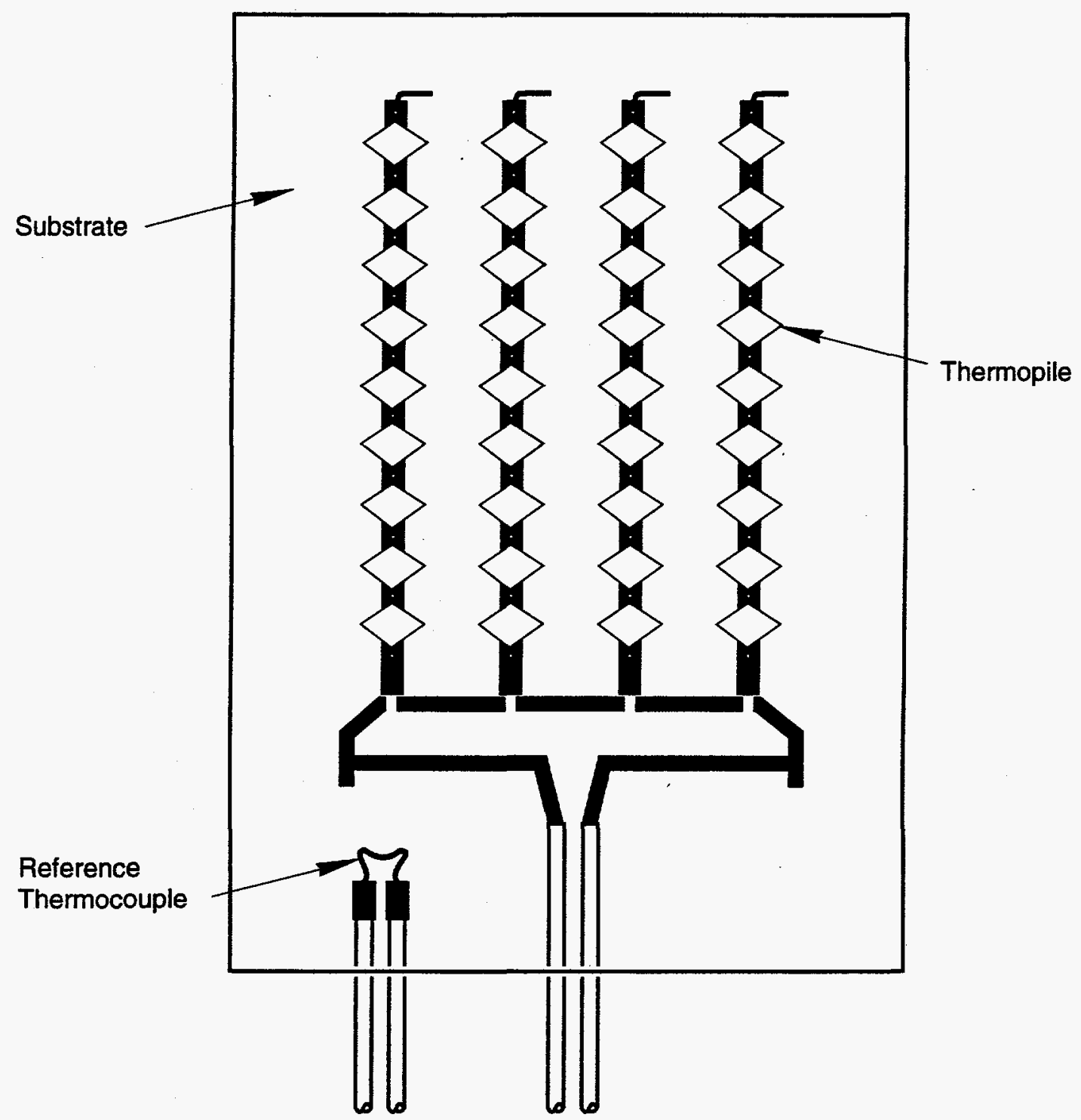

Electrical

Leads

$T M-16060-14$

Figure 3.8.1. Thermal Flux Meter 


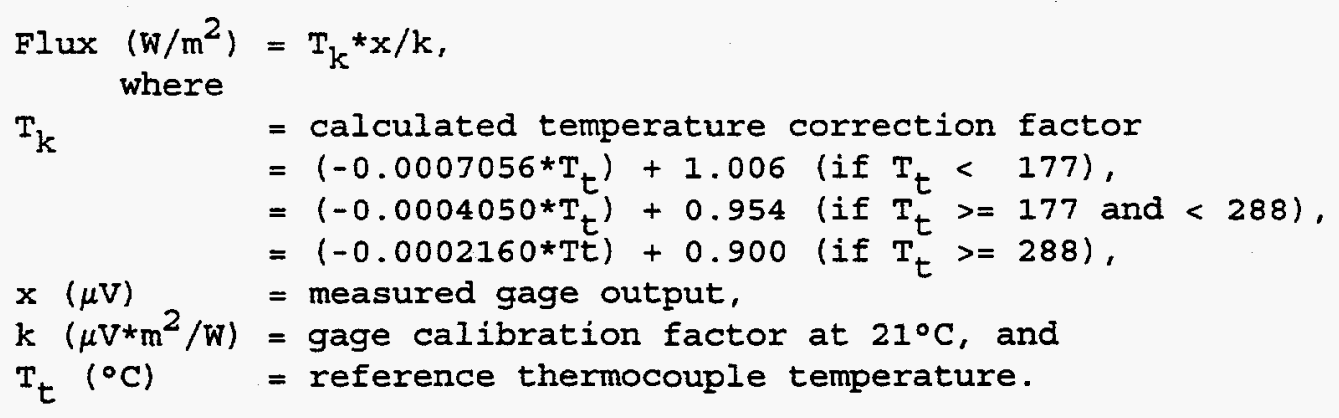

The reference thermocouple voltage output was converted to temperature units by NIST Thermocouple Reference Tables [32, 33] .

Installation: Flux meters were mounted on the exterior surfaces of selected heaters and on the walls of the associated heater holes (Figure 3.8.2) prior to heater installation [TOP 095]. Before mounting the gages, the heater surfaces were cleaned to bare metal, the formation surfaces were brushed and blown clean, and all surfaces were cleaned with aerosol Freon. After cleaning, the gages were mounted to the surfaces with five-minute epoxy adhesive. Teflon blocks cut to the appropriate radius were used to hold the gage to the surface while the adhesive cured. The blocks were held in place on the heaters with bungee cords, while the blocks on the borehole wall were held in place with a specially designed and remotely controlled pneumatic tool. After the adhesive had set, the gages were coated with cotronics 940 ceramic adhesive for protection. Stainless steel tubing was used to protect the electrical leads in the annulus of the borehole.

Flux meters were also installed in the floors of the $A$ and $B$ test rooms, and in the Room $\mathrm{H}$ pillar. In these installations, $150 \mathrm{~mm}(6 \mathrm{in})$ diameter cores up to $0.5 \mathrm{~m}(1.5 \mathrm{ft}$ ) in length (Figure 3.8 .3 ) were taken from the rock mass with a masonry bit. Each core was then cut in two with a band saw. A $1.3 \mathrm{~mm}(0.050 \mathrm{in})$ deep recessed notch was milled in one sawed surface to accommodate the gage and its electrical leads, and all 


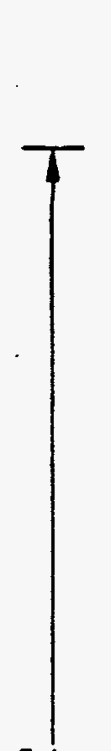

$$
N
$$
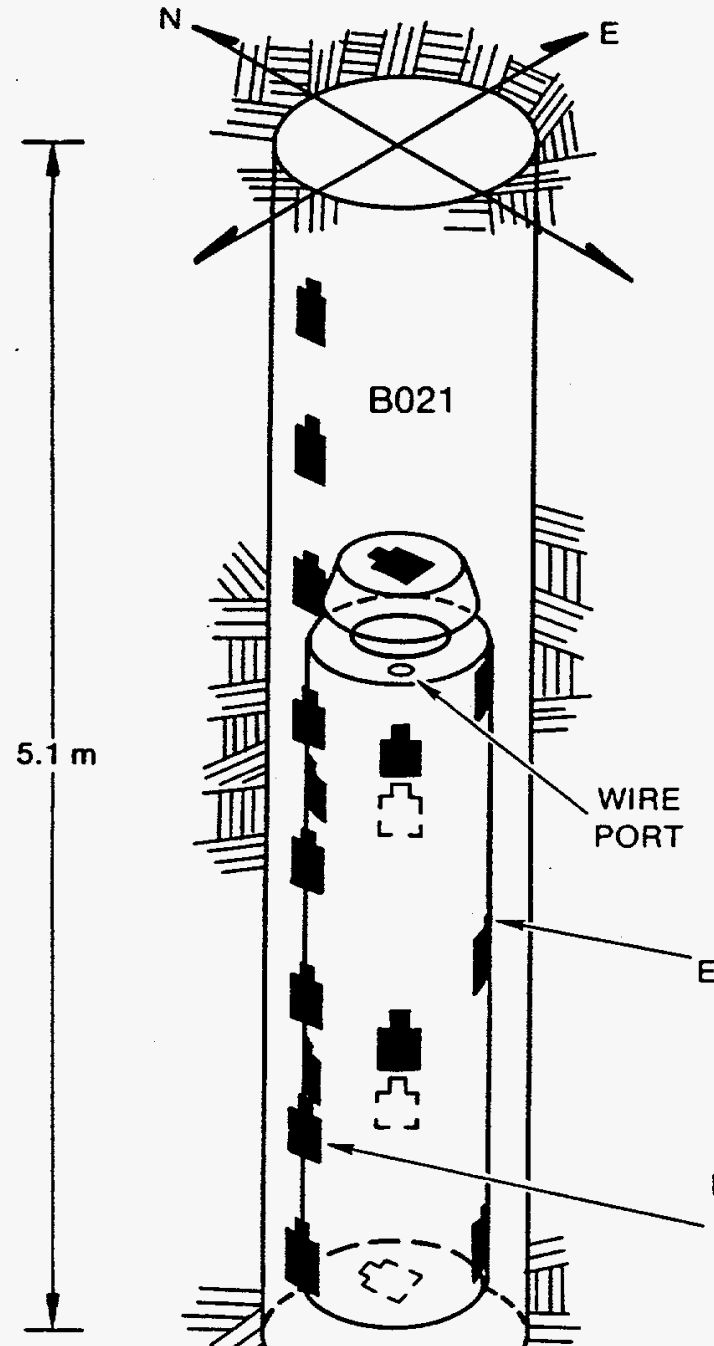

PORT 

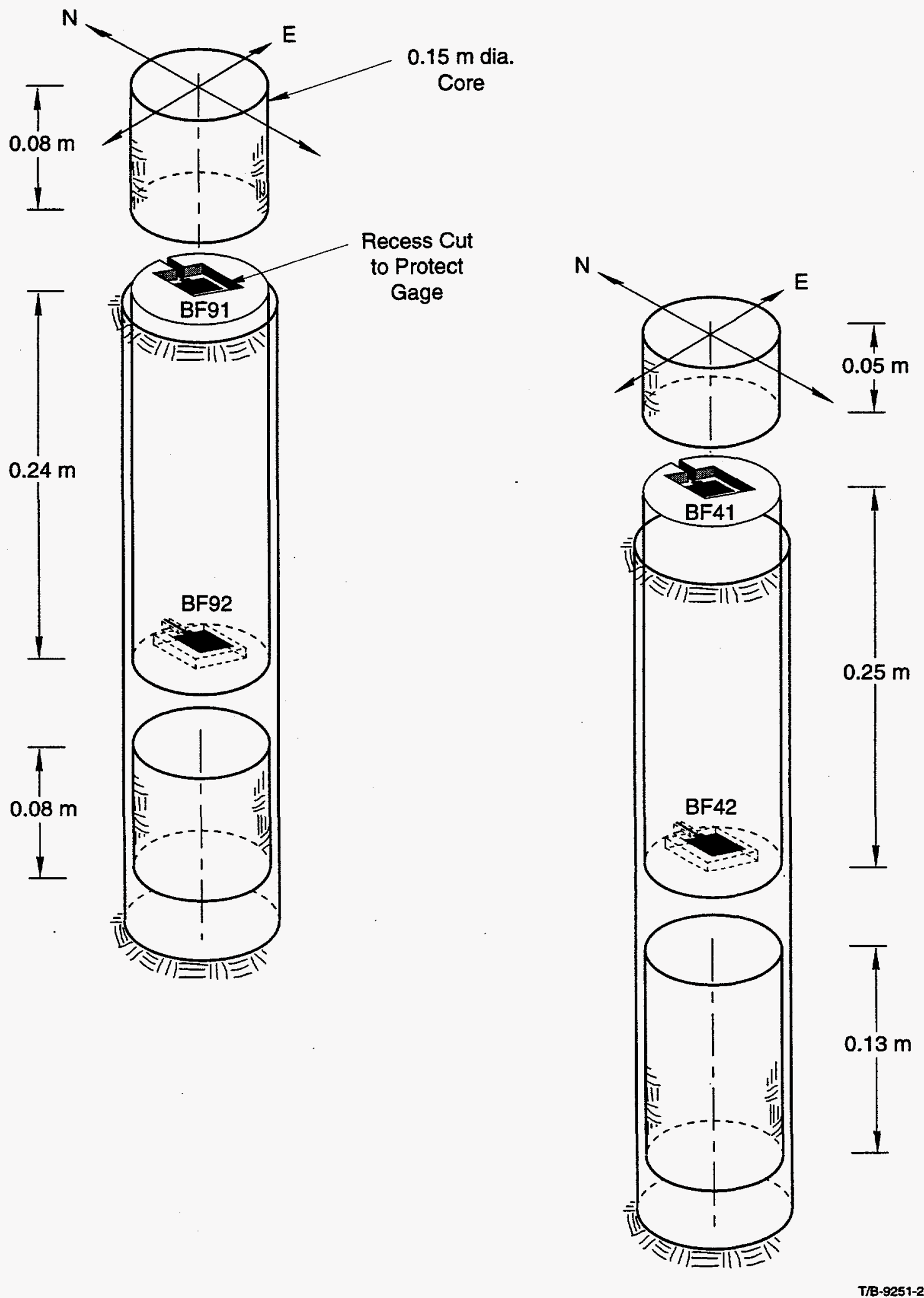

Figure 3.8.3. Thermal Flux Meter Installations in Room Floor 
surfaces were cleaned with aerosol Freon. The gage was then cemented in the notch, and the core pieces cemented back together with epoxy adhesive. Finally, the core assembly was cemented back in its hole with "Scotch-Cast" electrical insulating epoxy. This procedure placed the flux meters parallel to the room floor (or pillar surface in Room $H$ ) with the sensing direction normal to the floor. Care was taken to maintain the original orientation of the core during all steps of this process.

Continuity of the electrical leads and gages was checked before and after installation. The resistances of the flux meters and reference thermocouples were also measured and recorded to verify gage operation before connecting the gage to the DAS.

Operation: The flux meters were monitored by the DAS (Section 2.5) and required no manual operations. The flux meters were very sensitive and responded almost instantly to changes in the thermal field and produced very good data when functioning. The gages and their electrical leads were fragile, however, and many failed during heater installation and operation. Over $60 \%$ of the flux meters failed during the periods (two to five years) covered by the Data Reports [13-17].

Maintenance: Failure of a flux meter was indicated by erratic data and confirmed by gage resistance values that were higher or lower than normal. High resistance indicated an open circuit caused by broken leads or a damaged sensor, while low resistance was caused by the leads shorting together some distance from the gage. It most cases it was not practical to repair a flux gage because the damage usually occurred in a heater hole annulus or within an epoxied core. Flux gages that had failed were generally deactivated from the DAS. However, broken leads were occasionally accessible and could be repaired easily. In other instances, 
flux meter damage was limited to the reference thermocouple but operation of the gage could continue by using a nearby thermocouple for reference temperatures.

\subsection{Power Meters}

Power meters were used to measure the electric power consumed by the canister, guard, WPP, and strip heaters. Electric power consumption was in turn used to evaluate the amount of heat generated in the tests. In the $A$ and $B$ test rooms, power meters were assigned to individual heaters. In Room H, power meters monitored pairs of heater panels. Table 3.0.1 gives the quantity of power gages installed in the test rooms.

Design: A heater power meter was comprised of a current-viewing resistor (CVR) and a voltage divider. The CVR was a precision resistor with a nominal rating of 0.0025 ohms that was placed in series with a heater. Measuring the voltage drop across the CVR and dividing it by the CVR resistance gave the heater current. Heater voltage was measured from a voltage divider that reduced the line voltage by a set ratio to a much lower level that was safer to handle inside the instrument sheds.

Calibration: Heater power was calculated as the product of heater current and heater voltage, both of which were monitored by the DAS:

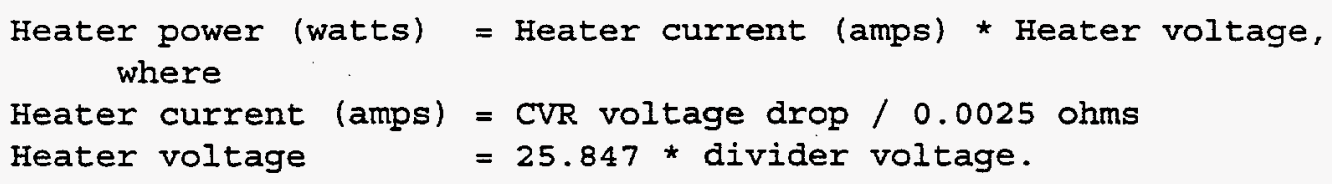

There was no power factor to be considered since the load was purely resistive. The above equations were stored in the ModComp Function Routine File. The coefficients were based on the nominal resistance values of the CVRs and voltage dividers. 
Installation: The power meter components were installed in the instrument sheds during test construction.

operation: The power meters were monitored by the DAS and no manual operations were required. None of the power gages failed during the periods (two to five years) covered by the Data Reports [13-17] and all generated reliable data. Data from the power meters was not smooth but was in the form of bands. The bands were caused by normal fluctuations in line voltage and had a width of up to 150 watts. Despite the nature of the data, the power meters gave a good evaluation of the mean power supplied to the heaters.

Maintenance and Modifications: The power meters required no maintenance or modifications after the initial installation.

\subsection{Environmental and Ventilation Gages}

Environmental and ventilation gages were installed in conjunction with the TSI in situ tests to evaluate thermal losses from the heated test rooms to the underground ventilation system. The environmental gages consisted of thermocouples that were emplaced inside the heated test rooms to measure the temperature of the air within the rooms. The ventilation gages included thermocouples and air velocity sensors that were installed in access drifts in the vicinity of the heated test rooms. The ventilation thermocouples measured air temperatures upstream and downstream from the heated test rooms, while the air velocity sensors measured the velocity of the air moved through the access drifts by the mine ventilation system. Table 3.0 .1 gives the quantities of environmental and ventilation gages installed in the test rooms.

Significant heat was lost through the bulkheads at the entrances to the test rooms, even though they were insulated and fitted to the opening 
as closely as possible. A reasonable estimation of the heat lost from the $A$ and $B$ Test Rooms (see Figure 1.0 .3 for locations) could be obtained by evaluating the difference in air temperatures upstream and downstream from the test rooms, and by estimating the air flow in the access drifts [15, 17]. To obtain the temperature differential, ventilation thermocouples were located in the $\mathrm{N} 1420$ and $\mathrm{N} 1100$ drifts upstream and downstream from the $A$ and $B$ Test Rooms as shown in Figure 3.10.1. Although the ventilation temperatures had diurnal and seasonal variations, data showed that the downstream temperature was elevated with respect to the upstream temperature. An average temperature difference could readily be estimated by comparing graphs from the upstream and downstream gages [15].

Air flow in the $N 1100$ and N1420 access drifts could be estimated from air velocity data and by making some simple assumptions. If the surface drag were assumed to be insignificant and the flow to be laminar, then the air velocity across the width of the drift would be constant. The velocity over time was also fairly constant, as shown by air velocity data [15]. Given the dimensions of the access drifts, an assessment of the ventilation air flow could be made.

Similarly, data from the ventilation gages in the Room $\mathrm{H}$ access drift could be used to measure the heat lost from the test room during maintenance activities (such as roof bolting) when the test room was ventilated for significant periods of time. Room $\mathrm{H}$ was a dead end in the underground ventilation system, but was ventilated by duct work and auxiliary fans for health and safety considerations during maintenance activities.

Design: The environmental and ventilation thermocouples were made from Type-E (chromel and constantan conductors) thermocouple extension 


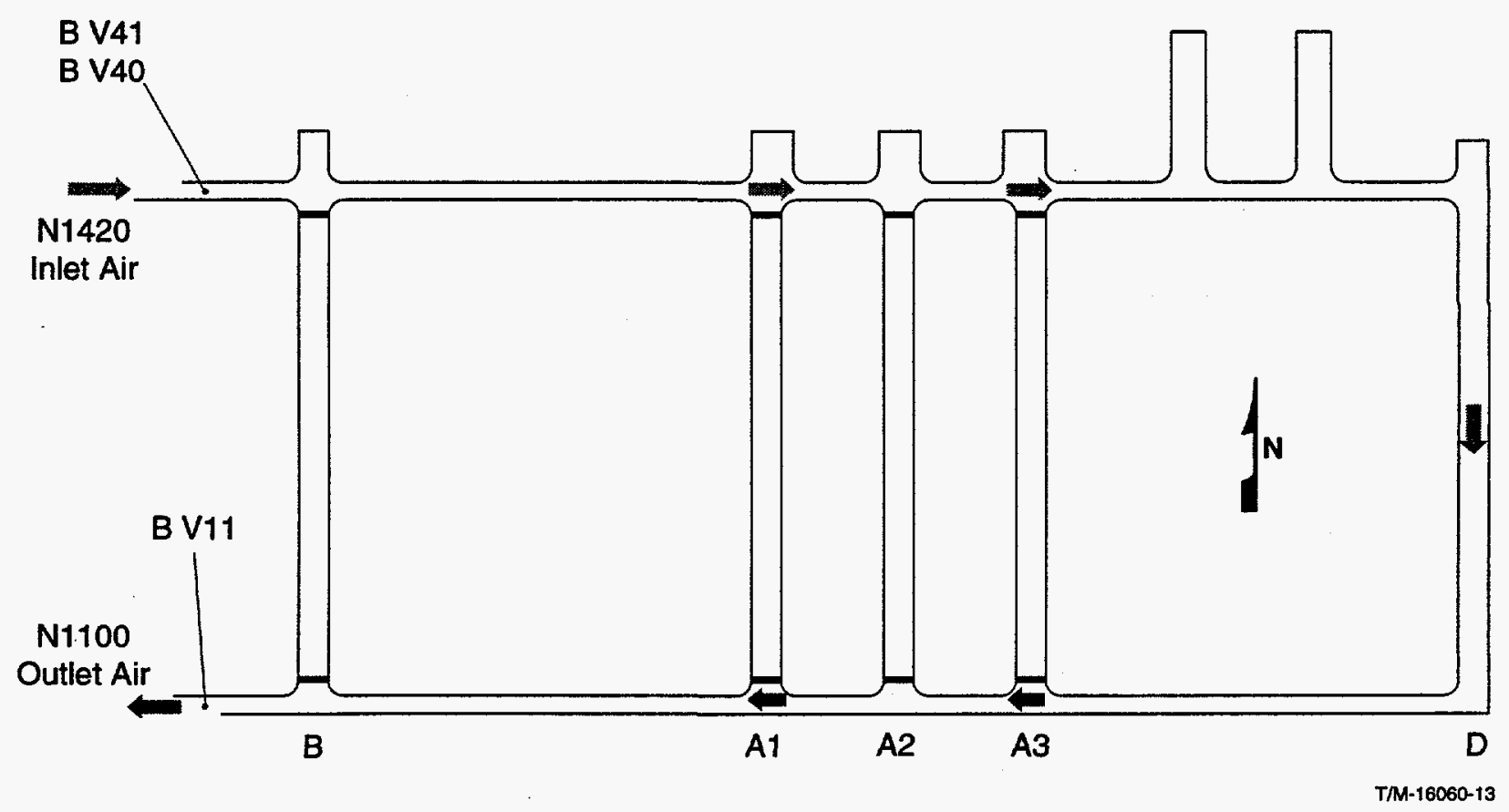

Figure 3.10.1. Location of Ventilation Gages Near the A and B Test Rooms

cable with the ends of the conductors welded together to form junctions.

The air velocity gages used in the TSI in situ tests were manufactured by Kurz Instruments Inc. The Kurz Air Velocity system was based on a constant-temperature anemometer that measured air velocity by the cooling effect of the air on a sensor. Changes in electric current maintained the sensor at a constant temperature and were converted to an analog voltage by a signal conditioner. The analog output was in turn converted to a linear voltage output by a linearizing circuit. A control unit provided excitation to the gage and controlled its operation; only the output signal was monitored by the DAS.

Calibration: The voltage output of the environmental and ventilation thermocouples was converted to temperature units by NIST Thermocouple Reference Tables $[32,33]$, (see Section 3.7).

The air velocity gage was originally calibrated by the manufacturer. 
By using the linearization circuit, the gage calibrations could be expressed as a linear relationship:

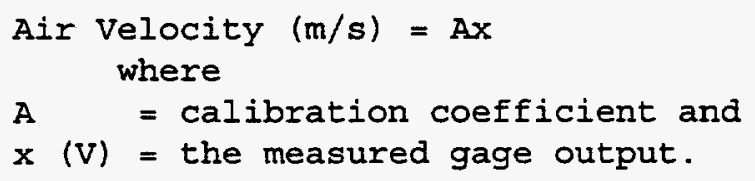

Installation: The environmental thermocouples in the $A$ and $B$ Test Rooms were installed in pairs and were located near the center of the test rooms. The Room $H$ environmental thermocouples were placed in pairs at opposite sides of the room pillar. The pairs were mounted on electrical junction boxes with one thermocouple positioned to monitor the temperature of the air and the other positioned to monitor the temperature of the box.

Air velocity gages were installed in the N1420 drift and in the Room $\mathrm{H}$ access drift (see Figure 1.0 .3 for locations) on arms that could be swung out into the drift when needed, and swung back against the rib when not in use [TOP 148]. The arms were designed so that the sensor was at the vertical and horizontal midpoint of the drift when the arm was swung out.

Four ventilation thermocouples were placed in the access drifts of the $A$ and $B$ test rooms, all about $15 \mathrm{~m}(50 \mathrm{ft})$ west of Room $B$. One was instalied on the swinging arm in the N1420 drift along with the air velocity sensor, and an array of three were installed along the back of the N1100 drift. This arrangement placed thermocouples both upstream (N1420 drift) and downstream (N1100 drift) from the A and B Test Rooms.

Two ventilation thermocouples were placed in the access drift to Room $H$. One was located on the swinging arm along with the air velocity sensor; the other was located in the ventilation duct. This placed one thermocouple upstream from the test room and the other downstream. 
Operation: The environmental and ventilation gages were monitored by the DAS (Section 2.5) and little manual work was required. The gages were monitored for a period after installation to establish base line data. After that, the velocity gages were capped and the arms were swung back against the rib. During the opening of a test room for maintenance, or for any other reason, the gages could be swung out into the drift for measurements. The gages were very reliable and were readily accessible for maintenance and repair.

Maintenance: The air velocity probe was cleaned periodically to ensure accuracy. Although the probe was not required to be free of dust for accurate readings, the cleaning was required to prevent blockage. The probe and signal conditioner were replaced periodically to allow the old units to be calibrated.

Modifications: The original ventilation thermocouples described above were eventually replaced with the sheathed Type-E thermocouples described in section 3.7. At this time, the junctions were fitted with thermal masses (Figure 3.10.2) to damp the effects of thermal transients such as rises in temperature due to passing vehicles. The thermal mass was made from a $75 \mathrm{~mm}$ (3 in) long piece of $13 \mathrm{~mm}(1 / 2 \mathrm{in})$ diameter stainless steel round stock that was drilled lengthwise with a $3.3 \mathrm{~mm}(0.129$ in) diameter hole for three quarters of its length. The thermocouple was inserted in the hole and held in place with a small set screw. The thermal mass and thermocouple were held by a fixture made of Teflon that was designed to thermally insulate the thermocouple from its mounting. One end of the Teflon fixture was drilled and threaded so that the assembly could be bolted to the swinging arms or to anchors set in the formation. The original environmental thermocouples in the test rooms, however, remained 


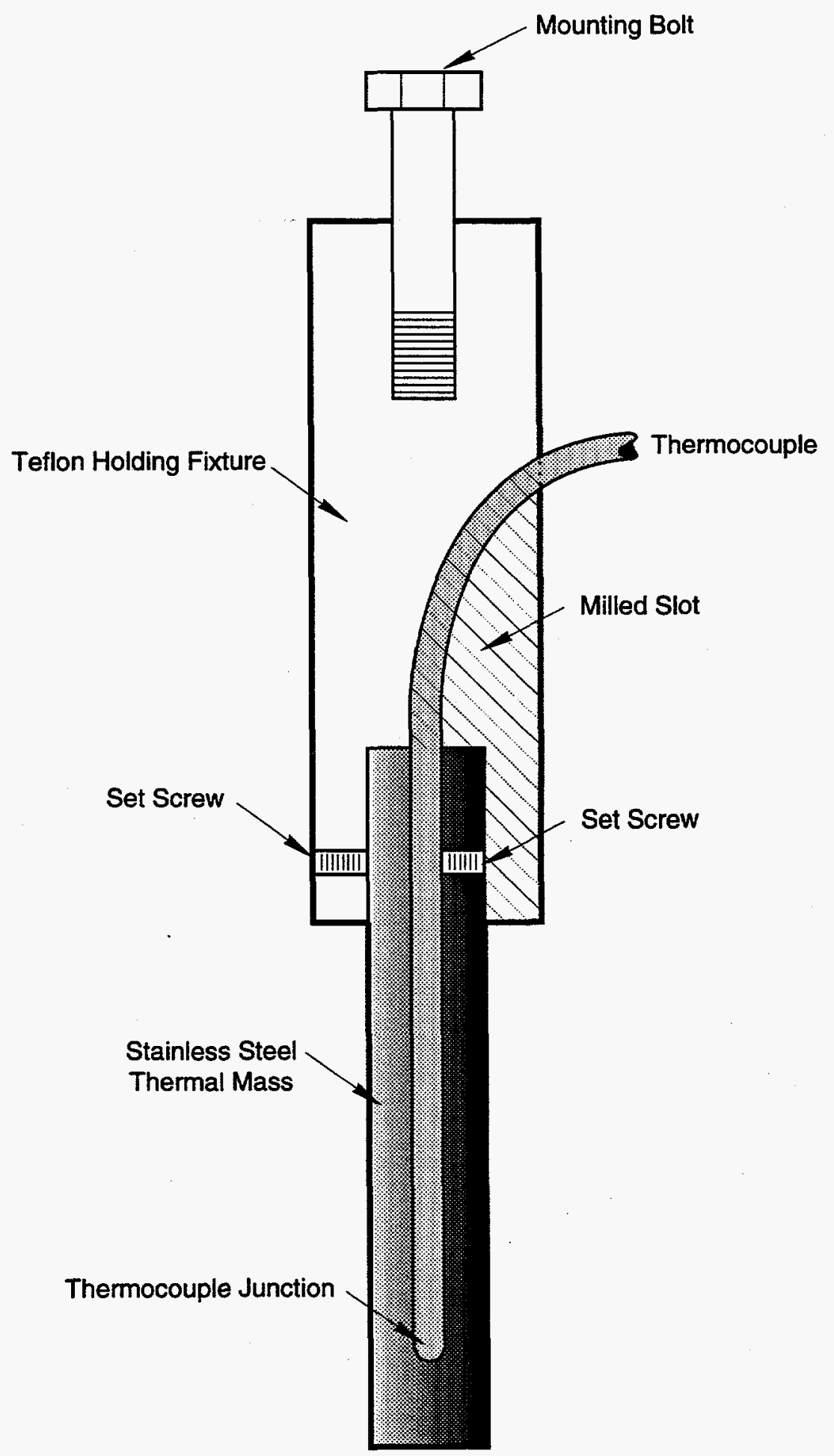

T/M-16060-7

Figure 3.10.2. Ventilation Thermocouple Installation 
as welded junctions of thermocouple extension cable.

Later in the experimental program, a portable wind tunnel was acquired by the Sandia WIPP Site Calibration Laboratory and was used along with a digital multimeter, differential pressure meter, platinum resistance thermometer, and barometer to calibrate the air velocity gages on a regular basis [TOP 320]. The linearization circuit complicated the calibration process, however, and soon thereafter the control unit was rewired (an option provided by the manufacturer) to bypass this circuit. Use of the nonlinear output simplified the calibration process and increased the accuracy of the measurements. The results of the calibrations were fit to third order polynomial equations using regression analysis. The voltage signals were thereafter read directly by the DAS and the calibration coefficients were used to convert gage output (volts) to engineering units (meters per second):

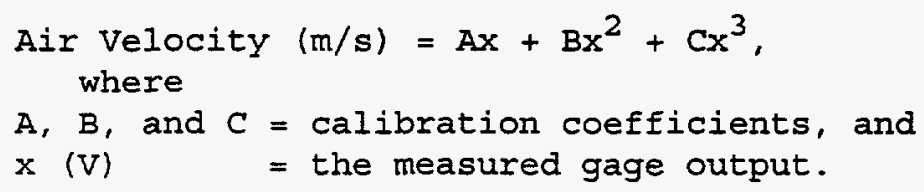

Another modification was to reduce the operating range of the sensor in order to enhance the sensitivity of the instrument. In addition, rigid mounting plates were provided for the signal conditioner to replace the Ramset fasteners and make removal and replacement of the signal conditioners and easier task. Finally, a permanent AC circuit was wired to the station to eliminate the use of extension cords.

\subsection{Shear Detectors}

Various instruments were conceived of and experimented with to measure shear displacement in conjunction with the Clay seam Shear Test which was never commissioned. These instruments were all designed to be mounted 
between two anchors that were attached to opposite sides of the shear plane to be monitored [TOPs 057 and 080]. The first design was published in the test plans $[5,6,7$, and 8], but was never built. This device consisted of a length of inclinometer casing (Section 3.4) anchored to both sides of the shear plane. The change in inclination of the casing, as measured over time, was to be used to evaluate shear in the plane. This design was followed by an instrument that consisted of a pointer mounted to one anchor and a circular target mounted to the other. A few of these devices were fabricated, although they did not function well in practice.

A more functional and rigid instrument was designed later that consisted of a rectangular block mounted to one anchor and a target with three orthogonal surfaces mounted to the other. The components were installed so that the block was close to but not touching the target surfaces. Distance from the faces of the block to the target surfaces could then be measured in three dimensions with depth gages or three linear variable differential transformers (LVDTs). A few of these devices were tested in Rooms 3 and 4 of the SPDV test panel, the N1420 drift, and in Room B (see Figure 1.0 .3 for locations), but their development was not pursued far enough to provide any meaningful data. 
An evaluation of measurement accuracy was made for the various types of closure gages, extensometers, and thermocouples used in the TSI in situ tests. The accuracy for each gage type was actually derived as the sum of various uncertainties in the measurement and calibration processes. In reality, the probability that the various components of uncertainty were all at their maximum is small; it is more likely that compensating errors occurred and a root-sum-square of the components would give the most probable error. However, the conservative approach is taken here and a simple sum of the components is provided to give the maximum possible derived error [43]. The evaluations are discussed in the following sections and the resulting accuracies are summarized in Table 4.0.1.

Table 4.0.1. Gage Measurement Accuracy

\begin{tabular}{|c|c|c|c|}
\hline Gage & $\begin{array}{l}\text { Measurement } \\
\text { Uncertainty }\end{array}$ & $\begin{array}{l}\text { Gage } \\
\text { Range }\end{array}$ & $\begin{array}{l}\text { Eull-scale } \\
\text { Accuracy }\end{array}$ \\
\hline $\begin{array}{l}\text { SINCO Tape } \\
\text { Extensometer }\end{array}$ & \pm 0.088 in $( \pm 2.235 \mathrm{~mm})$ & 36 in $(900 \mathrm{~mm})$ & $\pm 0.2 \div$ \\
\hline $\begin{array}{l}\text { Anchor Bolt } \\
\text { Extensometer }\end{array}$ & \pm 0.003 in $( \pm 0.076 \mathrm{~mm})$ & 6 in $(150 \mathrm{~mm})$ & $\pm 0.05 \%$ \\
\hline $\begin{array}{l}\text { R.I. Room } \\
\text { Closure }\end{array}$ & $\begin{array}{l} \pm 0.034 \text { in }( \pm 0.864 \mathrm{~mm}) \\
\pm 0.074 \text { in }( \pm 1.880 \mathrm{~mm})\end{array}$ & $\begin{array}{l}12 \text { in }(300 \mathrm{~mm}) \\
36 \text { in }(900 \mathrm{~mm})\end{array}$ & $\begin{array}{l} \pm 0.3 \% \\
\pm 0.2 \%\end{array}$ \\
\hline $\begin{array}{l}\text { Serata E-200L } \\
\text { Extensometer }\end{array}$ & $\begin{array}{l} \pm 0.024 \text { in }( \pm 0.610 \mathrm{~mm}) \\
\pm 0.056 \text { in }( \pm 1.422 \mathrm{~mm})\end{array}$ & $\begin{array}{r}8 \text { in }(200 \mathrm{~mm}) \\
30 \text { in }(750 \mathrm{~mm})\end{array}$ & $\begin{array}{l} \pm 0.3 \% \\
\pm 0.2 \%\end{array}$ \\
\hline $\begin{array}{l}\text { Serata } \mathrm{E}-3.00 \\
\text { Extensometer }\end{array}$ & \pm 0.011 in $( \pm 0.279 \mathrm{~mm})$ & 3 in $(75 \mathrm{~mm})$ & $\pm 0.4 \%$ \\
\hline $\begin{array}{l}\text { IRAD Rod } \\
\text { Extensometer }\end{array}$ & \pm 0.021 in $( \pm 0.533 \mathrm{~mm})$ & 4 in $(100 \mathrm{~mm})$ & $\pm 0.5 \div$ \\
\hline $\begin{array}{l}\text { Serata C-300 } \\
\text { Creepmeter }\end{array}$ & \pm 0.015 in $( \pm 0.381 \mathrm{~mm})$ & 4 in $(100 \mathrm{~mm})$ & $\pm 0.4 \%$ \\
\hline $\begin{array}{l}\text { Thermocouple } \\
\text { (Type-E) }\end{array}$ & $\pm 2.35 \circ \mathrm{\circ}$ & $250 \circ \mathrm{C}$ & $\pm 1.0 \%$ \\
\hline
\end{tabular}


The above table expresses measurement uncertainties in engineering units as well as percentages of the gages' full-scale range. It must also be noted that closure gages and extensometers were calibrated and operated using inches as the unit of measurement. While the main body of this report was written using metric units, inches was retained for the discussion of accuracy to avoid unnecessary complications. As is often the case, the English system of units was the standard during the fielding of the tests.

\subsection{SINCO Tape Extensometers}

SINCO tape extensometers (Section 3.1.2) were used for making manual closure measurements in the TSI in situ test rooms. Since different tape extensometers were used for making measurements, it was necessary to calibrate the individual instruments in order to obtain accurate closure measurements. These calibrations were made on special frames [TOP 462] that were estimated by the Sandia WIPP site Calibration Laboratory to have an uncertainty of \pm 0.010 inch. In addition, experience showed that calibration measurements were repeatable within 0.005 inch when made by an experienced technician. Eventually this repeatability became a criterion in the procedure for calibrating the instruments [TOP 393]. BY this procedure, the tape extensometers were calibrated on a frame by averaging a set of four measurements at each calibration step. The calibration was accepted if each set of four measurements varied within 0.005 inch; if any set of measurements was not repeatable within this range, the instrument would be sent to the manufacturer for inspection and repair. It also became a general practice to limit the calibration operations to a small number of experienced technicians in a further effort to reduce the human error in the readings. summing the above uncertainties gives a total of 
\pm 0.015 inch for the calibration process when using experienced technicians. However, experience also showed that a measurement could err by as much as 0.020 inch depending on how the instrument hooks were centered on the measurement points (presumed to be an error of 0.010 inch for each eyebolt). These large errors could occur if the measurement were made by a less experienced technician. As a worst case, then, the total calibration error could be as much as \pm 0.030 inch.

Experience showed that closure measurements could generally be made with a repeatability within 0.008 inch. This limit eventually became a criterion in the measurement procedure [TOP 393]; readings were repeated until two successive readings agreed within 0.008 inch. However, as a worst case, the reading could be in error by as much as \pm 0.020 inch depending on the centering of the hooks in the eyebolts.

This measurement uncertainty applied only to horizontal measurements, however, because vertical closure measurements were taken with the aid of extension rods. The length of these rods was determined by averaging a set of four measurements at a closure point with and without the rod. If either set of four measurements varied by more than 0.005 inch [TOP 153], the measurement was not accepted and the extensometer was sent to the manufacturer for inspection and repair. However, a worst-case uncertainty of \pm 0.010 inch must be included for the centering of the hook in the additional eyebolt added to the vertical measurement system.

The frames used to calibrate the tape extensometers were mounted in the horizontal position. Since the tapes sagged under their own weight in this position, a bias was induced in the measurements. The amount of sag was investigated in 1995 when the underground calibration frame was moved from the E300 shop to the core library (see Figure 1.0.3 for locations). This 
move provided an opportunity to calibrate an instrument in both the vertical and horizontal positions and it was found that sag caused a bias of +0.045 inch in the horizontal measurements. The calibration process removed this bias from the horizontal measurements, but the bias would need to be subtracted from vertical measurements if the absolute distance between closure points were desired. However, the measurement of primary interest was the amount of closure (the change in distance), not the distance itself. The bias affected all vertical tape extensometer measurements, regardless of the instrument used, and was removed during the data reduction process when the amount of closure was calculated. Because it was not a factor in the measurements, the bias caused by tape sag will be ignored for the purposes of this discussion.

The tape extensometer calibrations and measurements were generally made by a small group of experienced technicians and human error was thereby minimized. Combining the errors discussed above for these conditions would give a total uncertainty of \pm 0.028 inch for vertical measurements. However, for measurements made by less experienced technicians, the worst-case errors discussed above would total \pm 0.060 inch for vertical measurements. As a result, the worst-case uncertainty over a measurement range of 36 inches (the vertical closure in Room B over a period of several years) yields a full-scale accuracy of $\pm 0.2 \%$ for the tape extensometers (Table 4.0 .1 ).

The weakness of these gages is the amount of human error in the measurements. A review of the closure data in the Data Reports shows that the data curves for the manual closure gages are not as smooth as those of the remotely monitored closure gages. Human error, however, was held to a minimum because obviously erroneous data points were omitted during the 
data reduction process. The data plots in the Data Reports [13-21] show, with rare exception, that the deviation of any point from the trend is indeed within the \pm 0.060 inch uncertainty derived above.

The strength of the manual closure gage measurements is that errors in measurement are not additive because each reading is based on the absolute distance between closure points. A data point with a large error, therefore, does not affect the accuracy of the successive measurements; a measurement taken after several years of test operation is not influenced by any errors made earlier in the test program. In conclusion, the amount of error in the manual closure data is indeed small.

The accuracies of the remotely monitored closure gages (Section 4.3), on the other hand, are not greatly influenced by human error and the data plots from these gages are typically smooth. These data are derived from the change in distance between closure points, however, and errors are cumulative: the error in any one data point includes the error in earlier data points. From this, the importance of redundant measurements can be seen. The manual and remote gages with their different measurement methods provide a system of checks on data accuracy.

\subsection{Terrametrics Anchor Bolt Extensometers}

Manually read Terrametrics anchor bolt extensometers were used to monitor borehole extension in Room $G$ (see Figure 1.0.3 for location). Anchor bolts were monitored with dial or digital depth gages that had a resolution of \pm 0.001 inch. The accuracy of the depth gages was assessed by using a surface plate and gage blocks, or depth standards [TOP 450]; a gage was deemed acceptable if calibration readings were within \pm 0.001 inch of the standards. Experience showed that anchor bolt measurements could be made with a repeatability within 0.002 inch and this eventually became a 
criterion; readings were made until two successive readings agreed within 0.002 inch. Combining the uncertainties of gage calibration and measurement resulted in a total uncertainty of \pm 0.003 inch. Over the depth gages' range of 6 inches, the full-scale accuracy was $\pm 0.05 \%$ (Table 4.0.1).

The anchor bolt extensometer's simple design and measurement method made these gages very reliable and accurate. Human error in the manual measurements, however, introduced an undefined uncertainty in the data. Because the anchor bolts were manual gages, the same statements can be made about their accuracy as were made about the manual closure gages in Section 4.1. The data plots for these gages are not as smooth as those of the remotely monitored gages because of human error. However, the errors are not cumulative. The two different measurement systems for the manual and remote extensometers provided a redundancy of measurement.

\subsection{Remote Displacement Gages}

Several varieties of remotely monitored displacement gages were used in the TSI in situ tests to monitor room closure and borehole extension. These gages included R.I. Inc. displacement transducers, IRAD rod extensometers, and three types of serata wire extensometers (Column 1 of Table 4.3.1). These gages were all similar in that they used linear potentiometers to convert displacement to a voltage output. Furthermore, they were calibrated with the same equipment and methods (section 3.1.3), although unique calibration coefficients were derived for each gage. The measurement accuracy of these gages was dependent on the uncertainty of the gage measurements (as determined from calibration data), the uncertainty of the voltmeters used to monitor and calibrate the gages, and the uncertainty of the calibration standards. The measurement accuracy of the displacement 
Table 4.3.1. Remote Displacement Gage Measurement Uncertainties

\begin{tabular}{|c|c|c|c|c|c|c|c|}
\hline $\begin{array}{l}1 \\
\text { Gage } \\
\text { Type }\end{array}$ & $\begin{array}{l}2 \\
\text { Gages } \\
\text { Sampled }\end{array}$ & $\begin{array}{l}3 \\
\text { Average } \\
\text { Maximum } \\
\text { Deviation }\end{array}$ & $\begin{array}{l}4 \\
\text { Total } \\
\text { Voltmeter } \\
\text { Uncertainty }\end{array}$ & $\begin{array}{l}5 \\
\text { Average } \\
\text { Gage } \\
\text { Sensitivity }\end{array}$ & $\begin{array}{l}6 \\
\text { Total } \\
\text { Voltmeter } \\
\text { Uncertainty }\end{array}$ & $\begin{array}{l}7 \\
\text { Calibration } \\
\text { Standard } \\
\text { Uncertainty }\end{array}$ & $\begin{array}{l}8 \\
\text { Total } \\
\text { Measurement } \\
\text { Uncertainty }\end{array}$ \\
\hline $\begin{array}{l}\text { R.I. Room } \\
\text { Closure } \\
\text { (12 in range) } \\
\text { ( } 36 \text { in range) }\end{array}$ & $\begin{array}{l}30 \\
51\end{array}$ & $\begin{array}{l} \pm 0.018 \text { in } \\
\pm 0.027 \text { in }\end{array}$ & $\begin{array}{l} \pm 0.012 \mathrm{~V} \\
\pm 0.012 \mathrm{~V}\end{array}$ & $\begin{array}{l}1.212 \mathrm{in} / \mathrm{V} \\
3.846 \mathrm{in} / \mathrm{V}\end{array}$ & $\begin{array}{l} \pm 0.015 \text { in } \\
\pm 0.046 \text { in }\end{array}$ & $\begin{array}{l} \pm 0.001 \text { in } \\
\pm 0.001 \text { in }\end{array}$ & $\begin{array}{l} \pm 0.034 \text { in } \\
\pm 0.074 \text { in }\end{array}$ \\
\hline $\begin{array}{l}\text { Serata } \mathbf{E}-200 \mathrm{~L} \\
\text { Extensometer } \\
\text { ( } 8 \text { in range) } \\
\text { ( } 30 \text { in range) }\end{array}$ & $\begin{array}{l}40 \\
50\end{array}$ & $\begin{array}{l} \pm 0.012 \text { in } \\
\pm 0.017 \text { in }\end{array}$ & $\begin{array}{l} \pm 0.012 \mathrm{~V} \\
\pm 0.012 \mathrm{~V}\end{array}$ & $\begin{array}{l}0.943 \mathrm{in} / \mathrm{V} \\
3.135 \mathrm{in} / \mathrm{V}\end{array}$ & $\begin{array}{l} \pm 0.011 \text { in } \\
\pm 0.038 \text { in }\end{array}$ & $\begin{array}{l} \pm 0.001 \text { in } \\
\pm 0.001 \text { in }\end{array}$ & $\begin{array}{l} \pm 0.024 \text { in } \\
\pm 0.056 \text { in }\end{array}$ \\
\hline $\begin{array}{l}\text { Serata E-300 } \\
\text { Extensometer }\end{array}$ & 32 & $\pm 0.005 \mathrm{in}$ & $\pm 0.012 \mathrm{~V}$ & $0.429 \mathrm{in} / \mathrm{V}$ & $\pm 0.005 \mathrm{in}$ & $\pm 0.001 \mathrm{in}$ & $\pm 0.011 \mathrm{in}$ \\
\hline $\begin{array}{l}\text { IRAD } 4000 \mathrm{~L} \text { Rod } \\
\text { Extensometer }\end{array}$ & 44 & $\pm 0.015 \mathrm{in}$ & $\pm 0.012 \mathrm{~V}$ & $0.417 \mathrm{in} / \mathrm{V}$ & \pm 0.005 in & \pm 0.001 in & \pm 0.021 in \\
\hline $\begin{array}{l}\text { Serata C- } 300 \\
\text { Creepmeter }\end{array}$ & 32 & \pm 0.009 in & $\pm 0.012 \mathrm{~V}$ & $0.444 \mathrm{in} / \mathrm{V}$ & $\pm 0.005 \mathrm{in}$ & \pm 0.001 in & $\pm 0.015 \mathrm{in}$ \\
\hline
\end{tabular}

Notes: Column 4 is the sum of voltmeter uncertainties for the calibration excitation, and the measurement excitation and signal.

Column 6 is the product of Columns 4 and 5 .

Column 8 is the sum of columns 3,6 , and 7 . 
gages is discussed in the paragraphs below and summarized in Table 4.3 .1 . To evaluate the uncertainty of the gage measurements, a sampling of calibration results was made; between 30 and 51 gages (Column 2 of Table 4.3.1) were included in a sample for each type of displacement gage. During the calibration of a gage (Section 3.1.3), the deviations between the measured displacements and displacements calculated by Equation 3.1 .3 were noted for each step made on the calibration fixture. The maximum deviation for each gage in the sample was identified and an average of the maxima was then taken for each gage type. The average maximum deviations for the different types of displacement gages ranged between \pm 0.005 and \pm 0.027 inch (Column 3 of Table 4.3 .1 ).

Measurement accuracy was also dependent on the voltmeters used to calibrate and monitor the gages. As can be seen from Equation 3.1.3, three voltages were used in obtaining a measurement from these gages: the signal and excitation voltages from the measurement process, and the excitation voltage from the calibration process. All of the displacement gages were powered by a $10 \mathrm{~V}$ excitation and produced a voltage signal that ranged between 0 and $10 \mathrm{~V}$. The voltmeters used to measure these voltages were calibrated by measuring voltage signals from an Electronic Development Corporation EDC-501J programmable DC voltage standard in parallel with Datron precision voltmeters (Models 1081 and 1082 ). HP-3456A voltmeters were utilized by the DAS to monitor gage signals as well as gage excitation. These voltmeters were calibrated to be within $0.001 \mathrm{~V}$ of the standard in the $10 \mathrm{~V}$ range [TOP 001] and therefore contributed a combined measurement uncertainty of \pm 0.002 for the excitation and signal voltage measurements. The HP-3467A was originally used to measure voltages during calibration, but was later replaced by the 
more accurate HP-3456A. As a worst case, it will be assumed that the calibrations were performed with the less accurate HP-3467A meter. The HP-3467A meters were calibrated to be within $0.004 \mathrm{~V}$ in the $10 \mathrm{~V}$ range [TOP 048], and so the uncertainty for the calibration excitation would be $\pm 0.004 \mathrm{~V}$. As a result, the combined voltmeter uncertainty for the three voltage measurements is a total of $\pm 0.006 \mathrm{~V}$.

Two other uncertainties can be added to those of the voltmeters. First, the excitation was monitored during calibration to ensure that it did not drift more than $\pm 0.001 \mathrm{mV}$ during the calibration of a single gage. Second, after a gage had been calibrated through its range, the gage was brought back below the first calibration point on the calibration table, and then returned to the first point. The gage output voltage was then checked to ensure that it was within $\pm 0.005 \mathrm{mV}$ of the first reading. Although this error was not necessarily a function of the voltmeter, it is convenient to include it at this point. These two uncertainties total $\pm 0.006 \mathrm{mV}$ and were added to the uncertainties discussed in the previous paragraph for a total voltmeter uncertainty of $\pm 0.012 \mathrm{mV}$ (Column 4 of Table 4.3 .1$)$

There are other possible sources of voltmeter error that need to be discussed, although in fact these sources contributed no error. First, high-impedance voltmeters were used to monitor the voltages, so errors in voltage measurements due to line resistance were insignificant. Second, the uncertainty of the analog-to-digital conversion that was performed by the voltmeters was included in the uncertainty attributed to the voltmeters and need not be considered separately. Finally, it is assumed that no degradation of measurement accuracy took place beyond the DAs voltmeters because the data were thereafter handled in digital form. 
Gage sensitivities were used to convert voltmeter uncertainties from volts to units of displacement (inches). Gage sensitivity was a nominal value representing the slope of the calibration relationship. Gage sensitivity was dependent on the design of the mechanism Iinking the potentiometer in the gage head to the displacement rod or wire, and to the design of the potentiometer itself. Average sensitivities for each gage type were made from the sampling of gage calibrations discussed above and ranged from $0.417 \mathrm{in} / \mathrm{V}$ to $3.846 \mathrm{in} / \mathrm{V}$ for the various types of displacement gages (Column 5 of Table 4.3.1). Voltage uncertainties were then multiplied by gage sensitivities (in/v) to obtain uncertainties in terms of inches. When expressed in units of displacement, voltmeter uncertainties ranged from \pm 0.005 to \pm 0.046 inch (Column 6 of Table 4.3 .1 ).

The calibration standards must also be considered in the evaluation of measurement accuracy. The calibration fixtures used to calibrate the displacement gages were certified by the Sandia standards Laboratory to have an uncertainty of \pm 0.001 inch (Column 7 of Table 4.3 .1 ).

The total measurement uncertainty for the remote displacement gages was the combination of the uncertainties of the gages themselves, the voltmeters used to calibrate and monitor the gages, and the calibration fixtures used to calibrate the gages-. The total measurement uncertainties for the various remote displacement gage types ranged from \pm 0.011 inch to \pm 0.074 inch. These values are listed in Column 8 of Table 4.3 .1 , and in the second column of Table 4.0.1. Dividing the total uncertainties by the gages' full-scale range resulted in accuracies between $\pm 0.2 \%$ and $\pm 0.5 \%$ (Column 8 of Table 4.0.1).

It must be emphasized that the evaluations discussed above concern 
only the accuracy of the measurement transducers as measured in a laboratory environment. Field conditions, however, added an undefined uncertainty to most of the measurements. The serata E-200I extensometers, for example, were affected by "hysteresis" (see section 3.2.2) that resulted in steps in the data curves.

\subsection{Stressmeters}

The derived resolutions for the stressmeters do not appear in Table 4.0.I because it is not currently possible to determine the uncertainty in the stress. At this time, the analysis of the stress transfer between the salt mass and the gage is itself very uncertain and not readily amenable to calibration. The calibration was determined from only a few gages and the calibration process destroyed those gages. In addition, the calibrations assumed that the process was time independent. Uncertainty arrises because of the time-dependent nature of the salt deformation.

\subsection{Thermocouples}

Premium grade, Type-E thermocouples were used in many applications in the TSI in situ tests. These thermocouples were manufactured to be accurate within the uncertainty specified by the American National Standards Institute (ANSI) [44]. According to this standard, the thermocouples had an accuracy of $\pm 1.0^{\circ} \mathrm{C}$ in the range below $250^{\circ} \mathrm{C}$, and an accuracy of $\pm 0.4 \%$ above $250^{\circ} \mathrm{C}$. Since most, if not all, of the temperatures recorded in these experiments were in the range between $25^{\circ} \mathrm{C}$ and $250^{\circ} \mathrm{C}$, the uncertainty in the thermocouple output would be $\pm 1.0^{\circ} \mathrm{C}$. Although a comprehensive program of thermocouple calibration was never instituted in the TSI tests, samples of the thermocouples were tested against temperature standards and about $98 \%$ were found to operate within ANSI standards. Thermocouples that exceeded standards did so only 
marginally and were flagged for inspection or repair. Short circuits caused by moist insulation material (see section 3.7) were found to be the cause of these exceptions. Since lead-to-shield resistance was checked regularly during installation and maintenance, and since thermocouples with short circuits in the insulation produced noisy data, it can be assumed that any thermocouple producing clean data was operating within ANSI standards.

Thermocouple output was monitored by HP-3456A digital multimeters. These meters were certified to be accurate within $0.01 \mathrm{mV}$ in the $100 \mathrm{mV}$ range that was used to monitor thermocouple output [TOP 001]. Multiplying the voltmeter uncertainty by the typical Type-E thermocouple sensitivity of about $15^{\circ} \mathrm{C} / \mathrm{mV}$ gives a voltmeter uncertainty of $\pm 0.15^{\circ} \mathrm{C}$.

HP3497A data control units were used to terminate the thermocouples. The reference temperature measured by these units had an uncertainty of $1^{\circ} \mathrm{C}$, as stated by the manufacturer. In addition, the temperature difference across the isothermal block is stated to be within $0.2^{\circ} \mathrm{C}$. These two uncertainties give a total uncertainty of $1.2^{\circ} \mathrm{C}$ for the data control units.

Combining the uncertainty of the thermocouple output with that of the voltmeters and data control units gives a total measurement uncertainty of $\pm 2.35^{\circ} \mathrm{C}$. Over the measurement range of $25^{\circ} \mathrm{C}$ through $250^{\circ} \mathrm{C}$, the full-scale uncertainty was $\pm 1.0 \%$ (Table 4.0.1).

\subsection{Comments}

Because the maximum uncertainties of the various components were used to derive the combined accuracy, the derived uncertainties will in general be larger than the actual uncertainties. As a result, the derived uncertainties, because they are within $1 \%$, provide a large degree of 
confidence in the data.

While the derived uncertainties can be taken as a measure of the actual uncertainty, other factors may modify the conclusions drawn from these derived values. Specifically, the calibration data, when represented by a least squares fit to the linear Equation 3.1 .3 (for remote closure gages and extensometers), typically showed deviations well within 1\% [31]. However, on rare occasion, the maximum deviations were slightly greater than $1 \%$. These occasions are the result of the uncertainty in the calibration data measurements and the intentionally limited (linear) degree of fit.

The result of the evaluations of uncertainty is that the data are probably accurate to within $1 \%$, which is within the stated requirements in the original test plans. This is confirmed by comparisons of independent gage data from both similar and dissimilar types of gages, where such comparisons are possible. 
This page intentionally left blank. 


\section{SUMMARY}

The underground test activities at the waste Isolation Pilot Plant WIPP in southeastern New Mexico were the responsibility of Sandia National Laboratories and included the Thermal/structural Interactions TSI in situ tests. The instrumentation of the TSI tests was a major undertaking that involved the installation of over 4,200 gages of various types in several large underground test rooms. The TSI in situ tests that have been conducted to date include the following major tests:

(1) the In Situ Stress Field - Hydraulic Fracturing Tests (conducted at various locations in the Experimental Area),

(2) the Overtest for Simulated Defense High-Level Waste (Room B),

(3) the $18-\mathrm{W} / \mathrm{m}^{2}$ Mockup for Defense High-Level Waste (Rooms A1, A2, and $A 3$ ),

(4) the Geomechanical Evaluation (Room G),

(5) the Heated Axisymmetric Pillar (Room H),

(6) the Air Intake Shaft Performance Tests (Shaft V) and,

(7) the Intermediate Scale Borehole Test (between Rooms C1 and C2).

Other tests, such as the Large-Scale Brine Inflow Test in Room Q, contained instrumentation that supported the TSI test program.

The gages installed in these tests were used to measure the mechanical and thermal response of the rock mass surrounding the test rooms, and to measure the environment of the test rooms. The mechanical response gages included room closure gages, borehole extensometers, stress gages, inclinometers, survey references, and borehole strain gages. The thermal response gages included thermocouples, thermal flux meters, and heater power gages. The environmental gages comprised a small number of air velocity gages and air temperature thermocouples that were installed to 
evaluate heat loss from the test rooms.

Most of the gages installed were electronic instruments that could be remotely monitored by an automated Data Acquisition system. Automated data collection was necessary because of the large number of instruments used and the frequency of measurement required. The DAS also facilitated the building of an engineering database that is available for data reduction and analysis.

Manually read gages were used in addition to the remote gages for a variety of reasons. Manual closure gages provided early closure histories immediately following excavation, and have continued to provide closure data on a permanent basis. Manual extensometers were installed in Room $\mathrm{G}$ as heavy-duty instruments. that could withstand long-term use. An important aspect of the manual closure gages and extensometers was that they provided redundant measurements to the remotely acquired displacement data. Finally, the inclinometer sensors were electronically read units, but were operated manually. The manually acquired data were ultimately added to the remote data to form a complete database.

Gages were selected that could accommodate the range of responses predicted by pretest calculations and that could operate in the harsh underground environment of the WIPP site. Gages were evaluated prior to TSI test construction and design modifications were made prior to manufacturing that would improve gage operation and longevity. In addition, much of the instrumentation was modified as the testing progressed using knowledge gained from test operation and maintenance programs. The extensometers in particular had several small changes made to their design that greatly improved their reliability and longevity.

Gages were calibrated by sandia or by the manufacturer to assure 
measurement accuracy. The results of the calibrations were fit to equations that were used by the DAS to convert gage voltages to engineering units. The mechanical displacement gages were calibrated by Sandia personnel and contractors on fixtures that were traceable to NIST standards. The stress meters were calibrated by sandia with a two-step process that calibrated gage output to formation stress. Thermal flux meters were calibrated by gage factors and temperature corrections supplied by the manufacturer. The air velocity gages were calibrated by the manufacturer and later at the WIPP site with a portable wind tunnel. The thermocouples were an exception as the DAS used NIST Thermocouple Reference Tables $[32,33]$ to convert voltages to temperatures. (Later in the experimental program, however, NIST polynomials were used.) The measurement accuracy of the various types of closure gages, extensometers, and thermocouples was evaluated and it was found that these gages all had an uncertainty less than $\pm 1 \%$ of the gages' full scale range.

Gage output was reviewed on a regular schedule and gages were maintained on a routine basis to ensure long-term success for the experiments. Simple problems were corrected in the field while malfunctioning gages were replaced with new or refurbished units. Gages that could not be repaired or replaced were deactivated and data acquisition was discontinued.

Most of the gages performed well throughout the life of the tests. The gages in Room $\mathrm{D}$, as the extreme case, continue to monitor room response after 12 years of service. The instrumentation has generated an exceptional database that will aid in characterizing the behavior of the WIPP stratigraphy and in predicting repository performance. 
This page intentionally left blank. 
[TOPxxx] "Technical Operating Procedures", which are contained in the Thermal/Structural Interactions (TSI) Notebook system which is kept in the sandia WIPP Central Files (SWCF) in the Nuclear waste Management Program Library in Albuquerque, NM.

[I] R. V. Matalucci, C. I. Christensen, T. O. Hunter, M. A. Molecke, and D. E. Munson, Waste Isolation Pilot Plant (WIPP) Research and Development program: In Situ Testing Plan, March 1982, SAND81-2628, Sandia National Laboratories, Albuquerque, NM, 1982.

[2] D. E. Munson and R. V. Matalucci, "Planning, Developing, and Fielding of Thermal/Structural Interactions In Situ Tests for the Waste Isolation Pilot Plant (WIPP)," Proceedings Waste Management Symposium '84: Vol. I, University of Arizona, Tucson, Az, pp. $317-333,1984$.

[3] D. E. Munson, R. V. Matalucci, and T. M. Torres, "Implementation of Thermal/structural Interactions In Situ Tests at the Waste Isolation Pilot Plant Facility," Proc. of the 2nd International conf. On the Mechanical Behavior of Salt, Trans Tech Publications, Clausthal Zellerfield, FRG, pp. 361-390, 1988.

[4] R. V. Matalucci and D. E. Munson, "Planning, Developing, and Organizing In Situ Tests for the Waste Isolation Pilot Plant (WIPP) Facility," Proc. of the 2nd International conf. on the Mechanical Behavior of Salt, Trans Tech Publications, Clausthal Zellerfield, FRG, pp. 329-360, 1988.

[5] D. E. Munson, Test Plan: Overtest for Simulated Defense High-Level waste (DHLW), Sandia National Laboratories, Albuquerque, NM, 1983.

[6] D. E. Munson, Test Plan: $18-\mathrm{W} / \mathrm{m}^{2}$ Mockup for Defense High-Level Waste (DHLW), Sandia National Laboratories, Albuquerque, NM, 1983.

[7] D. E. Munson, Test Plan: Geomechanical Evaluation, Sandia National Laboratories, Albuquerque, NM, 1983.

[8] T. M. Torres, Test Plan: Heated Axisymmetric Pillar, Sandia National Laboratories, Albuquerque, NM, 1983.

[9] W. R. Wawersik, Test Plan: In Situ Stress Field - Hydraulic Fracturing Tests, Sandia National Laboratories, Albuquerque, NM, 1983.

[10] R. V. Matalucci, Test Plan: Air Intake Shaft Performance Tests, Sandia National Laboratories, Albuquerque, NM, 1987.

[11] D. E. Munson, Test Plan: Intermediate Scale Borehole Test, Sandia National Laboratories, Albuquerque, NM, 1989. 
[12] E. J. Nowak, Test Plan: Brine Inflow and Related Tests in the Brine Inflow Room (Room 0 ) of the Waste Isolation Pilot plant (WIPP), Sandia National Laboratories, Albuquerque, NM, 1990.

[13] D. E. Munson, R. L. Jones, D. L. Hoag, and J. R. Ball, Heated Axisymmetric Pillar Test (Room H): In Situ Data Report, (February 1985 - April 1987), Waste Isolation Pilot Plant (WIPP), Thermal/structural Interactions Program, SAND87-2488, Sandia National Laboratories, Albuquerque, NM, 1987.

[14] D. E. Munson, R. I. Jones, D. I. Hoag, and J. R. Ball, Mining Development Test (Room D): In Situ Data Report, (March 1984 - May 1988), Waste Isolation Pilot Plant (WIPP). Thermal/structural Interactions Program, SAND88-1460, Sandia National Laboratories, Albuquerque, NM, 1988.

[15] D. E. Munson, R. L. Jones, J. R. Ball, R. M. Clancy, D. L. Hoag, and S. V. Petney, Overtest for Simulated Defense High-Level Waste (Room B): In Situ Data Report, (May 1984 - February 1988), Waste Isolation Pilot Plant (WIPP). Thermal/structural Interactions Program, SAND89-2671, Sandia National Laboratories, Albuquerque, NM, 1990.

[16] D. E. Munson, S. V. Petney, R. M. Clancy, J. R. Ball, R. I. Jones, and C. L. Northrop-Salazar, $18 \mathrm{~W} / \mathrm{m}^{2}$ Mockup for Defense High-Level Waste (Rooms A): In Situ Data Report: Vol. I Mechanical Response Gages, (February 1985 - June 1990), Waste Isolation Pilot Plant (WIPP), Thermal/structural Interactions Program, SAND90-2748, Sandia National Laboratories, Albuquerque, NM, 1991.

[17] D. E. Munson, S. V. Petney, T. L. Christian-Frear, J. R. Ball, R. L. Jones, and C. L. Northrop-Salazar, $18 \mathrm{~W} / \mathrm{m}^{2}$ Mockup for Defense High-Level Waste (Rooms A): In Situ Data Report, Vol. II - Thermal Response Gages, (February 1985 - June 1990), Waste Isolation Pilot Plant (WIPR), Thermal/Structural Interactions Program, SAND90-2749, Sandia National Laboratories, Albuquerque, NM, 1992.

[18] D. E. Munson, R. L. Jones, C. L. Northrop-Salazar, and S. J. Woerner, Multipass Mining Sequence Room Closures: In Situ Data Report, Waste Isolation Pilot Plant (WIPP), Thermal/structural Interactions Program, SAND87-2687, Sandia National Laboratories, Albuquerque, NM, 1992.

[19] D. E. Munson, S. V. Petney, T. L. Christian-Frear, J. R. Ball, R. L. Jones, and C. L. Northrop-Salazar, Geomechanical Evaluation (Room G): In Situ Data Report (December 1984 - November 1990), Waste Isolation Pilot Plant (WIPP), Thermal/Structural Interactions Program, SAND92-0582, Sandia National Laboratories, Albuquerque, NM, 1992. 
[20] D. E. Munson, T. L. Christian-Frear, G. T. Baird, D. A. Labreche, J. R. Ball, R. L. Jones, and C. L. Northrop-Salazar, Intermediate Scale Borehole (Room C): In Situ Data Report, (January 1989June 1993), Waste Isolation Pilot Plant (WIPP), Thermal/ Structural Interactions Program, SAND92-2470, Sandia National Laboratories, Albuquerque, NM, 1994.

[21] D. E. Munson, D. L. Hoag, J. R. Ball, G. T. Baird, and R. L. Jones, Air Intake Shaft Performance Tests (Shaft V): In Situ Data Report, (May 1988 - July 1995), SAND94-1311, Sandia National Laboratories, Albuquerque, NM, 1995.

[22] W. R. Wawersik and C. M. Stone, Application of Hydraulic Fracturing to Determine Virgin In Situ stress State Around Waste Isolation Pilot Plant - In Situ Measurements, SAND85-1776, Sandia National Laboratories, Albuquerque, NM, 1985.

[23] J. D. Miller, C. M. Stone, and L. J. Branstetter, Reference Calculations for Underground Rooms of the WIPP, SAND82-1176, Sandia National Laboratories, Albuquerque, NM, 1982.

[24] L. J. Branstetter, Pretest Parametric Calculations for the Heated Pillar Experiment in the WIPP In situ Experimental Area, SAND82-2781, Sandia National Laboratories, Albuquerque, NM, 1983.

[25] I. J. Branstetter, Second Reference Calculation for the WIPP, SAND83-2461, Sandia National Laboratories, Albuquerque, NM, 1985.

[26] H. S. Morgan and C. M. Stone, Pretest Reference Calculation for the Overtest for Simulated Defense Hiqh Level waste (WIPP Room B In Situ Experiment), SAND85-0213, Sandia National Laboratories, Albuquerque, NM, 1985.

[27] H. S. Morgan and C. M. Stone, pretest Reference Calculation for the $18 \mathrm{~W} / \mathrm{m}^{2}$ Mockup for Defense High-Level Waste (WIPP Room A In Situ Experiment), SAND85-0807, Sandia National Laboratories, Albuquerque, NM, 1985.

[28] H. S. Morgan and C. M. Stone, pretest Reference Calculation for the 6.1 Meter $(20 \mathrm{ft})$ Wide Drifts of the Geomechanical Evaluation (WIPP Room G In Situ Experiment), SAND85-0893, Sandia National Laboratories, Albuquerque, NM, 1985.

[29] H. S. Morgan and C. M. Stone, pretest Reference Calculation for the Heated Axisymmetric Pillar (WIPP Room $H$ In Situ Experiment), SAND85-1146, Sandia National Laboratories, Albuquerque, NM, 1985.

[30] D. S. Preece, Pretest 3-D Finite Element Modeling of the Wedge Pillar Portion of the WIPP Geomechanical Evaluation (Room G) In Situ Experiment, SAND87-0472, Sandia National Laboratories, Albuquerque, NM, 1987. 
[31] M. D. Schuhen and T. A. Dean, Sandia WIPP Calibration Traceability, SAND96-0886, Sandia National Laboratories, Albuquerque, NM, 1996.

[32] R. L. Powell, W. J. Hall, C. H. Hyink Jr., L. L. Sparks, G. W. Burns, M. G. Scroger, and H. H. Plumb, Thermocouple Reference Tables Based on the IPTS-68, Monograph 125, U. S. Dept. of Commerce, National Bureau of Standards, Gaithersburg, MD, 1974.

[33] G. W. Burns, M. G. Scroger, G. F. Strouse, M. C. Croarkin, and W. F. Guthrie, Temperature-Electromotive Force Reference Functions and Tables for the Letter-Designated Thermocouple Types Based on the IPTS-90, Monograph 175, U. S. Dept. of Commerce, National Institute for standards and Technology, Gaithersburg, MD, 1993.

[34] D. E. Munson, D. L. Hoag, D. A. Blankenship, R. L. Jones, S. J. woerner, G. T. Baird, and R. V. Matalucci, Construction of the Thermal/structural Interactions In situ Tests at the waste Isolation pilot Plant (WIPP), SAND87-2685, Sandia National Laboratories, Albuquerque, NM, 1996.

[35] J. T. McIlmoyle, R. V. Matalucci, and H. C. Ogden, The Data Acquisition System for the Waste Isolation Pilot Plant In Situ Tests, SAND86-1031, Sandia National Laboratories, Albuquerque, NM, 1987.

[36] D. E. Munson, J. R. Ball, and R. L. Jones, Data Quality Assurance Controls Through the WIPP In Situ Data Acquisition, Analysis, and Management System, SAND88-2845, Sandia National Laboratories, Albuquerque, NM, 1990.

[37] D. E. Munson, K. L. DeVries, D. M. Schiermeister, W. F. DeYonge, and R. L. Jones, "Measured and Calculated Closures of Open and Brine Filled Shafts and Deep Vertical Boreholes in Salt," Proc. of the $33 \mathrm{rd}$ U.S. Symposium on Rock Mechanics, Santa Fe, New Mexico, June 3-5, 1992, A. A. Balkema, Brookfield, VT, pp. $439-448,1992$.

[38] P. H. Lu, "Determination of Ground Pressure Existing in a Viscoelastic Rock Mass by Use of Hydraulic Borehole Pressure Cells," Proc. of the International symposium on Weak Rock, Tokvo, Japan, September 21-24, 1981. A. A. Balkema, Rotterdam, Netherlands, pp. 459-465, 1981.

[39] J. B. Sellers, "The Measurement of Stress Changes in Rock Using the Vibrating wire stressmeter," Proc. of the International Symposium on Field Measurements in Rock Mechanics, Zurich, Switzerland, April 4-6, 1977, A. A. Balkema, Rotterdam, Netherlands, pp. 275-288, 1977.

[40] C. W. Cook and E. S. Ames, "Borehole-Inclusion Stressmeter Measurements in Bedded Salt," Proc. of the 20th U. S. Symposium on Rock Mechanics, Austin, $\mathrm{TX}_{\text {, June } 4-6,1979}$, University of Texas, Austin, TX, pp. 481-489, 1979. 
[41] J. C. Stormont, R. V. Matalucci, and H. S. Morgan, Field Tests of Stress Measurement Techniques in Rock Salt, SAND83-2507, Sandia National Laboratories, Albuquerque, NM, 1984.

[42] H. S. Morgan, Analysis of Borehole Inclusion Stress Measurement Concepts Proposed for Use in the Waste Isolation Pilot Plant In Situ Testing Program, SAND82-1192, Sandia National Laboratories, Albuquerque, NM, 1982 .

[43] E. O. Doebelin, Measurement Systems, Application and Design, Revised Edition, McGraw-Hill, New York, pp. 39-69, 1975.

[44] American National Standards Institute, Temperature Measurement Thermocouples, ANSI/MC96.1-1982, Instrument Society of America, Research Triangle Park, NC, 1982. 
This page intentionally left blank. 


\section{WIPP \\ UC721 - DISTRIBUTION LIST \\ SAND87-2686}

\section{Federal Agencies}

US Department of Energy (4)

Office of Civilian Radioactive Waste Mgmt.

Attn: Deputy Director, RW-2

Acting Director, RW-10

Office of Human Resources \& Admin.

Director, RW-30

Office of Program Mgmt. \& Integ.

Director, RW-40

Office of Waste Accept., Stor., \& Tran.

Forrestal Building

Washington, DC 20585

Attn: Project Director

Yucca Mountain Site Characterization Office

Director, RW-3

Office of Quality Assurance

P.O. Box 30307

Las Vegas, NV 89036-0307

US Department of Energy

Albuquerque Operations Office

Attn: National Atomic Museum Library

P.O. Box 5400

Albuquerque, NM 87185-5400

US Department of Energy

Research \& Waste Management Division

Attn: Director

P.O. Box E

Oak Ridge, TN 37831

US Department of Energy (5)

Carlsbad Area Office

Attn: G. Dials

D. Galbraith

M. McFadden

R. Lark

J. A. Mewhinney

P.O. Box 3090

Carlsbad, NM 88221-3090

US Department of Energy

Office of Environmental Restoration and

Waste Management

Attn: M. Frei, EM-30

Forrestal Building

Washington, DC 20585-0002
US Department of Energy (3)

Office of Environmental Restoration and Waste Management

Attn: J. Juri, EM-34, Trevion II

Washington, DC 20585-0002

US Department of Energy

Office of Environmental Restoration and Waste Management

Attn: S. Schneider, EM-342, Trevion II

Washington, DC 20585-0002

US Department of Energy (2)

Office of Environment, Safety \& Health

Attn: C. Borgstrom, EH-25

R. Pelletier, EH-231

Washington, DC 20585

US Department of Energy (2)

Idaho Operations Office

Fuel Processing \& Waste Mgmt. Division 785 DOE Place

Idaho Falls, ID 83402

US Environmental Protection Agency (2)

Radiation Protection Programs

Attn: M. Oge

ANR-460

Washington, DC 20460

\section{Boards}

Defense Nuclear Facilities Safety Board

Aitn: D. Winters

625 Indiana Ave. NW, Suite 700

Washington, DC 20004

Nuclear Waste Technical Review Board (2)

Attn: Chairman

J. L. Cohon

1100 Wilson Blvd., Suite 910

Arlington, VA 22209-2297 
State Agencies

Attorney General of New Mexico

P.O. Drawer 1508

Santa Fe, NM 87504-1508

Environmental Evaluation Group (3)

Attn: Library

7007 Wyoming NE

Suite F-2

Albuquerque, NM 87109

NM Energy, Minerals, and Natural

Resources Department

Attn: Library

2040 S. Pacheco

Santa Fe, NM 87505

NM Environment Department (3)

Secretary of the Environment

Attn: Mark Weidler

1190 St. Francis Drive

Santa Fe, NM 87503-0968

NM Bureau of Mines \& Mineral Resources

Socorro, NM 87801

\section{Laboratories/Corporations}

Battelle Pacific Northwest Laboratories

Battelle Blvd.

Richland, WA 99352

INTERA, Inc.

Attn: G. A. Freeze

1650 University Blvd. NE, Suite 300

Albuquerque, NM 87102

INTERA, Inc.

Attn: J. F. Pickens

6850 Austin Center Blvd., Suite 300

Austin, TX 78731

INTERA, Inc.

Attn: W. Stensrud

P.O. Box 2123

Carlsbad, NM 88221

Los Alamos National Laboratory

Attn: B. Erdal, INC-12

P.O. Box 1663

Los Alamos, NM 87544
RE/SPEC, Inc

Attn: Angus Robb

4775 Indian School NE, Suite 300

Albuquerque, NM 87110-3927

RE/SPEC, Inc (10)

Attn: D. Hoag

4775 Indian School NE Suite 300

Albuquerque, NM 87110-3927

RE/SPEC, Inc (3)

Attn: J. L. Ratigan

G.D. Callahan

D. Blankenship

P.O. Box 725

Rapid City, SD 57709

Tech Reps, Inc. (4)

Attn: J. Chapman (1)

Loretta Robledo (2)

R. Jones (1)

5000 Marble NE, Suite 222

Albuquerque, NM 87110

Westinghouse Electric Corporation (5)

Attn: Library

J. Epstein

J. Lee

B. A. Howard

R. Kehrman

P.O. Box 2078

Carlsbad, NM 88221

S. Cohen \& Associates

Attn: Bill Thurber

1355 Beverly Road

McLean, VA 22101

\section{National Academy of Sciences, WIPP Panel}

Howard Adler

Oxyrase, Incorporated

7327 Oak Ridge Highway

Knoxville, TN 37931

\section{Tom Kiess}

Board of Radioactive Waste Management

GF456

2101 Constitution Ave.

Washington, DC 20418 
Rodney C. Ewing

Department of Geology

University of New Mexico

Albuquerque, NM 87131

Charles Fairhurst

Department of Civil and Mineral Engineering

University of Minnesota

500 Pillsbury Dr. SE

Minneapolis, MN 55455-0220

B. John Garrick

PLG Incorporated

4590 MacArthur Blvd., Suite 400

Newport Beach, CA 92660-2027

Leonard F. Konikow

US Geological Survey

431 National Center

Reston, VA 22092

Carl A. Anderson, Director

Board of Radioactive Waste Management

National Research Council

HA 456

2101 Constitution Ave. NW.

Washington, DC 20418

Christopher G. Whipple

ICF Kaiser Engineers

1800 Harrison St., 7th Floor

Oakland, CA 94612-3430

John O. Blomeke

720 Clubhouse Way

Knoxville, TN 37909

Sue B. Clark

University of Georgia

Savannah River Ecology Lab

P.O. Drawer E

Aiken, SC 29802

Konrad B. Krauskopf

Department of Geology

Stanford University

Stanford, CA 94305-2115

Della Roy

Pennsylvania State University

217 Materials Research Lab

Hastings Road

University Park, PA 16802
David A. Waite

$\mathrm{CH}_{2} \mathrm{M}$ Hill

P.O. Box 91500

Bellevue, WA 98009-2050

Thomas A. Zordon

Zordan Associates, Inc. 3807 Edinburg Drive

Murrysville, PA 15668

\section{Universities}

University of New Mexico

Geology Department

Attn: Library

141 Northrop Hall

Albuquerque, NM 87131

University of Washington

College of Ocean \& Fishery Sciences

Attn: G. R. Heath

583 Henderson Hall, HN-15

Seattle, WA 98195

\section{Libraries}

Thomas Brannigan Library

Attn: D. Dresp

106 W. Hadley St.

Las Cruces, NM 88001

Government Publications Department

Zimmerman Library

University of New Mexico

Albuquerque, NM 87131

New Mexico Junior College

Pannell Library

Attn: R. Hill

Lovington Highway

Hobbs, NM 88240

New Mexico State Library

Attn: N. McCallan

325 Don Gaspar

Santa Fe, NM 87503

New Mexico Tech

Martin Speere Memorial Library

Campus Street

Socorro, NM 87810 
WIPP Public Reading Room

Carlsbad Public Library

$101 \mathrm{~S}$. Halagueno St.

Carlsbad, NM 88220

\section{Foreign Addresses}

Atomic Energy of Canada, Ltd.

Whiteshell Laboratories

Attn: B. Goodwin

Pinawa, Manitoba, CANADA R0E ILO

Professor Michel Aubertin

Ecole Polytechnique de Montreal

Mineral Engineering Dept. P.O. Box 6079,

Succursale Centre-Ville

Montreal, Quebec H3C 3A7

CANADA

Pierre Berest

Laboratoire de Mecanique des Solides

Ecole Polytechnique

Palaiseau

FRANCE 91128

Francois Chenevier (2)

ANDRA

Route de Panorama Robert Schumann

B. P. 38

92266 Fontenay-aux-Roses, Cedex

FRANCE

Claude Sombret

Centre d'Etudes Nucleaires de la Vallee Rhone

CEN/VALRHO

S.D.H.A. B.P. 171

30205 Bagnols-Sur-Ceze, FRANCE

Commissariat a L'Energie Atomique

Attn: D. Alexandre

Centre d'Etudes de Cadarache

13108 Saint Paul Lez Durance Cedex

FRANCE

Bundesanstalt fur Geowissenschaften und

Rohstoffe

Attn: M. Langer

Postfach 510153

D-30631 Hannover, GERMANY
Bundesministerium fur Forschung und

Technologie

Postfach 200706

5300 Bonn 2, GERMANY

Institut fur Tieflagerung

Attn: K. Kuhn

Theodor-Heuss-Strasse 4

D-3300 Braunschweig, GERMANY

Gesellschaft fur Anlagen und Reaktorsicherheit (GRS)

Attn: B. Baltes

Schwertnergasse 1

D-50667 Cologne, GERMANY

Shingo Tashiro

Japan Atomic Energy Research Institute

Tokai-Mura, Ibaraki-Ken, 319-11

JAPAN

Netherlands Energy Research Foundation ECN

Attn: J. Prij

3 Westerduinweg

P.O. Box 1

1755 ZG Petten

THE NETHERLANDS

Svensk Karnbransleforsorjning AB

Attn: F. Karlsson

Project KBS (Karnbranslesakerhet)

Box 5864

S-102 48 Stockholm

SWEDEN

Nationale Genossenschaft fur die Lagerung

Radioaktiver Abfalle (2)

Attn: S. Vomvoris

P. Zuidema

Hardstrasse 73

CH-5430 Wettingen

SWITZERLAND

AEA Technology

Attn: J. H. Rees

D5W/29 Culham Laboratory

Abington, Oxfordshire OX14 3DB

UNITED KINGDOM

AEA Technology

Attn: W. R. Rodwell

044/A31 Winfrith Technical Centre

Dorchester, Dorset DT2 8DH

UNITED KINGDOM 
AEA Technology

Attn: J. E. Tinson

B4244 Harwell Laboratory

Didcot, Oxfordshire OXI1 ORA

UNITED KINGDOM

Internal

$\begin{array}{lll}\underline{\text { MS }} & \text { Org. } & \\ \mathbf{0 7 0 6} & \mathbf{6 1 1 3} & \text { J. K. Linn } \\ 0706 & 6113 & \text { B. L. Ehgartner } \\ 0706 & 6113 & \text { D. E. Munson (10) } \\ 1324 & 6115 & \text { P. B. Davies } \\ 1320 & 6831 & \text { E. J. Nowak } \\ 1322 & 6121 & \text { J. R. Tillerson } \\ 1322 & 6121 & \text { F. D. Hansen } \\ 1328 & 6849 & \text { D. R. Anderson } \\ 1328 & 6848 & \text { H. N. Jow } \\ 1335 & 6801 & \text { M. Chu } \\ 1341 & 6832 & \text { J. T. Holmes } \\ 1335 & 6000 & \text { W. Weart } \\ 1395 & 6800 & \text { L. Shephard } \\ 1395 & 6821 & \text { M. Marietta } \\ 1395 & 6841 & \text { V. H. Slaboszewicz } \\ 1330 & 6811 & \text { K. Hart (2) } \\ 1330 & 4415 & \text { NWM Library (20) } \\ 9018 & 8940-2 & \text { Central Technical Files } \\ 0899 & 4414 & \text { Technical Library (5) } \\ 0619 & 12690 & \text { Review and Approval Desk (2) } \\ & & \text { for DOE/OSTI }\end{array}$

